Universidade de São Paulo

Instituto de Astronomia, Geofísica e Ciências Atmosféricas

Departamento de Astronomia

Elvis William Carvalho dos Santos Cantelli

\title{
Enriquecimento de elementos pesados no aglomerado globular do bojo NGC 6522: Traços da primeira geração de estrelas
}

São Paulo 

Elvis William Carvalho dos Santos Cantelli

\section{Enriquecimento de elementos pesados no aglomerado globular do bojo NGC 6522: Traços da primeira geração de estrelas}

Dissertação apresentada ao Departamento de Astronomia do Instituto de Astronomia, Geofísica

e Ciências Atmosféricas da Universidade de São Paulo como requisito parcial para a obtenção do título de Mestre em Ciências.

Área de Concentração: Astronomia

Orientador(a): Profa. Dra. Beatriz Leonor Silveira Barbuy

São Paulo 

às estrelas mais brilhantes do meu universo, minhas filhas Gaia e Indra. 



\section{Agradecimentos}

À professora Beatriz Barbuy que desde a iniciação científica me garantiu inúmeras oportunidades, acreditou no meu potencial e me guiou em todo meu trajeto científico até então, me colocando em contato com tudo o que foi de melhor para que eu pudesse construir o conhecimento e experiência que tenho.

Aos meus pais que proporcionaram minha integridade e sempre me deram todo o apoio que precisei.

À minha esposa Luana que esteve junto comigo em todos os momentos, me dando suporte e força para continuar.

Aos pesquisadores César Siqueira-Mello, Bruno Dias e Marina Trevisan pela paciência e valiosíssima ajuda ao compartilharem seus conhecimentos.

Ao Julio Trevisan pelo inestimável apoio em software e valiosa amizade e companhia.

Ao professor Jorge Meléndez que sempre esteve disponível para me ajudar e apoiar em todas as horas.

Às professoras Jane Gregorio-Hetem e Silvia Rossi pelos grandes conselhos e incentivo.

Ao "benevolente ditador para a vida", Guido van Rossum, por ter criado a linguagem Python, que me conferiu o enorme prazer em programar.

Aos meus amigos Docinho, Gubs, Vara, André, Morango, Rosicky, Johnny, Rafa, Coruja, Gêeh, Lemos, Renato, Neiva, Amanda, Porteiro, Fabio, e todos que estiveram junto comigo em minha graduação e mestrado.

À CAPES pelo investimento.

Às Instituições: IAG-USP, ESO, LNA.

Esta tese/dissertação foi escrita em LATEX com a classe IAGTESE, para teses e dissertações do IAG. 

"To try to make a model of an atom by studying its spectrum is like trying to make a model of a grand piano by listening to the noise it makes when thrown downstairs."

Anônimo em The British Journal of Radiology. Wertheimer, 1924

"A ciência está atrás do que o universo realmente é, não do que nos faz sentir bem."

Carl Sagan 



\section{Resumo}

Há uma concentração de aglomerados globulares moderadamente pobres em metais no bojo galáctico, e muitos deles mostram um Ramo Horizontal Azul (BHB). Essas características juntas apontam para uma idade antiga. Para entender melhor a origem desses aglomerados, o estudo de seu padrão de abundâncias pode ajudar a identificar o tipo das primeiras supernovas nas partes centrais da Galáxia. O NGC 6522 na janela do Baade é um representante desta classe de aglomerados. Análises de abundância de estrelas individuais nesses aglomerados confirmaram sua metalicidade de $[\mathrm{Fe} / \mathrm{H}] \sim-1.0$, enriquecimento em elementos- $\alpha$ e detectaram uma variação nas abundâncias dos elementos pesados de processo-s. Entre os maiores enriquecimentos em Y e Ba, a explicação usual da transferência de massa de uma companheira do ramo assintótico das gigantes pode não se aplicar, e um enriquecimento por estrelas massivas de alta rotação foi sugerido.

A fim de estudar melhor as abundâncias em NGC 6522, obtivemos um programa com o FLAMES em 2012, a partir da qual, com os dados de UVES, mostramos que o enriquecimento em elementos-s ainda poderia ser acomodado com o modelo de transferência de massa de uma estrela companheira. Além disso, obtivemos novos dados com o FLAMES em 2016. No presente trabalho analisamos outras 6 estrelas observadas em alta resolução com UVES, e 32 estrelas em resolução média-alta observadas com GIRAFFE, onde foram selecionadas por suas velocidades radiais em torno de $-14,3 \mathrm{~km} \cdot \mathrm{s}^{-1}$ com uma abrangência de $\pm 15 \mathrm{~km} \cdot \mathrm{s}^{-1}$.

Os parâmetros atmosféricos e as abundâncias dos elementos leves C, N, O, elementos de Z ímpar $\mathrm{Na}$ e Al, elementos-alpha Mg, Si, Ca, Ti, elementos de pico de ferro Mn, Cu, Zn, elementos de processo-s Y, Zr, Ba, La, Ce, Nd e o elemento de processo-r Eu são derivados para a amostra UVES e preliminarmente para a amostra GIRAFFE. Entre as estrelas 
UVES, duas delas mostram um enriquecimento significativo nos elementos do processo-s e uma com alto valor nas razões $[\mathrm{Y} / \mathrm{Ba}]$ e $[\mathrm{Zr} / \mathrm{Ba}]$, sugerindo um enriquecimento por estrelas massivas de alta rotação. 


\section{Abstract}

There is a concentration of moderately metal-poor globular clusters in the Galactic bulge, and many of them show a Blue Horizontal Branch (BHB). These characteristics together point to an old age. In order to better understand the origin of these clusters, the study of their abundance pattern can help identifying the kind of the earliest supernovae in the central parts of the Galaxy. NGC 6522 in Baade's Window is a representative of this class of clusters. Abundance analyses of individual stars in this clusters have confirmed its metallicity of $[\mathrm{Fe} / \mathrm{H}] \sim-1.0$, enhanced $\alpha$-elements, and detected a variation in the abundances of the s-process heavy elements. Among the highest enhancements of $\mathrm{Y}$ and $\mathrm{Ba}$, the usual explanation of mass transfer from a companion in the Asymptotic Giant Branch might not apply, and an enrichment by early fast-rotating massive stars was suggested.

In order to further study the abundances in NGC 6522 we obtained a run with FLAMESUVES in 2012, from which with the UVES data we have shown that the enhancement in s-elements could still be accommodated with the companion transfer model. We further obtained new data with FLAMES-UVES in 2016. In the present work we analyze another 6 stars observed at high resolution with UVES, and 32 stars at medium-high resolution observed with GIRAFFE. The latter were selected from their radial velocities of $-14.3 \pm 15$ $\mathrm{km} \cdot \mathrm{s}^{-1}$.

The abundances of the light elements C, N, O, odd-Z elements Na, Al, $\alpha$-elements $\mathrm{Mg}$, $\mathrm{Si}, \mathrm{Ca}, \mathrm{Ti}$, iron-peak elements $\mathrm{Mn}, \mathrm{Cu}, \mathrm{Zn}$, s-process elements $\mathrm{Y}, \mathrm{Zr}, \mathrm{Ba}, \mathrm{La}, \mathrm{Ce}, \mathrm{Nd}$ and r-process element Eu are derived. Among the UVES stars, two of them show a significant enrichment in s-process elements and one of them show high $[\mathrm{Y} / \mathrm{Ba}]$ and $[\mathrm{Zr} / \mathrm{Ba}]$ ratios, suggesting that an early enrichment by fast rotating massive stars is a probable scenario. 



\section{Lista de Figuras}

1.1 Modelos de abundâncias de spinstars . . . . . . . . . . . . . 26

1.2 Razão $[\mathrm{Y} / \mathrm{Ba}]$ vs $[\mathrm{Fe} / \mathrm{H}]$ de Chiappini $(2011) \ldots \ldots \ldots \ldots$

2.1 Método iterativo de normalização . . . . . . . . . . . . . . . . . 39

2.2 GREPPy data view . . . . . . . . . . . . . . . . 42

2.3 Normalização por spline segmentada . . . . . . . . . . . . . . . . . . . 44

2.4 Comparação da combinação dos espectros UVES . . . . . . . . . . . . . . 45

2.5 Comparação média-mediana em linha espectral . . . . . . . . . . . . . 47

2.6 Distribuição de velocidades radiais GIRAFFE . . . . . . . . . . . . 50

2.7 Campo do NGC 6522 e estrelas selecionadas . . . . . . . . . . . . . . . . 51

2.8 Campo do NGC 6522 obtido com o MUSE . . . . . . . . . . . . . . 52

2.9 Inspeção dos alvos detectados para o MUSE . . . . . . . . . . . . . . . 53

3.1 Síntese decomposta de linhas de ferro . . . . . . . . . . . . . . 62

3.2 Deblend realizado com Python . . . . . . . . . . . . . . . 63

3.3 Ajuste do DOOp+Daospec . . . . . . . . . . . . . . . . 64

3.4 Comparação de EW medidas manualmente e via DOOp - GIRAFFE . . . 65

3.5 Comparação de EW medidas manualmente e via DOOp - UVES . . . . . . 66

3.6 Ajuste do DOOp para a estrela $234816 \ldots \ldots$. . . . . . . . . . 67

3.7 Comparação das EW manuais das estrelas UVES e GIRAFFE . . . . . . . 71

3.8 Comparação das EW DOOp das estrelas UVES e GIRAFFE . . . . . . . . 72

3.9 Curva de crescimento . . . . . . . . . . . . . . . 73

3.10 Equilíbrio de excitação e ionização . . . . . . . . . . . . . . . . 774

3.11 Comparação dos parâmetros GIRAFFE - DOOp vs manual . . . . . . . . . 77 
3.12 Comparação dos parâmetros UVES - DOOp vs manual . . . . . . . . . 77

3.13 Mapa de resíduos . . . . . . . . . . . . . . . . . 78

3.14 Mapa de metalicidade e velocidades da amostra do MUSE . . . . . . . 82

4.1 Janela de execução do Pfant . . . . . . . . . . . . . . . . . . 86

4.2 Síntese decomposta da estrutura hiperfina de Mn . . . . . . . . . 88

4.3 Determinação da abundância de Ca de $\mu$ Leo . . . . . . . . . . . . . . . 90

4.4 Exemplo de derivação do $\mathrm{C}, \mathrm{N}$ e $\mathrm{O} \ldots \ldots$. . . . . . . . . . . . . . 92

4.5 Exemplo de utilização do LinePlot . . . . . . . . . . . . . . . . . . . 94

4.6 Abundâncias solares vs Z . . . . . . . . . . . . . . . . . . . 95

4.7 Estimativa de carbono e nitrogênio em estrelas GIRAFFE . . . . . . . . 96

5.1 Razão $[\mathrm{Y} / \mathrm{Ba}]$ vs $[\mathrm{Fe} / \mathrm{H}]$ de Barbuy $(2014) \ldots \ldots$. . . . . . . . . . 112

5.2 Elementos leves vs Fe . . . . . . . . . . . . . . . . . 116

5.3 Elementos- $\alpha$ vs $\mathrm{Fe} \ldots \ldots \ldots$. . . . . . . . . . . . . . . . . . . . . . . .

5.4 Elementos do pico do $\mathrm{Fe}$ vs $\mathrm{Fe}$. . . . . . . . . . . . . . . . 118

5.5 Elementos do primeiro pico vs $\mathrm{Fe} \ldots \ldots$. . . . . . . . . . . . . . . 119

5.6 Elementos do segundo pico vs $\mathrm{Fe} \ldots$. . . . . . . . . . . . 120

6.1 Relações Na-O e $\mathrm{Mg}-\mathrm{Al}$. . . . . . . . . . . . . . . . . . . . . . . 122

6.2 Razão de $\mathrm{Y} / \mathrm{Ba}$ e Zr/Ba vs Fe . . . . . . . . . . . . . . . . . 124

6.3 Razão de elementos do primeiro e segundo picos . . . . . . . . . . . . . 125

A.1 Ajustes de Mn nas estrelas de referência . . . . . . . . . . . . . . 143

A.2 Ajustes de $\mathrm{Cu}$ nas estrelas de referência . . . . . . . . . . . . . . . 144

A.3 Ajustes de Sr nas estrelas de referência . . . . . . . . . . . . . . . . . . . 144

A.4 Ajustes de Zr nas estrelas de referência . . . . . . . . . . . . . . 145

A.5 Ajustes de Ba nas estrelas de referência . . . . . . . . . . . . . 145

A.6 Ajustes de La nas estrelas de referência . . . . . . . . . . . . . . . . . . 146

A.7 Ajustes de Eu nas estrelas de referência . . . . . . . . . . . . . . 146

C.1 Elementos leves vs Fe-GIRAFFE . . . . . . . . . . . . . . . 157

C.2 Elementos- $\alpha$ vs Fe - GIRAFFE . . . . . . . . . . . . . . . . 158

C.3 Elementos do pico do Fe vs Fe - GIRAFFE . . . . . . . . . . . . . 159

C.4 Elementos do primeiro pico vs Fe - GIRAFFE . . . . . . . . . . . . . 160 
C.5 Elementos do segundo pico vs Fe - GIRAFFE . . . . . . . . . . 161

C.6 Razão de Y/Ba e Zr/Ba vs Fe - GIRAFFE . . . . . . . . . . . . . . . . 161

C.7 Razão de elementos do primeiro e segundo picos - GIRAFFE . . . . . . . . 162

D.1 Movimentos próprios no campo do NGC 6522 . . . . . . . . . . . 164

D.2 $[\mathrm{Fe} / \mathrm{H}]$ vs velocidade radial das estrelas GIRAFFE . . . . . . . . . . . 166

D.3 $[\mathrm{Fe} / \mathrm{H}]$ vs velocidade radial das estrelas MUSE . . . . . . . . . . . 167

D.4 Diagramas gravidade $\mathrm{x}$ temperatura da amostra do FLAMES . . . . . 168

D.5 Diagramas gravidade x temperatura da amostra do MUSE . . . . . . . . 169

E.1 Diagrama gravidade $\mathrm{x}$ temperatura de outros trabalhos . . . . . . . . 174

E.2 Imagens multi-banda do NGC-6522 . . . . . . . . . . . . . . . . 175 



\section{Lista de Tabelas}

1.1 Parâmetros do NGC 6522 da literatura . . . . . . . . . . . . . . . 25

$2.1 \quad \log$ das observações . . . . . . . . . . . . . . . . . . . . . . . . . . [34

2.2 Velocidades radiais e fatores $\mathrm{S} / \mathrm{N}$ - UVES . . . . . . . . . . . 46

2.3 Coordenadas e velocidades radiais das estrelas selecionadas . . . . . . . . . 49

3.1 Parâmetros fotométricos . . . . . . . . . . . . 57

3.2 Lista de linhas de ferro . . . . . . . . . . . . . . . . 59

3.3 Parâmetros atmosféricos das estrelas de referência . . . . . . . . . . . . 61

3.4 Larguras equivalentes de UV2016 - DOOp . . . . . . . . . . . . . 68

3.5 Larguras equivalentes de GI2012 - DOOp . . . . . . . . . . . . . . . . 69

3.6 Larguras equivalentes de GI2016 - DOOp . . . . . . . . . . . . . . . . 70

4.1 Lista de linhas atômicas . . . . . . . . . . . . . . . . . . 89

4.2 Abundâncias elementais adotadas para Sol, Arcturus e $\mu L e o$. . . . . . . . 91

4.3 Abundâncias linha-a-linha da amostra UV2016 . . . . . . . . . . . . . . 101

4.4 Abundâncias linha-a-linha da amostra GI2012 . . . . . . . . . . . . . . . 102

4.5 Abundâncias linha-a-linha da amostra GI2016 . . . . . . . . . . . . . . . 103

4.6 Faixas da escala de calibração de erros . . . . . . . . . . . . . . . . . . . . 104

4.7 Variação das abundâncias - temperatura . . . . . . . . . . . . . 105

4.8 Variação das abundâncias - gravidade . . . . . . . . . . . . . . . . . 106

4.9 Variação das abundâncias - velocidade de micro-turbulência . . . . . . . . 106

5.1 Parâmetros e abundâncias de Barbuy et al. (2009) . . . . . . . . . . . . . 111

5.2 Parâmetros e abundâncias de Barbuy et al. (2014) . . . . . . . . . . . . . . 113 
5.3 Parâmetros espectroscópicos atuais - UVES . . . . . . . . . . . . 114

5.4 Abundâncias para as estrelas da amostra UV2016 . . . . . . . . . . . 115

B.1 Estruturas hiperfinas $-\mathrm{Na} \ldots \ldots \ldots$. . . . . . . . . . . . . . . . . . .

B.2 Estruturas hiperfinas - Mn . . . . . . . . . . . . . . . . 148

B.3 Estruturas hiperfinas $-\mathrm{Cu} \ldots \ldots \ldots$. . . . . . . . . . . . . . . . . . .

B.4 Estruturas hiperfinas $-\mathrm{Ba} \ldots \ldots . \ldots . . \ldots 150$

B.5 Estruturas hiperfinas - $\mathrm{La} \ldots \ldots \ldots$. . . . . . . . . . . . . . . .

B.6 Estruturas hiperfinas $-\mathrm{Eu} \ldots \ldots \ldots$. . . . . . . . . . . . . . . . . .

C.1 Parâmetros espectroscópicos atuais - GIRAFFE . . . . . . . . . . 154

C.2 Abundâncias para as estrelas da amostra GI2012 . . . . . . . . . . . . . 155

C.3 Abundâncias para as estrelas da amostra GI2016 . . . . . . . . . . . . 156

D.1 Parâmetros dinâmicos da amostra do GIRAFFE . . . . . . . . . . . . 165

E.1 Parâmetros dinâmicos de Barbuy 09 . . . . . . . . . . . . . 172 


\section{Sumário}

1. Introdução . . . . . . . . . . . . . . . . . . . . . . 23

2. Observações, redução e tratamento de dados . . . . . . . . . . . . . . . . . 31

2.1 Observações . . . . . . . . . . . . . . . . . . . . . . . . 31

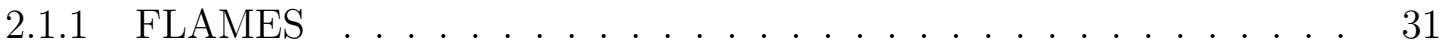

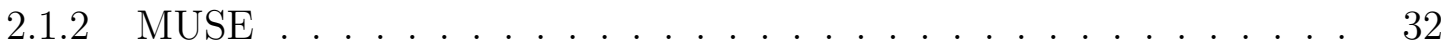

2.2 Redução de dados . . . . . . . . . . . . . . . . . . . . . . . . . . . 33

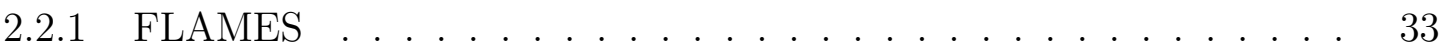

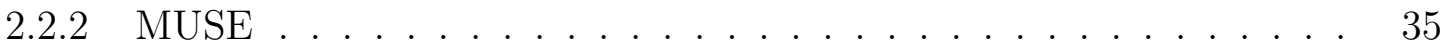

2.3 Tratamento dos dados . . . . . . . . . . . . . . . . . . [36

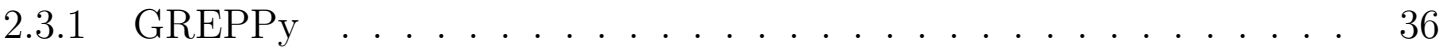

2.3.1.1 computeSNR ................... 37

2.3.1.2 normalize .................. . . . . . . . . .

2.3.1.3 cosmiclean ..................... 38

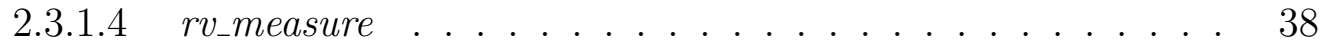

2.3.1.5 rv_dopshift ..................... . . 40

2.3.1.6 struc_targets . . . . . . . . . . . . . 40 40

2.3.1.7 combine_targets ................ 40

2.3.1.8 data_view ...................... 41

2.3.1.9 write_data ................... 41

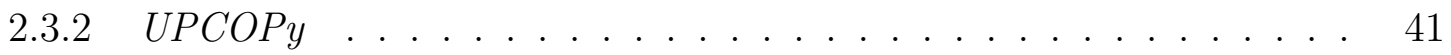

2.3.2.1 Rippling do contínuo e normalização segmentada . . . . . 43

2.3.2.2 Medição das velocidades radiais . . . . . . . . . . . . . . 44 
2.3.2.3 Determinação do S/N e combinação . . . . . . . . . 4 45

2.3.3 Pré-filtragem de estrelas-membro . . . . . . . . . . . . 48

2.3.4 Extração dos espectros dos cubos de dados do MUSE . . . . . . . 48

2.3.4.1 Catálogo de estrelas ............. 50 50

2.3.4.2 PampelMUSE ................... 52

3. Parâmetros atmosféricos .................... 55

3.1 Parâmetros fotométricos . . . . . . . . . . . . . 56

3.2 Lista de linhas de ferro . . . . . . . . . . . . . . 56

3.2.1 Síntese espectral decomposta . . . . . . . . . . . . 60

3.3 Larguras equivalentes . . . . . . . . . . . . . . . . . 61

$3.3 .1 \quad$ Daospec e DOOp ..................... 63

3.3.2 Medições das larguras equivalentes . . . . . . . . . . . . . 64

3.4 Derivação dos parâmetros atmosféricos . . . . . . . . . . . 67 67

3.4.1 Modelos de atmosfera . . . . . . . . . . . . . 75

3.4 .2 abon2 ........................... 75

3.4 .3 Convergência dos parâmetros . . . . . . . . . . 76

3.4 .4 Análise de erros . . . . . . . . . . . . . . 77

3.5 Determinação dos parâmetros atmosféricos da amostra do MUSE . . . . . 80

3.5.1 Etoile ........................... 80

4. Abundâncias elementais . . . . . . . . . . . . . . . 83

4.1 Síntese espectral . . . . . . . . . . . . . . . . . . . 84

4.2 Linhas moleculares . . . . . . . . . . . . . . . . . . . . 85

4.3 Linhas atômicas . . . . . . . . . . . . . . . . 85

4.3.1 Estrutura hiperfina . . . . . . . . . . . . . . . 87

4.3.2 Síntese espectral decomposta . . . . . . . . . . . 87

4.3.3 Lista de linhas atômicas . . . . . . . . . . . . . 88

4.4 Abundâncias adotadas para as estrelas de referência . . . . . . . . . . . 88

4.5 Ajuste e derivação das abundâncias . . . . . . . . . . . . . . . . 92

4.5.1 LinePlot. . . . . . . . . . . . . . . . . 92

4.6 Elementos analisados . . . . . . . . . . . . . . . . . . . . . 95

4.6 .1 Elementos leves . . . . . . . . . . . . . . 95 


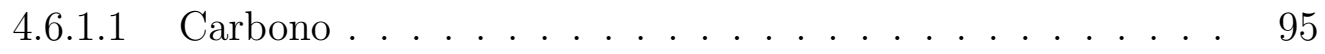

4.6.1.2 Nitrogênio . . . . . . . . . . . . . . . . . . . . . 96

4.6.1.3 Sódio e Alumínio . . . . . . . . . . . . . . . . . . . 96

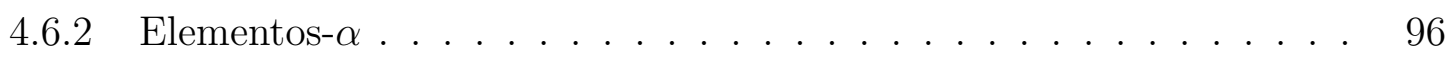

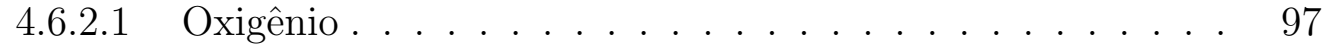

4.6.2.2 Magnésio . . . . . . . . . . . . . . . . . . 97

4.6.2.3 Silício e cálcio . . . . . . . . . . . . . . . . . 97 97

4.6.2.4 Titânio . . . . . . . . . . . . . . . . . . . . 98

4.6 .3 Elementos do pico do ferro . . . . . . . . . . . . . . . . 98

4.6.3.1 Manganês . . . . . . . . . . . . . . . . . . . 98

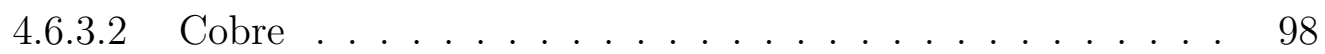

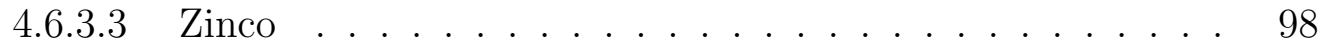

4.6.4 Elementos pesados . . . . . . . . . . . . . . . . . . . . 99

4.6.4.1 Elementos do primeiro pico - estrôncio, ítrio e zircônio . . 99

4.6.4.2 Elementos do segundo pico - bário, lantânio, cério e neodímio 99

4.6.4.3 Európio . . . . . . . . . . . . . . . . . . 100

4.6.5 Abundâncias linha-a-linha . . . . . . . . . . . . . . . . 100

4.7 Análise de erros . . . . . . . . . . . . . . . . . . . . . 100

4.7.1 Escala de calibração da variação das abundâncias . . . . . . . . . 104

5. Resultados . . . . . . . . . . . . . . . . . . . . . . 109

5.1 Resultados anteriores . . . . . . . . . . . . . . . . . . . . 110

5.2 Resultados atuais . . . . . . . . . . . . . . . . . . . 112

5.2 .1 Parâmetros atmosféricos ‥ . . . . . . . . . . . . . 112

5.2 .2 Abundâncias elementais . . . . . . . . . . . . . . . . . . 114

6. Discussão ． . . . . . . . . . . . . . . . . . . . . . . . . . . 121

6.1 Padrões das abundâncias . . . . . . . . . . . . . . . . . . . . . . . . 121

6.1 .1 Elementos leves . . . . . . . . . . . . . . . . . . . . . 121

6.1 .2 Elementos- $\alpha \ldots \ldots$. . . . . . . . . . . . . . . . . . 122

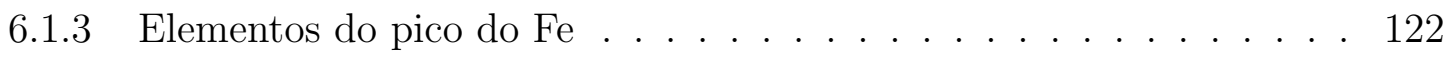

6.1 .4 Elementos pesados . . . . . . . . . . . . . . . . . . 123 
7. Conclusões . . . . . . . . . . . . . . . . . . . . . . . 127

Referências . . . . . . . . . . . . . . . . . . . 129

Apêndice

141

A. Ajustes das linhas espectrais para derivação das abundâncias nas estrelas de referência . . . . . . . . . . . . . . . . . . . 143

B. Estruturas hiperfinas calculadas . . . . . . . . . . . . . . . . 147

C. Resultados preliminares da amostra do GIRAFFE . . . . . . . . . . . . . 153

D. Movimentos próprios . . . . . . . . . . . . . . . . . . . . 163

E. Análise de pertinência das amostras GIRAFFE . . . . . . . . . . . . 171 
Capítulo 1

\section{Introdução}

Os aglomerados globulares moderadamente pobres em metais do bojo Galáctico constituem provavelmente a primeira população estelar da Galáxia. Por esta razão, há grande interesse em estudar as abundâncias dos elementos em estrelas individuais destes aglomerados, a fim de entender a evolução química dos estágios iniciais da Galáxia. Estrelas e aglomerados pobres em metais do bojo representam uma peça crucial no quebra-cabeça da formação da Via Láctea. NGC 6522 e seus campos circundantes, localizados na Grande Nuvem de Sagitário, foram observados por Baade (1946). Ele identificou parte da nuvem como uma janela atingindo o bojo nuclear, desde então chamada de Janela de Baade. Baade concluiu, pela primeira vez, que sua população estelar é do tipo II. Blanco e Blanco (1984) e Walker e Mack (1986) apresentaram magnitudes B, V sobre NGC 6522, e os últimos autores concluíram que o NGC 6522 é moderadamente pobre em metais. Walker e Terndrup (1991) mostraram que a distribuição de metalicidade das variáveis RR Lyrae no bojo galáctico é mais rica em metais do que no halo, com uma metalicidade de pico em $[\mathrm{Fe} / \mathrm{H}]-1,0$. Lee (1992) interpretou como um efeito de idade, dado que se espera que mais estrelas ricas em metal povoem o ramo horizontal vermelho (RHB), e apenas estrelas de menor massa (e mais velhas) seriam mais azuis no intervalo RR Lyrae. Isto implica também que a população estelar mais antiga da Galáxia é encontrada no bojo galáctico. Lee et al. (2007) mostram que todos os aglomerados com ramos horizontais azuis estendidos (EHB) são os aglomerados globulares mais massivos e brilhantes da Via Láctea, todos eles mais brilhantes que as magnitudes $M_{V}<-7$.

O NGC 6522 é classificado como tendo um EHB moderadamente estendido e magnitude integral estimada de $M_{V}=-7,67$ (Harris, 1996), ou -7,99 (Armandroff, 1989), e está,

portanto, no limiar da distribuição de aglomerados massivos. Lee et al. (2007) sugeriram 
que NGC 6522 está entre as relíquias dos primeiros blocos de construção que primeiro foram montados para formar o núcleo galáctico e que agora são observados como aglomerados globulares EHB, relativamente pobres em metais. Portanto, NGC 6522, juntamente com outros aglomerados protuberantes, como HP 1 (Barbuy et al. 2006 e Barbuy et al. 2016) e NGC 6558 (Barbuy et al., 2007), poderiam ser relíquias de subsistemas de formação estelar primitivos que primeiro formaram a população do centro galáctico. Isso poderia ter sido alcançado tanto por fusões dissipativas quanto por fusões sem dissipação, como foi previsto por simulações recentes de $\Lambda$ CDM de picos de alto $\sigma$ (por exemplo, Diemand et al. 2005; Moore et al. 2006). O aglomerado globular NGC 6522, também designado por GCl 82, C 1800-300 e Cl VDBH 256, está localizado em J2000 $\alpha=18: 03: 34.08, \delta=$ $-30: 02: 02.3$, e projetado a $4^{\circ}$ do centro galáctico $\left(l=1,0246^{\circ}, b=-3,9256^{\circ}\right)$. Kerber et al. (2018) derivou uma distância $d_{\odot}=7.2 \mathrm{kpc}$ do Sol e a $\mathrm{R}_{G C}=0.96 \mathrm{kpc}$ do centro Galáctico. Rossi et al. (2015) derivaram movimentos próprios de $\mu_{l}=0.4 \pm 0,6$ mas/ano, $\mu_{b}=-3.1 \pm 0,34 \mathrm{mas} /$ ano, e Barbuy et al. (2014) deriva uma velocidade radial média de -14.3 km/s para o NGC 6522, de onde conclui-se que o aglomerado é confinado ao bojo. Os parâmetros básicos de NGC 6522 estão reunidos na tabela 1.1 .

Minniti et al. (1995) apresentou um primeiro diagrama cor-magnitude K vs. J-K (CMD) de NGC 6522. O aglomerado é pós-colapso de núcleo (parâmetro de concentração c $=2,50$ ), um raio de núcleo $\mathrm{rc}=12.32$ " Kerber et al., 2018) e um raio de meia luz de log $\mathrm{rh}=1.78^{\prime}$ (Trager et al., 1995). Entre os aglomerados pobres em metal do bojo interno, Terzan 4 $([\mathrm{Fe} / \mathrm{H}]=-1,6)$ foi estudado com espectroscopia de alta resolução no infravermelho Origlia e Rich (2004), revelando um aumento significativo dos elementos- $\alpha$. HP $1([\mathrm{Fe} / \mathrm{H}]=-1.0)$ e NGC $6558([\mathrm{Fe} / \mathrm{H}]=-1.0)$ foram estudados com espectroscopia de alta resolução no óptico (Barbuy et al. 2006, Barbuy et al. 2007, Barbuy et al. 2016), mostrando enriquecimento moderado em elementos- $\alpha$.

As abundâncias de elementos pesados em estrelas muito antigas foram interpretadas por Truran (1981) por corresponder a produtos de processo-r (processo nucleossintético de captura rápida de nêutrons) em supernovas de tipo II, pois o enriquecimento do processo-s (processo nucleossintético de captura lenta de nêutrons) não pode ocorrer prontamente no início da Galáxia. Por outro lado, é bem conhecido que a rotação em estrelas massivas pode explicar abundâncias de nitrogênio primário em estrelas de baixa metalicidade, devido à mistura interna induzida pela rotação (por exemplo,Barbuy 1983; Chiappini et al. 2006). 
Tabela 1.1 - Parâmetros do NGC 6522 da literatura. Referências: 1: Zinn (1985); 2: Armandroff (1989); 3: Harris (1996); 4: Rutledge et al. (1997); 5: Rutledge et al. (1997) (dados em escalas de metalicidade de Zinn \& West 1984 e Carretta \& Gratton); 6: Terndrup e Walker (1994); 7: Terndrup et al. (1998) $\left(A_{v}\right.$ $=1.42$ ); 8: Piotto et al. (2002); 9: Kraft e Ivans (2003); 10: Bica et al. (2006)); 11: Kerber et al. (2018) $\left([\mathrm{Fe} / \mathrm{H}]\right.$ e $V_{r}$ de Barbuy et al. 2014.

\begin{tabular}{cccccc}
\hline \hline E(B-V) & {$[\mathrm{Fe} / \mathrm{H}]$} & $\begin{array}{c}V_{r} \\
(\mathrm{~km} / \mathrm{s})\end{array}$ & $(\mathrm{m}-\mathrm{M})_{0}$ & $\begin{array}{c}d_{\odot} \\
(\mathrm{kpc})\end{array}$ & Ref. \\
\hline 0.45 & -1.44 & +8 & 15.37 & 6.2 & 1 \\
- & -1.44 & -3 & - & - & 2 \\
0.48 & -1.44 & -21.1 & 16.52 & 7.8 & 3 \\
0.50 & -1.44 & -18.7 & - & - & 4 \\
- & $-1.50 /-1.21$ & - & - & - & 5 \\
0.52 & -1.60 & - & - & - & 6 \\
0.39 & -1.28 & -28.5 & - & 7.3 & 7 \\
0.48 & -1.44 & - & - & 7.4 & 8 \\
- & $-1.44 /-1.42 /-1.35$ & - & - & - & 9 \\
0.48 & -1.44 & - & - & 7.8 & 10 \\
0.54 & -0.95 & -14.3 & 14.29 & 7.2 & 11 \\
\hline \hline
\end{tabular}

Foi agora demonstrado que elementos-s também podem ser produzidos em estrelas massivas de rotação rápida, ou spinstars (Pignatari et al. 2008, Frischknecht et al. 2016). Chiappini (2013) descreveu o impacto das spinstars no enriquecimento químico das primeiras estrelas do Universo, e como alguns dos dados do halo de estrelas muito pobres em metais podem ser mais bem correspondidos quando a contribuição das spinstars é levada em conta. Chiappini et al. (2011) relatou os primeiros cálculos de nucleossíntese detalhados do processo-s feitos por Frischknecht e colaboradores para uma estrela massiva de 40 massas solares com rápida rotação, com uma metalicidade $[\mathrm{Fe} / \mathrm{H}]=-3.8$ e velocidade rotacional Vrot $=500 \mathrm{~km} / \mathrm{s}$. Mostrou-se que os elementos do processo-s nesta estrela foram enriquecidos em até quatro ordens de grandeza em relação a uma estrela sem rotação de mesma massa e metalicidade (figura 1.1). Uma grade estendida de modelos de spinstars foi posteriormente computada e publicada em Frischknecht et al. (2016). Em particular, estes cálculos indicam um aumento dos elementos pesados Sr, Y, La e Ba que são mensuráveis em espectros estelares.

Os produtos das primeiras supernovas muito pobres em metais no halo galáctico podem ser estudados nas estrelas mais pobres em metais (por exemplo, Cayrel et al. 2004), 

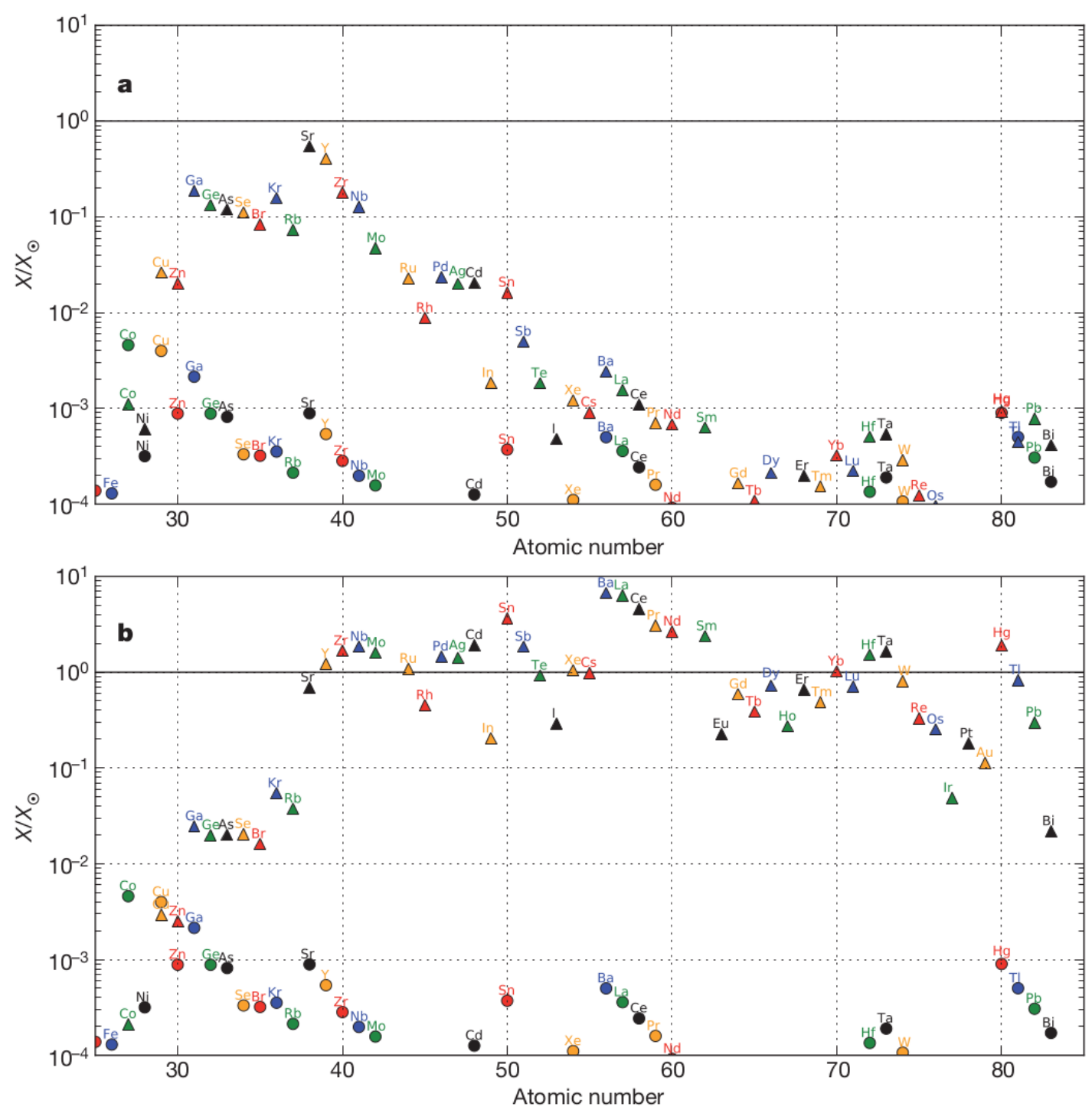

Figura 1.1: Impacto da rotação na produção de elementos de processo-sem estrelas massivas pobres em metal (Chiappini et al., 2011). Os modelos mostram a produção de elementos-s (onde $X / X_{\odot}$ é a fração de massa dos átomos normalizada para solar) previsto em uma estrela de $40 M_{\odot} \operatorname{com}[\mathrm{Fe} / \mathrm{H}]=-3.8$, que não gira (círculos), e com uma velocidade de rotação inicial de $500 \mathrm{~km} / \mathrm{s}$ (triângulos). Estes modelos são mostrados em duas fases diferentes de queima de He: a, no início do processo-s (cerca de 127000 anos antes da exaustão de He); e b, no final da fase da queima central de He. A rotação aumenta a produção de elementos do processo-s em quatro ordens de magnitude vezes $X_{\odot}$, abundância solar de determinado elemento.

enquanto que no bojo galáctico uma taxa de formação de estrelas aumentada por um fator 10 em relação ao halo (por exemplo, Ballero et al. 2007) resultou nas estrelas de bojo mais antigas com $[\mathrm{Fe} / \mathrm{H}]=-1.0$ Chiappini et al. (2015). Evidência para as populações estelares do bojo mais antigas com $[\mathrm{Fe} / \mathrm{H}]=-1,0$ foram relatadas em Lee (1992) e Dékány et al. (2013), em estudos de estrelas RR Lyrae no bojo com essa metalicidade. Além disso, 
um número significativo de aglomerados globulares muito antigos com essa metalicidade também foi encontrado no bojo interno (Minniti et al. 1995; Rich et al. 1998; Barbuy et al. 2009: Bica et al. 2016, Barbuy et al. 2018). Em Chiappini et al. (2011) os produtos estelares das spinstars de $40 \mathrm{M}_{\odot}$ foram comparados com as razões [Y/Ba] e [Sr/Ba] observadas em estrelas de halo muito pobres em metais e com as abundâncias derivadas de estrelas gigantes vermelhas do aglomerado globular do bojo NGC 6522, relatadas pela primeira vez por Barbuy et al. (2009) (figura 1.2). Chiappini et al. (2011) sugeriu que estrelas do bojo com uma metalicidade de $[\mathrm{Fe} / \mathrm{H}]=-1$ poderiam também conter informações sobre a natureza das primeiras gerações de estrelas, como é sabido ser o caso de estrelas de halo com metalicidades abaixo de $[\mathrm{Fe} / \mathrm{H}]=-3$ (por exemplo, Truran 1981; Cayrel et al. 2004). Embora existam estrelas do bojo com metalicidades mais baixas, a distribuição de metalicidade do bojo mostra um corte acentuado em torno de $[\mathrm{Fe} / \mathrm{H}]=-1$ (por exemplo, Ness et al. 2014; Zoccali et al. 2017). Apesar das incertezas nos dados de NGC 6522, as oito estrelas medidas mostraram uma dispersão na razão [Y/Ba] similar àquela observada em estrelas de halo pobres em metais $(\mathrm{com}[\mathrm{Fe} / \mathrm{H}]<-3)$. Em Chiappini et al. (2011) foi então sugerido que os maiores valores de $[\mathrm{Y} / \mathrm{Ba}]$ observados no halo (em torno de $[\mathrm{Fe} / \mathrm{H}]$ $=-3$ ) e bojo (em torno de $[\mathrm{Fe} / \mathrm{H}]=-1$ ) foram causados pela contribuição de processo-s das spinstars. De fato, de acordo com os modelos de spinstars, sua produção seria fortemente dependente da massa e da velocidade de rotação, o que explicaria a dispersão observada na razão de dois elementos químicos dominados pela nucleossíntese do processo-s de dois picos distintos do processo. Embora esta explicação pareça única para três estrelas da NGC 6522, outras explicações alternativas para estrelas com menor razão [Y/Ba] em metalicidades próximas a $[\mathrm{Fe} / \mathrm{H}]=-1$ não podem ser descartadas, como a contribuição da transferência de massa de estrelas no ramo assintótico das gigantes Bisterzo et al. (2010).

Além disso, também ficou claro que a contribuição das spinstars é provavelmente complementar àquela proveniente de sítios nucleossintéticos de processo-r (por exemplo, Goriely et al. 2013; Nakamura et al. 2013; Wanajo 2013; Qian 2012; Winteler et al. 2012; Arcones e Martínez-Pinedo 2011). Mais recentemente, foi possível testar quantitativamente essas ideias para as estrelas do halo graças à grade mais completa de modelos estelares do tipo spinstar, fornecida em Frischknecht et al. (2016). Com esta grade foram calculados modelos de evolução química não homogênea para o halo (Cescutti et al. 2013; Cescutti e Chiappini 2014) e mostraram que de fato a dispersão nas razões de abundâncias observadas 


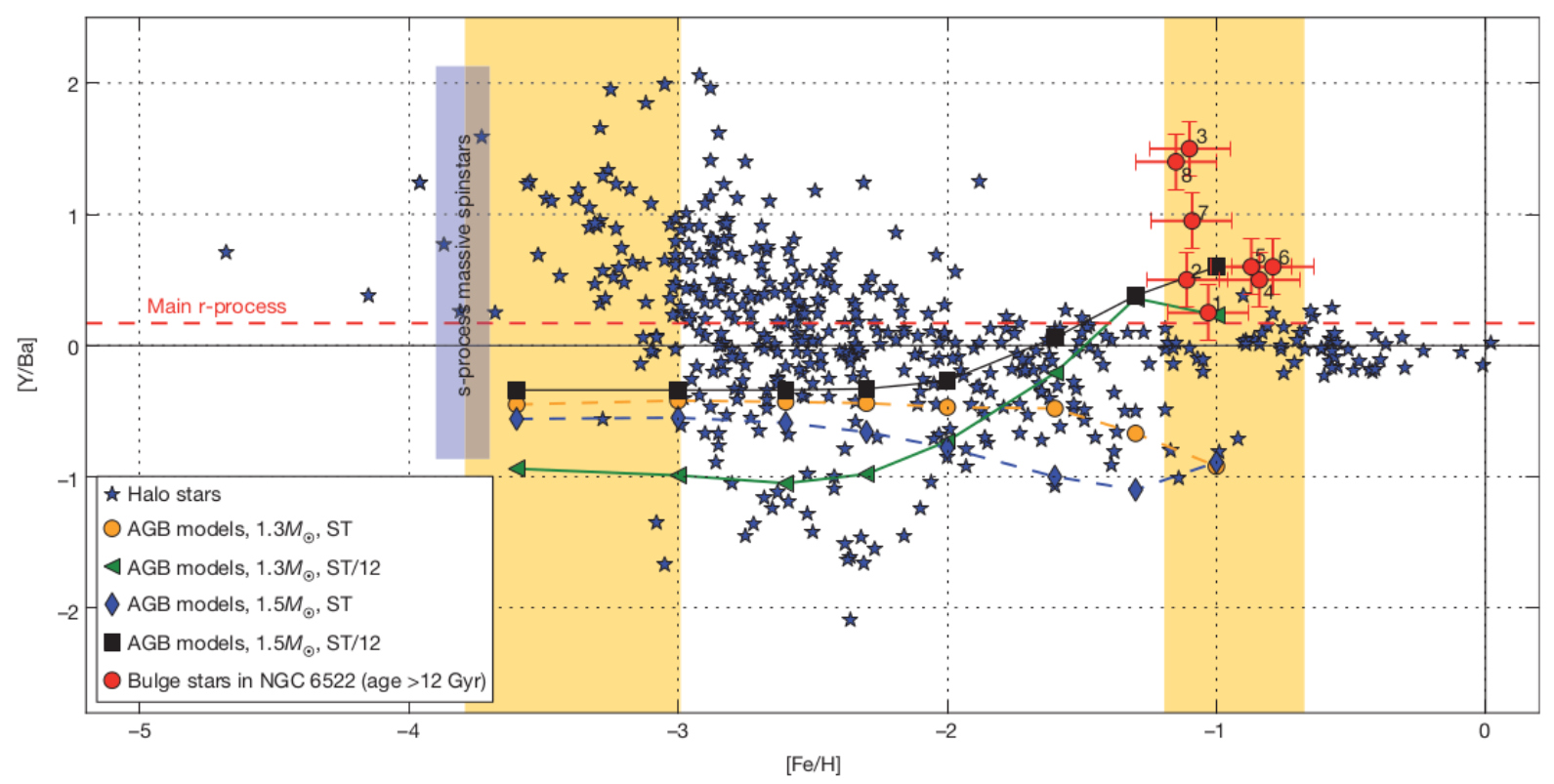

Figura 1.2: Razão $[\mathrm{Y} / \mathrm{Ba}]$ vs $[\mathrm{Fe} / \mathrm{H}]$ (Chiappini et al. (2011)) para estrelas do halo e do aglomerado do bojo NGC 6522 .

de dois elementos predominantemente de processo-s em estrelas com metalicidade entre -4 $<[\mathrm{Fe} / \mathrm{H}]<-3$ pode ser bem explicada se a contribuição do processo-s das spinstars no início do enriquecimento químico do Universo for considerada.

Aoki et al. (2013) propuseram um cenário alternativo para a dispersão em [Sr/Ba]. Sua sugestão é que a explosão por colapso do núcleo das supernovas de tipo II poderia produzir o processo-r, mas em alguns casos o material rico em processo-r não é ejetado por causa do colapso subsequente da estrela de prótons/nêutrons em um buraco negro. Por outro lado, não há atualmente nenhuma evidência clara de simulações de evolução química galáctica de que processos primários explosivos isolados possam explicar a distribuição observada de $[\mathrm{Sr} / \mathrm{Ba}]$ vs $[\mathrm{Fe} / \mathrm{H}]$ no halo Galáctico, com um pico observado em cerca de $[\mathrm{Fe} / \mathrm{H}] \approx-3$, enquanto este é o caso para o processo de spinstars (Cescutti e Chiappini, 2014). Este resultado também é confirmado tendo em conta uma recente re-análise de observações de Sr em uma grande amostra de estrelas pobres em metais (Hansen et al., 2013). Essa característica peculiar do processo-s de spinstars deve-se à natureza intrínseca do processo neste cenário, que não é primária, mesmo que a principal fonte de nêutrons não dependa da metalicidade inicial da estrela (Pignatari et al. 2008; Frischknecht et al. 2012).

Para o bojo (Chiappini et al., 2015), foi encontrado que a dispersão nessas razões de abundância é menor, o que é uma consequência da maior taxa de formação de estrelas. 
Curiosamente, esses novos modelos não podem explicar as grandes superabundâncias relatadas em Barbuy et al. (2009) e Chiappini et al. (2011). Como mostrado em Barbuy et al. (2014), os novos espectros de alta qualidade analisados sugerem valores [Sr/Ba] e [Y/Ba] mais baixos do que os relatados anteriormente com base nos espectros de resolução inferior do GIRAFFE e, portanto, estão de acordo com as previsões do modelo.

Buscando desembaralhar os cenários de evolução química para melhor explicar as abundâncias observadas no NGC 6522, uma maior amostra das estrelas do aglomerado se faz necessária, derivando as abundâncias dos elementos chave que caracterizam o enriquecimento por processo-s via spinstars.

No presente trabalho, analisamos novos espectros de alta resolução $(\mathrm{R} \sim 22000$ e $\mathrm{R}$ $\sim 45000$ ) de estrelas no campo do aglomerado NGC 6522, obtidos com o espectrógrafo multi-objetos FLAMES, instalado no UT-2 do Very Large Telescope.

Como comparativo, também foram analisados os cubos de dados disponíveis publicamente para o NGC 6522, obtidos com o espectrógrafo de campo integral MUSE, instalado no UT-4 do Very Large Telescope.

Os dados e sua redução são descritos no Capítulo 2, a análise das larguras equivalentes e derivação dos parâmetros atmosféricos é descrita no Capítulo 3, as listas de linhas e derivação das abundâncias químicas são descritas no Capítulo 4, os resultados são apresentados no Capítulo 5, a discussão é feita no Capítulo 6 e as conclusões são apresentadas no Capítulo 7. Figuras e tabelas contendo derivações de abundâncias das estrelas de referência, ajustes de linhas espectrais, dados de estruturas hiperfinas e análise de movimentos próprios são apresentadas no Apêndice, bem como resultados e discussão sobre a análise preliminar das amostras obtidas com o GIRAFFE e comparação com os resultados obtidos para o MUSE. 
Capítulo 2

\section{Observações, redução e tratamento de dados}

\subsection{Observações}

\subsubsection{FLAMES}

As observações espectroscópicas das estrelas analisadas foram obtidas no VLT (Very Large Telescope) do ESO, sob os programas 088.D-0398 (observado em outubro/2011 e março/2012) e 097.D-0175 (observado em março e julho/2016), utilizando o instrumento FLAMES (Fibre Large Array Multi Element Spectrograph, Pasquini et al. 2002), instalado em um dos focos Nasmyth do UT2 (Unit Telescope 2) do VLT, ambos como Principal Investigadora PI: B. Barbuy.

O FLAMES é um instrumento multi-objetos baseado em fibras ópticas, constituído pela interface OzPoz que posiciona fibras individuais ou IFUs (Integral Field Units) no foco do telescópio dentro de um campo de 25 arcmin, alimentando o espectrógrafo GIRAFFE (Hammer et al., 1999) no modo MEDUSA com 132 fibras a uma resolução espectral de R 5000 até $\mathrm{R} \sim 30000$, e o braço vermelho do espectrógrafo UVES (Ultraviolet and Visible Echelle Spectrograph, Dekker et al. 2000) com até 8 fibras a uma resolução espectral de R $\sim 45000$ quando utilizado juntamente com o FLAMES.

Os alvos para o GIRAFFE do programa de 2012 (GI2012) foram alocados com base nos dados fotométricos apresentados em Zoccali et al. (2008), onde são selecionadas estrelas do RGB (Red Giant Branch, ramo das gigantes vermelhas no diagrama H-R) com cerca de 1 magnitude mais brilhantes que o nível do red clump (agrupamento vermelho, estrelas da porção mais vermelha do ramo horizontal que intersectam o RGB), ao longo de todo o intervalo de cor do ramo no índice V-I. Na seleção dos alvos para o GIRAFFE de 2016 (GI2016), foram usados os dados fotométricos apresentados em Rossi et al. (2015), onde 
o catálogo é composto por estrelas que tiveram seus movimentos próprios determinados e selecionados dentro de $\left(\mu_{\alpha}, \mu_{\delta}\right)=(3.6 \pm 0.6,-1.2 \pm 0.3)$ milissegundos de arco por ano, de modo a aumentar a probabilidade de serem estrelas-membro do aglomerado. A alocação das fibras do GIRAFFE foi feita de maneira automática pelo software de posicionamento do OzPoz, de maneira a alocar o máximo número de fibras disponíveis, cobrindo aleatoriamente a lista de possíveis alvos fornecidos ao longo de todo o campo de 25 arcmin. Como resultado, foram alocadas 112 estrelas a serem observadas no programa de 2012 e 110 estrelas no programa de 2016. A alocação das fibras do UVES de 2016 (UV2016) foi feita manualmente, de modo a selecionar as estrelas de interesse apresentadas previamente. Os dados UVES de 2012 já haviam sido analisados em trabalho anterior e publicados em Barbuy et al. (2014).

A faixa espectral escolhida para GI2012 inclui 4 exposições no setup HR11 (559.7 $584.0 \mathrm{~nm})$ e 3 exposições no setup HR12 (582.1 - $614.6 \mathrm{~nm})$ do FLAMES, cobrindo a banda molecular de $\mathrm{C}_{2}$ em $5635 \AA$, e a linha do $\mathrm{Cu}$ em $5781 \AA$. A faixa do GI2016 possui 3 exposições no setup HR11, 4 no setup HR13 (612.0 - 640.5 nm), e 3 no setup HR14A (630.8 - $670.1 \mathrm{~nm}$ ), cobrindo também a banda molecular de $\mathrm{C}_{2}$ e as linhas de BaII, EuII, [OI], CaI, TiI e TilI. Nestas configurações, os espectros possuem resolução em torno de R 22000. Para o UV2012 e UV2016, ambas observações utilizaram a configuração centrada em $5800 \AA$ A, cobrindo de $\sim 4780$ a $\sim 6810 \AA$ A. Como o braço vermelho do UVES possui um mosaico de 2 detectores CCD, e por consequência há um espaço entre eles, a cobertura espectral possui uma descontinuidade que vai de $\sim 5770$ a $\sim 5830 \AA$.

\subsubsection{MUSE}

Observações do campo central do NGC 6522 foram obtidas sob o programa 095.D0629 entre maio e setembro/2015, disponíveis publicamente desde 12 de setembro/2016, utilizando o instrumento MUSE (Multi-Unit Spectroscopic Explorer, Bacon et al. 2010), instalado em um dos focos Nasmyth do UT4 (Unit Telescope 4) do VLT. Estes dados são parte de um grande programa espectroscópico em aglomerados globulares, liderado pelo PI: S. Dreizler.

O MUSE é um espectrógrafo de campo integral panorâmico que cobre a região do óptico, baseado em 24 unidades espectrográficas onde cada uma delas amostra secções adjacentes do campo de 1'x1' minuto de arco a uma resolução espacial de 0.3"segundos 
de arco e a uma resolução espectral de $\mathrm{R} \sim 2000$ (no azul) até $\mathrm{R} \sim 4000$ (no vermelho), cobrindo de $\sim 4800$ a $\sim 9300 \AA$.

Os dados disponíveis pelo MUSE amostram o campo central do NGC 6522, com um ligeiro deslocamento em ascensão reta, para incluir estrelas mais distantes do centro.

O log das observações espectroscópicas é exibido na tabela 2.1. Cada exposição é denominada Observation block (OB) pelo próprio ESO, e no caso, o rótulo de cada OB tem por recomendação levar o setup utilizado para o GIRAFFE. No caso do MUSE, a denominação original foi seguida.

\subsection{Redução de dados}

\subsubsection{FLAMES}

A redução dos dados obtidos com o GIRAFFE foi realizada utilizando a versão 2.16.2 da pipeline de redução do GIRAFFE (Blecha et al., 2000) fornecida pelo ESO em ambiente Reflex (Freudling et al., 2013). O Reflex é um ambiente de redução de dados do ESO que automaticamente associa os tipos de arquivo utilizados no processo da redução, categoriza cada um, canaliza as imagens e tabelas brutas e processadas por cada etapa da cascata de calibração e extração dos espectros, e retorna os produtos finais organizados por data de execução nos subdiretórios estipulados pelo usuário. A pipeline do GIRAFFE consiste em "receitas", programas sequenciais que processam uma ou mais imagens brutas obtidas pelas exposições do espectrógrafo (objeto científico e calibrações), retornando imagens e/ou tabelas de dados processados a serem utilizadas nas próximas etapas (receitas) do processo de redução.

As etapas de redução de dados do GIRAFFE consistem em:

- Combinação das imagens de ruído de leitura do CCD (bias);

- Combinação das imagens flat-field com cálculo das posições dos espectros das fibras e da transmissão individual de cada fibra;

- Calibração dos comprimentos de onda ao longo do eixo de dispersão espectral na imagem por meio de fibras dedicadas usando uma lâmpada de Th-Ar;

- Remoção de bias, correção do flat-field, correção da transmissão das fibras e - Extração dos espectros das fibras da imagem bruta do objeto científico.

Após a redução, cada exposição tem seus produtos salvos em uma imagem (datapack) 
Tabela 2.1 - Log das observações espectroscópicas dos programas 088.D-0398(A) e 097.D-0175(A), realizadas entre 2011-2012 e em 2016, respectivamente. Os valores de airmass e seeing são valores médios ao longo das exposições.

\begin{tabular}{|c|c|c|c|c|c|}
\hline Data & $\mathrm{UT}$ & exposição(s) & Airmass & Seeing $\left({ }^{\prime \prime}\right)$ & OB \\
\hline \multicolumn{6}{|c|}{ Programa 088.D-0398(A) } \\
\hline 2011-10-08 & $00: 45: 54$ & 2750 & 1.462 & 0.82 & H11-1 \\
\hline 2011-10-08 & $01: 34: 37$ & 2750 & 1.853 & 1.29 & H11-2 \\
\hline 2012-03-06 & $07: 38: 32$ & 2750 & 1.579 & 1.15 & H11-3 \\
\hline 2012-03-06 & $08: 28: 44$ & 2750 & 1.260 & 0.93 & H11-4 \\
\hline 2012-03-07 & $07: 47: 56$ & 2750 & 1.489 & 0.81 & $\mathrm{H} 12-1$ \\
\hline 2012-03-07 & $08: 39: 16$ & 2750 & 1.270 & 0.73 & $\mathrm{H} 12-2$ \\
\hline $2012-03-25$ & $08: 31: 47$ & 2750 & 1.087 & 0.64 & $\mathrm{H} 12-3$ \\
\hline \multicolumn{6}{|c|}{ Programa 097.D-0175(A) } \\
\hline 2016-05-17 & $07: 22: 18$ & 2400 & 1.007 & 0.40 & H11-1 \\
\hline 2016-05-17 & 08:05:08 & 2400 & 1.033 & 0.47 & H11-2 \\
\hline 2016-05-17 & $08: 52: 35$ & 2400 & 1.099 & 0.47 & H11-3 \\
\hline 2016-07-11 & $02: 33: 35$ & 2400 & 1.028 & 0.96 & H13-1 \\
\hline 2016-07-21 & $03: 27: 16$ & 2400 & 1.016 & 0.51 & H13-2 \\
\hline 2016-07-21 & $04: 43: 37$ & 2400 & 1.112 & 0.54 & H13-3 \\
\hline 2016-07-21 & 06:03:32 & 2400 & 1.373 & 0.54 & H13-4 \\
\hline 2016-07-22 & $04: 48: 26$ & 2400 & 1.131 & 0.48 & H14A-1 \\
\hline $2016-07-22$ & $05: 40: 15$ & 2400 & 1.288 & 0.45 & H14A-2 \\
\hline 2016-07-22 & $06: 33: 29$ & 2400 & 1.574 & 0.63 & H14A-3 \\
\hline \multicolumn{6}{|c|}{ Programa 095.D-0629(A) } \\
\hline 2015-05-12 & 09:42:00 & 100 & 1.158 & 0.87 & $2003564791 / 3$ \\
\hline 2015-05-12 & $09: 45: 20$ & 100 & 1.167 & 0.83 & $2003564792 / 3$ \\
\hline 2015-05-12 & 09:48:38 & 100 & 1.176 & 0.83 & $2003564793 / 3$ \\
\hline 2015-09-12 & 01:50:43 & 100 & 1.192 & 1.34 & $2003615671 / 3$ \\
\hline 2015-09-12 & 01:54:01 & 100 & 1.202 & 1.34 & $2003615672 / 3$ \\
\hline 2015-09-12 & $01: 57: 21$ & 100 & 1.212 & 1.30 & $2003615673 / 3$ \\
\hline
\end{tabular}


contendo os espectros unidimensionais extraídos e outra com os respectivos erros, ambas contendo tabelas de informação sobre cada fibra.

Na redução dos dados UVES foi utilizada a versão 5.7.0 da pipeline de redução do UVES modo fibra (Modigliani et al., 2004) fornecida pelo ESO, também em ambiente Reflex. O procedimento da pipeline e das receitas é a mesma descrita para o GIRAFFE, com a exceção de vários processos adicionais em receitas próprias para a caracterização das fibras e ordens da dispersão echelle, bem como a junção destas ordens na extração do espectro unidimensional. Como etapa final da redução de cada exposição, os espectros de cada fibra, seus respectivos erros e tabelas de informação são salvos em arquivos separados.

\subsubsection{MUSE}

A redução dos dados do MUSE foi realizada utilizando a versão 2.4.1 da pipeline de redução do MUSE (Weilbacher et al., 2006) fornecida pelo ESO, também em ambiente Reflex. As etapas de redução do MUSE consistem em:

- Combinação das imagens de bias;

- Combinação das imagens flat-field e traçagem dos espectros das secções do campo;

- Calibração do comprimento de onda;

- Criação da função de espalhamento de linhas;

- Localização do espectro de cada secção no campo do instrumento;

- Correção de iluminação utilizando flat-fields do céu;

- Pre-processamento das exposições do objeto, removendo as assinaturas instrumentais e deslocamentos espectrais originários do movimento terrestre;

- Calibração astrométrica para as coordenadas do cubo de dados reconstruído;

- Pós-processamento das exposições do objeto e subtração de céu.

Após a redução, para cada exposição, é criado um cubo de dados, uma pixel table e uma imagem do campo, com a soma das secções do cubo (no eixo do comprimento de onda). Para a combinação dos cubos, é utilizado outro workflow da pipeline dedicado à esta tarefa, onde cada exposição é alinhada por meio das imagens do campo, e as pixel tables correspondentes são combinadas em um cubo final. Nesta etapa é possível gerar imagens do cubo em diferentes filtros, para uso na criação de catálogos ou outras tarefas. 


\subsection{Tratamento dos dados}

De posse dos espectros unidimensionais reduzidos, é necessário executar uma limpeza de raios cósmicos (partículas de alta energia que eventualmente atravessam a óptica do instrumento e atingem o detector CCD, saturando pixels que podem pertencer à região do espectro), normalizar o espectro para o nível do contínuo e corrigi-los do deslocamento Doppler provocado pela velocidade radial da estrela e efeitos do movimento terrestre no momento da observação. Estas etapas são necessárias para combinar as exposições individuais das estrelas em um espectro final, de modo a aumentar o fator de sinal-para-ruído ( $\mathrm{S} / \mathrm{N}$, signal-to-noise ratio) desejado para a análise.

Para cada instrumento (GIRAFFE e UVES), foi desenvolvida uma pipeline de tratamento escrita em linguagem Python para realizar as tarefas, devido ao grande volume de dados. Cada uma delas é descrita a seguir.

\subsubsection{GREPPy}

O Giraffe REduced Product Python Pipeline (Pipeline em Python de Produtos Reduzidos do GIRAFFE) é uma biblioteca para Python 3 desenvolvida com orientação a objetos, que contém uma série de ferramentas e interface gráfica para tratamento e pré-análise de espectros reduzidos do instrumento GIRAFFE, podendo ser utilizada em qualquer set de dados obtido no modo Medusa. A biblioteca foi construída de modo que o usuário possa executar as etapas de tratamento tanto em tempo de execução (via iPython, Jupyter notebook, e afins) quanto em script, possibilitando a adaptação às necessidades particulares de cada set de dados.

O principal elemento é a classe GiDatabase, que herda as propriedades de um dicionário do Python e guarda os dados e informações em uma estrutura de árvore. As ferramentas de tratamento são implementadas como métodos da classe, sendo aplicadas ao objeto GiDatabase como um todo, e como cada cada fibra contém um alvo independente, as tarefas são executadas de forma paralelizada. O objeto GiDatabase, após ser instanciado, deve receber os datapacks por meio do método build, que automaticamente identifica todos os arquivos dentro de um dado diretório e carrega os arquivos dos espectros e dos erros, que saem diretamente da pipeline de redução do GIRAFFE, dentro da estrutura em árvore do objeto. O conteúdo de cada fibra será aqui nomeado objeto-alvo, sendo estes (na 
grande maioria dos casos) as estrelas da amostra. A árvore é organizada por chaves que hierarquicamente listam: ID do programa; bloco de observação; objetos-alvo, fibras de céu e informações do bloco; espectros e informações de cada objeto-alvo. Após isso, as ferramentas podem ser aplicadas aos dados, e uma descrição de cada uma é apresentada a seguir na ordem recomendada de execução.

\subsubsection{1 computeSNR}

O método computeSNR calcula a razão $\mathrm{S} / \mathrm{N}$ simplesmente dividindo o fluxo do espectro pelos erros correspondentes de cada pixel, ignorando valores nulos ou negativos. Após isso, toma-se a mediana dos valores resultantes e esta é salva para cada objeto-alvo do database.

\subsubsection{2 normalize}

Afim de realizar uma normalização onde o nível do contínuo é bem estimado, tomase como base um espectro com o formato do contínuo pré-normalizado, de modo que ao se construir uma função de distribuição dos valores de fluxo, assume-se que o nível do contínuo esteja muito próximo do valor máximo da distribuição, considerando o fato de que o contínuo real seja afetado por ruído e pela opacidade provocada por linhas espectrais fracas. Dado isso, espera-se que a distribuição assuma um formato que é composto por uma distribuição normal (assumindo-se em boa aproximação que o contínuo real seja constante e possui uma dispersão aleatória devido ao ruído) e por uma cauda que é devida aos fluxos das linhas espectrais, assemelhando-se a uma distribuição normal com skewness, de forma que a moda da distribuição seja o nível do pseudo-contínuo (considerando a opacidade provocada por linhas fracas) em boa aproximação. A ideia é, iterativamente, rejeitar as linhas espectrais de modo que o ajuste do polinômio leve em consideração apenas o contínuo, e reproduza seu formato e nível com boa aproximação.

O método primeiramente limpa os valores nulos e negativos, e faz uma primeira estimativa do contínuo, ajustando ao espectro um polinômio de Legendre de ordem fornecida. Após isso, é aplicado um procedimento iterativo que consiste em:

- construir um histograma com o fluxo pré-normalizado;

- ajustar uma função gaussiana com skewness ao histograma utilizando o pacote LmFit;

- determinar a moda da distribuição ajustada;

- rejeitar do espectro original os valores do fluxo que desviam da moda em mais de $c_{k} \sigma$, 
sendo

$$
c_{i}=c_{i-1}-d \cdot(i-1) \cdot c_{i-1} \quad i=1,2, \ldots, n
$$

onde k é o número da iteração, $\sigma$ é o desvio-padrão da gaussiana com skewness ajustada, n é o número de iterações, d é um fator fornecido de velocidade de decréscimo, e $c_{0}$ é o fator inicial fornecido;

- ajustar um novo polinômio ao espectro original com os pontos rejeitados.

O procedimento é repetido conforme o número de iterações fornecido, e, ao final, os espectros normalizados têm se mostrado visualmente satisfatórios em termos de formato e nível do contínuo. Um exemplo é mostrado na figura 2.1. Feito o procedimento de normalização, cada objeto-alvo do database tem adicionado um vetor com o fluxo normalizado, um vetor com o comprimento de onda da normalização, um vetor com os erros normalizados e outro vetor contendo a função final utilizada na normalização.

\subsubsection{3 cosmiclean}

Este método baseia-se no processo descrito para a função normalize, e consiste em limpar o espectro de raios cósmicos construindo um histograma com o fluxo previamente normalizado, ajustando uma função gaussiana com skewness a este utilizando o pacote $L m F i t$, e rejeitando os pixels cujos valores superam $m+r \cdot \sigma$, onde $m$ é a moda do ajuste, $\mathrm{r}$ é um fator multiplicativo fornecido e $\sigma$ é o desvio-padrão do ajuste. Ao final, cada objetoalvo do database tem adicionado um vetor com o fluxo limpo, um com o comprimento de onda (excluindo os pontos rejeitados), e outro com os erros.

\subsubsection{4 rv_measure}

Este método recebe um espectro de referência e realiza uma correlação-cruzada deste com o espectro normalizado e/ou limpo de cada objeto-alvo utilizando a função crosscor$r R V$ do pacote PyAstronomy, que retorna a função de correlação no espaço de velocidades. Desta, é selecionado o maior valor de correlação, ao redor do qual espera-se um pico indicando a máxima correlação para os deslocamentos de velocidade aplicados ao espectro de referência. É fornecido o número de pontos ao redor do pico a serem considerados para o ajuste de uma gaussiana pelo pacote LmFit, cujo valor ajustado do centro será salvo na 

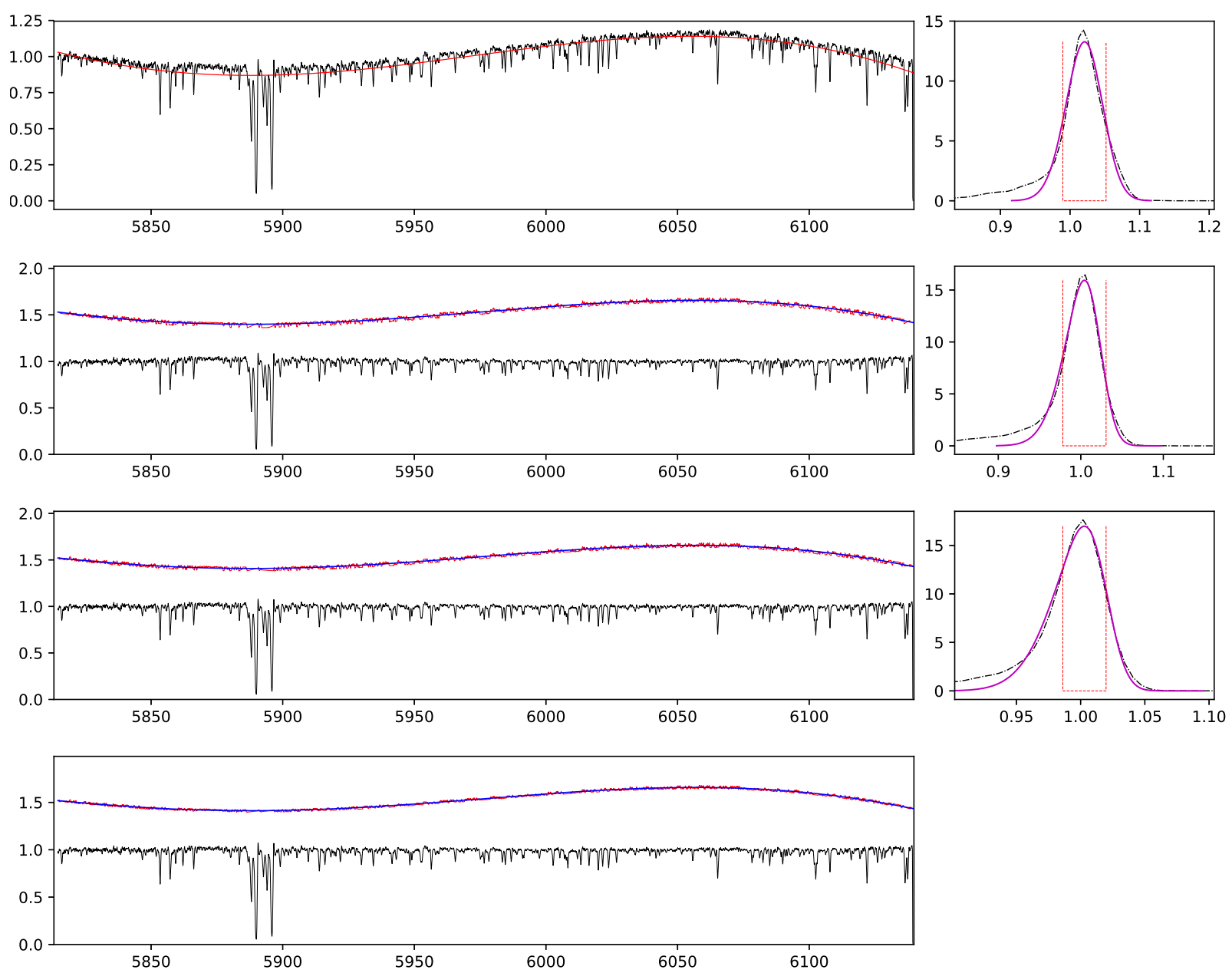

Figura 2.1: Demonstração do método de normalização utilizado no tratamento dos dados. No painel esquerdo superior, é exibido o espectro original em preto e a primeira estimativa do ajuste em vermelho. Nos demais painéis esquerdos, as iterações mostrando em vermelho o continuo sem as linhas espectrais, em azul o ajuste polinomial do contínuo, em preto: o espectro normalizado. Nos painéis da direita, são exibidas em tracejado preto: as funções de distribuição, em magenta: a função gaussiana com skewness ajustada, em tracejado vermelho: o intervalo de corte, onde dentro deste os valores de fluxo são assumidos como o contínuo.

chave do objeto-alvo como a sua velocidade radial. O espectro utilizado por padrão foi o atlas solar do FLAMES-UVES, disponível em

https://www.eso.org/observing/dfo/quality/GIRAFFE/pipeline/solar.html. O valor do centro da gaussiana ajustada é considerado como o valor da velocidade radial, e para o erro desta é adotado o erro no ajuste do centro, determinado utilizando a matriz de covariância do ajuste da gaussiana. Um exemplo é mostrado no quadro superior da janela de gráficos da figura 2.2, com a função de correlação em azul e o pico ajustado em laranja. 


\subsubsection{5 rv_dopshift}

Este método utiliza o valor da velocidade radial previamente medida para corrigir o comprimento de onda do espectro do deslocamento Doppler provocado pela velocidade radial do objeto-alvo e movimento terrestre. É utilizada a equação

$$
\lambda_{\text {corrigido }}=\lambda_{\text {original }}-\frac{v}{c} \cdot \lambda_{\text {original }}
$$

onde $v$ é a velocidade radial medida e $c$ é a velociade da luz, ambas em km/s. Esta correção é aplicada a cada valor de comprimento de onda do espectro e o novo vetor é incluído na chave do objeto-alvo.

\subsubsection{6 struc_targets}

Este método cria, para cada alvo de exposição (centro do campo do telescópio), uma chave adicional dentro do ID do programa contendo os alvos observados, e dentro deles em estrutura hierarquizada: objetos-alvo, setups do GIRAFFE utilizados, blocos de observação das exposições, espectros das exposições e respectivas informações. Este é um passo obrigatório para realizar a combinação das exposições afim de obter os espectros finais.

\subsubsection{7 combine_targets}

Este é o método que combina as exposições individuais dentro de cada setup do GIRAFFE. Primeiramente é necessário re-amostrar os espectros a serem combinados, de modo que seus valores de comprimento de onda coincidam. Para tal, é usada a função interp1d do pacote SciPy para realizar a interpolação dos espectros, sendo possível escolher entre os métodos de interpolação disponíveis para a função interp1d, como linear e spline cúbica. Para a combinação dos espectros reamostrados, é possível escolher entre usar a média ou a mediana, com pesos (utiliza-se o pacote wquantiles para a mediana) ou sem pesos, e a base dos pesos pode ser o tempo de exposição ou a razão S/N. Os erros combinados são estimados pela média quadrática (com ou sem pesos) dos erros das exposições individuais. Os espectros e erros finais são incluídos nas chaves dos objetos-alvo estruturados. Para a presente amostra, foi utilizada a mediana ponderada pelo fator sinal-para- ruído, devido à característica da mediana ser um valor que se aproxima mais do valor da variável independente de maior densidade populacional, ou seja, em cada comprimento de onda, o 
fluxo resultante da combinação se situa mais próximo da maior concentração dos fluxos das exposições separadas, de modo a eliminar a influência de possíveis pontos outliers, mesmo que estes se encontrem em espectros de maior peso devido ao fator S/N. Como vantagem, o perfil das linhas espectrais são mais bem conservados, como exemplificado mais a seguir para o caso de um espectro do UVES na figura 2.5 .

\subsubsection{8 data_view}

Este método invoca a interface gráfica do GREPPy, desenvolvida em Tkinter, onde o usuário pode visualizar a árvore do database a qualquer instante posterior à sua construção, aplicar as ferramentas por meio de botões, e plotar os espectros em gráficos separados ou sobrepostos, incluindo legendas. Um exemplo da janela exibindo os dados estruturados e as funcionalidades, juntamente com as janelas de gráficos é mostrado na figura 2.2

\subsubsection{9 write_data}

Este método salva em disco os espectros e tabelas de informações, podendo o usuário escolher entre os formatos fits e ascii, bem como o tipo de produto a ser salvo, entre eles espectros combinados, espectros extraídos, espectros intermediários, ou todos os disponíveis.

Durante e ao final da etapa de tratamento, os espectros foram verificados visualmente para assegurar a correta execução das ferramentas e qualidade dos espectros finais.

\subsubsection{UPCOPy}

O Uves Product COmbination Python Pipeline (Pipeline de Combinação de Produtos do UVES em Python) é um script em Python 3 desenvolvido de maneira procedural para o tratamento e combinação dos espectros reduzidos que saem da pipeline de redução do UVES modo fibra, podendo ser utilizado também para qualquer set de dados do FLAMESUVES. Por ter sido desenvolvido para suprir somente as necessidades atuais, o UPCOPy atualmente se apresenta mais rudimentar que o GREPPy, porém, futuramente o código será reformulado de modo a ser uma contrapartida UVES do GREPPy, contando com os mesmos recursos.

O código atualmente realiza essencialmente os mesmos procedimentos adotados para o tratamento e combinação dos espectros GIRAFFE, porém com algumas diferenças por 


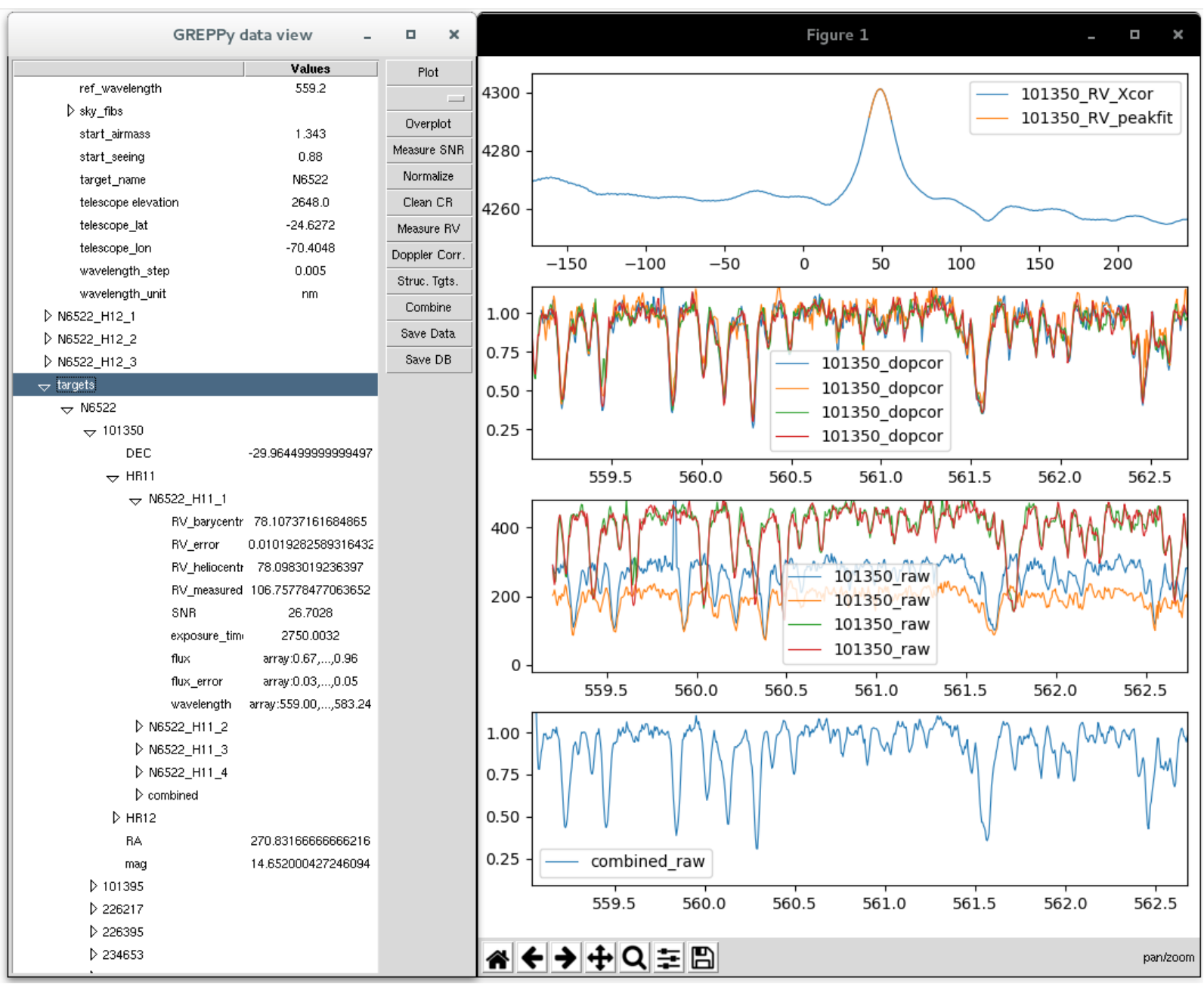

Figura 2.2: Janela do data_view com gráficos exemplificando o uso de algumas ferramentas. A interface possui a opção de plotar gráficos separados e/ou sobrepostos de praticamente qualquer informação contida nas chaves. Os quadros não possuem os nomes dos eixos para aproveitar o máximo espaço possível dentro da janela.

conta da natureza dos espectros. Adicionalmente, possui um sistema de logging (registro de informações, mensagens, avisos e erros) para identificação de possíveis problemas durante o processo. Para cada fibra, são salvas em um arquivo de texto, para cada exposição, informações de velocidades radiais medidas e heliocêntricas, fator S/N, massa de ar e seeing da observação, placa do OzPoz utilizada, tempo de exposição e data, bem como velocidade radial heliocêntrica média e fator $\mathrm{S} / \mathrm{N}$ do espectro final combinado. Figuras com o ajuste do contínuo e função de correlação da medida de velocidade radial também são salvas para referência. 


\subsubsection{Rippling do contínuo e normalização segmentada}

Devido às fracas magnitudes das estrelas, a pipeline de redução produz um rippling (efeito ondulatório) nas junções de ordens de comprimentos de onda menores nos espectros de várias exposições, e este efeito torna-se bastante prejudicial à qualidade dos espectros finais. Isto se mostra no fato de que ao se corrigir o deslocamento Doppler, o rippling deixa de coincidir entre os espectros, de maneira que os contínuos das exposições individuais não coincidam, produzindo além de efeitos da superposição ondulatória do rippling, valores incorretos de fluxo que resultarão em problemas, como por exemplo defeitos nos perfis das linhas espectrais.

Para contornar este problema, foi desenvolvido um método de normaização onde o espectro é dividido em segmentos de intervalos estipulados pelo usuário (requer uma inspeção visual prévia para determinar uma valor adequado, grande o suficiente para não eliminar bandas moleculares e linhas fortes, e pequeno o suficiente para cobrir a variação do rippling), tipicamente de $\sim 12 \AA$ para o CCD de menor comprimento de onda (chip lower) e $\sim 30 \AA$ para o CCD de maior comprimento de onda (chip upper). Este procedimento baseia-se no método descrito na função normalize do GREPPy para estimativa do nível do contínuo. Para cada segmento, são consideradas porções a sobrepor dos segmentos adjacentes (tipicamente $0.3 \AA$ ), e é ajustado um polinômio de ordem fornecida (tipicamente ordem 1) para linearizar o contínuo. Feito isso, é produzida uma estimativa de densidade de kernel (EDK) dos valores de fluxo usando a função gaussianKDE do pacote SciPy, de modo a facilitar o posterior ajuste de uma gaussiana com skewness à EDK, para com isso, encontrar a moda da distribuição e estimar o valor do contínuo local, bem como o desviopadrão $\sigma$ da distribuição. O valor ajustado do nível do contínuo é associado ao ponto médio do intervalo de comprimento de onda do segmento e então de-normalizado do ajuste polinomial prévio para encaixar-se no local correto que representa o nível do contínuo no ponto médio do intervalo. Em seguida, é ajustada uma spline cúbica a estes pontos, traçando uma função que descreve em primeira aproximação a forma do contínuo, para posteriormente ser aplicado o método de rejeição descrito na função normalize. Também são levados em conta os valores $\sigma$ de cada intervalo, onde é ajustada também uma spline cúbica aos $\sigma$ versus comprimento de onda, produzindo uma função- $\sigma$. Esta função é uti-

lizada na rejeição de pontos por conta das regiões que contêm muitas linhas espectrais, 
que aumentam a incerteza do nível do contínuo determinado para o segmento. O processo de rejeição descarta pixels do espectro cujo valor do fluxo desvia em mais de $\sigma_{n} \cdot F_{r}$ do valor do contínuo ajustado, onde $\sigma_{n}$ é o valor da função- $\sigma$ no comprimento de onda do pixel e $F_{r}$ é um fator de ruído fornecido (o valor adotado no tratamento dos dados foi 1.2). Como resultado, o contínuo "limpo" de linhas espectrais se apresenta com dispersão maior onde a determinação do nível do contínuo é mais ambígua, sendo este submetido a uma segunda iteração do processo de segmentação e ajuste da spline. Após isso, o espectro é normalizado pela spline, retificando o contínuo. Um exemplo das etapas do processo de normalização é mostrado na figura 2.3, e na figura 2.4 é exibida uma região espectral de uma das estrelas com as exposições normalizadas antes da combinação e o espectro final combinado pela mediana.
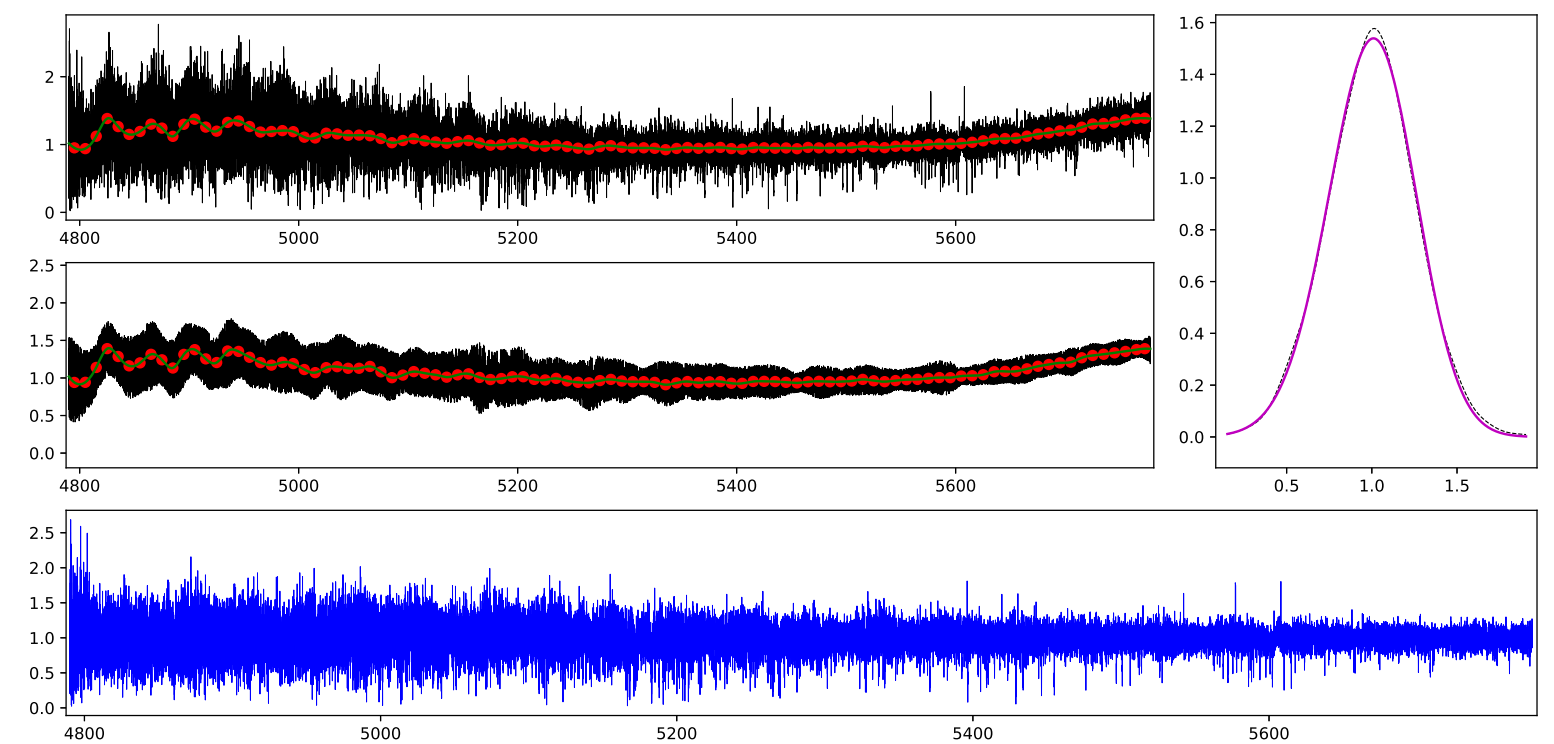

Figura 2.3: Detalhamento do processo de normalização segmentada. No quadro superior à esquerda é exibida a primeira etapa, com o espectro bruto em preto, os pontos de contínuo em vermelho e a spline ajustada em verde. Imediatamente abaixo, a segunda iteração com a rejeição de pontos, eliminando parcialmente as linhas de absorção. À direita, a distribuição do fluxo para um dos segmentos em preto, e a gaussiana ajustada em magenta. No quadro abaixo, o espectro normalizado em azul.

\subsubsection{Medição das velocidades radiais}

Para a determinação das velocidades radiais, foi utilizado o mesmo atlas solar como espectro de referência, mencionado anteriormente para o GREPPy. Devido ao fator S/N 

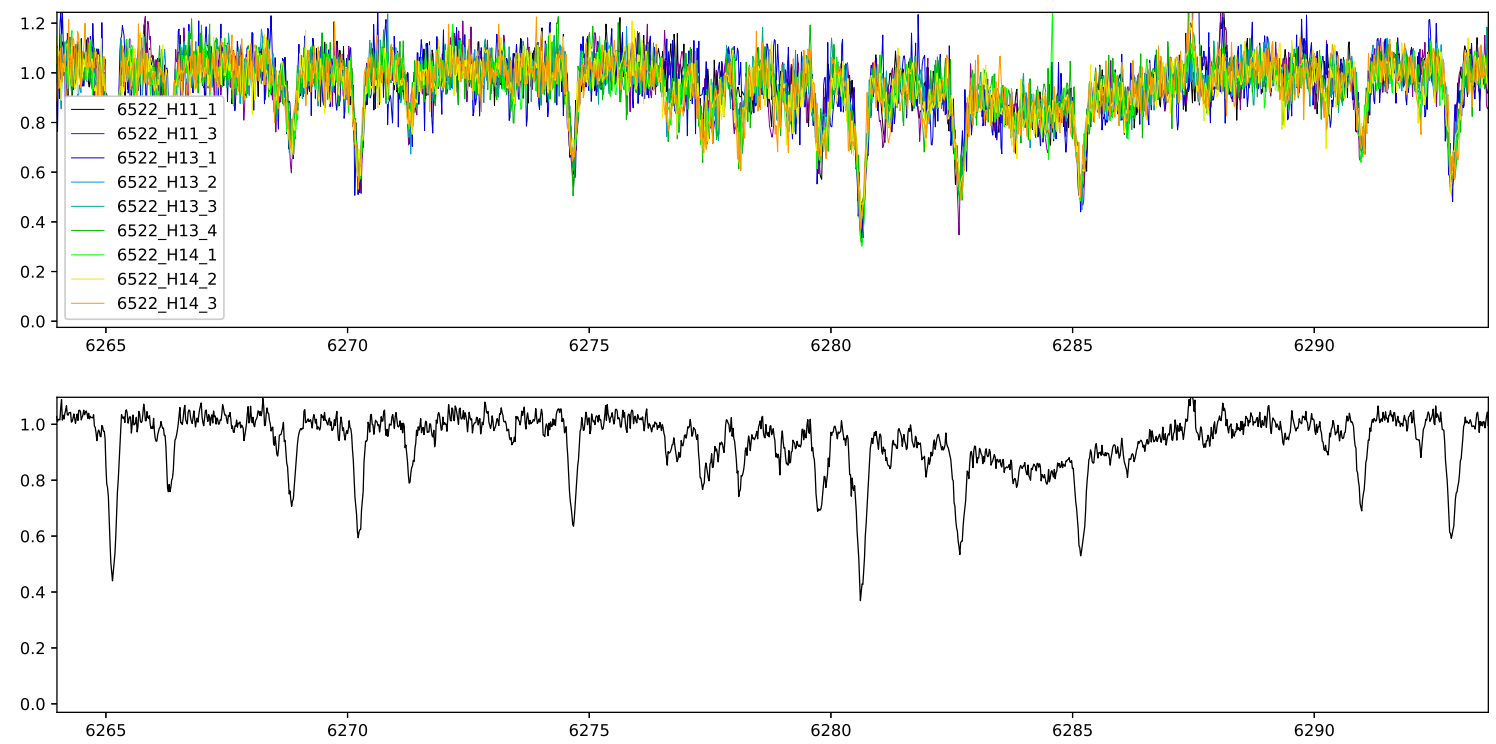

Figura 2.4: Região espectral como exemplo da normalização segmentada das exposições separadas no quadro superior, e sua respectiva combinação no quadro inferior. É possível notar que o nível do fluxo nos espectros está bem definido e sobreposto, e também a banda molecular interestelar difusa em $6283.8 \AA$ é preservada.

do chip upper ser, em média, de 2 a 3 vezes maior que o do chip lower, a determinação da velocidade radial levou em conta somente o chip upper. Isto pode ser realizado devido ao fato de os dois chips pertencerem à mesma exposição. Os erros individuais de cada exposição, determinados pela matriz de covariância do ajuste da gaussiana, exibem valores da ordem de $0.01 \mathrm{~km} / \mathrm{s}$, claramente subestimados. Isto ocorre devido ao perfil do pico ser muito bem descrito por uma gaussiana, e devido também à resolução de $1 \mathrm{~km} / \mathrm{s}$ utilizada na função de correlação cruzada, produzindo um pico quase perfeitamente gaussiano. Para a estimativa do erro final da velocidade radial heliocêntrica, foi utilizado o desvio-padrão das velocidades heliocêntricas das exposições dividido pela raiz quadrada do número de exposições. As velocidades radiais e fatores $\mathrm{S} / \mathrm{N}$ de cada exposição, bem como os valores finais para cada estrela são exibidos na tabela 2.2 .

\subsubsection{Determinação do $S / N$ e combinação}

Devido ao fato de as estimativas de erro do fluxo dos espectros FLAMES-UVES ser subestimada (os valores de fluxo são da ordem de $10^{-3}$, enquanto os erros fornecidos pela pipeline são da ordem de $10^{-8}$ ), o fator $\mathrm{S} / \mathrm{N}$ foi estimado com base em regiões adotadas 
Tabela 2.2 - Velocidades radiais heliocêntricas e fatores $\mathrm{S} / \mathrm{N}$ de cada exposição e médias para as estrelas da amostra do UVES.

\begin{tabular}{|c|c|c|c|c|c|c|c|c|}
\hline OB & $\mathrm{VR}_{\text {medida }}$ & $\mathrm{VR}_{\text {helio }}$ & S/ $\mathrm{N}_{\text {lower }}$ & S/N $\mathrm{N}_{\text {upper }}$ & $\mathrm{VR}_{\text {medida }}$ & $\overline{\mathrm{VR}_{\text {helio }}}$ & $\mathrm{S} / \mathrm{N}_{\text {lower }}$ & $\mathrm{S} / \mathrm{N}_{\text {upper }}$ \\
\hline & \multicolumn{4}{|c|}{234816} & \multicolumn{4}{|c|}{244523} \\
\hline H11-1 & $-32.41 \pm 0.01$ & $-15.47 \pm 0.01$ & 7.28 & 17.13 & $-30.32 \pm 0.01$ & $-13.39 \pm 0.01$ & 11.09 & 28.01 \\
\hline H11-2 & $-32.62 \pm 0.00$ & $-15.63 \pm 0.00$ & 3.19 & 5.56 & $-30.39 \pm 0.01$ & $-13.40 \pm 0.01$ & 6.93 & 19.57 \\
\hline H11-3 & $-31.95 \pm 0.01$ & $-14.90 \pm 0.01$ & 6.73 & 15.48 & $-30.15 \pm 0.00$ & $-13.10 \pm 0.00$ & 11.23 & 25.49 \\
\hline H13-1 & $-6.51 \pm 0.00$ & $-15.54 \pm 0.00$ & 3.89 & 9.90 & $-4.81 \pm 0.00$ & $-13.84 \pm 0.00$ & 6.94 & 14.37 \\
\hline H13-2 & $-1.74 \pm 0.01$ & $-15.16 \pm 0.01$ & 9.38 & 18.30 & $-0.13 \pm 0.01$ & $-13.55 \pm 0.01$ & 10.81 & 17.97 \\
\hline H13-3 & $-1.63 \pm 0.00$ & $-14.97 \pm 0.00$ & 9.01 & 19.05 & $-0.08 \pm 0.01$ & $-13.42 \pm 0.01$ & 9.13 & 18.01 \\
\hline H13-4 & $-1.59 \pm 0.00$ & $-14.85 \pm 0.00$ & 6.85 & 18.16 & $-0.11 \pm 0.01$ & $-13.37 \pm 0.01$ & 7.33 & 14.09 \\
\hline H14-1 & $-1.15 \pm 0.00$ & $-14.91 \pm 0.00$ & 9.34 & 20.44 & $0.42 \pm 0.01$ & $-13.34 \pm 0.01$ & 14.34 & 26.69 \\
\hline H14-2 & $-1.59 \pm 0.01$ & $-15.30 \pm 0.01$ & 5.79 & 14.95 & $0.07 \pm 0.01$ & $-13.64 \pm 0.01$ & 7.87 & 16.88 \\
\hline H14-3 & $-1.16 \pm 0.01$ & $-14.83 \pm 0.01$ & 7.33 & 14.98 & $0.34 \pm 0.01$ & $-13.33 \pm 0.01$ & 11.04 & 16.60 \\
\hline \multicolumn{2}{|c|}{$\mathrm{VR}_{\text {helio }}$ média } & \multicolumn{3}{|l|}{$-15.16 \pm 0.09$} & & \multicolumn{3}{|l|}{$-13.44 \pm 0.06$} \\
\hline \multicolumn{2}{|c|}{$\mathrm{S} / \mathrm{N}$ final ${ }_{\text {lower }}$} & 31.90 & & & & 47.08 & & \\
\hline \multicolumn{2}{|c|}{$\mathrm{S} / \mathrm{N}$ final $_{\text {upper }}$} & 86.77 & & & & 81.24 & & \\
\hline & \multicolumn{4}{|c|}{244819} & \multicolumn{4}{|c|}{256289} \\
\hline H11-1 & $-37.10 \pm 0.01$ & $-20.16 \pm 0.01$ & 8.07 & 19.34 & $-32.42 \pm 0.01$ & $-15.49 \pm 0.01$ & 10.41 & 22.80 \\
\hline H11-2 & $-37.08 \pm 0.01$ & $-20.09 \pm 0.01$ & 3.07 & 6.45 & $-32.59 \pm 0.01$ & $-15.60 \pm 0.01$ & 4.51 & 12.33 \\
\hline H11-3 & $-37.00 \pm 0.01$ & $-19.95 \pm 0.01$ & 4.64 & 16.71 & $-32.31 \pm 0.01$ & $-15.26 \pm 0.01$ & 5.62 & 16.73 \\
\hline H13-1 & $-11.37 \pm 0.02$ & $-20.40 \pm 0.02$ & 5.92 & 11.71 & $-6.65 \pm 0.01$ & $-15.68 \pm 0.01$ & 7.61 & 13.51 \\
\hline H13-2 & $-5.78 \pm 0.01$ & $-19.20 \pm 0.01$ & 9.96 & 21.32 & $-1.97 \pm 0.01$ & $-15.39 \pm 0.01$ & 10.60 & 15.56 \\
\hline H13-3 & $-5.42 \pm 0.01$ & $-18.75 \pm 0.01$ & 8.22 & 17.27 & $-1.82 \pm 0.01$ & $-15.15 \pm 0.01$ & 8.81 & 20.20 \\
\hline H13-4 & $-5.45 \pm 0.01$ & $-18.71 \pm 0.01$ & 7.88 & 19.37 & $-1.80 \pm 0.01$ & $-15.06 \pm 0.01$ & 5.67 & 17.68 \\
\hline H14-1 & $-5.65 \pm 0.01$ & $-19.41 \pm 0.01$ & 9.59 & 23.12 & $-1.29 \pm 0.01$ & $-15.05 \pm 0.01$ & 12.39 & 28.98 \\
\hline H14-2 & $-5.55 \pm 0.01$ & $-19.25 \pm 0.01$ & 5.98 & 15.63 & $-1.89 \pm 0.01$ & $-15.60 \pm 0.01$ & 6.71 & 15.84 \\
\hline H14-3 & $-5.49 \pm 0.00$ & $-19.15 \pm 0.00$ & 5.86 & 17.94 & $-1.27 \pm 0.01$ & $-14.94 \pm 0.01$ & 7.26 & 20.93 \\
\hline \multicolumn{2}{|c|}{$\mathrm{VR}_{\text {helio }}$ média } & \multicolumn{3}{|l|}{$-19.51 \pm 0.18$} & & \multicolumn{3}{|l|}{$-15.32 \pm 0.08$} \\
\hline \multicolumn{2}{|c|}{$\mathrm{S} / \mathrm{N}$ final $_{\text {lower }}$} & 32.55 & & & & 38.25 & & \\
\hline \multicolumn{2}{|c|}{$\mathrm{S} / \mathrm{N}$ final ${ }_{\text {upper }}$} & 60.48 & & & & 81.51 & & \\
\hline & \multicolumn{4}{|c|}{402370} & \multicolumn{4}{|c|}{402322} \\
\hline H11-1 & $-28.09 \pm 0.00$ & $-11.16 \pm 0.00$ & 9.06 & 19.57 & $-40.10 \pm 0.00$ & $-23.16 \pm 0.00$ & 3.37 & 7.86 \\
\hline H11-2 & $-28.15 \pm 0.01$ & $-11.16 \pm 0.01$ & 3.17 & 9.27 & $-40.05 \pm 0.01$ & $-23.06 \pm 0.01$ & 2.09 & 2.84 \\
\hline H11-3 & $-27.83 \pm 0.01$ & $-10.79 \pm 0.01$ & 5.85 & 14.93 & $-39.81 \pm 0.01$ & $-22.76 \pm 0.01$ & 2.85 & 9.30 \\
\hline H13-1 & $-2.30 \pm 0.00$ & $-11.33 \pm 0.00$ & 6.05 & 11.78 & $-14.38 \pm 0.01$ & $-23.41 \pm 0.01$ & 4.28 & 10.86 \\
\hline H13-2 & $1.79 \pm 0.01$ & $-11.63 \pm 0.01$ & 8.22 & 15.85 & $-8.72 \pm 0.03$ & $-22.15 \pm 0.03$ & 5.98 & 13.37 \\
\hline H13-3 & $1.83 \pm 0.01$ & $-11.50 \pm 0.01$ & 7.15 & 18.62 & $-8.49 \pm 0.03$ & $-21.83 \pm 0.03$ & 5.25 & 14.90 \\
\hline $\mathrm{H} 13-4$ & $1.91 \pm 0.01$ & $-11.35 \pm 0.01$ & 5.26 & 15.33 & $-8.67 \pm 0.03$ & $-21.92 \pm 0.03$ & 5.80 & 17.04 \\
\hline H14-1 & $2.85 \pm 0.01$ & $-10.91 \pm 0.01$ & 7.94 & 22.18 & $-8.68 \pm 0.02$ & $-22.44 \pm 0.02$ & 6.61 & 18.96 \\
\hline H14-2 & $1.98 \pm 0.01$ & $-11.73 \pm 0.01$ & 4.39 & 15.11 & $-8.77 \pm 0.02$ & $-22.47 \pm 0.02$ & 4.42 & 15.91 \\
\hline H14-3 & $2.72 \pm 0.02$ & $-10.95 \pm 0.02$ & 6.86 & 21.10 & $-8.41 \pm 0.02$ & $-22.08 \pm 0.02$ & 4.17 & 17.91 \\
\hline \multicolumn{2}{|c|}{$\mathrm{VR}_{\text {helio }}$ média } & $-11.25 \pm 0.09$ & & & & $-22.53 \pm 0.17$ & & \\
\hline \multicolumn{2}{|c|}{$\mathrm{S} / \mathrm{N}$ final ${ }_{\text {lower }}$} & 36.77 & & & & 17.50 & & \\
\hline \multicolumn{2}{|c|}{$\mathrm{S} / \mathrm{N}$ final ${ }_{\text {upper }}$} & 72.70 & & & & 59.89 & & \\
\hline
\end{tabular}


como regiões de contínuo utilizado a relação

$$
F S R=\frac{F_{r}}{\sigma}
$$

onde $F S R$ é o fator $\mathrm{S} / \mathrm{N}, F_{r}$ é o fluxo na região e $\sigma$ o desvio-padrão da região. As regiões de contínuo utilizadas foram os intervalos de comprimento de onda entre 5060.6 - 5061.2 A para o chip lower, e 6184.15 - 6185.2 A para o chip upper.

Para o OB H11-2 foi determinado o fator $\mathrm{S} / \mathrm{N}$ mais baixo do set de dados, e devido a isto, a combinação que o utilizava apresentava fator $\mathrm{S} / \mathrm{N}$ mais baixo do que a combinação feita sem seu uso, portanto este OB foi excluído da combinação final.

Para a combinação foi utilizada a mediana simples entre as exposições, devido aos fatores $\mathrm{S} / \mathrm{N}$ não representarem uma estimativa suficientemente realista para serem usados como peso para a mediana. Uma comparação entre os espectros combinados pela média e pela mediana é exibida na figura 2.5, onde o perfil da linha espectral é mais bem conservado em relação ao espectro sintético. Também é possível notar na figura 2.4 que ao se utilizar a mediana, as linhas telúricas em $\sim 6277 \AA$ Åão preservadas quase inalteradas na combinação, mesmo estas estando ausentes nos espectros dos blocos H11_1, H11_3 e H13_1.

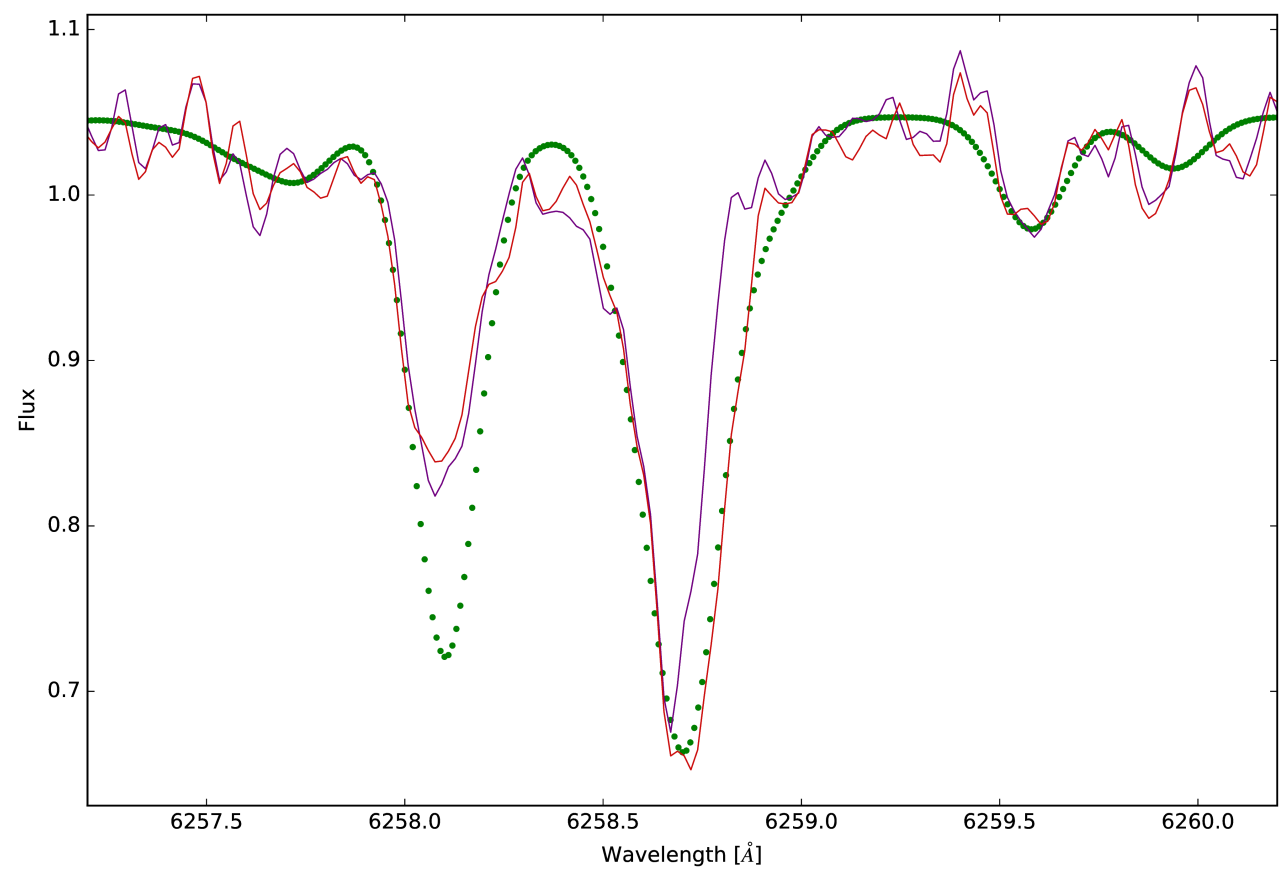

Figura 2.5: Região espectral da linha de Ti I em $6258.7 \AA$ no espectro combinado da estrela B118. Em azul: combinação pela média; em vermelho: combinação pela mediana; em pontilhado verde: espectro sintético com os parâmetros atmosféricos e abundâncias finais determinados. 
Os espectros finais, para cada estrela, foram exportados em formato FITS (Flexible Image Transport System) sendo um arquivo para cada chip (upper e lower), e em formato ASCII (American Standard Code for Information Interchange) em um único arquivo de texto para os dois chips.

\subsubsection{Pré-filtragem de estrelas-membro}

As estrelas UV2012 já haviam sido selecionadas pelo seu interesse a partir de Barbuy et al. (2009), e as estrelas UV2016 foram selecionadas a partir de uma pré-análise dos dados GI2012. Fez-se então necessária a filtragem das estrelas de ambos os conjuntos de dados GIRAFFE, afim de pré-selecionar possíveis estrelas-membro por suas velocidades radiais. Como os aglomerados globulares são associações estelares gravitacionalmente ligadas, estima-se que as velocidades radiais das estrelas-membro não divirja muito da velocidade radial determinada de $-14.3 \pm 0.5 \mathrm{~km} / \mathrm{s}$ em Barbuy et al. (2014) para o NGC 6522. De fato, a distribuição de velocidades radiais da amostra de todas as estrelas de GI2012 e GI2016 possui um pico coincidente com $-14.3 \mathrm{~km} / \mathrm{s}$ (figura 2.6), indicando que o pico representa o aglomerado. O valor de $\pm 15 \mathrm{~km} / \mathrm{s}$ foi adotado por equivaler aproximadamente à largura do pico no nível de corte na distribuição das estrelas de campo. Este critério foi utilizado para filtrar a amostra, resultando em 20 candidatos para GI2012 e 25 candidatos para GI2016. Os valores das velocidades radiais heliocêntricas são reportados na tabela 2.3.

O campo do NGC 6522 com as estrelas selecionadas é exibido na figura 2.7.

\subsubsection{Extração dos espectros dos cubos de dados do MUSE}

O cubo de dados resultante da redução tem cerca de 660x660 pixels, cada um contendo um espectro. Uma imagem do campo do cubo é exibida na figura 2.8. Para a extração dos espectros das estrelas, foi criado um catálogo com base na imagem do cubo na banda $\mathrm{I}_{\text {Cousins }}$ e em uma imagem no filtro f658n do telescópio espacial Hubble, pertencente ao programa GO-9690 (PI: J. Grindlay). Este catálogo é fornecido ao software PampelMUSE (Kamann, 2018), que realiza, para cada fonte, fotometria PSF em cada secção do cubo (em comprimento de onda). O catálogo e o software são descritos nas seções a seguir. 
Tabela 2.3 - Coordenadas e velocidades radiais heliocêntricas das estrelas selecionadas. Os valores finais da velocidade radial são a média das velocidades radiais determinadas para cada setup.

\begin{tabular}{|c|c|c|c|c|c|c|c|}
\hline \multirow[b]{2}{*}{ Objeto } & \multicolumn{2}{|c|}{ Coordenadas } & \multicolumn{4}{|c|}{ Velocidade radial por setup $(\mathrm{km} / \mathrm{s})$} & \multirow{2}{*}{$\begin{array}{l}\text { Velocidade radial final } \\
\qquad(\mathrm{km} / \mathrm{s})\end{array}$} \\
\hline & RA & DEC & HR11 & HR12 & HR13 & HR14 & \\
\hline 78126 & 18:03:09.08 & $-30: 03: 48.1$ & - & $1.15 \pm 0.12$ & - & - & $1.15 \pm 0.12$ \\
\hline 89531 & 18:03:19.88 & $-29: 58: 37.0$ & $-6.87 \pm 0.45$ & $-6.36 \pm 0.12$ & - & - & $-6.61 \pm 0.35$ \\
\hline 234816 & 18:03:26.52 & $-30: 06: 38.1$ & $-15.47 \pm 0.26$ & $-15.43 \pm 0.21$ & - & - & $-15.45 \pm 0.17$ \\
\hline 234822 & 18:03:27.76 & $-30: 06: 31.8$ & $-17.04 \pm 0.13$ & $-17.33 \pm 0.04$ & - & - & $-17.18 \pm 0.16$ \\
\hline 234932 & 18:03:31.59 & $-30: 05: 08.3$ & $-29.07 \pm 0.41$ & $-30.61 \pm 0.12$ & - & - & $-29.84 \pm 0.80$ \\
\hline 244523 & $18: 03: 27.56$ & $-30: 03: 45.1$ & $-13.48 \pm 0.08$ & $-12.38 \pm 0.05$ & - & - & $-12.93 \pm 0.55$ \\
\hline 244652 & 18:03:30.74 & $-30: 04: 21.2$ & $-28.92 \pm 0.56$ & $-29.50 \pm 0.14$ & - & - & $-29.21 \pm 0.41$ \\
\hline 244819 & 18:03:33.51 & $-30: 02: 25.2$ & $-19.93 \pm 0.36$ & $-18.90 \pm 0.29$ & - & - & $-19.42 \pm 0.56$ \\
\hline 244853 & 18:03:34.13 & $-30: 02: 11.1$ & $-12.84 \pm 0.26$ & $-10.73 \pm 0.10$ & - & - & $-11.79 \pm 1.07$ \\
\hline 256289 & 18:03:31.58 & $-30: 00: 51.0$ & $-16.08 \pm 0.33$ & $-14.14 \pm 0.29$ & - & - & $-15.11 \pm 0.99$ \\
\hline 256322 & 18:03:31.82 & $-29: 59: 30.8$ & $-20.48 \pm 0.26$ & $-19.73 \pm 0.35$ & - & - & $-20.11 \pm 0.43$ \\
\hline 267939 & $18: 03: 24.91$ & $-29: 56: 19.7$ & $1.19 \pm 0.30$ & $0.31 \pm 0.06$ & - & - & $0.75 \pm 0.47$ \\
\hline 392942 & 18:03:49.35 & $-30: 05: 53.5$ & $-3.06 \pm 0.27$ & $-4.20 \pm 0.09$ & - & - & $-3.63 \pm 0.59$ \\
\hline 402322 & $18: 03: 42.25$ & $-30: 03: 40.0$ & $-23.29 \pm 0.26$ & $-22.57 \pm 0.02$ & - & - & $-22.93 \pm 0.38$ \\
\hline 402370 & 18:03:42.35 & $-30: 02: 08.5$ & $-11.06 \pm 0.24$ & $-10.66 \pm 0.04$ & - & - & $-10.86 \pm 0.23$ \\
\hline 402384 & 18:03:42.55 & $-30: 01: 40.5$ & $-20.89 \pm 0.47$ & $-19.19 \pm 0.09$ & - & - & $-20.04 \pm 0.88$ \\
\hline 402386 & 18:03:49.04 & $-30: 01: 39.5$ & $-7.84 \pm 0.20$ & $-9.25 \pm 0.16$ & - & - & $-8.54 \pm 0.72$ \\
\hline 412759 & 18:03:47.35 & $-30: 00: 36.4$ & $-0.20 \pm 0.24$ & $-0.50 \pm 0.03$ & - & - & $-0.35 \pm 0.20$ \\
\hline 423375 & 18:03:48.41 & $-29: 57: 53.7$ & $-22.51 \pm 0.21$ & $-21.18 \pm 0.11$ & - & - & $-21.85 \pm 0.68$ \\
\hline 554709 & 18:03:58.36 & $-30: 02: 11.9$ & $-27.12 \pm 0.33$ & $-26.41 \pm 0.15$ & - & - & $-26.77 \pm 0.40$ \\
\hline 256646 & 18:03:24.78 & $-29: 58: 00.9$ & $-9.02 \pm 0.06$ & $-9.26 \pm 0.07$ & $-9.22 \pm 0.42$ & $-8.16 \pm 0.30$ & $-8.91 \pm 0.46$ \\
\hline 78151 & 18:03:10.99 & $-30: 02: 48.4$ & $-19.35 \pm 0.13$ & - & $-18.70 \pm 0.22$ & $-18.23 \pm 0.10$ & $-18.76 \pm 0.47$ \\
\hline 78161 & 18:03:10.78 & $-30: 02: 20.9$ & $-16.93 \pm 0.22$ & - & $-16.71 \pm 0.22$ & $-16.07 \pm 0.17$ & $-16.57 \pm 0.38$ \\
\hline 89489 & 18:03:10.10 & $-29: 59: 55.5$ & $-27.63 \pm 0.12$ & - & $-26.48 \pm 0.42$ & $-26.80 \pm 0.14$ & $-26.97 \pm 0.51$ \\
\hline 89544 & $18: 03: 16.20$ & $-29: 58: 04.0$ & $-13.92 \pm 0.22$ & - & $-13.68 \pm 0.38$ & $-12.73 \pm 0.06$ & $-13.44 \pm 0.54$ \\
\hline 234728 & $18: 03: 22.10$ & $-30: 08: 07.9$ & $-17.80 \pm 0.23$ & - & $-16.93 \pm 0.22$ & $-16.64 \pm 0.06$ & $-17.12 \pm 0.51$ \\
\hline 244518 & $18: 03: 34.80$ & $-30: 04: 05.9$ & $-0.28 \pm 0.09$ & - & $-0.30 \pm 0.26$ & $0.59 \pm 0.05$ & $0.00 \pm 0.42$ \\
\hline 244551 & 18:03:33.61 & $-30: 02: 38.9$ & $-8.61 \pm 0.16$ & - & $-9.13 \pm 0.66$ & $-8.14 \pm 0.14$ & $-8.63 \pm 0.47$ \\
\hline 244555 & $18: 03: 34.67$ & $-30: 02: 32.2$ & $-2.18 \pm 0.42$ & - & $-2.97 \pm 0.20$ & $-1.85 \pm 0.25$ & $-2.33 \pm 0.50$ \\
\hline 244813 & 18:03:29.00 & $-30: 02: 28.3$ & $-10.96 \pm 0.09$ & - & $-11.04 \pm 0.44$ & $-10.39 \pm 0.26$ & $-10.80 \pm 0.34$ \\
\hline 256298 & 18:03:32.13 & $-30: 00: 34.9$ & $-23.36 \pm 0.13$ & - & $-21.84 \pm 0.29$ & $-21.96 \pm 0.30$ & $-22.39 \pm 0.71$ \\
\hline 256361 & 18:03:27.43 & $-29: 58: 06.2$ & $-14.54 \pm 0.04$ & - & $-14.02 \pm 0.26$ & $-13.33 \pm 0.10$ & $-13.96 \pm 0.50$ \\
\hline 256386 & $18: 03: 20.27$ & $-30: 01: 12.3$ & $-11.72 \pm 0.18$ & - & $-11.74 \pm 0.36$ & $-10.87 \pm 0.20$ & $-11.44 \pm 0.43$ \\
\hline 402297 & 18:03:51.78 & $-30: 04: 39.4$ & $-13.13 \pm 0.08$ & - & $-12.89 \pm 0.35$ & $-11.98 \pm 0.27$ & $-12.67 \pm 0.52$ \\
\hline 402333 & 18:03:47.92 & $-30: 03: 24.7$ & $-26.11 \pm 0.07$ & - & $-25.57 \pm 0.22$ & $-25.17 \pm 0.27$ & $-25.62 \pm 0.41$ \\
\hline 402371 & 18:03:38.57 & $-30: 02: 07.3$ & $-18.46 \pm 0.48$ & - & $-17.09 \pm 0.15$ & $-17.00 \pm 0.15$ & $-17.52 \pm 0.69$ \\
\hline 402508 & 18:03:40.16 & $-30: 03: 18.1$ & $-4.44 \pm 0.45$ & - & $-4.46 \pm 0.36$ & $-4.07 \pm 0.46$ & $-4.32 \pm 0.30$ \\
\hline 402537 & 18:03:47.59 & $-30: 02: 59.3$ & $-10.14 \pm 0.09$ & - & $-10.36 \pm 0.41$ & $-9.49 \pm 0.17$ & $-10.00 \pm 0.40$ \\
\hline 402608 & 18:03:36.91 & $-30: 02: 07.0$ & $-8.86 \pm 0.05$ & - & $-9.56 \pm 0.49$ & $-8.12 \pm 0.24$ & $-8.85 \pm 0.62$ \\
\hline 412777 & 18:03:39.60 & $-29: 59: 43.0$ & $-24.74 \pm 0.10$ & - & $-23.80 \pm 0.37$ & $-23.72 \pm 0.28$ & $-24.09 \pm 0.49$ \\
\hline 412801 & 18:03:48.19 & $-29: 58: 32.9$ & $-11.19 \pm 0.06$ & - & $-10.95 \pm 0.30$ & $-10.24 \pm 0.07$ & $-10.80 \pm 0.42$ \\
\hline 413052 & 18:03:40.20 & $-29: 58: 11.0$ & $-28.98 \pm 0.84$ & - & $-29.04 \pm 0.35$ & $-28.81 \pm 0.34$ & $-28.94 \pm 0.34$ \\
\hline 423385 & 18:03:41.44 & $-29: 57: 44.1$ & $-10.47 \pm 0.15$ & - & $-10.55 \pm 0.16$ & $-9.62 \pm 0.04$ & $-10.22 \pm 0.43$ \\
\hline 423575 & $18: 03: 36.65$ & $-29: 55: 13.8$ & $-19.64 \pm 0.13$ & - & $-18.68 \pm 0.18$ & $-18.35 \pm 0.10$ & $-18.89 \pm 0.55$ \\
\hline 545289 & 18:03:53.99 & $-30: 05: 02.0$ & $-1.71 \pm 0.09$ & - & $-4.76 \pm 0.66$ & $-3.92 \pm 0.19$ & $-3.47 \pm 1.31$ \\
\hline
\end{tabular}




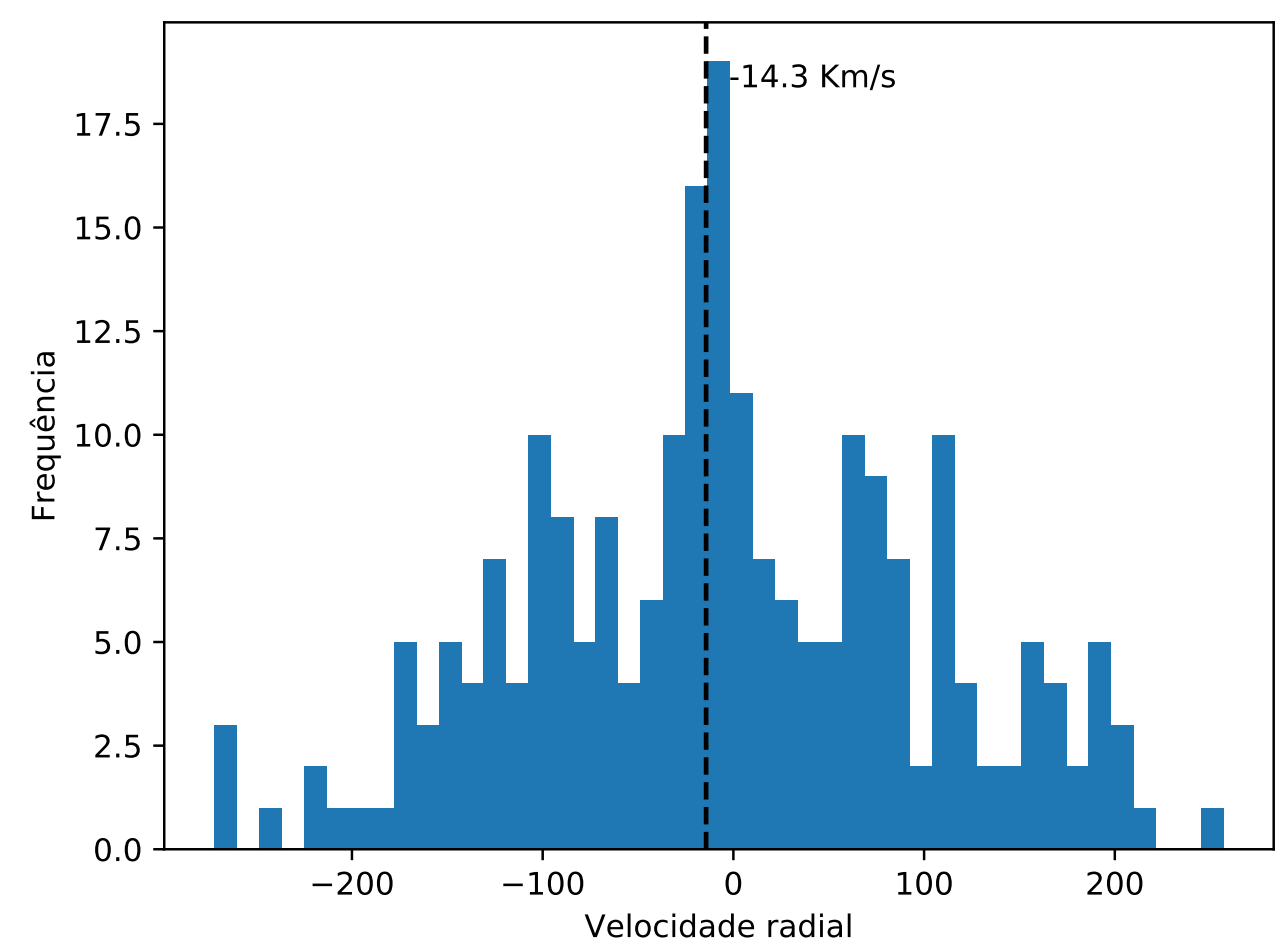

Figura 2.6: Distribuição das velocidades radiais da amostra completa das estrelas Gi2012 e GI2016.

\subsubsection{Catálogo de estrelas}

Utilizando de base a imagem do cubo na banda $\mathrm{I}_{\text {Cousins }}$, foi escrito um código em Python 3 que faz uso dos pacotes photutils e astropy para identificar automaticamente as fontes via a função DAOStarFinder, posicionar aberturas circulares nas fontes e exportar suas posições. Uma inspeção visual é feita neste processo, de modo a controlar a identificação.

Por meio do software DS9, são abertas lado a lado as imagens do Hubble e do MUSE, e posicionads as regiões correspondentes às fontes identificadas. Uma análise visual é realizada afim de identificar se as fontes na imagem do MUSE são de fato estrelas únicas ou grupos de estrelas muito próximas, como o caso exibido na figura 2.9. Nesta inspeção, são manualmente removidas fontes múltiplas, e adicionadas fontes que não foram previamente identificadas e que são passíveis de detecção e separação pelo PampelMUSE.

Feita a inspeção e seleção final dos alvos, a lista de coordenadas foi exportada, totalizando 1330 fontes. Utilizando o survey VVV (Vista Variables in Via-Lactea, Minniti et al. 2010) do telescópio VISTA, é feita uma correlação para encontrar as estrelas do catálogo 


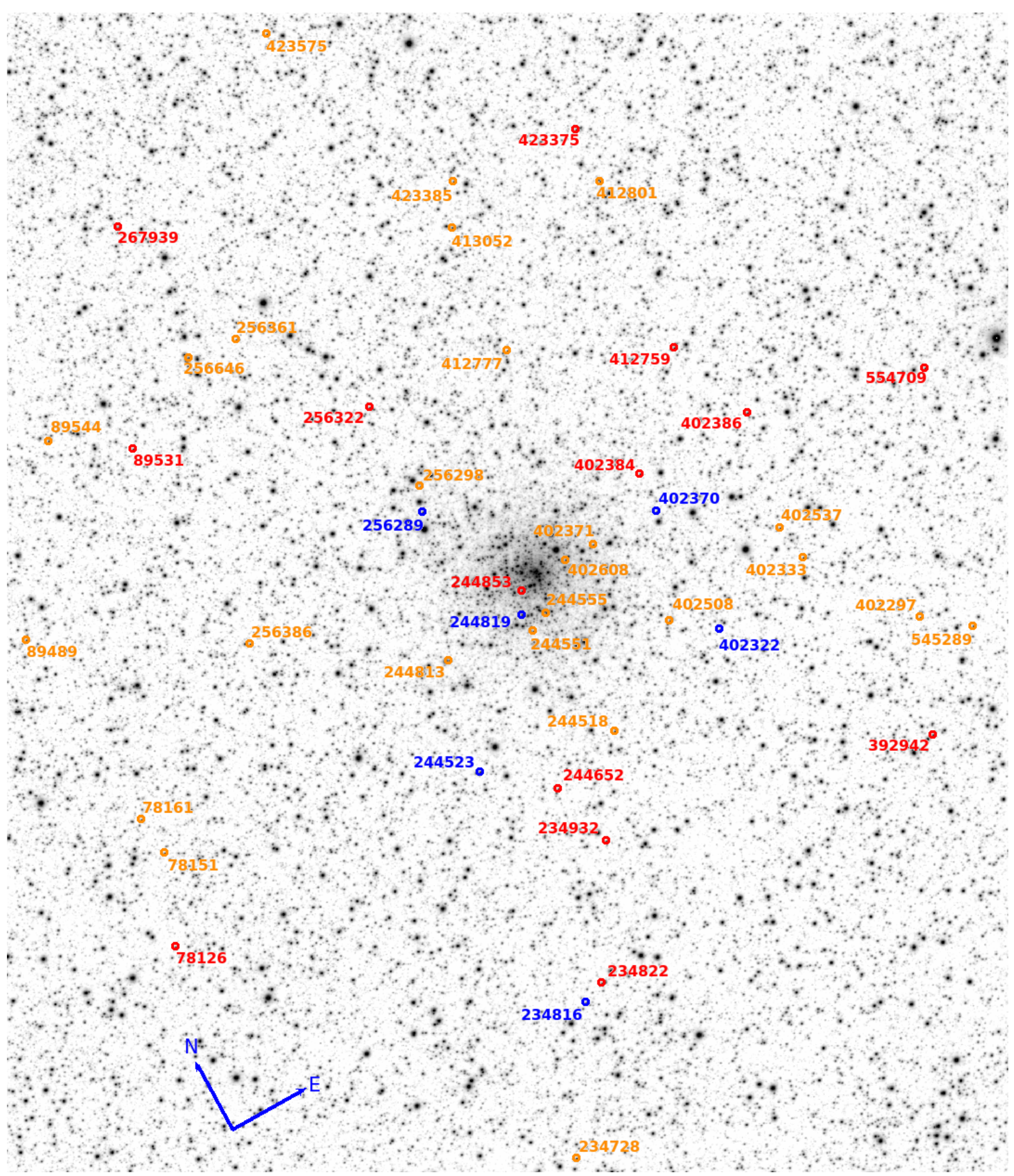

Figura 2.7: Campo do aglomerado globular NGC 6522 do survey Vista Variables in Vialactea e as estrelas selecionadas. Em azul: estrelas comuns entre as amostras UV2016 e GI2012, em vermelho: estrelas da amostra GI2012, em laranja: estrelas da amostra GI2016.

e suas magnitudes nas bandas J, H e Ks. Devido à resolução espacial do survey, é de se esperar que poucas das estrelas do catálogo foram encontradas, e destas, foram extraídas suas magnitudes na banda Ks, que possuía o maior número de fontes correlatas. Todas as 


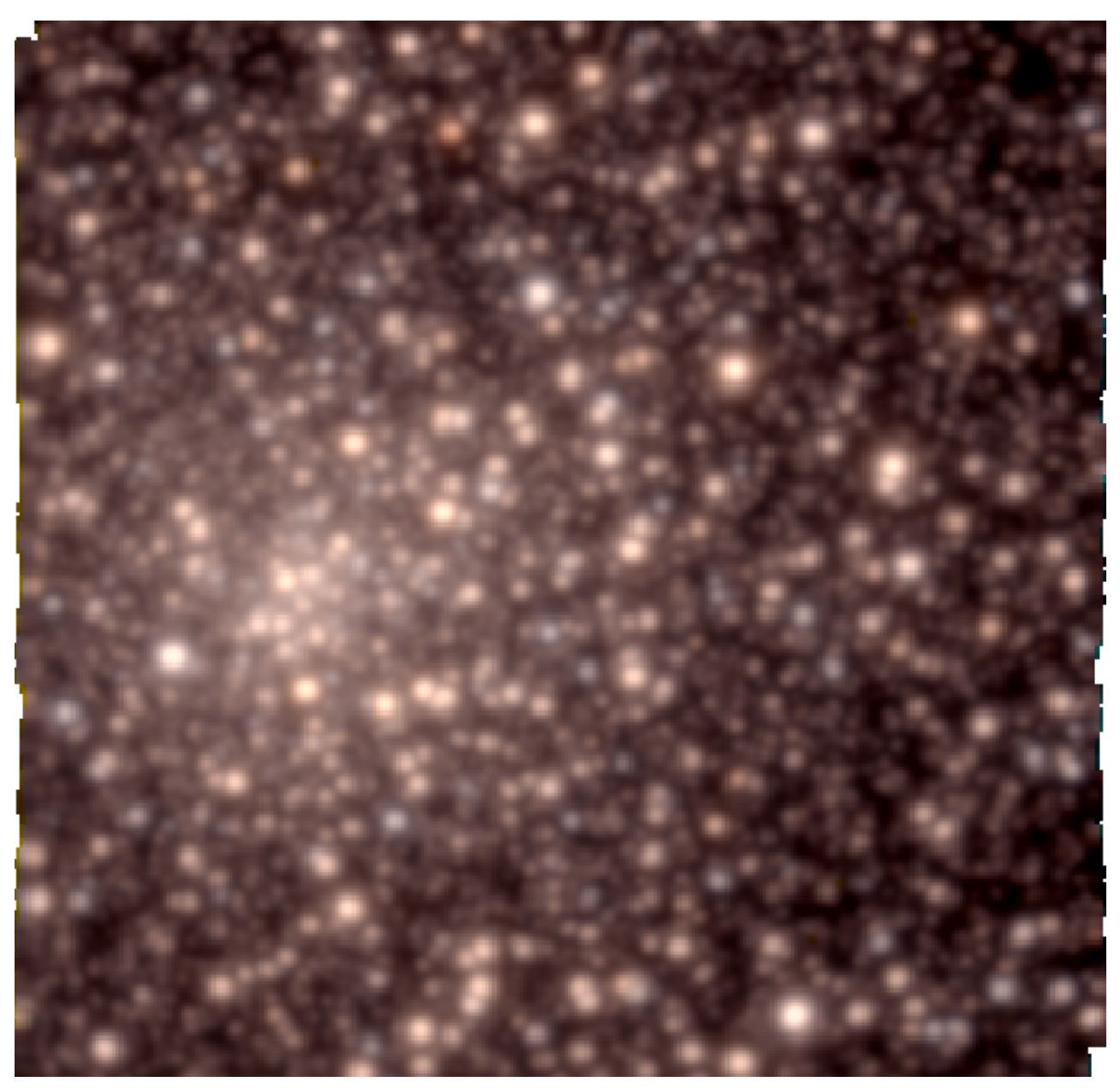

Figura 2.8: Imagem combinada nos filtros $\mathrm{B}_{\text {Johnson }}, \mathrm{V}_{\text {Johnson }}$ e $\mathrm{R}_{\text {Cousins }}$ do campo central do aglomerado globular NGC 6522, extraídos do cubo de dados do MUSE.

estrelas que não foram encontradas tiveram sua magnitude assumida em 18.8. As magnitudes do catálogo têm relevância apenas no processo de alinhamento pelo PampelMUSE, que leva em conta as magnitudes dos alvos para realizar uma correlação inicial da posição do catálogo com as coordenadas do cubo.

\subsubsection{PampelMUSE}

Em campos com um grande número de estrelas, onde estas apresentam muito crowding (termo usado quando muitas estrelas se aglomeram de modo que a resolução espacial não é capaz de separá-las claramente), uma das possíveis maneiras de medir o fluxo de uma fonte puntual é via fotometria por PSF (Point-Spread Function, função de espalhamento puntual, que representa o perfil que uma fonte puntual apresenta ao ser amostrada por um instrumento), onde ajusta-se um perfil bidimensional (como por exemplo o perfil de 

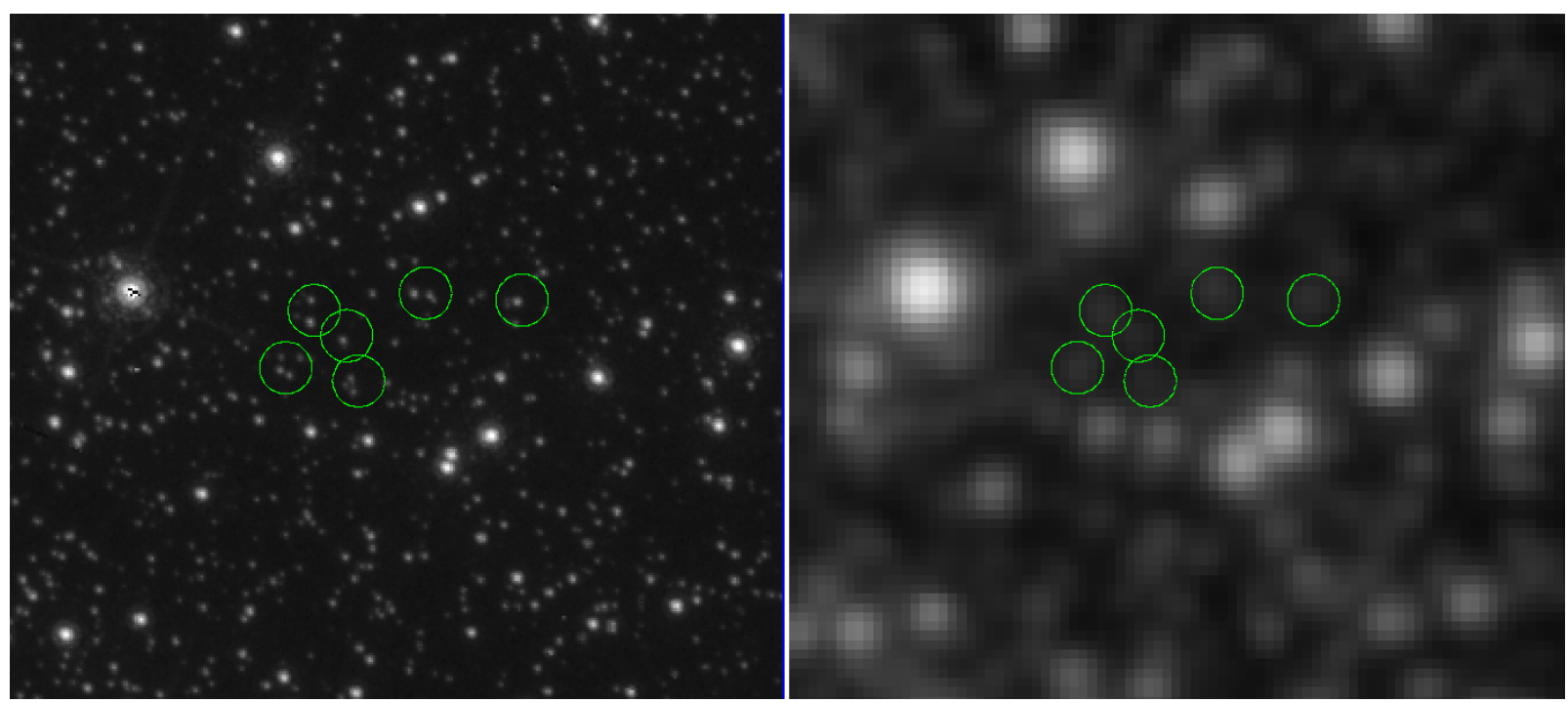

Figura 2.9: Comparação entre a imagem do Hubble (à esquerda) e a imagem do MUSE (à direita) para a identificação e limpeza de fontes múltiplas. É possível notar que o que se assemelha a uma única fonte na imagem do MUSE são na verdade grupos de estrelas mais fracas na imagem do Hubble.

moffat, que combina o perfil gaussiano e o lorentziano para reproduzir a PSF de estrelas) à fonte, e analisando-se os resíduos é possível determinar se esta fonte é única, ou se existe mais de uma fonte contribuindo para a formação do perfil, produzindo assimetrias.

O PampelMUSE é um código escrito em Python que realiza fotometria por PSF em cada seção de comprimento de onda do cubo de dados, baseado em um catálogo de fontes com sua magnitude, com a finalidade de obter espectros individuais livres de contaminação por estrelas vizinhas.

Por meio da tarefa INITFIT, o código faz inicialmente um alinhamento do catálogo com as fontes detectadas no cubo, apresentando posteriormente uma interface gráfica para que o usuário possa refinar o alinhamento. Após isso, é estimado o fator $\mathrm{S} / \mathrm{R}$ de todas as fontes, e posteriormente as fontes são caracterizadas como resolvidas ou não-resolvias e preparadas para extração.

Em seguida, a tarefa CUBEFIT parte das estimativas iniciais para as PSF e transformações de coordenadas para ajustar as fontes em cada secção (em comprimento de onda) do cubo. Inicialmente, esta tarefa é feita agrupando-se as seç̧ões iniciais em um número menor de secções para estimar a variação das transformações de coordenadas e parâmetros das PSF (tipicamente colapsando grupos de 30 secções adjacentes) em função do comprimento de onda. Para normalizar os efeito de espalhamento dos parâmetros (como 
FWHM daPSF e correções de coordenadas) ao longo do comprimento de onda, utiliza-se a tarefa POLYFIT para ajustar polinômios a estes parâmetros, onde estes ajustes serão utilizados pela próxima execução a tarefa CUBEFIT.

Após a inspeção visual e ajuste dos polinômios aos parâmetros, executa-se novamente o CUBEFIT, desta vez com o número total de secções, para realizar o ajuste final das fontes em todo o cubo. Para extrair os espectros das estrelas, utiliza-se a tarefa GETSPECTRA, que irá extrair os fluxos de cada fonte em cada comprimento de onda por meio da PSF ajustada. Por fim, o espectro de cada fonte é salvo em um arquivo de texto com duas colunas: comprimento de onda e fluxo.

Por fim, dos espectros extraídos, foram rejeitados aqueles cuja mediana do fluxo era menor que 100 (baseado em uma análise visual para determinar a qualidade dos espectros) para preservar os de melhor qualidade. Esta seleção não prejudica a posterior análise, visto que o interesse está mais focado nas estrelas gigantes, e portanto, de maior brilho. Após este último filtro, um total de 1191 alvos foram considerados para a análise. 
Capítulo 3

\section{Parâmetros atmosféricos}

Para a caracterização das estrelas no âmbito das populações estelares, é fundamental conhecer as condições físicas de sua fotosfera, onde é formada a principal informação acerca do seu caráter químico e evolutivo, que é seu espectro. A fotosfera é a última camada da estrela pela qual a luz proveniente de seu interior interage (no caso das estrelas gigantes, onde os efeitos da cromosfera e da corona são desprezíveis), sendo também uma componente estrutural que conserva quase o mesmo padrão químico desde sua formação (com exceção de alguns elementos, como por exemplo o carbono e nitrogênio, que sofrem alterações em suas abundâncias e razões isotópicas devido aos eventos de dragagem de matéria durante a evolução da estrela), construindo assim a forma da luz da estrela que chega até o observador. Os principais parâmetros físicos da fotosfera são a temperatura efetiva, a gravidade e a metalicidade.

A fotosfera possui um gradiente de temperaturas onde cada profundidade é responsável por uma contribuição à formação do espectro, e a temperatura efetiva representa a temperatura de um corpo negro que melhor se ajusta ao espectro da estrela. No modelo atmosférico, a temperatura de cada estratificação da fotosfera (assumindo-se equilíbrio termodinâmico local) é calculada com base na temperatura efetiva, para com isso estimar os níveis de ionização e excitação das espécies químicas presentes. A gravidade superficial da estrela tem um papel fundamental na estimativa da pressão no ambiente físico da fotosfera, afetando diretamente o equilíbrio de excitação e ionização das espécies químicas. A metalicidade, além de afetar diretamente o peso molecular médio do ambiente, contribui para a opacidade do meio, sendo uma componente fundamental no transporte radiativo.

Nos modelos atmosféricos utilizados (unidimensionais), um quarto parâmetro é a velocidade de micro-turbulência $(\xi)$, sendo a componente não-térmica da velocidade do gás, 
causando um alargamento das linhas espectrais devido ao efeito doppler da convecção em pequenas escalas.

Para a derivação espectroscópica (isto é, utilizando-se linhas espectrais) dos parâmetros fotosféricos, utiliza-se um modelo fotosférico contendo as condições físicas de cada estratificação da atmosfera, para que via transferência radiativa seja possível calcular as abundâncias individuais de linhas espectrais de ferro por meio de suas curvas de crescimento, com base nas larguras equivalentes (EW, equivalent width) de cada uma. Impõe-se equilíbrio de excitação e equilíbrio de ionização, e varia-se os parâmetros do modelo até que estas condições sejam atingidas. Neste processo, o objetivo é eliminar a tendência na abundância de ferro de cada linha $([\mathrm{Fe} / \mathrm{H}])$ versus seu respectivo potencial de excitação $\left(\chi_{\text {exc }}\right)$, igualar as abundâncias de ferro neutro $(\mathrm{FeI})$ e ferro ionizado (FeII), e eliminar a tendência de $[\mathrm{Fe} / \mathrm{H}]$ versus EW. A metalicidade resulta da média das abundâncias individuais das linhas de ferro quando convergidos os parâmetros.

\subsection{Parâmetros fotométricos}

Os parâmetros atmosféricos, em especial a temperatura, podem ser obtidos em primeira aproximação utilizando as magnitudes e cores das estrelas em filtros determinados. As temperaturas fotométricas são utilizadas como ponto inicial para a determinação dos parâmetros espectroscópicos, e para seu cálculo, são utilizadas as escalas de calibração de Alonso et al. (1999) para determinar as temperaturas com base em faixas de cor e metalicidade a que se aplicam. Foram utilizadas as magnitudes dos surveys 2MASS (TwoMicron All-Sky Survey, Skrutskie et al. 2006) e VVV para calcular as cores, e com isto, as temperaturas, bem como as correções e magnitudes bolométricas para a determinação das gravidades fotométricas, exibidas na tabela 3.1 .

\subsection{Lista de linhas de ferro}

As linhas espectrais são formadas na fotosfera da estrela (onde as temperaturas permitem a recombinação de elétrons aos núcleos atômicos, possibilitando que as transições eletrônicas em níveis quantizados de energia ocorram), onde os elétrons nos átomos dos elementos realizam transições dos níveis de energia devido à sua excitação ao absorver fótons (e posteriormente os reemitir em uma direção aleatória) de energia específica (equivalente 
Tabela 3.1 - Parâmetros fotométricos das estrelas, obtidos a partir das magnitudes dos surveys 2MASS e VVV.

\begin{tabular}{|c|c|c|c|c|c|c|c|c|}
\hline Objeto & $\mathrm{T}_{V-I}(K)$ & $\begin{array}{c}\mathrm{T}_{V-K}(\mathrm{~K}) \\
\text { 2MASS }\end{array}$ & $\begin{array}{c}\mathrm{T}_{J-K}(\mathrm{~K}) \\
\text { 2MASS }\end{array}$ & $\begin{array}{c}\mathrm{T}_{V-K}(\mathrm{~K}) \\
\mathrm{VVV}\end{array}$ & $\begin{array}{c}\mathrm{T}_{J-K}(\mathrm{~K}) \\
\mathrm{VVV}\end{array}$ & $\mathrm{BC}_{V}$ & $\mathrm{M}_{b o l}$ & $\log G$ \\
\hline 78126 & 4367.9 & 4376.0 & 4349.7 & 4390.0 & 4593.3 & -0.570 & 1.41 & 2.523 \\
\hline 89531 & 4754.8 & 4693.3 & 4496.3 & 4692.5 & 4587.1 & -0.360 & 0.93 & 2.478 \\
\hline 234816 & 4511.5 & 4361.6 & 4260.3 & 4362.6 & 4306.3 & -0.479 & 1.36 & 2.558 \\
\hline 244523 & 4783.6 & 3671.1 & - & 4796.8 & 4801.6 & -0.348 & 0.82 & 2.444 \\
\hline 244819 & 4851.8 & 3618.2 & - & 4760.1 & 4783.7 & -0.322 & 1.11 & 2.586 \\
\hline 244853 & 4865.8 & 3653.2 & - & 3653.3 & - & -0.317 & 0.89 & 2.501 \\
\hline 256289 & 4979.2 & 4908.2 & 4869.9 & 4936.8 & 4831.6 & -0.279 & 0.68 & 2.458 \\
\hline 256322 & 4868.2 & 4447.0 & 4626.4 & 4818.6 & 4704.4 & -0.316 & 0.90 & 2.509 \\
\hline 402322 & 4709.4 & 4696.0 & 4638.5 & 4673.7 & 4658.7 & -0.379 & 0.87 & 2.437 \\
\hline 402370 & 4765.8 & 4884.0 & 4873.3 & 4785.4 & 4776.1 & -0.355 & 1.06 & 2.536 \\
\hline 402386 & 4192.3 & 4190.1 & 4189.6 & 4199.7 & 4194.0 & -0.705 & 1.47 & 2.477 \\
\hline 554709 & 4808.3 & 4833.8 & 4573.2 & 4837.3 & 4773.4 & -0.338 & 0.78 & 2.437 \\
\hline 234822 & 4810.6 & 3614.3 & - & 4824.0 & 4977.8 & -0.337 & 1.16 & 2.589 \\
\hline 234932 & 4089.0 & 4114.3 & 4089.2 & 4175.9 & 4271.1 & -0.804 & 1.92 & 2.614 \\
\hline 244652 & 4274.4 & 4300.5 & 4409.5 & 4324.2 & 4420.8 & -0.638 & 1.75 & 2.620 \\
\hline 267939 & 4217.0 & 4139.7 & 4241.2 & 4242.7 & 4189.0 & -0.684 & 1.72 & 2.587 \\
\hline 392942 & 4821.9 & 4730.1 & 4665.9 & 4827.8 & 4885.4 & -0.333 & 0.89 & 2.488 \\
\hline 402384 & 4776.9 & 4839.9 & 4611.5 & 4778.2 & 4782.4 & -0.351 & 0.89 & 2.471 \\
\hline 412759 & 4824.2 & 4554.1 & 4869.9 & 4742.0 & 4782.1 & -0.332 & 0.78 & 2.444 \\
\hline 423375 & 4792.5 & 4785.4 & 5030.1 & 4778.5 & 4882.6 & -0.344 & 1.11 & 2.565 \\
\hline 256646 & 4961.9 & 3623.6 & - & 4662.2 & 5015.8 & -0.285 & 1.03 & 2.594 \\
\hline 78151 & 4519.0 & 4614.1 & 4696.8 & 4530.0 & 4606.9 & -0.474 & 1.38 & 2.571 \\
\hline 78161 & 4838.0 & 4731.1 & 4406.8 & 4812.4 & 4729.8 & -0.327 & 1.06 & 2.559 \\
\hline 89489 & 5029.6 & 4862.3 & 5067.5 & 4989.8 & 4899.2 & -0.264 & 0.86 & 2.549 \\
\hline 89544 & 4964.3 & 4246.7 & 4734.6 & 4892.9 & 4751.4 & -0.284 & 0.98 & 2.575 \\
\hline 234728 & 4172.4 & 4197.6 & 4159.9 & 4233.8 & 4478.0 & -0.723 & 1.81 & 2.604 \\
\hline 244518 & 4095.5 & 4105.0 & 4326.9 & 4185.5 & 4281.4 & -0.797 & 1.81 & 2.570 \\
\hline 244551 & 4750.5 & 4953.3 & 5026.4 & 4776.3 & 4791.3 & -0.362 & 0.98 & 2.497 \\
\hline 244555 & 4102.0 & 3590.7 & - & 3590.8 & - & -0.791 & 1.81 & 2.574 \\
\hline 244813 & 5006.8 & 3642.3 & - & 4846.2 & 4994.8 & -0.271 & 0.90 & 2.556 \\
\hline 256298 & 4910.8 & 4698.8 & 4504.7 & 4810.3 & 4709.6 & -0.301 & 0.82 & 2.491 \\
\hline 256361 & 4600.2 & 4518.9 & 4672.0 & 4566.3 & 4570.9 & -0.429 & 1.33 & 2.580 \\
\hline 256386 & 4505.9 & 3928.6 & 3036.7 & 4443.4 & 4341.3 & -0.482 & 1.45 & 2.594 \\
\hline 256646 & 4961.9 & 3623.6 & - & 4662.2 & 5015.8 & -0.285 & 1.03 & 2.594 \\
\hline 402297 & 4136.5 & 4216.2 & 4297.0 & 4250.1 & 4454.3 & -0.756 & 1.53 & 2.479 \\
\hline 402333 & 4707.3 & 4415.6 & 3920.4 & 4687.4 & 4736.1 & -0.380 & 1.06 & 2.513 \\
\hline 402371 & 4819.7 & 4749.9 & 5525.2 & 4929.8 & 4994.4 & -0.334 & 0.88 & 2.483 \\
\hline 402508 & 4730.9 & 3622.1 & - & 3616.8 & 2504.0 & -0.370 & 1.13 & 2.549 \\
\hline 402537 & 4489.2 & 4473.2 & 4375.4 & 4460.7 & 4415.0 & -0.492 & 1.28 & 2.519 \\
\hline 402608 & 4877.6 & 3618.6 & - & 4762.1 & 4848.7 & -0.313 & 1.10 & 2.592 \\
\hline 412777 & 4709.4 & 4420.7 & 3692.3 & 4627.5 & 4502.8 & -0.379 & 0.93 & 2.461 \\
\hline 412801 & 4654.9 & 4259.6 & 4584.9 & 4576.7 & 4750.7 & -0.400 & 0.92 & 2.437 \\
\hline 413052 & 4957.0 & 4828.8 & 4737.8 & 4881.6 & 4795.3 & -0.286 & 1.04 & 2.597 \\
\hline 423385 & 5137.2 & 5042.1 & 4890.5 & 5089.3 & 4989.2 & -0.235 & 0.80 & 2.563 \\
\hline 423575 & 4553.3 & 4459.7 & 4388.4 & 4525.9 & 4560.8 & -0.455 & 1.36 & 2.577 \\
\hline 545289 & 4636.5 & 4636.5 & 4653.7 & 4676.6 & 4725.1 & -0.410 & 1.17 & 2.530 \\
\hline
\end{tabular}


à diferença dos níveis de energia da transição), resultando em uma ausência de fótons na linha de visada do observador no comprimento de onda equivalente à energia da transição.

As transições atômicas possuem como propriedades seu comprimento de onda, o potencial de excitação $\left(\chi_{\text {exc }}\right.$, energia mínima para que o elétron excite, equivalente à energia do estado em que o elétron se encontra), a força de oscilador ( $\log g f$, a probabilidade da transição ocorrer), a seção de choque de Van der Waals (um parâmetro que influencia no alargamento das asas da linha), dentre outros que na presente análise não são considerados por não produzirem efeitos significativos. Estas propriedades determinam a intensidade e o perfil da linha espectral conforme o ambiente físico onde a transição ocorre, sendo estas imprescindíveis na análise espectroscópica.

O ferro, por ser o elemento que possui a maior quantidade de linhas espectrais na faixa da luz visível, é usado como referência para a abundância de elementos mais pesados que hidrogênio e hélio, ou seja, a metalicidade. Devido a esses fatores, este é utilizado para a determinação dos parâmetros atmosféricos via o equilíbrio de excitação e ionização.

Para garantir que as abundâncias individuais das linhas sejam corretamente calculadas, as linhas espectrais de ferro precisam ter suas larguras equivalentes determinadas de maneira a considerar somente a própria linha, sem que outros elementos a poluam em blends (onde duas ou mais linhas se sobrepõem, fundindo seus perfis), prejudicando o correto ajuste para sua medição. Para tal, uma cuidadosa seleção das linhas de ferro é necessária para escolher linhas que estejam livres de blends, ou facilmente separáveis de outras contribuições. As linhas selecionadas também precisam ter seus parâmetros bem determinados, reproduzindo corretamente o perfil e intensidade das linhas espectrais reais, para que com isso o cálculo das abundâncias individuais retorne valores confiáveis.

Fazendo uma varredura visual nos espectros do Sol e de Arcturus (ver seção 3.1.1), juntamente com seus respectivos espectros sintéticos com e sem linhas de ferro, e posteriormente com o auxílio da síntese espectral decomposta (descrita na seção 3.1.1), foram selecionadas linhas de Fe I e Fe II limpas e com parâmetros que reproduzem satisfatoriamente seus perfis nas estrelas de referência, de modo que pudessem ser medidas tanto manualmente quanto por códigos automatizados como o DAOSPEC (Stetson e Pancino, 2008), tanto em alta resolução (para o caso do UVES) quanto em resolução média-alta (GIRAFFE). A lista é exibida na tabela 3.2. O intervalo entre $5500 \AA$ e $6820 \AA$ foi escolhido para compreender a cobertura do setup 580 do UVES e evitar a região abaixo de 5500 
$\AA$, por esta conter um grande número de linhas espectrais fracas cujas opacidades contribuem para o abaixamento do contínuo (blanketing) nesta região, levando a uma estimativa incorreta do nível do contínuo, e por consequência, das larguras equivalentes medidas.

Tabela 3.2 - Lista de linhas espectrais de ferro selecionadas para medição e respectivos valores de comprimento de onda $(\lambda)$, potencial de excitação $\left(\chi_{\text {exc }}\right)$, forças de oscilador $(\log g f)$ e seção de choque de Van der Waals $(C 6)$. São exibidos os valores de $\log g f$ da base VALD3, NIST, e os valores adotados na análise. Todas as linhas da tabela estão habilitadas para uso com espectros UVES, e as linhas habilitadas para GIRAFFE estão discriminadas na coluna GR.

\begin{tabular}{|c|c|c|c|c|c|c|c|c|c|c|c|c|c|c|c|}
\hline \multirow[t]{2}{*}{ Ion } & \multirow[t]{2}{*}{$\lambda(\AA)$} & \multirow[t]{2}{*}{$\chi e x c$} & \multicolumn{3}{|c|}{$\log g f$} & \multirow[t]{2}{*}{$C 6$} & \multirow[t]{2}{*}{ GR } & \multirow[t]{2}{*}{ Ion } & \multirow[t]{2}{*}{$\lambda(\AA)$} & \multirow[t]{2}{*}{$\chi_{e x c}$} & \multicolumn{3}{|c|}{$\log g f$} & \multirow[t]{2}{*}{$C 6$} & \multirow[t]{2}{*}{ GR } \\
\hline & & & NIST & VALD & adt. & & & & & & NIST & VALD & adt. & & \\
\hline FeII & 5991.37 & 3.15 & -3.60 & -3.54 & -3.54 & $8.760 \mathrm{E}-33$ & ok & $\mathrm{FeI}$ & 5983.68 & 4.55 & - & -0.48 & -0.58 & $8.035 \mathrm{E}-32$ & ok \\
\hline FeII & 6084.10 & 3.20 & -3.90 & -3.78 & -3.79 & $8.913 \mathrm{E}-33$ & ok & $\mathrm{FeI}$ & 5984.81 & 4.73 & - & -0.20 & -0.20 & $1.349 \mathrm{E}-31$ & \\
\hline FeII & 6149.25 & 3.89 & -2.80 & -2.72 & -2.69 & $1.012 \mathrm{E}-32$ & ok & $\mathrm{FeI}$ & 5987.06 & 4.80 & - & -0.43 & -0.43 & $1.349 \mathrm{E}-31$ & ok \\
\hline FeII & 6247.56 & 3.89 & -2.40 & -2.31 & -2.30 & $1.012 \mathrm{E}-32$ & ok & $\mathrm{FeI}$ & 6003.01 & 3.88 & - & -1.12 & -1.12 & $5.339 \mathrm{E}-31$ & ok \\
\hline FeII & 6369.46 & 2.89 & -4.29 & -4.16 & -4.11 & $8.561 \mathrm{E}-33$ & ok & $\mathrm{FeI}$ & 6008.56 & 3.88 & - & -0.98 & -0.98 & $6.761 \mathrm{E}-32$ & ok \\
\hline FeII & 6416.92 & 3.89 & -2.90 & -2.65 & -2.64 & $9.943 \mathrm{E}-33$ & ok & $\mathrm{FeI}$ & 6012.21 & 2.22 & -4.04 & -4.04 & -3.94 & $3.610 \mathrm{E}-32$ & ok \\
\hline FeII & 6432.68 & 2.89 & -3.50 & -3.52 & -3.57 & $8.561 \mathrm{E}-33$ & ok & $\mathrm{FeI}$ & 6027.05 & 4.07 & -1.09 & -1.09 & -1.09 & $1.698 \mathrm{E}-32$ & ok \\
\hline FeII & 6456.38 & 3.90 & -2.20 & -2.10 & -2.05 & $9.943 \mathrm{E}-33$ & ok & $\mathrm{FeI}$ & 6056.00 & 4.73 & - & -0.46 & -0.46 & $7.161 \mathrm{E}-31$ & ok \\
\hline FeII & 6516.08 & 2.89 & -3.37 & -3.32 & -3.32 & $8.561 \mathrm{E}-33$ & ok & $\mathrm{FeI}$ & 6065.48 & 2.61 & -1.53 & -1.53 & -1.53 & $5.248 \mathrm{E}-32$ & ok \\
\hline $\mathrm{FeI}$ & 5501.47 & 0.96 & -3.05 & -3.05 & -3.05 & $1.939 \mathrm{E}-32$ & & $\mathrm{FeI}$ & 6078.49 & 4.80 & - & -0.32 & -0.32 & $1.429 \mathrm{E}-31$ & ok \\
\hline $\mathrm{FeI}$ & 5522.45 & 4.21 & -1.52 & -1.55 & -1.52 & $3.447 \mathrm{E}-31$ & & $\mathrm{FeI}$ & 6082.71 & 2.22 & -3.57 & -3.57 & -3.57 & $3.508 \mathrm{E}-32$ & \\
\hline $\mathrm{FeI}$ & 5529.16 & 3.64 & -2.68 & -2.73 & -2.68 & $5.099 \mathrm{E}-32$ & & $\mathrm{FeI}$ & 6096.66 & 3.98 & -1.88 & -1.93 & -1.88 & $6.310 \mathrm{E}-31$ & ok \\
\hline $\mathrm{FeI}$ & 5536.58 & 2.83 & -3.73 & -3.81 & -3.81 & $1.349 \mathrm{E}-32$ & & $\mathrm{FeI}$ & 6120.25 & 0.92 & -5.97 & -5.95 & -5.97 & $1.349 \mathrm{E}-32$ & ok \\
\hline $\mathrm{FeI}$ & 5543.94 & 4.22 & -1.11 & -1.14 & -1.11 & $3.330 \mathrm{E}-31$ & & $\mathrm{FeI}$ & 6127.91 & 4.14 & -1.40 & -1.40 & -1.40 & $1.603 \mathrm{E}-32$ & ok \\
\hline $\mathrm{FeI}$ & 5565.70 & 4.61 & - & -0.21 & -0.21 & $1.429 \mathrm{E}-31$ & & $\mathrm{FeI}$ & 6136.61 & 2.45 & -1.40 & -1.40 & -1.40 & $4.545 \mathrm{E}-32$ & ok \\
\hline $\mathrm{FeI}$ & 5569.62 & 3.42 & -0.49 & -0.49 & -0.49 & $4.677 \mathrm{E}-31$ & & $\mathrm{FeI}$ & 6136.99 & 2.20 & -2.95 & -2.95 & -2.95 & $2.835 \mathrm{E}-32$ & ok \\
\hline $\mathrm{FeI}$ & 5572.84 & 3.40 & -0.28 & -0.28 & -0.28 & $4.493 \mathrm{E}-31$ & & $\mathrm{FeI}$ & 6151.62 & 2.18 & -3.30 & -3.30 & -3.30 & $2.754 \mathrm{E}-32$ & ok \\
\hline $\mathrm{FeI}$ & 5576.09 & 3.43 & -0.94 & -1.00 & -0.94 & $4.759 \mathrm{E}-31$ & & $\mathrm{FeI}$ & 6165.36 & 4.14 & -1.47 & -1.47 & -1.47 & $1.698 \mathrm{E}-32$ & ok \\
\hline $\mathrm{FeI}$ & 5584.76 & 3.57 & -2.27 & -2.32 & -2.27 & $3.236 \mathrm{E}-32$ & & $\mathrm{FeI}$ & 6173.33 & 2.22 & -2.88 & -2.88 & -2.88 & $2.851 \mathrm{E}-32$ & ok \\
\hline $\mathrm{FeI}$ & 5586.76 & 3.37 & -0.14 & - & -0.12 & $3.000 \mathrm{E}-32$ & & $\mathrm{FeI}$ & 6180.20 & 2.73 & -2.65 & -2.59 & -2.65 & $4.467 \mathrm{E}-32$ & ok \\
\hline $\mathrm{FeI}$ & 5607.66 & 4.16 & - & -2.27 & -2.27 & $4.050 \mathrm{E}-31$ & ok & $\mathrm{FeI}$ & 6187.99 & 3.94 & -1.67 & -1.72 & -1.67 & $5.401 \mathrm{E}-31$ & ok \\
\hline $\mathrm{FeI}$ & 5615.30 & 2.59 & -2.25 & -2.44 & -2.25 & $2.265 \mathrm{E}-32$ & & $\mathrm{FeI}$ & 6200.31 & 2.61 & -2.44 & -2.44 & -2.44 & $5.099 \mathrm{E}-32$ & ok \\
\hline $\mathrm{FeI}$ & 5615.64 & 3.33 & 0.05 & 0.05 & 0.05 & $3.936 \mathrm{E}-31$ & & $\mathrm{FeI}$ & 6213.43 & 2.22 & -2.48 & -2.48 & -2.48 & $2.835 \mathrm{E}-32$ & ok \\
\hline $\mathrm{FeI}$ & 5618.63 & 4.21 & -1.28 & -1.28 & -1.28 & $3.311 \mathrm{E}-31$ & ok & $\mathrm{FeI}$ & 6219.28 & 2.20 & -2.43 & -2.43 & -2.43 & $2.786 \mathrm{E}-32$ & ok \\
\hline $\mathrm{FeI}$ & 5633.95 & 4.99 & -0.32 & -0.27 & -0.27 & $2.175 \mathrm{E}-31$ & ok & $\mathrm{FeI}$ & 6240.65 & 2.22 & -3.17 & -3.23 & -3.23 & $3.369 \mathrm{E}-32$ & ok \\
\hline $\mathrm{FeI}$ & 5636.69 & 3.64 & -2.56 & -2.61 & -2.61 & $5.339 \mathrm{E}-32$ & & $\mathrm{FeI}$ & 6246.32 & 3.60 & -0.88 & -0.73 & -0.88 & $4.241 \mathrm{E}-31$ & \\
\hline $\mathrm{FeI}$ & 5638.26 & 4.22 & -0.84 & -0.87 & -0.84 & $3.217 \mathrm{E}-31$ & ok & $\mathrm{FeI}$ & 6252.56 & 2.40 & -1.69 & -1.69 & -1.69 & $4.241 \mathrm{E}-32$ & ok \\
\hline $\mathrm{FeI}$ & 5652.32 & 4.26 & -1.92 & -1.95 & -1.78 & $3.569 \mathrm{E}-31$ & ok & $\mathrm{FeI}$ & 6265.13 & 2.18 & -2.55 & -2.55 & -2.55 & $2.692 \mathrm{E}-32$ & ok \\
\hline $\mathrm{FeI}$ & 5653.86 & 4.39 & -1.61 & -1.64 & -1.37 & $3.758 \mathrm{E}-31$ & ok & $\mathrm{FeI}$ & 6270.22 & 2.86 & -2.61 & -2.46 & -2.61 & $5.041 \mathrm{E}-32$ & ok \\
\hline $\mathrm{FeI}$ & 5661.34 & 4.29 & -1.76 & -1.74 & -1.78 & $3.715 \mathrm{E}-31$ & ok & $\mathrm{FeI}$ & 6286.13 & 5.62 & - & -0.57 & -0.57 & $7.161 \mathrm{E}-31$ & \\
\hline $\mathrm{FeI}$ & 5662.52 & 4.18 & -0.57 & -0.57 & -0.57 & $7.161 \mathrm{E}-32$ & ok & $\mathrm{FeI}$ & 6301.50 & 3.65 & -0.72 & -0.72 & -0.72 & $6.761 \mathrm{E}-32$ & ok \\
\hline $\mathrm{FeI}$ & 5678.38 & 3.88 & - & -3.02 & -3.02 & $6.761 \mathrm{E}-32$ & & $\mathrm{FeI}$ & 6302.49 & 3.69 & - & -0.97 & -0.97 & $6.761 \mathrm{E}-32$ & \\
\hline $\mathrm{FeI}$ & 5678.60 & 2.42 & - & -4.67 & -4.67 & $5.689 \mathrm{E}-32$ & & $\mathrm{FeI}$ & 6311.50 & 2.83 & -3.14 & -3.14 & -3.14 & $4.814 \mathrm{E}-32$ & ok \\
\hline $\mathrm{FeI}$ & 5679.02 & 4.65 & -0.90 & -0.92 & -0.90 & $8.561 \mathrm{E}-31$ & ok & $\mathrm{FeI}$ & 6322.69 & 2.59 & -2.43 & -2.43 & -2.43 & $4.898 \mathrm{E}-32$ & ok \\
\hline $\mathrm{FeI}$ & 5686.53 & 4.55 & -0.45 & -0.45 & -0.45 & $8.035 \mathrm{E}-32$ & ok & $\mathrm{FeI}$ & 6335.33 & 2.20 & -2.18 & -2.18 & -2.18 & $2.723 \mathrm{E}-32$ & ok \\
\hline $\mathrm{FeI}$ & 5691.50 & 4.30 & -1.49 & -1.52 & -1.49 & $3.408 \mathrm{E}-31$ & ok & $\mathrm{FeI}$ & 6336.82 & 3.69 & -0.86 & -0.86 & -0.86 & $4.597 \mathrm{E}-31$ & ok \\
\hline $\mathrm{FeI}$ & 5696.09 & 4.55 & -1.72 & -1.72 & -1.88 & $6.166 \mathrm{E}-31$ & & $\mathrm{FeI}$ & 6353.84 & 0.92 & - & -6.17 & -6.47 & $1.274 \mathrm{E}-32$ & \\
\hline $\mathrm{FeI}$ & 5698.02 & 3.64 & -2.63 & -2.68 & -2.68 & $6.383 \mathrm{E}-32$ & ok & $\mathrm{FeI}$ & 6385.72 & 4.73 & - & -1.91 & -1.77 & $5.158 \mathrm{E}-31$ & \\
\hline $\mathrm{FeI}$ & 5701.54 & 2.56 & -2.22 & -2.22 & -2.22 & $5.495 \mathrm{E}-32$ & ok & $\mathrm{FeI}$ & 6392.54 & 2.28 & - & -4.03 & -4.03 & 3.737E-32 & ok \\
\hline $\mathrm{FeI}$ & 5705.46 & 4.30 & -1.35 & -1.35 & -1.35 & $3.388 \mathrm{E}-31$ & ok & $\mathrm{FeI}$ & 6393.60 & 2.43 & -1.58 & -1.43 & -1.58 & $4.217 \mathrm{E}-32$ & ok \\
\hline $\mathrm{FeI}$ & 5709.93 & 4.26 & - & -2.34 & -2.34 & $5.012 \mathrm{E}-31$ & & $\mathrm{FeI}$ & 6400.00 & 3.60 & -0.29 & -0.29 & -0.29 & $3.981 \mathrm{E}-31$ & \\
\hline $\mathrm{FeI}$ & 5712.13 & 3.42 & -1.99 & -1.99 & -1.99 & $4.241 \mathrm{E}-31$ & & $\mathrm{FeI}$ & 6408.02 & 3.69 & -1.02 & -1.02 & -1.02 & $6.761 \mathrm{E}-32$ & \\
\hline $\mathrm{FeI}$ & 5717.83 & 4.29 & -1.10 & -1.13 & -1.10 & $3.631 \mathrm{E}-31$ & & $\mathrm{FeI}$ & 6411.65 & 3.65 & -0.72 & -0.59 & -0.72 & $4.241 \mathrm{E}-31$ & ok \\
\hline FeI & 5741.85 & 4.26 & -1.67 & -1.85 & -1.67 & $3.162 \mathrm{E}-31$ & ok & $\mathrm{FeI}$ & 6419.95 & 4.73 & -0.27 & -0.24 & -0.27 & $4.983 \mathrm{E}-31$ & \\
\hline
\end{tabular}

Continua na próxima página... 
Tabela 3.2 - Continuação

\begin{tabular}{|c|c|c|c|c|c|c|c|c|c|c|c|c|c|c|c|}
\hline \multirow[t]{2}{*}{ Ion } & \multirow[t]{2}{*}{$\lambda(\AA)$} & \multirow[t]{2}{*}{$\chi e x c$} & \multicolumn{3}{|c|}{$\log g f$} & \multirow[t]{2}{*}{$C 6$} & \multirow[t]{2}{*}{ GR } & \multirow[t]{2}{*}{ Ion } & \multirow[t]{2}{*}{$\lambda(\AA)$} & \multirow[t]{2}{*}{$\chi e x c$} & \multicolumn{3}{|c|}{$\log g f$} & \multirow[t]{2}{*}{$C 6$} & \multirow[t]{2}{*}{ GP } \\
\hline & & & NIST & VALD & adt. & & & & & & NIST & VALD & adt. & & \\
\hline $\mathrm{FeI}$ & 5752.03 & 4.55 & - & -1.17 & -0.94 & $8.035 \mathrm{E}-32$ & ok & $\mathrm{FeI}$ & 6430.85 & 2.18 & -2.01 & -2.01 & -2.01 & $2.630 \mathrm{E}-32$ & ok \\
\hline $\mathrm{FeI}$ & 5753.12 & 4.26 & -0.69 & -0.69 & -0.69 & $3.428 \mathrm{E}-31$ & ok & $\mathrm{FeI}$ & 6481.87 & 2.28 & -2.98 & -2.98 & -2.98 & $3.673 \mathrm{E}-32$ & \\
\hline $\mathrm{FeI}$ & 5760.34 & 3.64 & -2.44 & -2.49 & -2.44 & $6.419 \mathrm{E}-32$ & ok & $\mathrm{FeI}$ & 6494.98 & 2.40 & -1.27 & -1.27 & -1.27 & $4.050 \mathrm{E}-32$ & \\
\hline $\mathrm{FeI}$ & 5778.45 & 2.59 & -3.43 & -3.43 & -3.43 & $5.495 \mathrm{E}-32$ & ok & $\mathrm{FeI}$ & 6496.47 & 4.80 & -0.61 & -0.57 & -0.61 & $5.527 \mathrm{E}-31$ & \\
\hline $\mathrm{FeI}$ & 5784.66 & 3.40 & -2.53 & -2.53 & -2.53 & $3.936 \mathrm{E}-31$ & & $\mathrm{FeI}$ & 6498.94 & 0.96 & -4.69 & -4.70 & -4.69 & $1.679 \mathrm{E}-32$ & \\
\hline $\mathrm{FeI}$ & 5793.91 & 4.22 & -1.66 & -1.70 & -1.66 & $3.055 \mathrm{E}-31$ & ok & $\mathrm{FeI}$ & 6518.36 & 2.83 & -2.30 & -2.46 & -2.50 & $4.545 \mathrm{E}-32$ & \\
\hline $\mathrm{FeI}$ & 5811.91 & 4.14 & - & -2.43 & -2.43 & $1.514 \mathrm{E}-32$ & & $\mathrm{FeI}$ & 6546.24 & 2.76 & -1.54 & -1.54 & -1.54 & $4.121 \mathrm{E}-32$ & ok \\
\hline $\mathrm{FeI}$ & 5814.81 & 4.28 & -1.94 & -1.97 & -1.94 & $3.162 \mathrm{E}-31$ & ok & $\mathrm{FeI}$ & 6556.79 & 4.80 & - & -1.63 & -1.63 & $7.586 \mathrm{E}-32$ & \\
\hline $\mathrm{FeI}$ & 5837.70 & 4.29 & - & -2.34 & -2.34 & $9.550 \mathrm{E}-32$ & & $\mathrm{FeI}$ & 6569.21 & 4.73 & -0.45 & -0.42 & -0.35 & $4.315 \mathrm{E}-31$ & \\
\hline $\mathrm{FeI}$ & 5838.37 & 3.94 & -2.29 & -2.34 & -2.29 & $6.879 \mathrm{E}-31$ & & $\mathrm{FeI}$ & 6574.23 & 0.99 & -5.00 & -5.02 & -5.00 & $1.274 \mathrm{E}-32$ & ok \\
\hline $\mathrm{FeI}$ & 5849.68 & 3.69 & - & -2.99 & -2.99 & $5.788 \mathrm{E}-32$ & ok & $\mathrm{FeI}$ & 6593.87 & 2.43 & -2.42 & -2.42 & -2.42 & $4.050 \mathrm{E}-32$ & ok \\
\hline $\mathrm{FeI}$ & 5853.15 & 1.49 & - & -5.28 & -5.28 & $1.603 \mathrm{E}-32$ & & $\mathrm{FeI}$ & 6608.02 & 2.28 & - & -4.03 & -4.03 & $3.631 \mathrm{E}-32$ & ok \\
\hline $\mathrm{FeI}$ & 5858.78 & 4.22 & - & -2.26 & -2.26 & $3.694 \mathrm{E}-31$ & & $\mathrm{FeI}$ & 6609.11 & 2.56 & -2.69 & -2.69 & -2.69 & $4.519 \mathrm{E}-32$ & ok \\
\hline $\mathrm{FeI}$ & 5859.59 & 4.55 & - & -0.42 & -0.62 & $8.035 \mathrm{E}-32$ & ok & $\mathrm{FeI}$ & 6633.75 & 4.56 & -0.80 & -0.80 & -0.80 & $4.842 \mathrm{E}-31$ & \\
\hline $\mathrm{FeI}$ & 5862.35 & 4.55 & - & -0.12 & -0.19 & $7.586 \mathrm{E}-32$ & ok & $\mathrm{FeI}$ & 6646.93 & 2.61 & - & -3.99 & -3.99 & $4.677 \mathrm{E}-32$ & \\
\hline $\mathrm{FeI}$ & 5883.82 & 3.96 & -1.31 & -1.36 & -1.31 & $6.918 \mathrm{E}-31$ & ok & $\mathrm{FeI}$ & 6653.85 & 4.16 & - & -2.52 & -2.52 & $6.273 \mathrm{E}-31$ & \\
\hline $\mathrm{FeI}$ & 5902.47 & 4.59 & - & -1.81 & -1.81 & $1.698 \mathrm{E}-32$ & & $\mathrm{FeI}$ & 6677.98 & 2.69 & -1.42 & -1.42 & -1.42 & 3.737E-32 & ok \\
\hline $\mathrm{FeI}$ & 5905.67 & 4.65 & -0.77 & -0.73 & -0.77 & $6.607 \mathrm{E}-31$ & ok & $\mathrm{FeI}$ & 6703.56 & 2.76 & -3.06 & -3.16 & -3.06 & $3.958 \mathrm{E}-32$ & \\
\hline $\mathrm{FeI}$ & 5916.25 & 2.45 & -2.99 & -2.99 & -2.99 & $4.759 \mathrm{E}-32$ & ok & $\mathrm{FeI}$ & 6710.32 & 1.49 & - & -4.88 & -4.88 & $2.226 \mathrm{E}-32$ & \\
\hline $\mathrm{FeI}$ & 5927.79 & 4.65 & -1.07 & -1.09 & -1.09 & $6.457 \mathrm{E}-31$ & ok & $\mathrm{FeI}$ & 6726.67 & 4.61 & - & -1.09 & -1.09 & $8.511 \mathrm{E}-32$ & \\
\hline $\mathrm{FeI}$ & 5930.18 & 4.65 & - & -0.23 & -0.23 & $6.419 \mathrm{E}-31$ & ok & $\mathrm{FeI}$ & 6739.52 & 1.56 & -4.79 & -4.79 & -4.99 & $2.317 \mathrm{E}-32$ & \\
\hline $\mathrm{FeI}$ & 5934.65 & 3.93 & -1.12 & -1.17 & -1.12 & $6.273 \mathrm{E}-31$ & ok & $\mathrm{FeI}$ & 6746.95 & 2.61 & - & -4.35 & -4.35 & $4.597 \mathrm{E}-32$ & \\
\hline $\mathrm{FeI}$ & 5952.72 & 3.98 & -1.39 & -1.44 & -1.39 & $6.918 \mathrm{E}-31$ & ok & $\mathrm{FeI}$ & 6806.84 & 2.73 & -2.13 & -3.21 & -3.21 & $3.737 \mathrm{E}-32$ & \\
\hline FeI & 5956.69 & 0.86 & -4.61 & -4.61 & -4.61 & $1.698 \mathrm{E}-32$ & ok & $\mathrm{FeI}$ & 6810.26 & 4.61 & -0.99 & -0.99 & -0.99 & $4.814 \mathrm{E}-31$ & \\
\hline $\mathrm{FeI}$ & 5976.78 & 3.94 & - & -1.24 & -1.24 & $6.761 \mathrm{E}-32$ & ok & & & & & & & & \\
\hline
\end{tabular}

\subsubsection{Síntese espectral decomposta}

Para auxiliar a seleção, foi criado um método de análise que consiste em realizar a síntese espectral (descrita na seção 4.4) de estrelas de parâmetros atmosféricos e abundâncias químicas bem determinados, decompondo o espectro na contribuição das linhas moleculares, linhas de ferro individuais, contribuição das linhas atômicas gerais (exceto ferro), linhas separadas de um elemento especificado (usado na seleção das linhas elementais, detalhada na seção 4.2.1), e o espectro total. Para isto, foi escrito um código em Python que utiliza o pacote pyfant, uma interface para o código de síntese espectral Pfant (ambos descritos na seção 4.4), para executar sucessivas sínteses com base em um arquivo de parâmetros fornecido, contendo informações da faixa espectral, parâmetros atmosféricos das sínteses, listas de linhas, espectros observados e demais parâmetros de plotagem. Múltiplas sínteses podem ser executadas simultaneamente para auxiliar na análise, e um exemplo é exibido na figura 3.1 .

As estrelas utilizadas como referência para o ajuste das linhas foram o Sol (por possuir 
Tabela 3.3 - Parâmetros atmosféricos da literatura e valores adotados em negrito para as estrelas Sol, Arcturus e $\mu$ Leo.

\begin{tabular}{lccccc}
\hline \hline Referência & & $T_{\text {eff }}$ & $\log \mathrm{G}$ & {$[\mathrm{Fe} / \mathrm{H}]$} & $\mathrm{vt}$ \\
\hline & Sol & & & & \\
Grevesse \& Sauval (1998) & & $\mathbf{5 7 7 7}$ & $\mathbf{4 . 4 4}$ & $\mathbf{+ 0 . 0 0}$ & $\mathbf{1 . 0 0}$ \\
Allende-Prieto et al. (2001) & & 5767 & 4.437 & +0.00 & - \\
\hline & Arcturus & & & & \\
Ramirez \& Allende-Prieto (2011) & $\mathbf{4 2 8 6}$ & $\mathbf{1 . 6 6}$ & $\mathbf{- 0 . 5 4}$ & $\mathbf{1 . 6 5}$ \\
Meléndez et al. (2003) & & 4275 & 1.55 & -0.54 & 1.65 \\
MacWilliam et al. (2013) & 4290 & 1.60 & -0.49 & 1.60 \\
\hline & $\mu L e o$ & & & & \\
Smith \& Ruck (2000) & & $\mathbf{4 5 4 0}$ & $\mathbf{2 . 2 0}$ & $+\mathbf{0 . 2 9}$ & $\mathbf{1 . 2 0}$ \\
Lecureur et al. (2007) & 4540 & 2.30 & +0.30 & 1.30 \\
Smith et al. (2013) & & 4550 & 2.10 & +0.26 & 1.80 \\
Gratton \& Sneden (2013) & 4540 & 2.30 & +0.40 & 1.20 \\
\hline \hline
\end{tabular}

os parâmetros atmosféricos e abundâncias muito bem determinados), a gigante vermelha Arcturus ( $\alpha$ Boo, por seus parâmetros serem semelhantes às estrelas analisadas), e a gigante rica em metais $\mu$ Leo (por exibir linhas espectrais mais fortes, melhorando a detecção de possíveis blends). O espectro solar utilizado foi o descrito em Monroe et al. (2013), o espectro de Arcturus é o atlas descrito em Hinkle et al. (2000), e o espectro de $\mu$ Leo usado é o descrito em Lecureur et al. (2007)

Os parâmetros atmosféricos da literatura e os valores adotados para a verificação se encontram na tabela 3.3 .

A lista de linhas atômicas utilizada foi construída com base no banco de dados do VALD3 (Ryabchikova et al., 2015), e os valores de $\log (g f)$ utilizados foram escolhidos entre o VALD3 e os disponibilizados pelo NIST (Kramida et al., 2016), de acordo com o melhor ajuste visual. Para as linhas onde nenhum dos dois valores era satisfatório, o $\log (g f)$ foi ajustado astrofisicamente, onde o valor é modificado manualmente até que se ajuste bem simultaneamente às estrelas de referência.

\subsection{Larguras equivalentes}

A largura equivalente (EW, de equivalent width) de uma linha espectral é uma medida da intensidade da linha baseada na medida de sua área. A EW é encontrada formando um 

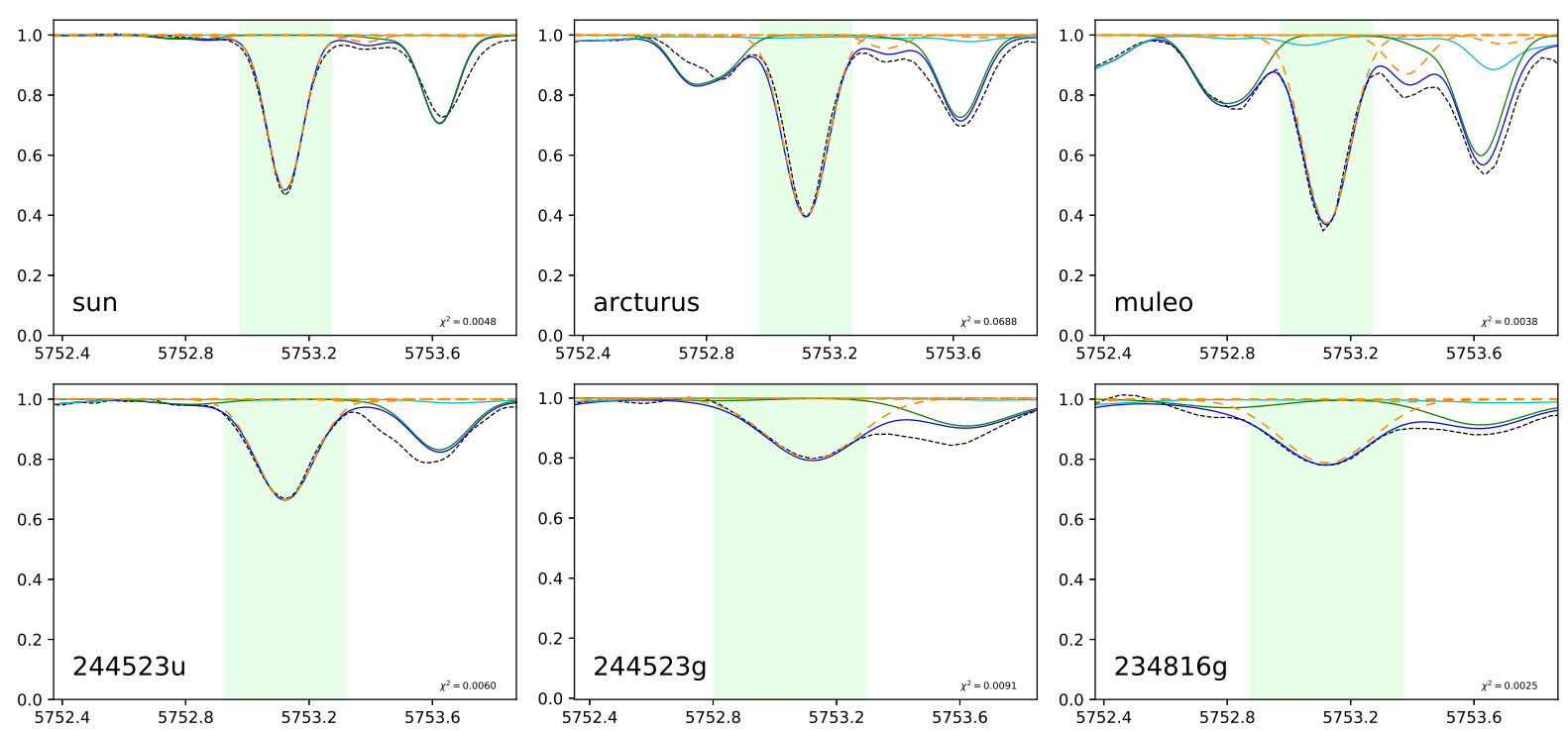

Figura 3.1: Síntese decomposta das estrelas de referência e estrelas da amostra com parâmetros atmosféricos determinados. Em ciano: linhas moleculares; em tracejado amarelo: linhas de ferro; em verde: demais linhas atômicas; em azul: espectro total. A letra u na legenda significa que o espectro é proveniente do UVES, e a letra g indica o GIRAFFE.

retângulo com uma altura igual ao nível do contínuo, e encontrando a largura de forma que a área do retângulo seja igual à área da linha espectral.

Formalmente, a largura equivalente $E W$ é dada pela equação

$$
E W=\int_{\lambda_{i}}^{\lambda_{f}}\left(1-\frac{F(\lambda)}{F_{0}}\right) \mathrm{d} \lambda
$$

onde $\lambda_{i}$ e $\lambda_{i}$ são os comprimentos de onda inicial e final a serem considerados, $F(\lambda)$ é o fluxo ao longo do comprimento de onda, e $F_{0}$ é o valor do fluxo no nível do contínuo.

As medidas de larguras equivalentes são realizadas por meio do ajuste de um perfil gaussiano (que representa linhas não-saturadas em boa aproximação) ao intervalo espectral contendo a linha, e calcula a integral da função ajustada no intervalo. Frequentemente é necessário fazer o deblend das linhas por estas se apresentarem fundidas à linhas adjacentes (blendadas), requisitando que se ajustem gaussianas à todas as linhas que fazem parte do blend.

As larguras equivalentes das linhas de ferro nos espectros UV2016 foram medidas manualmente utilizando a tarefa splot do IRAF (Image reduction and analysis facility), que possui ferramentas para o ajuste das linhas espectrais e cálculo das larguras equivalentes. As larguras equivalentes das linhas de ferro ionizado (Fe II) dos espectros GI2012 e GI2016 foram medidas por meio de um código escrito em Python que utiliza as bibliotecas mat- 
plotlib, scipy e LmFit para exibir e realizar o deblend das linhas espectrais pelo ajuste das gaussianas, retornando as larguras equivalentes ajustadas, como exibido na figura 3.2 . A indicação das posições e do nível do contínuo é realizada interativamente, similar à tarefa splot do IRAF.

Afim de garantir homogeneidade e comparar os procedimentos de medição e as larguras equivalentes resultantes, bem como a derivação dos parâmetros atmosféricos em diferentes métodos de obtenção das larguras equivalentes, as linhas de ferro da amostra UV2016 também foi medida usando o DOOp, descrito em mais detalhe a seguir na seção 3.2.1.

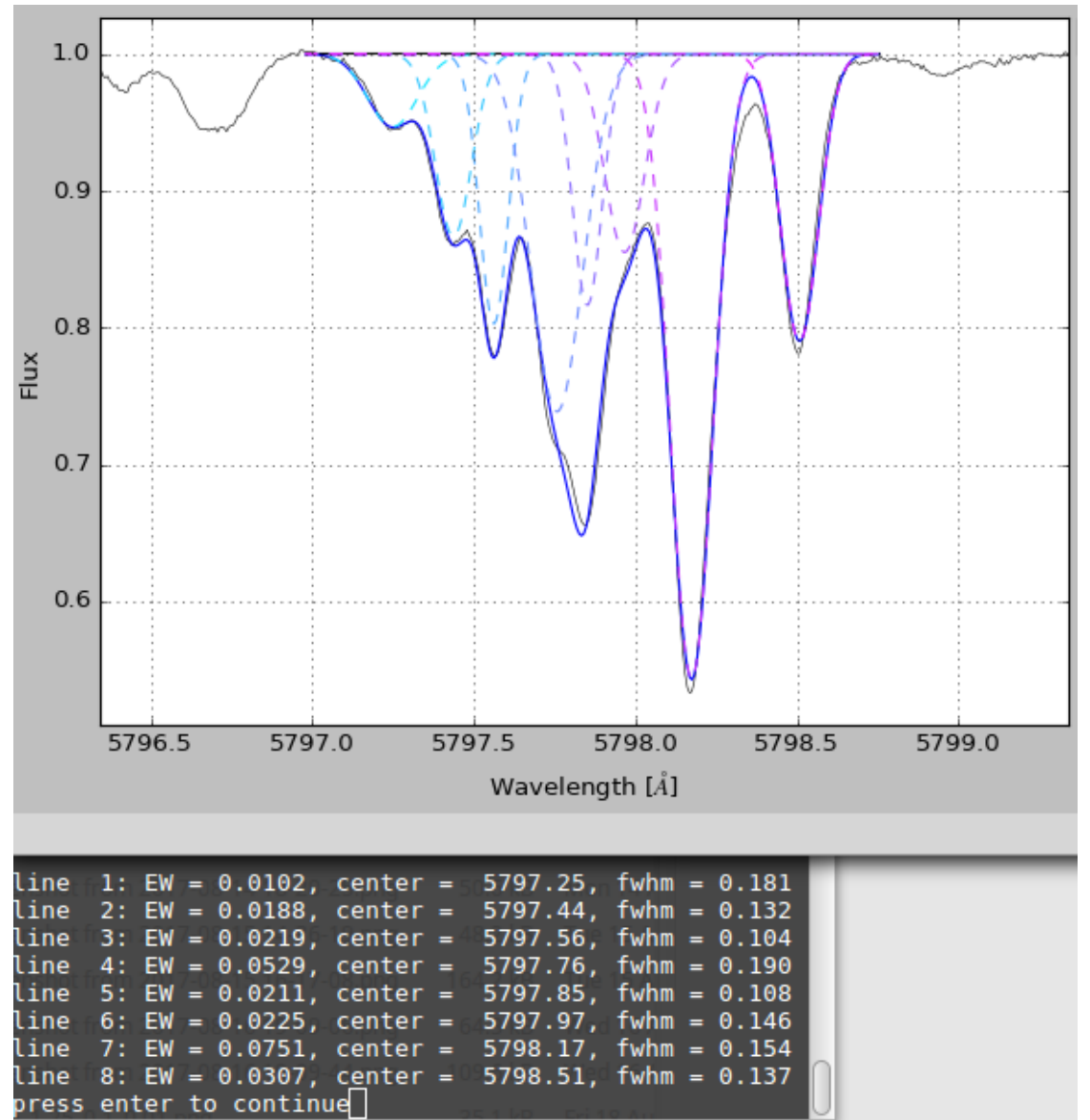

Figura 3.2: Deblend das linhas espectrais em uma região do espectro de Arcturus utilizando o código em Python descrito no texto. As medidas de largura equivalente são exibidas em $\AA$.

\subsubsection{Daospec e DOOp}

Devido ao grande volume de espectros GIRAFFE e à extensão da lista de linhas de ferro, foi utilizado o software de identificação e medição automática de linhas espectrais Daospec (Stetson e Pancino, 2008), juntamente com o DOOp (Cantat-Gaudin et al., 2014), um 
wrapper (programa exterior que chama a execução do Daospec) que otimiza os parâmetros de entrada do Daospec para os espectros obtidos com o FLAMES, buscando obter o melhor ajuste possível para as linhas espectrais. O DOOp faz a estimativa do nível do contínuo utilizando a tarefa continuum do IRAF, e posteriormente alimenta o Daospec com o espectro normalizado, iterando os valores de entrada do FWHM (full width at the half-maximum, largura à meia-altura). É também possível realizar a conferência dos ajustes posteriormente, como exibido na figura 3.3 .
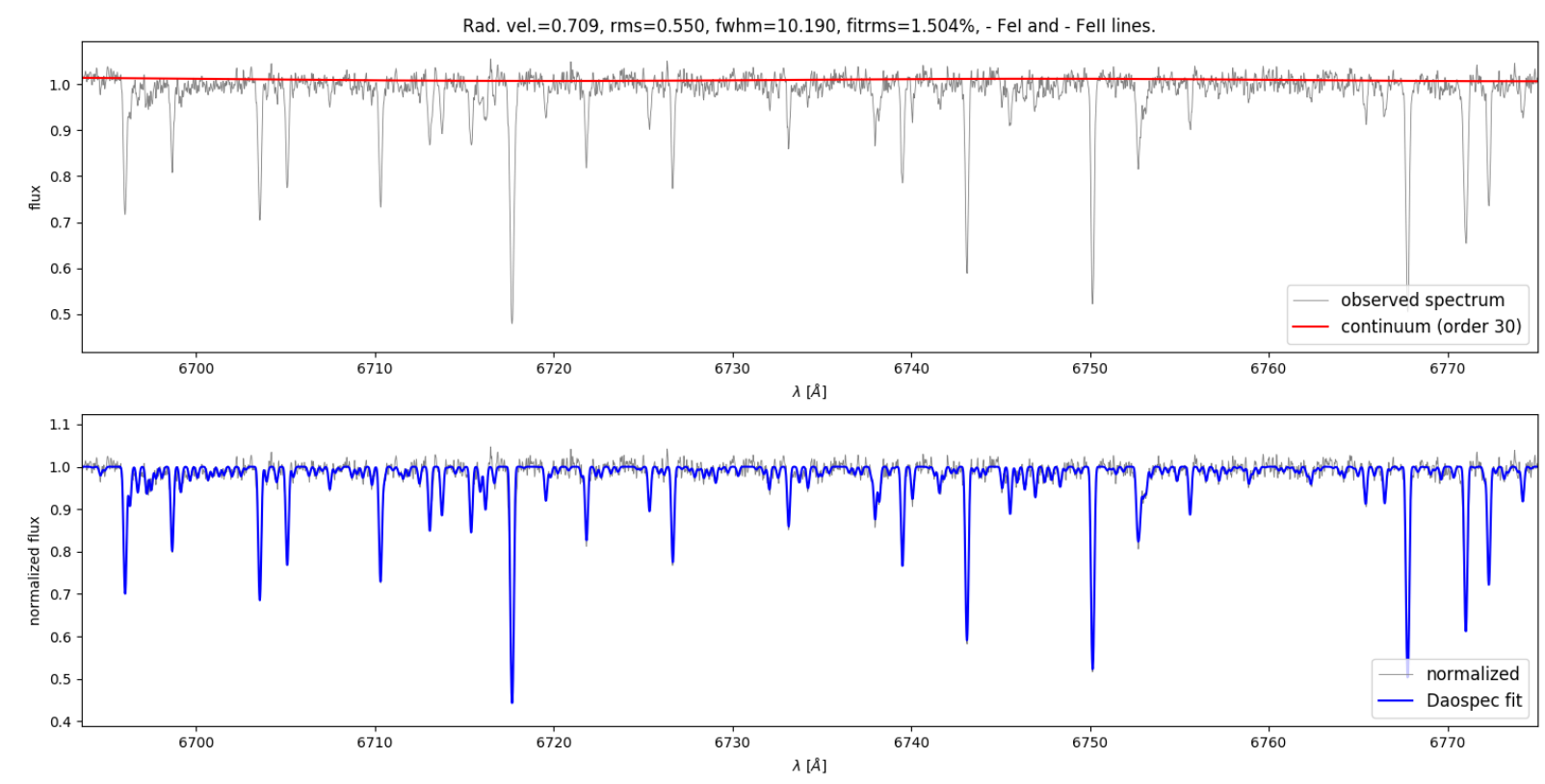

Figura 3.3: Conferência do ajuste realizado pelo Daospec via a execução do DOOp.

\subsubsection{Medições das larguras equivalentes}

Para os espectros que haviam sido previamente analisados da amostra GI2012, da mesma forma que foi feito com a amostra UV2016, foram medidas as larguras equivalentes via DOOp e manualmente, afim de verificar como a derivação dos parâmetros atmosféricos é afetada dependendo do método utilizado para as medições. Uma comparação entre as medidas é exibida na figura 3.4 para o GIRAFFE e na figura 3.5 para o UVES.

Uma análise dos parâmetros obtidos com ambas as medições é discutida mais adiante na seção 3.3.3.

As medidas manuais e via DOOp para as estrelas da amostra GI2012 apresentam um bom acordo como demonstrado na figura 3.4. porém para estrelas mais frias, com linhas 

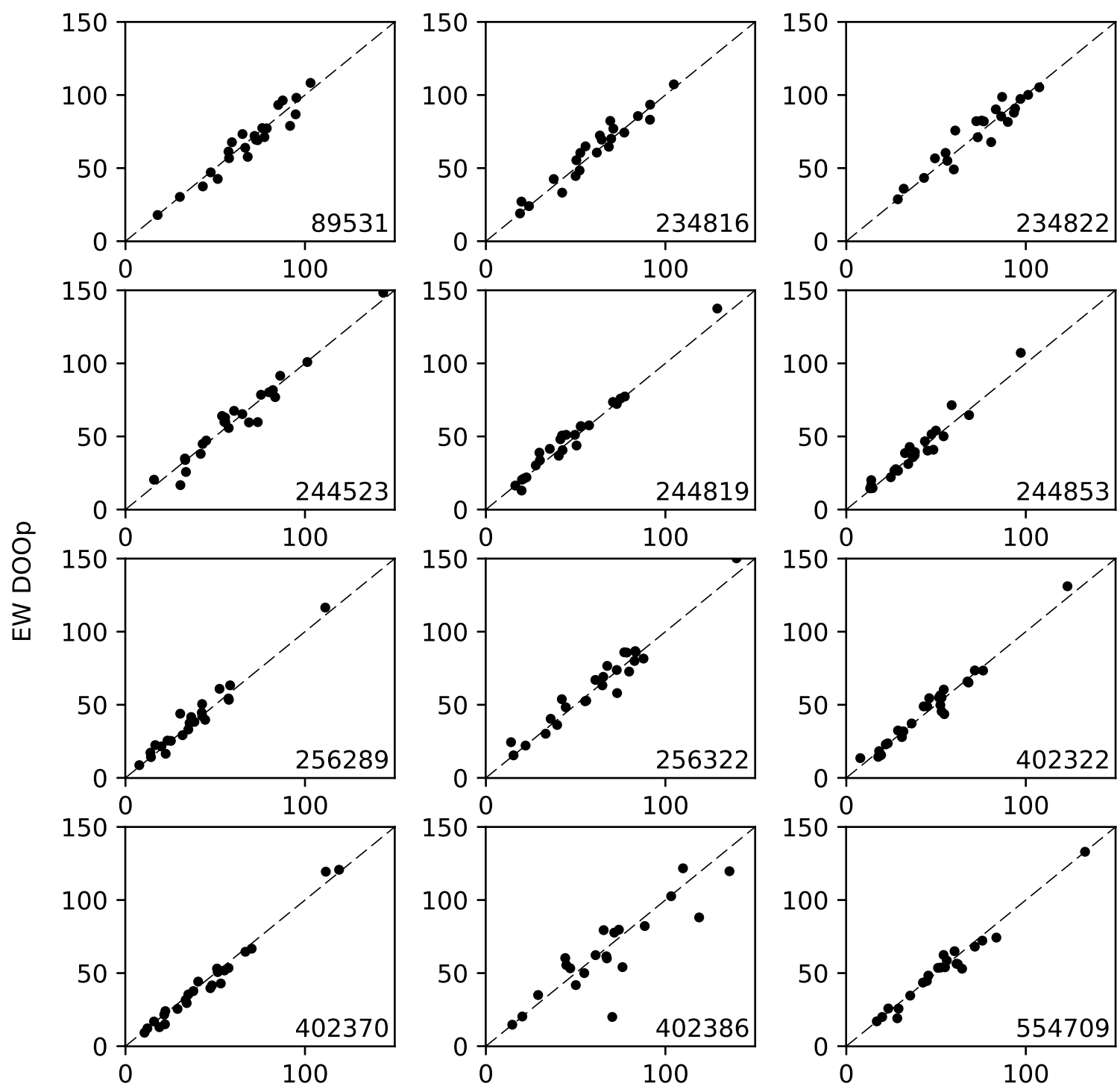

EW manual

Figura 3.4: Comparação das medidas de larguras equivalentes de parte da amostra GI2012 realizadas manualmente e utilizando o DOOp. As linhas tracejadas representam a razão 1:1.

muito fortes, o contínuo é sub-estimado por um valor abaixo do real devido às poucas regiões de contínuo disponíveis nesses espectros, de modo que as larguras equivalentes também sejam sub-estimadas, como é o caso da estrela 402386.

As medidas manuais e via DOOp para a amostra UV2016 apresentam acordo praticamente perfeito somente para as estrelas 402322 e 244819, enquanto que para 256289 e 402370 o DOOp parece fornecer medidas de EW ligeiramente menores. Um grande espalhamento é observado para a estrela 244523, e para a estrela 234816, duas hipóteses 

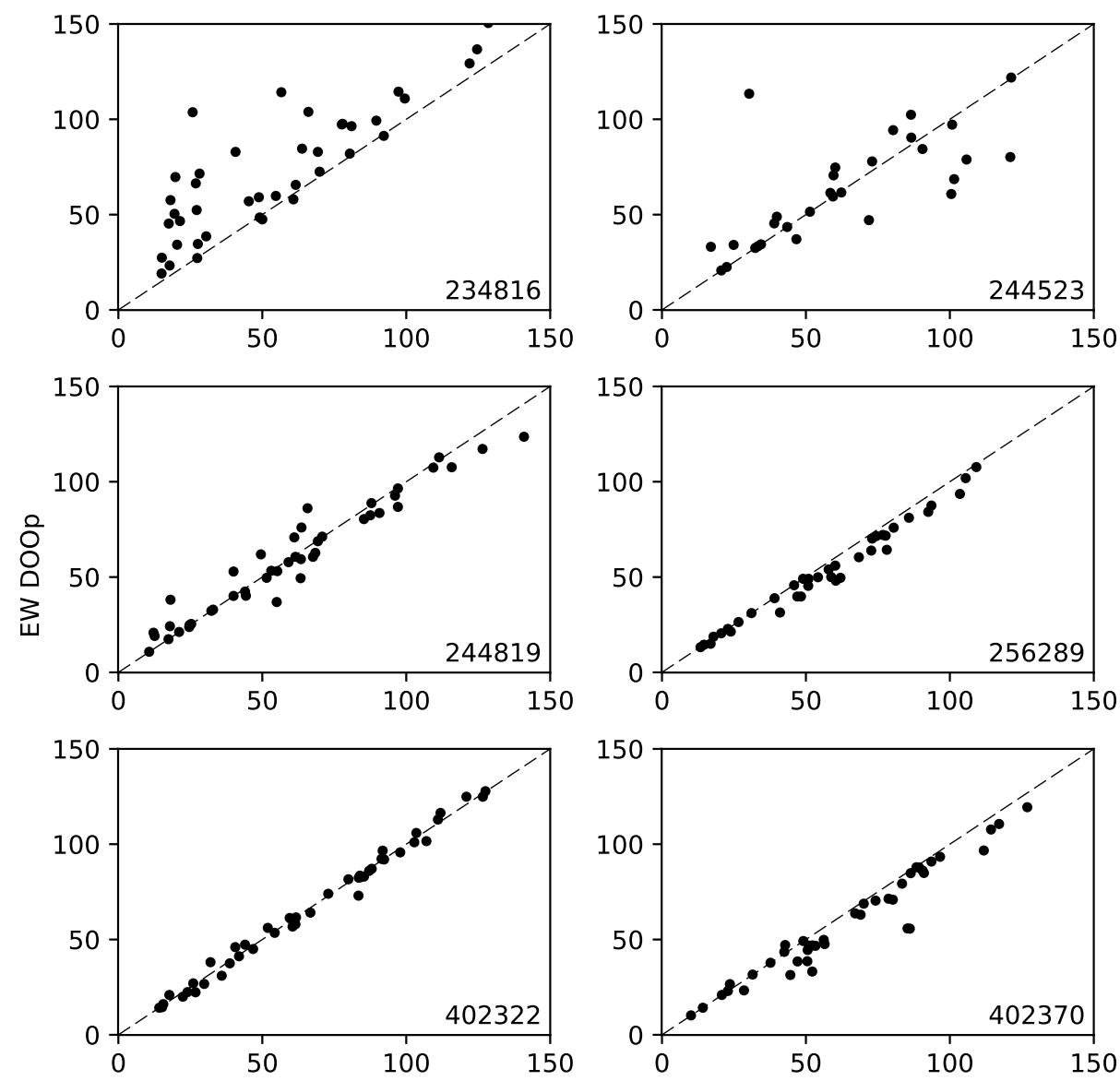

EW Manual

Figura 3.5: Comparação das medidas de larguras equivalentes de parte da amostra UV2016 realizadas manualmente e utilizando o DOOp. As linhas tracejadas representam a razão 1:1.

poderiam explicar o comportamento observado: uma super-estimativa do nível do contínuo pelo DOOp, ou uma sub-estimativa do mesmo nas medidas manuais. O ajuste feito pelo DOOp é exibido na figura 3.6.

Para uma verificação de consistência, foram comparadas as medidas de larguras equivalentes medidas nos espectros UVES e GIRAFFE entre as estrelas coincidentes nas amostras, tanto para as medidas manuais (figura 3.7) quanto para as realizadas pelo DOOp (figura 3.8). A comparação das medidas manuais do UVES conta com poucos pontos devido ao fato de terem sido consideradas apenas as linhas espectrais acima de $6000 \AA$ para evitar possíveis efeitos de blanketing do contínuo e blends com bandas moleculares, cobrindo apenas parte do espectro no setup HR12 do GIRAFFE. As medidas de todos os espectros GIRAFFE cobrem os comprimentos de onda acima de $5820 \stackrel{\AA}{A}$, evitando o setup HR11 por 

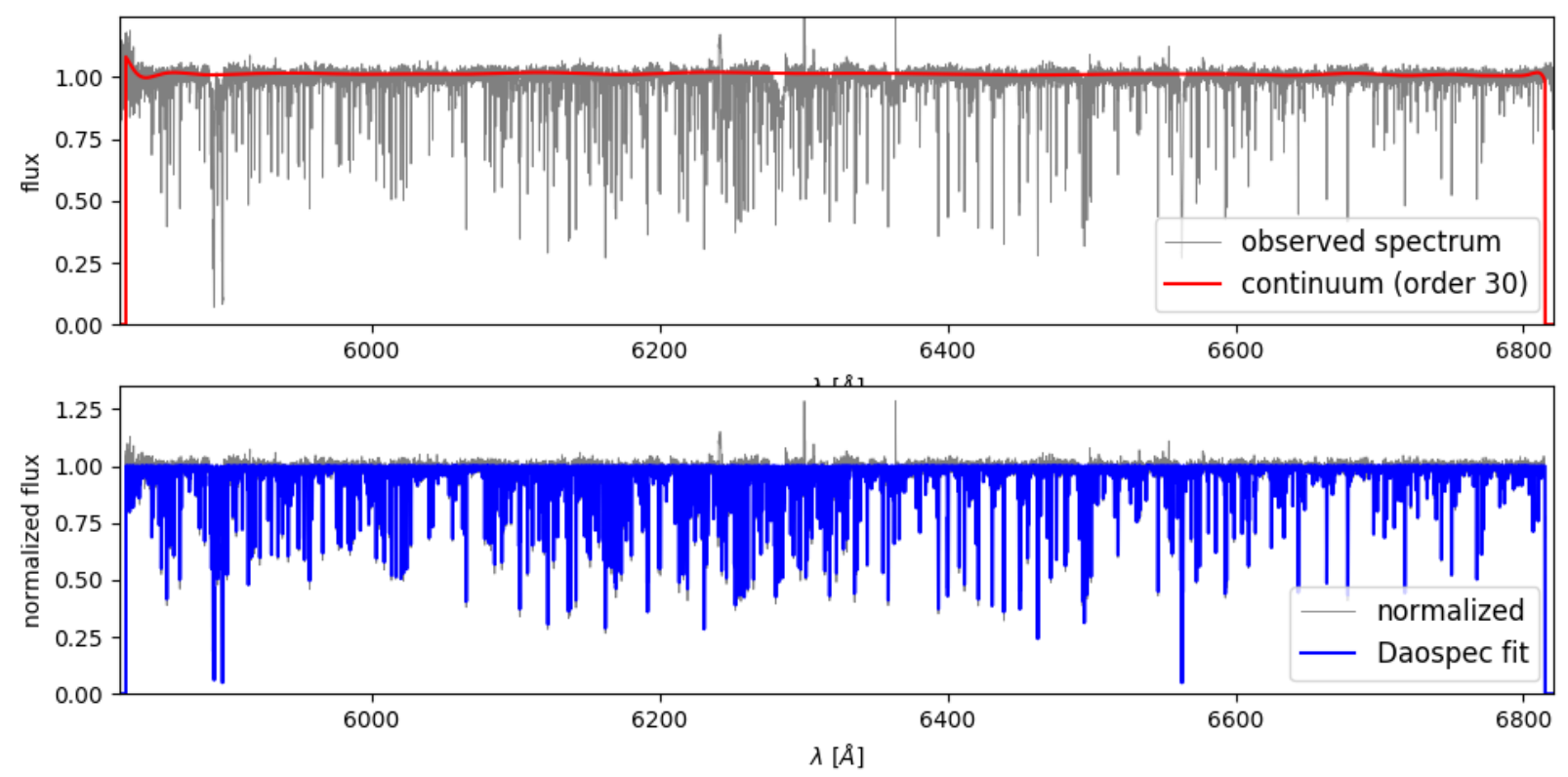

Figura 3.6: Ajustes do contínuo e das linhas espectrais realizadas pelo DOOp para a estrela 234816.

este produzir medidas cujas abundâncias retornam valores demasiado espalhados, prejudicando a derivação dos parâmetros atmosféricos.

As larguras equivalentes do restante da amostra GI2012 e da amostra GI2016 foram medidas utilizando o DOOp por estas terem sido consideradas satisfatórias, conforme discutido mais adiante na seção 3.3.4.

As larguras equivalentes medidas para as estrelas da amostra UV2016 são exibidas na tabela 3.4, para a amostra GI2012 na tabela 3.5. e para a amostra GI2016 na tabela 3.6. As estrelas exibidas na tabela 2.3 cujos parâmetros atmosféricos não convergiram para valores satisfatórios não são exibidas nas tabelas de larguras equivalentes.

\subsection{Derivação dos parâmetros atmosféricos}

A derivação dos parâmetros atmosféricos foi realizada por imposição de equilíbrio de excitação e ionização das linhas espectrais de ferro, assumindo-se equilíbrio termodinâmico local. Neste processo, calcula-se as abundâncias individuais das linhas de ferro neutro (Fe I) e ferro uma vez ionizado $\left(\mathrm{Fe}^{1+}\right.$, ou Fe II) com base em suas larguras equivalentes, por meio do método da curva de crescimento da linha espectral.

A curva de crescimento de uma determinada linha espectral é um gráfico que representa 
Tabela 3.4 - Larguras equivalentes da amostra UV2016 medidas utilizando o DOOp.

\begin{tabular}{|c|c|c|c|c|c|c|c|c|c|c|c|c|c|c|c|}
\hline Ion & $\lambda$ & 234816 & 244523 & 244819 & 256289 & 402322 & 402370 & Ion & $\lambda$ & 234816 & 244523 & 244819 & 256289 & 402322 & 402370 \\
\hline FeII & 5991.37 & 27.4 & 34.4 & 24.9 & 26.4 & 22.4 & - & $\mathrm{FeI}$ & 6302.49 & - & - & 76.6 & - & - & - \\
\hline FeII & 6084.10 & - & 20.7 & - & 14.5 & 16.1 & 10.2 & $\mathrm{FeI}$ & 6311.50 & 57.0 & 44.5 & 30.0 & 20.5 & 25.9 & 20.8 \\
\hline FeII & 6149.25 & 23.3 & 33.4 & 20.0 & 20.5 & 20.0 & 20.9 & $\mathrm{FeI}$ & 6322.69 & - & - & 83.7 & 71.9 & 81.4 & 72.3 \\
\hline FeII & 6247.56 & 38.6 & 51.5 & 34.6 & 38.9 & 37.5 & 37.8 & $\mathrm{FeI}$ & 6336.82 & - & - & 90.0 & 79.3 & 86.8 & 76.8 \\
\hline FeII & 6369.46 & 19.1 & 22.5 & 13.4 & 13.2 & 14.2 & 14.2 & $\mathrm{FeI}$ & 6353.84 & 18.4 & - & - & - & - & - \\
\hline FeII & 6416.92 & 27.2 & 32.5 & 25.5 & 22.8 & 27.0 & 23.0 & $\mathrm{FeI}$ & 6385.72 & 13.3 & - & - & - & - & - \\
\hline FeII & 6432.68 & 34.6 & 43.5 & 32.9 & 31.1 & 31.0 & 31.6 & $\mathrm{FeI}$ & 6392.54 & 45.3 & 33.1 & 18.8 & - & 17.9 & 14.1 \\
\hline FeII & 6456.38 & 50.4 & - & - & 49.1 & - & 49.2 & $\mathrm{FeI}$ & 6400.00 & - & - & - & - & - & 106.2 \\
\hline FeII & 6516.08 & 46.6 & 59.5 & 39.7 & 45.7 & 45.0 & 43.5 & $\mathrm{FeI}$ & 6408.02 & - & 97.2 & 87.9 & 75.0 & 81.9 & 71.1 \\
\hline $\mathrm{FeI}$ & 6003.01 & 86.7 & 84.4 & 71.3 & 56.5 & 62.3 & 55.7 & $\mathrm{FeI}$ & 6411.65 & - & - & 107.1 & 93.0 & 99.4 & 90.8 \\
\hline $\mathrm{FeI}$ & 6008.56 & 91.3 & - & 76.6 & 64.6 & 66.8 & 64.1 & $\mathrm{FeI}$ & 6419.95 & 71.5 & 70.6 & 59.2 & 50.1 & 60.6 & 47.4 \\
\hline $\mathrm{FeI}$ & 6012.21 & 59.8 & 41.8 & 24.6 & 18.7 & - & 21.0 & $\mathrm{FeI}$ & 6481.87 & 97.6 & 94.3 & 78.7 & 63.5 & 70.5 & 62.7 \\
\hline $\mathrm{FeI}$ & 6027.05 & 72.5 & 68.6 & 52.5 & 44.8 & 47.7 & 44.7 & $\mathrm{FeI}$ & 6496.47 & 59.1 & - & - & 34.0 & 39.7 & 34.8 \\
\hline $\mathrm{FeI}$ & 6056.00 & 65.6 & 61.6 & 50.1 & 40.8 & 47.3 & 36.6 & $\mathrm{FeI}$ & 6498.94 & - & - & - & - & - & 57.4 \\
\hline $\mathrm{FeI}$ & 6078.49 & 66.4 & 64.8 & 52.4 & 41.2 & 55.5 & 37.9 & $\mathrm{FeI}$ & 6518.36 & 84.6 & 80.2 & 60.1 & 49.1 & 56.7 & 46.6 \\
\hline $\mathrm{FeI}$ & 6082.71 & 69.7 & 61.4 & 42.6 & 35.0 & 42.5 & 31.1 & $\mathrm{FeI}$ & 6546.24 & - & - & 107.2 & 99.2 & 98.7 & 96.0 \\
\hline $\mathrm{FeI}$ & 6096.66 & 48.5 & 37.1 & 24.7 & 20.1 & 24.7 & - & $\mathrm{FeI}$ & 6556.79 & 13.0 & 8.4 & - & - & - & - \\
\hline $\mathrm{FeI}$ & 6120.25 & 34.2 & 21.7 & 14.7 & - & 14.5 & 11.1 & $\mathrm{FeI}$ & 6569.21 & 70.4 & 73.0 & 54.7 & 45.7 & 48.8 & 41.9 \\
\hline FeI & 6127.91 & 57.6 & 47.1 & 38.8 & 28.1 & 27.4 & 29.4 & $\mathrm{FeI}$ & 6574.23 & 82.9 & 74.7 & 57.3 & 41.9 & 51.9 & 40.0 \\
\hline $\mathrm{FeI}$ & 6136.99 & - & - & 86.4 & 71.1 & 78.7 & 68.5 & $\mathrm{FeI}$ & 6593.87 & - & - & 96.2 & 85.2 & 92.7 & 83.9 \\
\hline $\mathrm{FeI}$ & 6151.62 & - & - & 61.2 & 52.8 & 57.4 & 48.3 & $\mathrm{FeI}$ & 6608.02 & 47.5 & 34.1 & 18.1 & 15.9 & 22.3 & 12.3 \\
\hline $\mathrm{FeI}$ & 6165.36 & 52.4 & 45.4 & 37.2 & 23.5 & 42.2 & 24.3 & $\mathrm{FeI}$ & 6609.11 & 96.4 & 90.4 & 70.3 & 61.3 & 73.6 & 61.0 \\
\hline FeI & 6173.33 & - & 102.4 & 87.4 & 74.4 & 85.5 & 71.0 & $\mathrm{FeI}$ & 6633.75 & 65.3 & 59.1 & 43.4 & 33.6 & 39.7 & 31.2 \\
\hline FeI & 6180.20 & 82.9 & 78.9 & 63.3 & 50.9 & 59.8 & 48.8 & $\mathrm{FeI}$ & 6646.93 & 29.4 & 18.8 & - & - & - & - \\
\hline FeI & 6187.99 & 58.0 & 48.9 & 40.7 & 27.1 & 35.6 & 26.8 & $\mathrm{FeI}$ & 6653.85 & 14.7 & 8.0 & - & - & - & - \\
\hline FeI & 6200.31 & 99.3 & - & 82.9 & 69.6 & 80.7 & 69.8 & $\mathrm{FeI}$ & 6703.56 & 63.9 & 49.5 & 36.2 & 26.9 & 38.1 & 27.7 \\
\hline FeI & 6213.43 & - & - & 100.5 & 87.3 & 93.0 & 86.7 & $\mathrm{FeI}$ & 6710.32 & 54.5 & 38.4 & 36.6 & 20.0 & 31.2 & - \\
\hline FeI & 6219.28 & - & - & - & 94.1 & 96.4 & 93.7 & $\mathrm{FeI}$ & 6726.67 & 45.1 & 38.6 & 22.6 & 17.6 & 26.6 & 19.0 \\
\hline FeI & 6240.65 & - & - & 62.4 & 50.5 & 61.2 & 48.5 & $\mathrm{FeI}$ & 6739.52 & 47.0 & 31.5 & 18.6 & 15.1 & 22.8 & - \\
\hline $\mathrm{FeI}$ & 6246.32 & - & - & 99.9 & 86.2 & 90.8 & 88.0 & $\mathrm{FeI}$ & 6746.95 & 13.1 & - & - & - & 9.2 & - \\
\hline FeI & 6265.13 & - & - & 107.1 & 85.0 & - & 80.5 & $\mathrm{FeI}$ & 6806.84 & 56.8 & 51.4 & - & 25.7 & 41.5 & 24.5 \\
\hline $\mathrm{FeI}$ & 6270.22 & 82.0 & 77.9 & - & 50.9 & - & 46.5 & $\mathrm{FeI}$ & 6810.26 & 48.1 & - & - & 20.9 & 30.1 & - \\
\hline FeI & 6301.50 & - & - & - & - & 89.2 & 83.8 & & & & & & & & \\
\hline
\end{tabular}


Tabela 3.5 - Larguras equivalentes da amostra GI2012 medidas utilizando o DOOp.

\begin{tabular}{|c|c|c|c|c|c|c|c|c|c|c|}
\hline Ion & $\lambda$ & 78126 & 89531 & 234816 & 234822 & 234932 & 244523 & 244819 & 244853 & 256289 \\
\hline FeII & 5991.37 & 46.1 & 30.3 & 24.0 & 43.3 & 40.2 & 34.9 & 21.2 & 27.6 & 25.3 \\
\hline FeII & 6084.10 & 21.5 & 17.9 & 19.0 & 28.7 & 26.5 & 20.4 & 16.4 & 14.6 & 14.2 \\
\hline $\mathrm{FeI}$ & 5849.68 & - & - & - & - & 38.8 & - & - & - & - \\
\hline FeI & 5859.59 & 91.0 & 72.0 & - & - & 92.7 & 64.0 & 48.1 & 38.6 & - \\
\hline $\mathrm{FeI}$ & 5862.35 & - & 85.6 & 81.7 & 98.3 & - & 78.7 & 62.2 & 56.1 & 51.9 \\
\hline $\mathrm{FeI}$ & 5862.36 & - & - & - & - & - & - & - & - & - \\
\hline $\mathrm{FeI}$ & 5883.82 & - & - & - & 81.6 & - & 59.8 & 43.8 & 40.9 & 39.7 \\
\hline $\mathrm{FeI}$ & 5905.67 & 77.1 & 56.8 & 48.4 & 60.4 & 79.8 & 38.1 & 30.2 & 22.1 & - \\
\hline $\mathrm{FeI}$ & 5916.25 & - & - & 77.0 & - & - & 78.5 & 57.1 & 50.1 & - \\
\hline $\mathrm{FeI}$ & 5927.79 & - & 37.5 & 33.2 & 49.1 & - & 25.7 & 20.4 & 16.6 & 16.5 \\
\hline $\mathrm{FeI}$ & 5930.18 & - & 78.9 & 82.3 & 98.7 & 108.2 & 76.9 & - & 54.0 & 50.5 \\
\hline FeI & 5934.65 & - & 86.8 & 83.1 & 87.9 & - & 81.7 & 57.6 & 46.7 & 53.4 \\
\hline $\mathrm{FeI}$ & 5952.72 & - & 69.1 & - & - & - & 59.6 & 40.6 & 31.1 & 33.1 \\
\hline $\mathrm{FeI}$ & 5956.69 & - & 108.3 & 107.3 & - & - & 100.9 & - & 71.4 & 63.3 \\
\hline $\mathrm{FeI}$ & 5976.78 & - & 77.4 & 72.3 & 82.0 & 102.5 & 67.5 & 51.1 & 42.8 & 43.9 \\
\hline $\mathrm{FeI}$ & 5983.68 & - & 73.3 & 64.6 & 75.7 & 98.4 & 62.9 & 51.1 & 35.8 & 38.3 \\
\hline $\mathrm{FeI}$ & 5987.06 & 95.0 & 63.9 & 55.4 & 71.1 & 85.8 & 55.8 & 41.5 & - & - \\
\hline $\mathrm{FeI}$ & 6003.01 & - & 98.1 & 85.6 & 97.3 & - & 80.2 & 72.2 & 51.5 & 54.3 \\
\hline $\mathrm{FeI}$ & 6008.56 & - & 93.2 & 93.4 & 105.3 & - & 91.5 & 75.9 & 64.6 & 60.9 \\
\hline $\mathrm{FeI}$ & 6012.21 & 87.5 & 61.3 & - & 56.7 & 89.9 & 44.9 & 33.7 & 20.1 & 22.4 \\
\hline $\mathrm{FeI}$ & 6027.05 & 100.3 & 77.2 & 70.1 & 82.5 & 101.1 & 65.3 & 56.7 & 40.3 & 41.6 \\
\hline $\mathrm{FeI}$ & 6056.00 & 92.6 & 67.7 & 64.9 & 82.1 & - & 59.9 & 38.9 & 39.3 & - \\
\hline $\mathrm{FeI}$ & 6065.48 & - & - & - & - & - & - & - & 107.2 & - \\
\hline $\mathrm{FeI}$ & 6078.49 & 98.9 & 71.2 & 69.5 & 85.4 & 98.1 & 59.9 & 50.6 & 37.3 & 37.5 \\
\hline $\mathrm{FeI}$ & 6096.66 & 66.3 & 47.1 & 44.6 & 55.0 & 70.3 & 33.9 & 22.0 & 15.0 & 17.2 \\
\hline $\mathrm{FeI}$ & 6120.25 & 70.4 & 42.6 & 42.5 & 35.9 & 88.0 & 16.7 & 13.0 & - & 8.7 \\
\hline $\mathrm{FeI}$ & 6127.91 & - & - & 60.6 & 67.8 & - & 47.2 & 36.8 & 26.6 & 29.2 \\
\hline Ion & $\lambda$ & 256322 & 267939 & 392942 & 402322 & 402370 & 402384 & $402386 \mathrm{~m}$ & 412759 & 554709 \\
\hline FeII & 5991.37 & 22.1 & 27.7 & 40.5 & 31.8 & 21.6 & 18.4 & 20.3 & 31.7 & 20.0 \\
\hline FeII & 6084.10 & 15.4 & 20.2 & 34.0 & 18.3 & 12.2 & 10.5 & 14.7 & 16.9 & 17.0 \\
\hline $\mathrm{FeI}$ & 5849.68 & - & - & 47.1 & - & - & - & - & - & - \\
\hline FeI & 5859.59 & 67.0 & 87.4 & 104.1 & 54.9 & 42.9 & 48.7 & - & 72.4 & 54.0 \\
\hline FeI & 5862.35 & 86.0 & 104.3 & 102.5 & 64.2 & 59.5 & 68.5 & - & 85.3 & 65.7 \\
\hline $\mathrm{FeI}$ & 5862.36 & - & - & - & - & - & - & - & - & - \\
\hline $\mathrm{FeI}$ & 5883.82 & - & - & - & 43.6 & 41.6 & 40.6 & 70.4 & 64.6 & 53.0 \\
\hline $\mathrm{FeI}$ & 5905.67 & 48.3 & 72.6 & 76.3 & - & - & 29.0 & - & 51.9 & 34.6 \\
\hline $\mathrm{FeI}$ & 5916.25 & 81.6 & - & - & 60.4 & 53.1 & 55.6 & - & 84.6 & 62.4 \\
\hline $\mathrm{FeI}$ & 5927.79 & 30.2 & - & 59.7 & 15.6 & 13.0 & 14.6 & 29.1 & 30.3 & 19.1 \\
\hline $\mathrm{FeI}$ & 5930.18 & 85.9 & 101.1 & - & 65.9 & 51.8 & 65.2 & 74.1 & 89.5 & 65.0 \\
\hline $\mathrm{FeI}$ & 5934.65 & 80.0 & - & - & 56.5 & 50.7 & 50.7 & - & 86.9 & 68.1 \\
\hline FeI & 5952.72 & - & - & - & 48.9 & 29.5 & 31.5 & - & 69.8 & 56.4 \\
\hline $\mathrm{FeI}$ & 5956.69 & - & - & - & 73.5 & 64.6 & 70.2 & - & 106.7 & 77.5 \\
\hline $\mathrm{FeI}$ & 5976.78 & 76.6 & - & - & 55.0 & 44.2 & 47.7 & - & 69.1 & 58.6 \\
\hline $\mathrm{FeI}$ & 5983.68 & 73.8 & - & 103.7 & 48.9 & - & 33.7 & 65.6 & 64.1 & 48.3 \\
\hline $\mathrm{FeI}$ & 5987.06 & 52.8 & 88.6 & 95.3 & 37.2 & - & 30.7 & - & 58.3 & 44.6 \\
\hline $\mathrm{FeI}$ & 6003.01 & 86.7 & - & - & 65.2 & 53.5 & - & - & 97.2 & 72.2 \\
\hline FeI & 6008.56 & - & - & - & 73.4 & 66.7 & 71.6 & - & 90.5 & 74.3 \\
\hline FeI & 6012.21 & 53.8 & 81.3 & 80.8 & 27.9 & 17.0 & 25.8 & 47.0 & 46.7 & 25.8 \\
\hline FeI & 6027.05 & 72.7 & 93.3 & 91.1 & 49.8 & 39.7 & 43.8 & 67.4 & 72.3 & 56.2 \\
\hline $\mathrm{FeI}$ & 6056.00 & 63.3 & 83.2 & 99.1 & 45.5 & 35.4 & 44.3 & 61.1 & 70.5 & 53.6 \\
\hline FeI & 6065.48 & - & - & - & - & - & - & - & - & - \\
\hline $\mathrm{FeI}$ & 6078.49 & 69.1 & 92.2 & - & 54.5 & 37.7 & 44.3 & - & 66.6 & 53.8 \\
\hline $\mathrm{FeI}$ & 6096.66 & 40.4 & 64.9 & 70.6 & 22.9 & 15.0 & 16.1 & - & 38.0 & 25.7 \\
\hline $\mathrm{FeI}$ & 6120.25 & 36.2 & 75.4 & 53.2 & 14.4 & 9.2 & 13.2 & - & 30.7 & - \\
\hline $\mathrm{FeI}$ & 6127.91 & 52.4 & - & 95.2 & 32.4 & 25.5 & 31.4 & 44.8 & 54.5 & 43.5 \\
\hline
\end{tabular}


Tabela 3.6 - Larguras equivalentes da amostra GI2016 medidas utilizando o DOOp.

\begin{tabular}{|c|c|c|c|c|c|c|c|c|c|c|c|c|c|c|c|}
\hline Ion & $\lambda$ & 78161 & 89489 & 89544 & 244551 & 244555 & 256298 & 256386 & 256646 & 402371 & 402508 & 402537 & 402608 & 412777 & 413052 \\
\hline FeII & 5991.37 & - & - & - & - & - & - & - & 41.7 & - & - & - & - & - & - \\
\hline FeII & 6084.10 & - & - & - & - & - & - & - & 31.5 & - & - & - & - & - & - \\
\hline FeII & 6149.25 & 43.7 & 45.5 & 37.5 & 25.0 & 26.9 & 28.5 & - & 44.7 & 29.1 & 26.8 & 26.9 & - & - & 48.6 \\
\hline FeII & 6247.56 & 60.1 & 55.8 & 52.2 & 37.0 & 30.1 & 37.6 & 37.2 & 55.7 & 41.0 & 34.9 & 36.2 & 37.3 & 35.5 & 49.8 \\
\hline FeII & 6369.46 & 28.4 & 25.2 & 20.6 & 11.8 & 15.4 & 16.2 & 18.8 & - & 20.3 & 16.3 & 19.6 & 15.6 & 19.3 & 22.7 \\
\hline FeII & 6416.92 & 41.5 & 37.8 & 40.8 & 18.7 & 24.1 & - & 23.6 & 42.5 & - & 22.2 & 29.0 & 20.7 & 27.3 & 42.6 \\
\hline FeII & 6432.68 & 48.0 & 48.1 & 36.3 & - & 26.4 & 38.0 & 34.3 & - & 38.6 & 32.5 & 34.3 & 27.2 & 33.1 & 46.2 \\
\hline FeII & 6456.38 & 66.0 & 62.4 & 75.6 & - & 43.0 & - & 49.3 & 71.9 & - & 50.3 & 54.9 & 51.1 & 52.9 & 70.4 \\
\hline FeII & 6516.08 & 67.0 & 61.7 & - & 44.1 & 43.8 & 49.0 & 48.1 & 68.5 & 43.8 & 47.5 & 52.3 & - & 48.6 & 62.4 \\
\hline $\mathrm{FeI}$ & 5849.68 & - & - & - & - & - & - & - & 22.8 & - & - & - & - & - & - \\
\hline $\mathrm{FeI}$ & 5859.59 & - & - & - & - & - & - & - & 86.2 & - & - & - & - & - & - \\
\hline $\mathrm{FeI}$ & 5883.82 & - & - & - & - & - & - & - & 87.3 & - & - & - & - & - & - \\
\hline $\mathrm{FeI}$ & 5905.67 & - & - & - & - & - & - & - & 77.8 & - & - & - & - & - & - \\
\hline $\mathrm{FeI}$ & 5927.79 & - & - & - & - & - & - & - & 61.1 & - & - & - & - & - & - \\
\hline $\mathrm{FeI}$ & 5930.18 & - & - & - & - & - & - & - & 99.1 & - & - & - & - & - & - \\
\hline $\mathrm{FeI}$ & 5976.78 & - & - & - & - & - & - & - & 90.8 & - & - & - & - & - & - \\
\hline $\mathrm{FeI}$ & 6012.21 & - & - & - & - & - & - & - & 68.3 & - & - & - & - & - & - \\
\hline $\mathrm{FeI}$ & 6027.05 & - & - & - & - & - & - & - & 88.6 & - & - & - & - & - & - \\
\hline $\mathrm{FeI}$ & 6056.00 & - & - & - & - & - & - & - & 78.8 & - & - & - & - & - & - \\
\hline $\mathrm{FeI}$ & 6078.49 & - & - & - & - & - & - & - & 86.6 & - & - & - & - & - & - \\
\hline $\mathrm{FeI}$ & 6096.66 & - & - & - & - & - & - & - & 56.5 & - & - & - & - & - & - \\
\hline $\mathrm{FeI}$ & 6120.25 & 34.8 & - & 25.0 & - & - & - & 35.7 & 41.4 & - & 8.3 & - & - & 53.3 & - \\
\hline $\mathrm{FeI}$ & 6127.91 & 97.7 & 75.6 & 94.2 & 29.1 & 25.1 & 43.1 & 79.0 & 76.6 & 23.7 & - & 77.1 & 29.4 & - & 98.1 \\
\hline $\mathrm{FeI}$ & 6151.62 & 118.4 & 92.3 & 109.0 & 56.8 & 52.1 & 58.4 & 107.6 & - & 29.4 & 57.0 & 106.2 & 34.8 & 99.6 & 113.7 \\
\hline $\mathrm{FeI}$ & 6165.36 & 87.5 & 64.2 & 79.7 & 26.5 & 26.5 & 37.3 & 71.6 & 75.9 & 15.3 & - & 76.9 & 21.5 & 68.3 & 76.7 \\
\hline $\mathrm{FeI}$ & 6173.33 & - & - & - & 82.6 & 79.5 & 94.9 & - & - & 59.2 & 79.1 & - & 71.0 & - & - \\
\hline $\mathrm{FeI}$ & 6180.20 & - & 98.3 & 121.9 & 56.6 & 54.5 & 66.8 & 112.6 & - & 37.7 & 60.3 & 111.0 & 51.3 & 107.5 & 117.3 \\
\hline $\mathrm{FeI}$ & 6187.99 & 89.2 & 70.3 & 84.0 & 30.3 & 29.1 & 38.9 & 76.2 & 77.8 & 25.9 & 26.2 & 70.8 & 23.6 & 75.4 & 80.5 \\
\hline $\mathrm{FeI}$ & 6200.31 & - & 106.9 & - & 68.3 & 75.1 & 86.4 & - & - & 55.9 & 74.5 & - & 57.4 & - & - \\
\hline $\mathrm{FeI}$ & 6213.43 & - & - & - & 91.0 & 89.3 & 109.8 & - & - & 74.9 & 85.5 & - & - & - & - \\
\hline $\mathrm{FeI}$ & 6219.28 & - & - & - & - & 91.0 & 103.6 & - & - & 84.6 & 94.6 & - & 87.6 & - & - \\
\hline FeI & 6240.65 & 117.8 & 96.2 & 116.4 & 58.1 & 51.9 & 59.6 & - & - & 27.1 & 59.3 & 115.8 & 42.4 & 98.0 & 105.0 \\
\hline $\mathrm{FeI}$ & 6265.13 & - & - & - & 95.7 & 89.2 & 107.0 & - & - & 71.3 & 93.2 & - & - & - & - \\
\hline $\mathrm{FeI}$ & 6270.22 & - & - & 114.8 & - & - & - & 109.4 & 98.1 & - & - & 108.6 & - & 102.9 & 117.5 \\
\hline $\mathrm{FeI}$ & 6311.50 & - & 57.4 & - & 26.2 & 22.5 & 33.0 & 83.6 & 72.0 & 14.1 & 22.6 & 77.4 & 21.7 & 70.3 & 88.3 \\
\hline $\mathrm{FeI}$ & 6322.69 & - & 112.8 & - & 76.7 & 76.2 & 90.3 & - & - & 61.9 & 77.2 & - & 62.6 & - & - \\
\hline $\mathrm{FeI}$ & 6335.33 & - & - & - & - & 101.6 & - & - & - & 95.9 & - & - & 89.9 & - & - \\
\hline $\mathrm{FeI}$ & 6336.82 & - & - & - & 93.2 & 83.5 & 94.6 & - & - & 69.2 & 93.1 & - & 89.1 & - & - \\
\hline $\mathrm{FeI}$ & 6392.54 & 71.5 & 49.2 & - & 17.0 & 16.9 & - & 69.1 & 59.5 & - & 13.7 & 71.0 & - & 69.1 & 73.5 \\
\hline $\mathrm{FeI}$ & 6411.65 & - & - & - & 93.6 & 89.2 & - & - & - & 81.2 & - & - & 79.9 & - & - \\
\hline $\mathrm{FeI}$ & 6430.85 & - & - & - & - & - & - & - & - & 101.7 & - & - & - & - & - \\
\hline $\mathrm{FeI}$ & 6546.24 & - & - & - & - & 97.4 & - & - & - & 84.2 & - & - & - & - & - \\
\hline $\mathrm{FeI}$ & 6574.23 & 102.0 & 67.6 & 89.9 & 43.6 & 40.5 & 48.5 & 97.6 & 95.0 & 19.1 & 40.9 & - & 29.6 & 101.2 & 101.5 \\
\hline $\mathrm{FeI}$ & 6593.87 & - & - & - & 90.3 & 87.7 & 95.4 & - & - & 64.4 & 85.3 & - & 76.5 & - & - \\
\hline $\mathrm{FeI}$ & 6608.02 & 66.5 & 38.6 & 61.6 & 13.3 & 11.6 & - & 65.3 & 59.1 & - & 17.4 & 61.5 & - & 64.2 & 71.8 \\
\hline $\mathrm{FeI}$ & 6609.11 & - & 94.8 & 122.2 & 59.0 & 56.8 & 69.6 & 115.8 & - & 36.8 & 62.0 & 118.0 & - & 113.5 & - \\
\hline FeI & 6677.98 & - & - & - & - & - & - & - & - & 108.8 & - & - & - & - & - \\
\hline
\end{tabular}



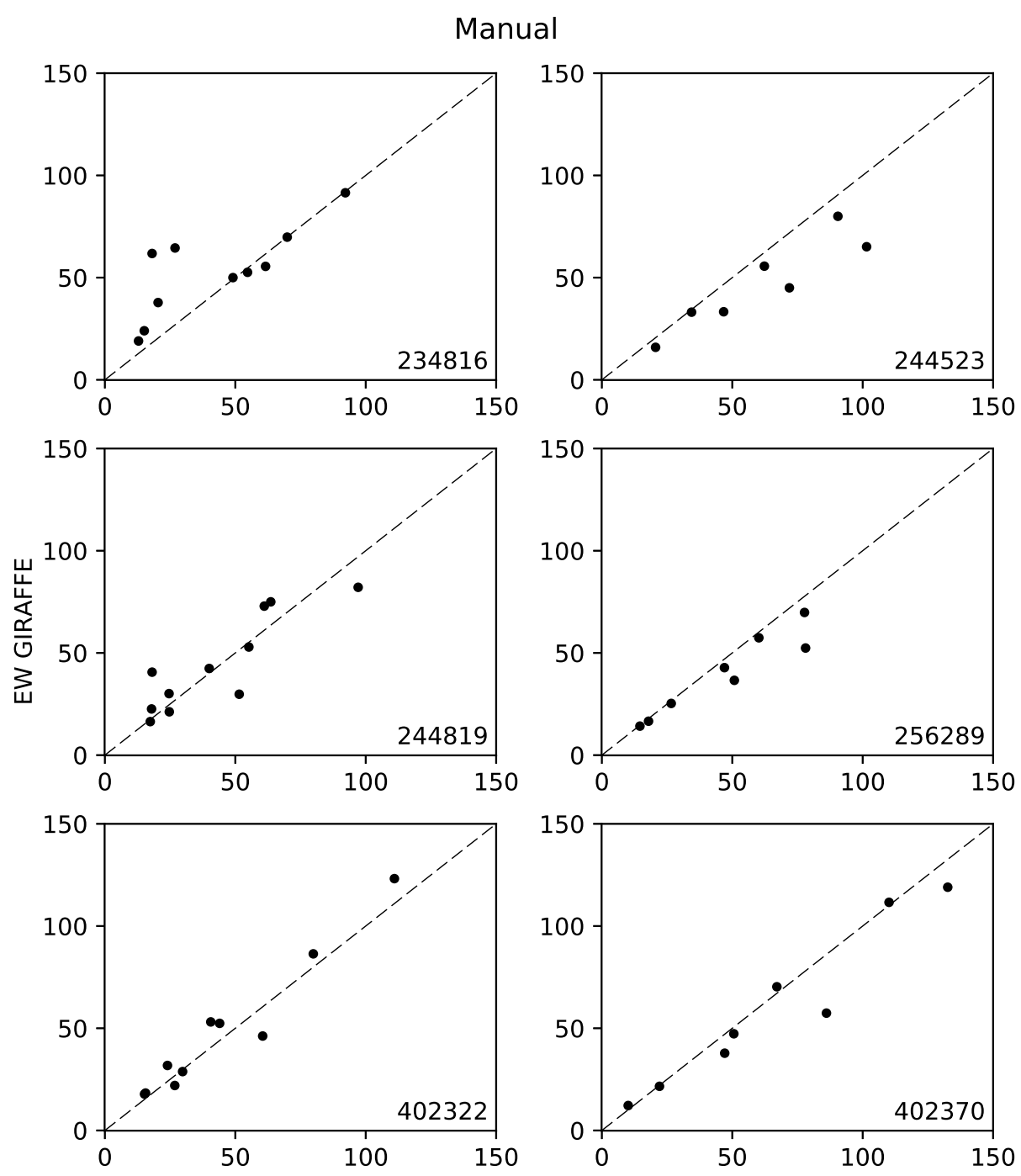

EW UVES

Figura 3.7: Comparação das larguras equivalentes medidas manualmente entre as estrelas coincidentes da amostra UV2016 e GI2012.

como a largura equivalente da linha cresce com o aumento do número de elementos absorsores na linha de visada (essencialmente a abundância química do elemento), possuindo esta três fases, como ilustrado na figura 3.9. A primeira fase, a linear, representa as linhas mais fracas, onde a linha é dominada pelo perfil gaussiano do efeito Doppler, causado pela distribuição de velocidades devido à temperatura. Nela, a largura equivalente cresce linearmente com a abundância. A segunda fase se dá à medida que a profundidade central da linha se aproxima do seu valor máximo e a linha satura, onde a largura equivalente cresce assintoticamente a um valor constante. A terceira fase do comportamento começa à 


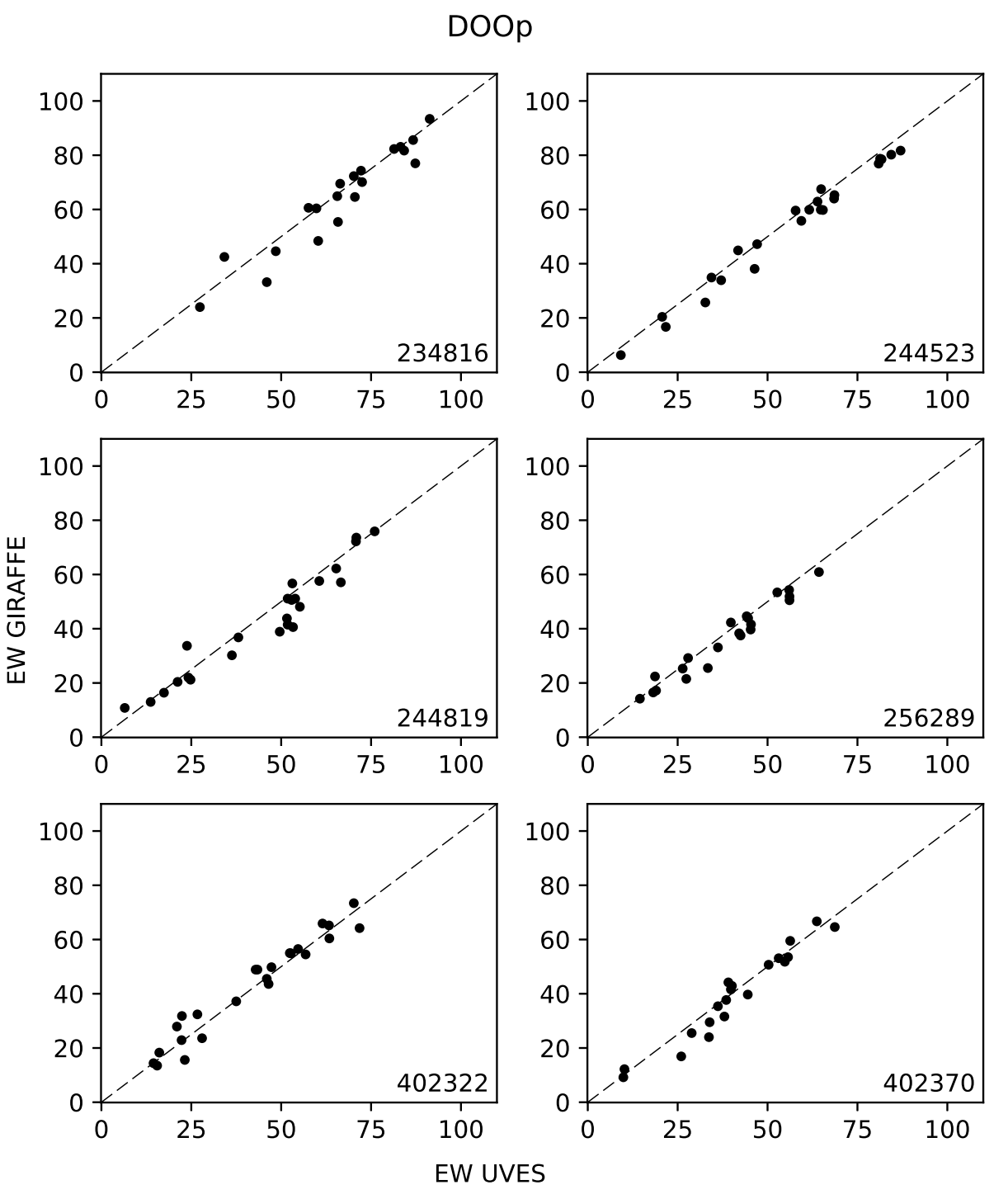

Figura 3.8: Comparação das larguras equivalentes medidas pelo DOOp entre as estrelas coincidentes da amostra UV2016 e GI2012.

medida que as asas da linha crescem, onde os efeitos de alargamento (efeito térmico, gravidade, efeito Stark, alargamento van der Waals) começam a aparecer devido ao aumento do número de absorsores, sendo a largura equivalente nesta fase proporcional à raíz quadrada da abundância.

O método da curva de crescimento para a derivação de abundâncias consiste em calcular a curva para uma determinada linha com base em um modelo atmosférico com as propriedades físicas do ambiente de formação da linha, e em seus parâmetros de formação $\chi_{e x} \mathrm{e}$ $\log g f$, para projetar a largura equivalente medida no eixo das abcissas, retornando assim sua abundância. Para isto, é preferível utilizar a fase linear da curva de crescimento, onde 

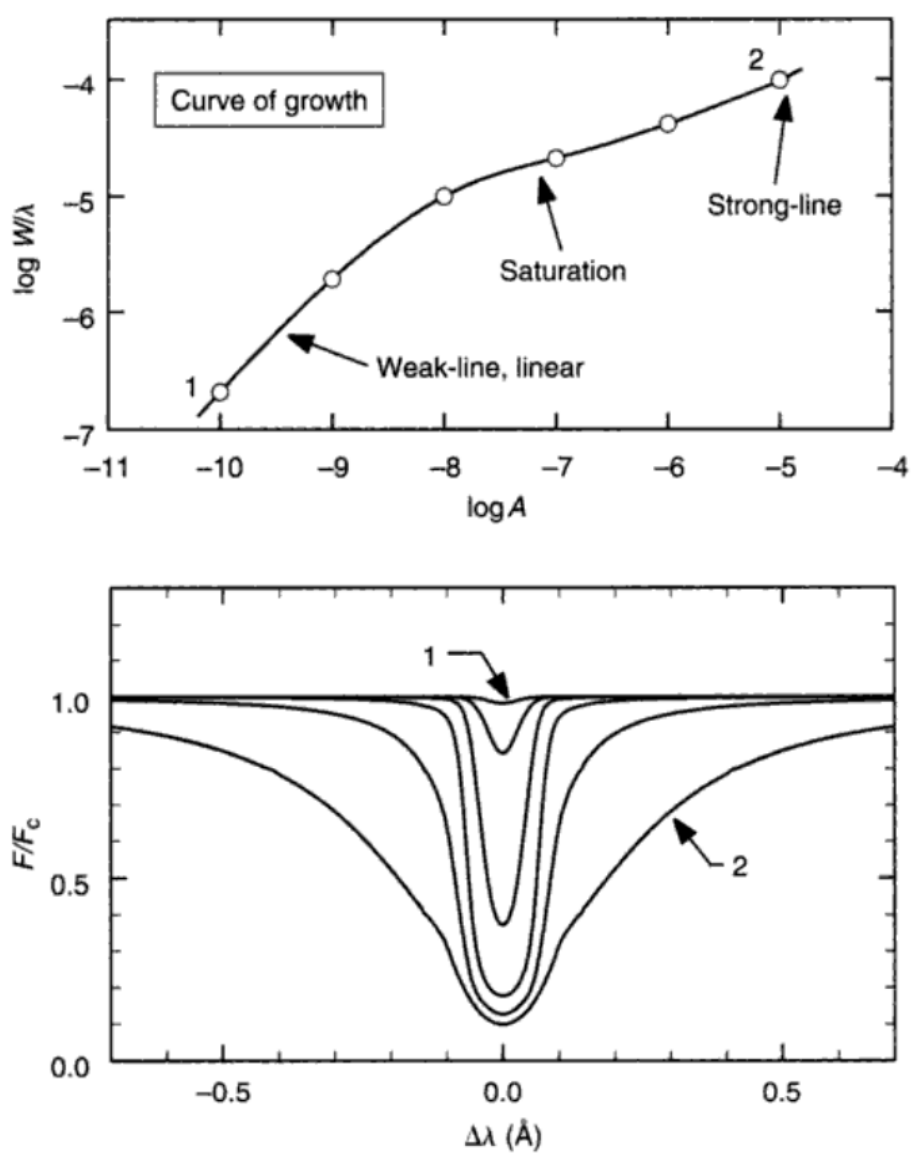

Figura 3.9: Curva de crescimento (acima) conforme a largura equivalente da linha espectral (abaixo). Figura 13.11 de Gray (2005).

os erros nas medidas de largura equivalente refletem erros proporcionais nas abundâncias. A utilização de linhas mais fortes implicaria numa projeção na fase saturada da curva de crescimento, refletindo em erros muito grandes na abundância.

De posse das larguras equivalentes das linhas de ferro e do modelo atmosférico da estrela, procede-se o cálculo das abundâncias para verificar o equilíbrio de excitação e ionização. Assumindo equilíbrio termodinâmico local, o equilíbrio de excitação é verificado quando as abundâncias das linhas de ferro se mostram uniformes conforme seu potencial de excitação, e o equilíbrio de ionização é verificado quando a média das abundâncias das linhas de Fe I e Fe II convergem para um mesmo valor. A velocidade de micro-turbulência é incorporada na análise de abundâncias para explicar o fato observacional de que as larguras equivalentes de linhas saturadas são maiores do que as preditas pelos modelos que contam somente com as constantes de alargamento (Gray, 2005), e esta é determinada ao se verificar uniformidade das abundâncias das linhas conforme suas larguras equivalentes, 
visto que o efeito da micro-turbulência não afeta as linhas mais fracas, e sim a parte saturada da curva de crescimento.

A derivação dos parâmetros atmosféricos é feita de maneira iterativa, variando-se os parâmetros do modelo no cálculo das abundâncias das linhas de ferro conforme as tendências observadas nos resultados do cálculo anterior, de maneira que, como resultado, se observe o equilíbrio simultâneo das situações acima descritas, conforme exemplificado na figura 3.10 .
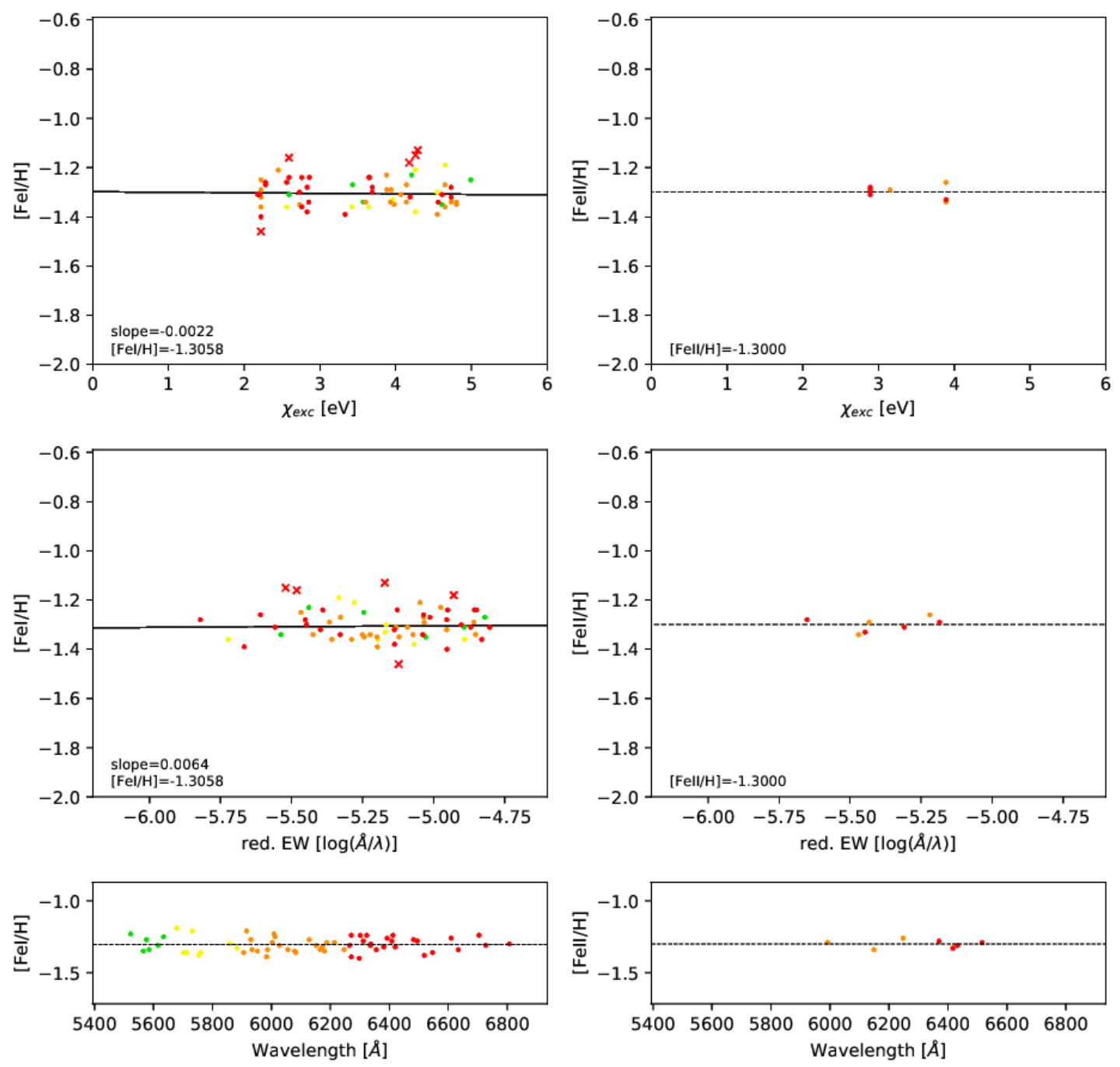

Figura 3.10: Exemplo do equilíbrio de excitação e ionização atingido. As cores das linhas representam os intervalos espectrais correspondentes. Os painéis inferiores são utilizados para verificar se as linhas sofreram efeitos relacionados ao intervalo espectral. 


\subsubsection{Modelos de atmosfera}

Os modelos da atmosfera da estrela são elaborados de maneira a simular as condições físicas na fotosfera, que por possuir um gradiente de temperaturas, é estratificada em camadas conforme suas profundidades ópticas. Esta aproximação, chamada plano-paralela, assume equilíbrio termodinâmico local em cada camada, onde todas as grandezas pertinentes (como por exemplo temperatura, pressão eletrônica, composição, etc.) são dadas para possibilitar o cálculo das funções de partição e a transferência radiativa ao longo das camadas.

Os modelos de atmosfera utilizados foram os modelos MARCS (Gustafsson et al., 2008) com composição alpha-enhanced (enriquecido em elementos- $\alpha$ ), visto que as estrelas analisadas são de população-II e ricas em elementos- $\alpha$. A grade de modelos é subdividida em incrementos de temperatura efetiva, gravidade e metalicidade, sendo que os modelos utilizados nos cálculos são interpolados desta grade.

\section{4 .2 abon2}

O código de transferência radiativa utilizado para o cálculo das abundâncias via curva de crescimento foi o abond (Spite et al., 1987), que toma como entrada um arquivo de configuração, outro com o modelo atmosférico e um arquivo de texto com a lista contendo os parâmetros das linhas e respectivas larguras equivalentes medidas, retornando um arquivo com as abundâncias calculadas para cada linha. O código é escrito em Fortran, e sua execução é feita através de um outro código escrito no Jupyter notebook, que automaticamente constrói o arquivo de configuração, interpola o modela e canaliza as entradas para executar o abon2. Este código foi feito de modo a utilizar blocos de execução, possuindo modos de derivação que incluem:

- A maneira iterativa com uma rodagem do abon2 por vez, variando-se manualmente os parâmetros;

- Derivação automatizada via uma grade de formato estipulado e os critérios de con- 
vergência explicitados na seção 3.4.3.

- Módulo de plotagem dos gráficos de equilíbrio e rejeição de outliers;

- Módulo de estimativa de erros nos parâmetros, explicitada na seção 3.4.4.

- Blocos adicionais de comparação das larguras equivalentes.

Os blocos podem ser executados de modo a se adaptar às necessidades de cada análise, trocando os parâmetros de execução e visualizando os resultados rapidamente.

\subsubsection{Convergência dos parâmetros}

O critério de convergência imposto para o equilíbrio foi determinado com base no coeficiente angular da reta de tendência na excitação $\left([\mathrm{Fe} / \mathrm{H}]\right.$ vs $\left.\chi_{\text {exc }}\right)$ e seu erro, no coeficiente angular da reta de tendência no alargamento ([Fe/H] vs $\log (E W / \lambda))$ e seu erro, na diferença entre as médias das abundâncias de Fe I e Fe II e seus desvios-padrão combinados, e na diferença entre a metalicidade do modelo e a média final de Fe I e Fe II com os desviospadrão combinados. No caso, os coeficientes angulares de excitação e alargamento devem resultar em valores menores que metade do seu erro, a diferença entre as médias de Fe I e Fe II deve ser menor que metade da média geométrica entre os desvios-padrão respectivos, e a diferença entre a metalicidade do modelo e a média final de Fe I e Fe II deve resultar em valor menor que metade da raíz da soma quadrática entre os desvios-padrão de Fe I e Fe II. Este critério exibe boa robustez estatística e adaptabilidade às diferentes distribuições de pontos nas amostras.

Frequentemente, linhas espectrais exibiam valores de abundância visivelmente desviantes do restante da distribuição, fazendo-se necessário um critério para a rejeição de outliers baseado na própria distribuição. O método utilizado foi rejeitar previamente as linhas cuja abundância desvia em mais de 3 desvios-padrão da média, realizar um primeiro ajuste linear, normalizar os pontos e calcular o desvio-padrão. Para cada caso, um fator multiplicativo do desvio-padrão era escolhido de modo a eliminar pontos cuja abundância excedesse este valor. Rejeitados os pontos espúrios da amostra de linhas inicial, procede-se o ajuste linear final a ser considerado.

Foi feita uma comparação entre os parâmetros atmosféricos de parte da amostra GI2012, derivados usando as larguras equivalentes medidas manualmente e via DOOp. Na figura 3.11 são exibidas as comparações em relação à uma referência 1:1, e é possível notar que, com exceção de uma estrela (no caso a 402386, que apresentou certa dificuldade 
na convergência devido à baixa temperatura e linhas muito fortes), a temperatura e a gravidade se comportam razoavelmente bem. Quanto à metalicidade, esta apresenta uma relação praticamente perfeita entre os dois métodos de medição. Devido a isso, as larguras equivalentes do DOOp foram consideradas razoáveis e os parâmetros obtidos com estas foram adotados, e para o restante da amostra GIRAFFE, foram realizadas somente as medidas com o DOOp.
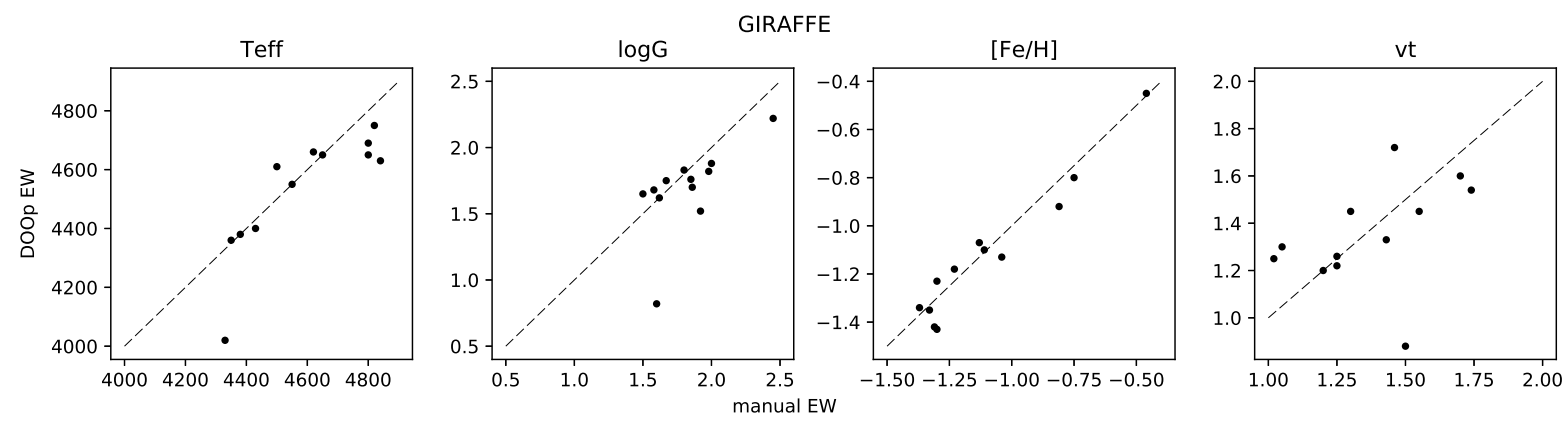

Figura 3.11: Comparação dos parâmetros atmosféricos obtidos com larguras equivalentes medidas manualmente e via DOOp para parte da amostra GI2012.

Para as estrelas UVES, a mesma comparação foi realizada, porém, como mostra a figura 3.12, a relação não foi satisfatória, e os parâmetros adotados foram os derivados utilizando as larguras equivalentes medidas manualmente.
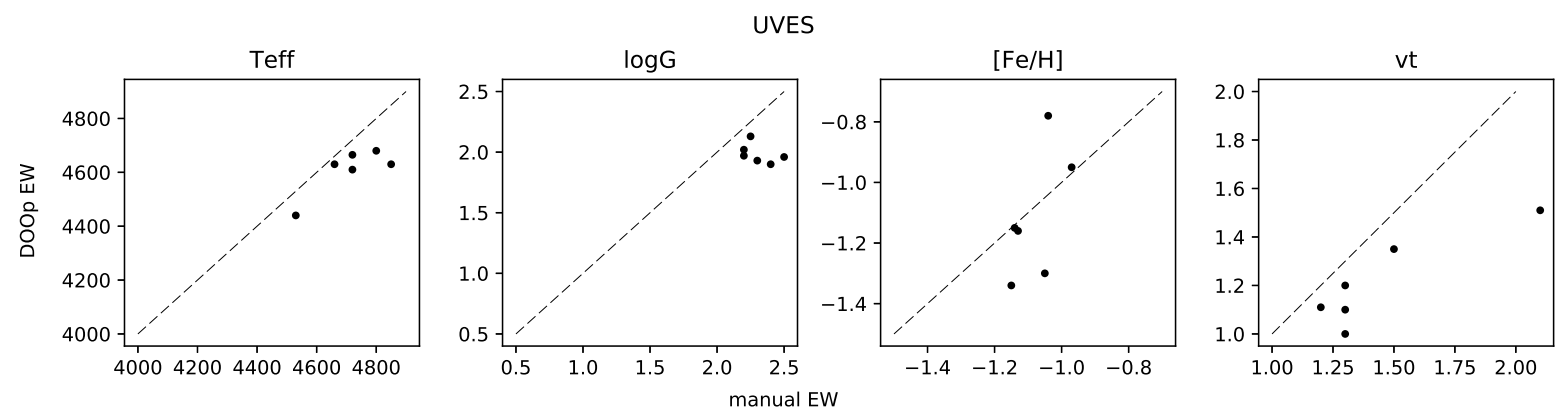

Figura 3.12: Comparação dos parâmetros atmosféricos obtidos com larguras equivalentes medidas manualmente e via DOOp para parte da amostra UV2016.

\subsubsection{Análise de erros}

Os erros associados aos parâmetros atmosféricos, por serem covariantes, podem ser estimados utilizando grades de variação dos parâmetros, comparando-os em pares, como mostra a figura 3.13. Os critérios de convergência citados anteriormente são utilizados de 
modo que as variáveis livres (coeficientes angulares e diferenças) são normalizadas pelos seus erros, somadas, e divididas por 4, de modo que seja produzido um resíduo final normalizado, onde valores menores que 1 são tomados como parâmetros convergidos.
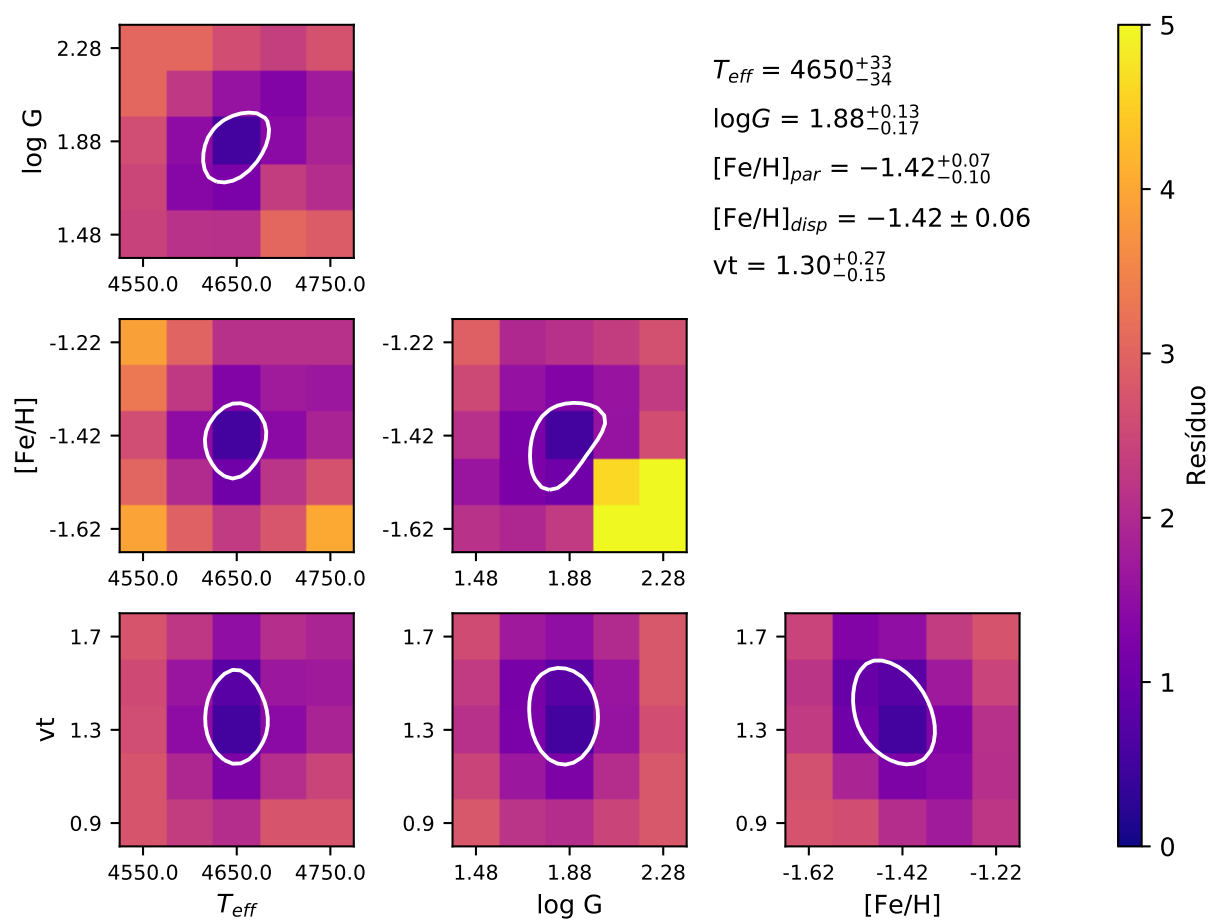

Figura 3.13: Exemplo de mapa de resíduos da estrela 402370, usado na determinação dos erros dos parâmetros atmosféricos das amostras do GIRAFFE.

Cada quadro da figura 3.13 contém um mapa de resíduos, onde é possível analisar o perfil da degenerescência na convergência dos parâmetros atmosféricos. A convergência é atingida quando o resíduo se torna menor que 1, portanto pode-se estabelecer um intervalo de confiança dentro do mapa para valores que se enquadram neste critério. Para tal, o mapa é re-amostrado em intervalos menores (o cálculo de uma grade muito refinada seria computacionalmente muito custoso) utilizando interpolação por spline cúbica bidimensional por meio das funções bisplrep e bisplev do pacote SciPy, para posteriormente extrair uma curva de nível (valores da superfície no nível onde o resíduo se iguala a 1) que representará o intervalo de confiança, exibida em branco em cada um dos mapas. Os limites inferiores e superiores das curvas rebatidos nos eixos dos parâmetros são tomados como os intervalos de confiança de um parâmetro em função do outro, e para estimar os erros, para cada parâmetro, é tomada um média entre os três valores inferiores (o parâmetro em 
função de cada um dos outros) e outra entre os valores superiores. Desta forma, obtémse um erro assimétrico para cada parâmetro atmosférico, o que é de se esperar devido à assimetria do perfil de degenerescência.

Os erros na metalicidade são originários tanto da dispersão das abundâncias individuais das linhas quanto da metalicidade como parâmetro atmosférico, porém, ambos os valores são codependentes. Como a fonte primordial dos erros na convergência é a própria dispersão das abundâncias das linhas, e a partir do momento em que a convergência é atingida entre o valor do modelo e a média das abundâncias linha-a-linha, assume-se o erro na metalicidade como sendo o desvio-padrão das abundâncias individuais calculadas para as linhas de ferro.

Obviamente, os erros estimados por este método são baseados apenas nos critérios de convergência do equilíbrio, e assumem total confiabilidade nas abundâncias obtidas para as linhas de ferro, o que claramente não é o caso. Os modelos plano-paralelo são uma aproximação bastante rudimentar da atmosfera estelar e não levam em conta efeitos como convecção, granulação, desvios do equilíbrio termodinâmico local e suas inúmeras consequências. As medidas de larguras equivalentes também estão sujeitas a diversos erros como estabelecimento do contínuo local, ruído, efeitos de assimetria originários da formação da linha, e além de tudo, blends com outras linhas. O parâmetro atmosférico mais sensível às incertezas originárias dos modelos é a temperatura, que por este método, apresenta erros sub-estimados em relação ao $\sigma_{T e f f} \sim 100 K$ tipicamente assumido nos estudos da área, porém os erros obtidos para as temperaturas e gravidades apresentam excelente compatibilidade com os erros apresentados em Recio-Blanco et al. (2017), computados pelo consórcio do Gaia-ESO Survey e descritos em Rojas-Arriagada et al. (2017). Também é importante ressaltar que este método assume somente os pontos utilizados na derivação dos parâmetros, que sofreram rejeição de outliers. A inclusão/exclusão de pontos altera sensivelmente a convergência e parâmetros resultantes, principalmente nas amostras do GIRAFFE, visto o baixo número de linhas espectrais de Fe I disponíveis em comparação com a amostra do UVES. O espalhamento das abundâncias também é um fator que influencia diretamente na amplitude da degenerescência dos parâmetros, visto que os critérios são baseados em uma normalização pelos erros dos coeficientes angulares e desvios-padrão das abundâncias, que por sua vez são determinados com base no espalhamento dos pontos.

$\mathrm{Na}$ amostra do UVES, foram calculados os erros para os parâmetros derivados com as medidas de larguras equivalentes tanto manuais quanto via DOOp. Nas derivações com 
medidas manuais, a metalicidade do modelo foi fixada em $[\mathrm{Fe} / \mathrm{H}]=-1$ e não foi refinada por retroalimentação do resultado. Isto implica em resíduos finais mais altos do que o esperado, devido a um dos critérios de convergência comparar a metalicidade do modelo com a média final entre Fe I e Fe II. Como resultado, os resíduos de modo geral são carregados para valores maiores, levando a intervalos de confiança ligeiramente subestimados, visto que as superfícies de nível serão interseccionadas a valores mais próximos do mínimo para a obtenção das curvas de nível.

Para as amostras do GIRAFFE foram calculados os erros apenas para os parâmetros derivados com as medidas realizadas via DOOp.

No capítulo 5 são apresentados os parâmetros atmosféricos e erros finais para as amostras do UVES na tabela 5.3 e para as amostras do GIRAFFE na tabela C.1.

\subsection{Determinação dos parâmetros atmosféricos da amostra do MUSE}

Para a determinação dos parâmetros atmosféricos, velocidades radiais e razão $[\mathrm{Mg} / \mathrm{Fe}]$ dos espectros extraídos do cubo de dados proveniente do MUSE, foi utilizado o método de ajuste de espectro completo, onde os espectros das estrelas observadas são correlacionados com os de uma biblioteca estelar que possui os valores dos parâmetros atmosféricos determinados para uma.

A biblioteca utilizada foi a MILES (Sánchez-Blázquez et al., 2006), que possui para cada estrela os parâmetros $\mathrm{T}_{\text {eff }}, \log g,[\mathrm{Fe} / \mathrm{H}]$ (Cenarro et al., 2007), e para a maioria delas, $[\mathrm{Mg} / \mathrm{Fe}]$ (Milone et al., 2010).

\subsubsection{Etoile}

O software que realiza o ajuste de espectro completo utilizado foi o Etoile (Katz, 2001), que realiza o ajuste e calcula a correlação do espectro de entrada com a biblioteca espectral, retornando um índice de correlação para cada item da biblioteca. O Etoile também possui um modo de execução que realiza a medição de velocidades radiais via correlação cruzada.

Visto o grande número de espectros observados, foi desenvolvido um código em Python que automatiza o processo de execução do Etoile, com a correção da velocidade radial, correlação com os espectros da biblioteca e determinação dos parâmetros finais de cada estrela. 
Primeiramente, determina-se o melhor espectro de referência da biblioteca para a determinação das velocidades radiais via correlação cruzada para cada estrela observada, executando o Etoile para toda a amostra. O espectro da biblioteca cuja correlação é a maior, é usado como referência para executar o Etoile, para cada estrela observada, no modo de velocidade radial. Feito isso, é aplicada a correção para todos os espectros observados e é feita uma nova execução do Etoile no modo de parâmetros atmosféricos para determinar as correlações dos espectros da biblioteca com os observados.

A faixa espectral considerada na análise foi de $4800 \AA<\lambda<7000 \AA$, afim de manter consistência com a faixa espectral do FLAMES-UVES, e considerar o tripleto do magnésio em $\lambda \sim 5200 \AA$. Comprimentos de onda maiores possuíam artefatos nos espectros do MUSE devido à subtração de céu, onde muitas linhas telúricas em emissão estão presentes, comprometendo a extração dos espectros.

Para a determinação dos parâmetros individuais, é aplicado o método descrito em Dias et al. (2015), com uma modificação no critério de filtragem dos espectros da biblioteca. A amostra possui muitas estrelas de sequência principal, estrelas RR Lyrae e outras que não se encaixam no critério de seleção apenas de gigantes vermelhas, que força a seleção deste tipo de parâmetro dentre uma lista de parâmetros correlatos que, por ventura podem apresentar uma maioria de estrelas que não pertencem ao ramo das gigantes. O uso deste critério na presente amostra produziu um pico pronunciado da distribuição de metalicidades centrado em $[\mathrm{Fe} / \mathrm{H}] \sim-1.6$, muito discordante do valor de referência $[\mathrm{Fe} / \mathrm{H}] \sim-1.0$, sem nenhuma população significativa nesta metalicidade. A solução encontrada foi, ao invés de forçar a seleção de gigantes, aplicar um sistema de rejeição de pontos por clipagem-sigma, onde toma-se a mediana e um fator de 1,5 do desvio-padrão das temperaturas da lista de parâmetros ordenada pela correlação normalizada (original de Dias et al. 2015, excluindo entradas com similaridades fora de 1.1), rejeitando parâmetros cuja temperatura desvie em mais de $1.5 \cdot \sigma$ da mediana. Adotando este método, o pico da distribuição de metalicidades ficou centrado em $[\mathrm{Fe} / \mathrm{H}] \sim-1.0$, conforme mostrado na figura 3.14, juntamente com a distribuição de velocidades radiais e distância ao centro do aglomerado. 


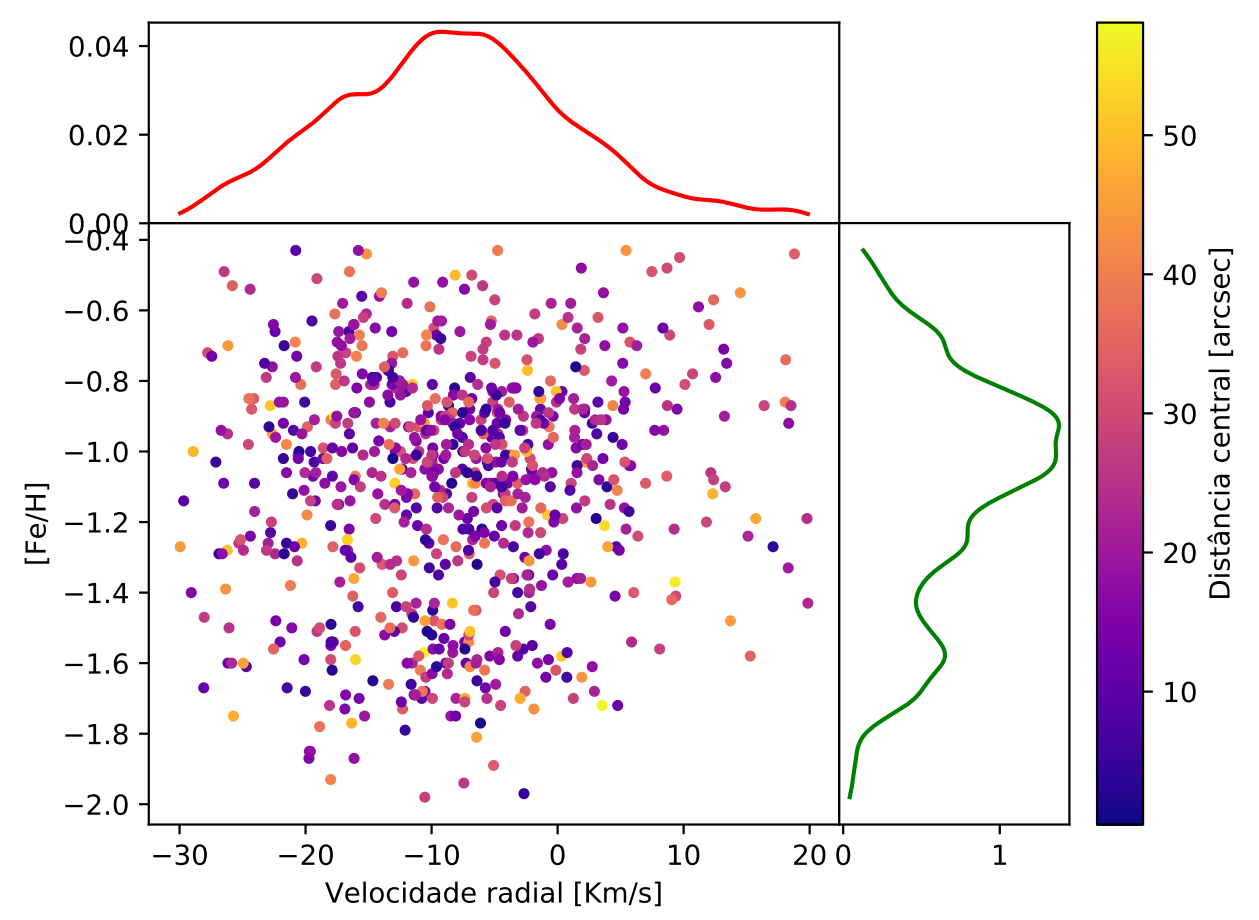

Figura 3.14: Mapa de velocidades e metalicidades da amostra do MUSE, com escala de distância central do aglomerado. À direita é exibida a função de distribuição de metalicidades em verde, e no quadro superior, a função de distribuição de velocidades em vermelho. 
Capítulo 4

\section{Abundâncias elementais}

As abundâncias químicas dos elementos presentes nas atmosferas estelares são estudados por meio das linhas de absorção nos espectros das estrelas, que por sua vez representam as transições eletrônicas que ocorrem nos átomos e moléculas que compõem a fotosfera por absorção/emissão dos fótons do campo radiativo presente no ambiente.

A medida padrão para os valores de abundância é uma escala logarítmica referenciada no Hidrogênio, tendo este por convenção o valor de $\log \epsilon(H) \equiv 12$. A abundância $\epsilon(X)$ de um elemento é dada pela equação

$$
\log \epsilon(X)=\log \left(\frac{n_{X}}{n_{H}}\right)+12
$$

onde $n_{X}$ é a densidade numérica do elemento em questão e $n_{H}$ é a densidade numérica do Hidrogênio.

Na análise de abundâncias químicas e populações estelares, normaliza-se a abundância do elemento em questão pela abundância de ferro da estrela (representado por $\left(\frac{X}{F e}\right)$ ), e toma-se esta razão relativa à razão solar (representado usando colchetes, como $\left[\frac{X}{F e}\right]$ ), de modo a comparar as proporções entre os elementos tanto na própria estrela quanto em relação às proporções solares que nos são bem conhecidas. Desta forma, é possível distinguir populações que apresentam enriquecimento ou deficiência de determinados elementos, e a diferentes metalicidades de maneira normalizada, de modo a fazer uma comparação independente da metalicidade.

A análise de abundâncias das linhas espectrais pode ser conduzida via curva de crescimento utilizando suas larguras equivalentes (conforme descrito na seção 3.3.2), ou via síntese espectral, onde modela-se um espectro teórico da estrela com base em seus parâmetros atmosféricos e ajusta-se suas abundâncias químicas comparando os perfis das linhas espectrais do espectro observado com o espectro sintético. A síntese espectral é uma poderosa 
ferramenta que se mostra indispensável ao analisar regiões espectrais que contém grande número de linhas que formam blends e espectros ruidosos, que outrora tornaria muito difícil e altamente incerta a medida das larguras equivalentes de linhas individuais para análise da curva de crescimento, que potencialmente levaria a resultados errôneos de valores de abundâncias. Por conta disso, a síntese espectral foi o método utilizado para a determinação das abundâncias químicas das estrelas analisadas.

\subsection{Síntese espectral}

O método da síntese espectral é uma das ferramentas mais utilizadas na determinação de abundâncias químicas estelares e na construção de bibliotecas de espectros sintéticos estelares. Por meio desta, é possível modelar o espectro estelar e comparar com o espectro observado afim de estimar diretamente as abundâncias das linhas espectrais pela análise de seus perfis e forças. A síntese espectral consiste em modelar e predizer o espectro de uma estrela baseado nas condições físicas na sua fotosfera (onde o perfil do espectro e as linhas são formadas), parâmetros físicos das transições eletrônicas nos átomos e moléculas (que produzem as linhas espectrais) e abundâncias químicas dos elementos presentes na atmosfera estelar. O ambiente físico da fotosfera é tratado utilizando um modelo, como explicado na seção 3.3.1. O efeito das transições eletrônicas são tratados diretamente como os parâmetros de formação das linhas espectrais, como explicado na seção 3.1. As abundâncias químicas dos elementos são utilizadas da maneira explicada na introdução do capítulo 4 .

Os códigos de síntese espectral realizam a tarefa de simular os fluxos de energia em cada comprimento de onda por meio do cálculo da transferência radiativa através de cada estratificação do modelo atmosférico fornecido, integrando as intensidades ao longo das profundidades ópticas. As listas de linhas atômicas e moleculares contendo seus parâmetros de formação, combinadas às condições físicas em cada estratificação do modelo e às abundâncias químicas dos respectivos elementos químicos, fornecem as opacidades que irão dar origem às linhas espectrais.

O código de transferência radiativa utilizado foi o Pfant (Coelho et al., 2005), que realiza um tratamento assumindo equilíbrio termodinâmico local. Neste código foram combinadas todas as faixas espectrais preparadas nas tese de doutorado por Castilho (1999), Schiavon 
(1998), Meléndez (2000). Este código é uma versão atualizada em 2005, dos códigos desenvolvidos por Spite (1967) e Barbuy (1982). O Pfant é um código escrito em FORTRAN que foi recentemente atualizado e será publicado em Barbuy, B., Trevisan, J., de Almeida, A. 2018, PASA, aceito. Atualmente conta com uma camada de interface com o usuário escrita em Python 3, que é parte integrante da biblioteca pyfant. O pyfant proporciona além de inúmeras ferramentas de manipulação dos arquivos de entrada e saída do Pfant e scripts de execução, conta com uma interface gráfica para auxiliar na execução das sínteses espectrais (figura 4.1). Os espectros que saem diretamente da síntese precisam passar por uma etapa que confere o perfil instrumental da observação e os efeitos de rotação da estrela, onde as linhas espectrais são convoluídas com um perfil gaussiano de FWHM (full width at the half-maximum, ou largura à meia-altura) especificado. Esta etapa é executada automaticamente no fim da execução da síntese.

Os modelos atmosféricos utilizados foram os modelos MARCS (Gustafsson et al., 2008), como descrito na seção 3.3.1. A lista de linhas e as abundâncias utilizadas foram as descritas anteriormente nas seções 4.2 .2 e 4.3, respectivamente.

\subsection{Linhas moleculares}

Para os elementos carbono e nitrogênio, foram utilizadas as bandas moleculares de $\mathrm{C}_{2}$ e CN para estimar suas abundâncias, levando em conta o equilíbrio dissosciativo entre as moléculas. Nos espectros estão disponíveis para o carbono a banda de $\mathrm{C}_{2}(0,1)$ Swan em $\sim 5635.5 \AA$, e para o nitrogênio as bandas $\mathrm{CN}(5,1)$ em $\sim 6332.16 \AA, \mathrm{CN}$ em $\sim 6498.5 \AA$ (Lecureur et al., 2007), e a banda de $\mathrm{CN}$ em 5634.5, do lado azul da banda de $\mathrm{C}_{2}$.

\subsection{Linhas atômicas}

Com a finalidade de compor uma lista de linhas espectrais confiável e abrangente, foi feita uma varredura de todos os elementos analisados no intervalo de $4800 \AA$ a $6800 \AA$. Foi feita uma busca por linhas suficientemente fortes e o mais limpas possível de blends, de modo a produzir sínteses que possam ser usadas para medidas de boa confiabilidade. O método utilizado incluiu, para cada elemento, a análise do espectro do Sol e de Arcturus, sobrepostos com três espectros sintéticos: um sem o elemento analisado; outro somente com as linhas do elemento utilizado; e outro com o espectro total. Com isto, foi feita 


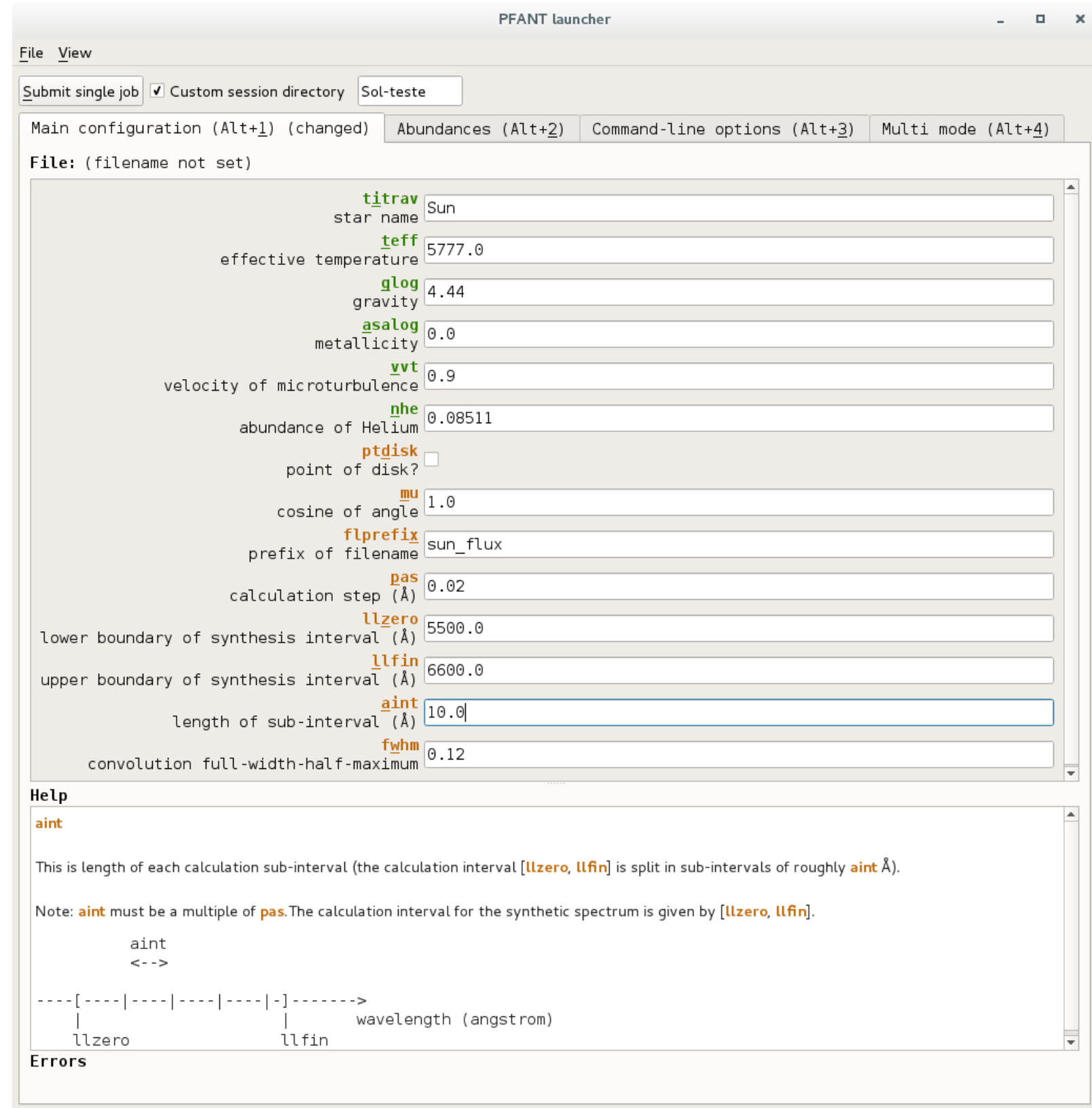

Figura 4.1: Janela de execução do Pfant pela interface do pyfant. Cada aba da janela contém as configurações dos parâmetros de entrada para a síntese. A última aba Multi-mode é utilizada para lançar sínteses simultâneas que utilizam abundâncias elementais diferentes, especificadas via dicionários do Python, bem como os rótulos de cada síntese e também múltiplos valores para a convolução do espectro.

a varredura visual dos espectros em busca de linhas com as características desejadas. Uma primeira lista foi composta para ser posteriormente analisada pelo método da síntese espectral decomposta, conforme descrito na seção 4.3.2. 


\subsubsection{Estrutura hiperfina}

Em átomos, as interações entre o estado quântico do núcleo e da eletrosfera geram pequenos desvios e separações entre seus níveis de energia, produzindo uma linha espectral que possui o que se chama de estrutura hiperfina. A estrutura hiperfina provém da interação entre o momento de dipolo magnético nuclear com o campo magnético gerado pelos elétrons, e da interação entre o momento de quadrupolo elétrico nuclear com o gradiente do campo elétrico da distribuição de cargas do átomo. Isto ocorre pelo fato de que, além dos elétrons possuírem um spin, o núcleo também pode girar em torno de seu eixo, e como estados de energia deste núcleo são quantizados, os níveis de energia apresentam separações correspondentes. O número quântico do spin é zero para núcleos de número atômico e número de massa pares, portanto a estrutura hiperfina é encontrada apenas em átomos cujo número de massa é ímpar.

Em espectroscopia, o perfil das linhas espectrais é afetado devido à estrutura hiperfina, produzindo assimetrias e insaturações (devido à separação em diversas componentes, sendo cada uma delas tratada como uma linha individual), fazendo-se necessário que se leve em conta a estrutura hiperfina das linhas analisadas para a correta reprodução de seus perfis.

Para o cálculo da estrutura hiperfina, são necessárias as constantes A (dipolo magnético) e B (quadrupolo elétrico) de Einstein para a transição, e as razões isotópicas do elemento, caso mais de um isótopo seja estável o suficiente para ser considerado na análise. Neste processo são produzidas as linhas espectrais correspondentes à cada componente da estrutura hiperfina da transição, cada uma com comprimentos de onda ligeiramente deslocados entre si (representando as diferenças nos níveis de energia dos estados quânticos) e com os valores de log gf escalados com a respectiva razão isotópica.

Nesta análise, foram levadas em conta as estruturas hiperfinas das linhas dos elementos $\mathrm{Na}, \mathrm{Mn}, \mathrm{Cu}, \mathrm{Ba}$, La e Eu.

\subsubsection{Síntese espectral decomposta}

As linhas espectrais selecionadas foram submetidas a uma conferência mais refinada utilizando a técnica da síntese espectral decomposta descrita na seção 3.1.1. Nesta análise, especifica-se um elemento e suas linhas são calculadas individualmente para uma melhor visualização, e também é possível inspecionar as contribuições individuais das linhas com 
estrutura hiperfina, como mostrado na figura 4.2. Por meio deste processo, os valores de log gf foram selecionados entre os disponíveis pelo VALD3 e NIST. As linhas que não reproduziram o espectro observado satisfatoriamente foram eliminadas (no caso de linhas fortes ou fracas demais, ou regiões de muito crowding), ou foram astrofisicamente ajustadas da maneira descrita para as linhas de ferro na seção 3.1.1. Tipicamente, as linhas presentes no NIST cujo log gf possuem classe de acurácia $\mathrm{C}$ ou pior não se ajustavam bem, porém a síntese se mostrava bastante próxima do observado. Todos os ajustes astrofísicos de log gf foram feitos de maneira simultânea para Sol, Arcturus e $\mu L e o$.
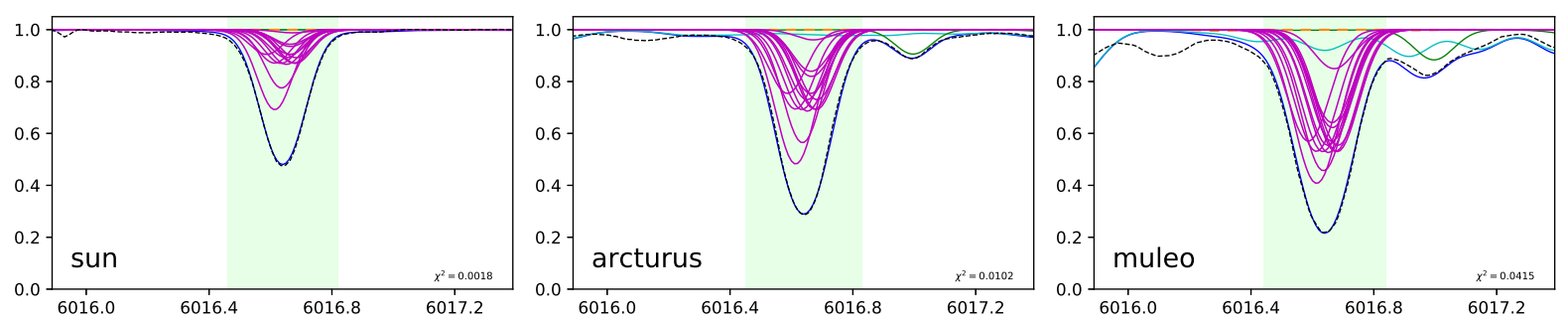

Figura 4.2: Síntese espectral decomposta da linha de manganês em $6016.64 \AA$ nas estrelas de referência. As curvas em magenta representam as linhas individuais da estrutura hiperfina.

\subsubsection{Lista de linhas atômicas}

Na compilação da lista de linhas foram incluídas as linhas que produziam um bom ajuste às estrelas de referência e que fossem mensuráveis nos espectros das estrelas das amostras, visto que estas apresentam baixas metalicidades em comparação às estrelas de referência.

A lista de linhas final com os valores adotados de log gf é exibida na tabela 4.1 a seguir. As estruturas hiperfinas calculadas para as linhas de Na, Mn, Cu, Ba, La e Eu são apresentadas no apêndice B.

\subsection{Abundâncias adotadas para as estrelas de referência}

As abundâncias elementais para o Sol, Arcturus e $\mu$ Leo foram adotadas com base na referência que melhor se ajustou ao espectro observado utilizando a síntese decomposta com os parâmetros atmosféricos adotados. Foram derivadas as abundâncias para Arcturus e $\mu L e o$ dos elementos ausentes na literatura, ou que não foram capazes de reproduzir 
Tabela 4.1 - Lista de linhas atômicas dos elementos utilizados na análise. As linhas que tiveram sua estrutura hiperfina calculada possuem "HFS"no lugar do log gf adotado.

\begin{tabular}{|c|c|c|c|c|c|c|c|c|c|c|c|}
\hline Elm. & $\lambda$ & $\chi_{e x c}$ & $\mathrm{gf}_{N I S T}$ & $\mathrm{gf}_{V A L D 3}$ & $\mathrm{gf}_{\text {adotado }}$ & Elm. & $\lambda$ & $\chi_{e x c}$ & $\mathrm{gf}_{N I S T}$ & $\mathrm{gf}_{V A L D 3}$ & $\mathrm{gf}_{\text {adotado }}$ \\
\hline $\mathrm{CI}$ & 5380.325 & 7.680 & -1.620 & -1.616 & -1.720 & TiI & 6064.626 & 1.046 & -1.944 & -1.944 & -1.944 \\
\hline I & 300.304 & 000 & 2.202 & -12.202 & & זר & & & & & -1.424 \\
\hline aI & 5682.633 & 102 & -0.706 & -0.706 & & TiI & 12.236 & 1.460 & -1.552 & & -1.550 \\
\hline aI & 5688.193 & 104 & -1.406 & -1.406 & -1.406 & TiI & 36.099 & 1.443 & -1.742 & -1.690 & -1.742 \\
\hline aI & 5688.205 & 104 & -0.452 & -0.452 & & TiI & 54.223 & 1.443 & -1.219 & & -1.219 \\
\hline $\mathrm{aI}$ & 6154.226 & 102 & -1.547 & -1.547 & HFS & TilI & 74.009 & 3.095 & 305 & & .860 \\
\hline I & 6160.747 & 104 & -1.246 & -1.246 & & TiII & & 3.123 & & & -0.640 \\
\hline gI & 5528.405 & .346 & -0.498 & -0.498 & -0.498 & TilI & 5336.786 & 1.582 & -1.700 & & -1.600 \\
\hline gI & 5711.088 & 4.346 & -1 & 4 & & TilI & & & & & -2.131 \\
\hline $\mathrm{gI}$ & 6318 & 108 & -2.103 & & & MnI & 677 & 0.000 & & & FS \\
\hline 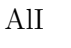 & 6696.018 & 3.143 & -1.569 & -1.347 & -1.569 & MnI & 510 & 3.072 & -0.252 & -0.352 & HFS \\
\hline 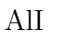 & 6698.667 & 143 & -1.870 & 17 & & MnI & & 3.073 & - & & HFS \\
\hline SiI & 5645.613 & 4.930 & -1 & & & $\mathrm{MnI}$ & & 3.075 & +0.035 & & HFS \\
\hline I & 5665 & 4.920 & -2.040 & -2 & & $\mathrm{JuI}$ & & 1.389 & - & & FS \\
\hline & 5666.677 & 5.617 & - & & & $\mathrm{uI}$ & & 3.820 & +0.260 & & FS \\
\hline SiI & 5684.484 & 4.953 & -1.420 & -1.650 & -1 & $\mathrm{CuI}$ & 126 & 3.820 & -1.781 & & HFS \\
\hline & 5690.425 & 4.930 & -1.870 & & & $\mathrm{ZnI}$ & & 4.078 & - & & -0.250 \\
\hline S & 5701 & 4.930 & -2.050 & & & $\mathrm{ZnI}$ & & & - & 150 & +0.050 \\
\hline S & 5772.146 & 5.082 & -1.750 & & & rI & & 1.798 & -0.070 & & -0.070 \\
\hline & 594 & 5.082 & -1. & & & & & 2.251 & 80 & & \\
\hline II & 6131.573 & 5.617 & - & -1 . & & YI & & 1.356 & - & & +0.640 \\
\hline & & 5.617 & - & & & 1 & & 0.066 & - & & 20 \\
\hline S & 6145.016 & 5.617 & - & & & YII & & 1.033 & - & & -1.290 \\
\hline & 615 & 5.621 & - & & & III & & & - & & -0.170 \\
\hline & 551 & & -0.300 & & & & & & - & & \\
\hline aI & 558 & 2.525 & +0.210 & +0 & & YII & & 1.839 & - & & -1.130 \\
\hline $\mathrm{aI}$ & & & & & & II & & & - & & 90 \\
\hline aI & $610^{\circ}$ & 1.880 & -0.790 & & & $\mathrm{ZrI}$ & & 0. & - & & 20 \\
\hline $\mathrm{aI}$ & 61 & 1.886 & -0 & & & $\mathrm{rl}$ & & 0.154 & - & & 80 \\
\hline $\mathrm{IJ}$ & 023 & 21 & & & & $\mathrm{ZrI}$ & & & - & & 26 \\
\hline aI & 6161.297 & 2.523 & -1.030 & & & $\mathrm{ZrI}$ & & 0.071 & - & & -1.300 \\
\hline & & & & & & & & & - & & \\
\hline 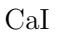 & 55 & 2.521 & & & & $\mathrm{ZrII}$ & & 1. & - & & \\
\hline & 6166 & & -0 & & & & & & - & & \\
\hline & 6169 & 2.523 & -0.540 & & & & & & - & & FS \\
\hline aI & 616 & 2.525 & -0.270 & -0 & -1 & BaII & 98 & 0.604 & - & & IFS \\
\hline & & 2.525 & & & & & & & - & & FS \\
\hline $\mathrm{CaI}$ & 645 & 2.523 & $-1:$ & -1 & -1 & LaII & 90 & 0.320 & - & -1 & HFS \\
\hline aI & & & & & & LaII & & & - & & HFS \\
\hline aI & 6493.781 & 2.521 & +0.140 & & & & & & - & & HFS \\
\hline aI & 6499.650 & 2.523 & -0.590 & -0.818 & & CeII & & 1.044 & - & & +0.150 \\
\hline it & 4899.909 & 1.879 & - & +0.310 & & & & 0.869 & - & & -0.450 \\
\hline TiI & 4926.148 & 0.818 & -2.171 & -2.090 & -2 & CeII & 5975.818 & 1.327 & - & -0 & -0.450 \\
\hline & & & -1.7 & & & & & & - & & -0.480 \\
\hline iI & 5219.702 & 0.021 & -2.260 & -2. & -2 & NdII & 4811.352 & 0.063 & - & & -0.850 \\
\hline 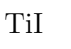 & 5295.776 & 1.067 & -1.633 & -1.590 & & NdII & 5319.810 & 0.550 & - & -0.140 & -0.380 \\
\hline TiI & 5384.629 & 0.826 & -2.910 & -2.770 & -2.910 & NdII & 5740.865 & 1.160 & - & -0.530 & -0.580 \\
\hline . & 5866.451 & 1.066 & -0.840 & -0.790 & & NdII & & 1.280 & - & & -0.700 \\
\hline$T \cdot I$ & 5903.315 & 1.067 & -2.145 & -2.145 & & NdII & 6740.078 & 0.064 & - & -2.100 & -1.876 \\
\hline TiI & 5918.536 & 1.067 & -1.470 & -1.640 & -1.640 & EuII & 6437.640 & 1.319 & - & -0.602 & HFS \\
\hline TiI & 5922.110 & 1.046 & -1.465 & & -1.465 & EuII & 6645.064 & 1.379 & - & -0.162 & HFS \\
\hline TiI & 5937.809 & .066 & -1.890 & -1.940 & -1.94 & & & & & & \\
\hline
\end{tabular}


ajustes satisfatórios com os parâmetros adotados. Para cada elemento, utilizou-se como base as linhas que se ajustavam bem ao espectro solar, e a partir delas foi realizada a síntese decomposta simultânea com as linhas selecionadas. Neste processo, ajustou-se visualmente o nível do contínuo para cada linha, e o valor da abundância elemental foi determinado via minimização de $\chi^{2}$, utilizando a soma entre os valores individuais de $\chi^{2}$ do ajuste na região de cada uma. Um exemplo é mostrado na figura 4.3 , com os valores de $\chi^{2}$ de cada linha e o total, onde a região considerada no cálculo do $\chi^{2}$ é sombreada em verde claro. Este método foi escolhido por tratar simultaneamente de todas as linhas, apresentando uma convergência robusta para o valor da abundância.
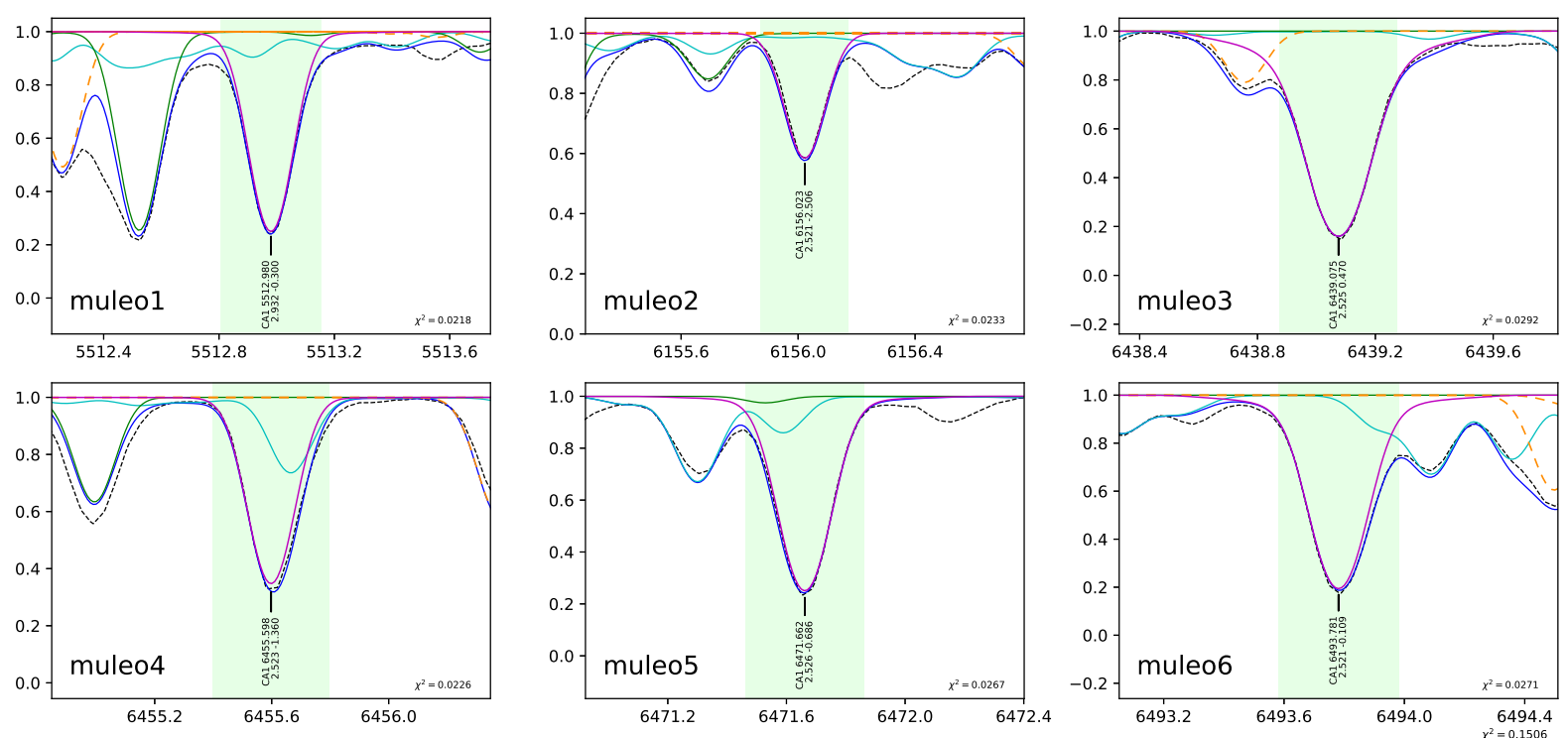

Figura 4.3: Síntese espectral decomposta na determinação da abundância de cálcio da estrela $\mu L e o$. São exibidos os valores de $\chi^{2}$ individuais e total, bem como a região considerada no seu cálculo (sombreada em verde claro).

Os ajustes das linhas espectrais dos elementos nas estrelas de referência são apresentados no apêndice A. As abundâncias elementais finais adotadas para Sol, Arcturus e $\mu L e o$ estão listadas na tabela 4.2. Os parâmetros atmosféricos adotados para Arcturus em Ernandes et al. (2018) e Barbuy et al. (2014) provém da derivação de Meléndez et al. (2003). Os parâmetros adotados para $\mu$ Leo em Barbuy et al. (2015) provém da derivação de Lecureur et al. (2007). 
Tabela 4.2 - Abundâncias elementais adotadas para Sol, Arcturus e $\mu L e o$. As referências utilizadas são 1: Grevesse, Sauval et.al. (1998), 2: Allende-Prieto et.al. (2001), 3: Meléndez et al. (2003), 4: Ramírez Allende-Prieto (2011), 5: Ernandes et al. (2018), 6: Barbuy et al. (2014), 7: MacWilliam et al. (2013), 8: Barbuy et al. (2015), 9: Smith, Ruck (2000), 10: Smith et al. (2013), 11: Gratton, Sneden (1990), 12: Presente trabalho

\begin{tabular}{lccccc}
\hline \hline Elemento & \multicolumn{2}{c}{ Sol } & \multicolumn{2}{c}{ Arcturus } & \multicolumn{2}{c}{$\mu$ Leo } \\
\hline $\mathrm{C}$ & $8.55[1]$ & 8.67 & $-0.08[3]$ & 8.35 & $+0.00[8]$ \\
$\mathrm{N}$ & $7.97[1]$ & 8.21 & $+0.30[3]$ & 8.53 & $+0.56[8]$ \\
$\mathrm{O}$ & $8.77[2]$ & 9.20 & $+0.16[3]$ & 8.67 & $-0.10[8]$ \\
$\mathrm{Na}$ & $6.33[1]$ & 6.44 & $+0.11[4]$ & 6.77 & $+0.44[9]$ \\
$\mathrm{Mg}$ & $7.58[1]$ & 7.95 & $+0.37[4]$ & 7.84 & $+0.26[10]$ \\
$\mathrm{Al}$ & $6.47[1]$ & 6.81 & $+0.34[4]$ & 6.92 & $+0.45[11]$ \\
$\mathrm{Si}$ & $7.55[1]$ & 7.88 & $+0.33[4]$ & 7.72 & $+0.17[11]$ \\
$\mathrm{Ca}$ & $6.36[1]$ & 6.47 & $+0.11[4]$ & 6.46 & $+0.10[12]$ \\
$\mathrm{TiI}$ & $5.02[1]$ & 5.29 & $+0.27[4]$ & 5.08 & $+0.06[9]$ \\
$\mathrm{TiII}$ & $5.02[1]$ & 5.23 & $+0.21[4]$ & 5.08 & $+0.06[9]$ \\
$\mathrm{Mn}$ & $5.39[1]$ & 5.18 & $-0.21[4]$ & 5.40 & $+0.01[11]$ \\
$\mathrm{Cu}$ & $4.21[1]$ & 4.21 & $+0.00[5]$ & 4.46 & $+0.25[12]$ \\
$\mathrm{Zn}$ & $4.60[1]$ & 4.60 & $+0.00[12]$ & 4.60 & $+0.00[12]$ \\
$\mathrm{Sr}$ & $2.90[1]$ & 2.80 & $-0.10[12]$ & 2.82 & $-0.08[12]$ \\
$\mathrm{Y}$ & $2.24[1]$ & 1.94 & $-0.30[6]$ & 1.94 & $-0.30[6]$ \\
$\mathrm{Zr}$ & $2.60[1]$ & 2.32 & $-0.28[7]$ & 2.50 & $-0.10[12]$ \\
$\mathrm{Ba}$ & $2.13[1]$ & 1.78 & $-0.35[12]$ & 2.03 & $-0.10[12]$ \\
$\mathrm{La}$ & $1.22[1]$ & 1.12 & $-0.10[12]$ & 0.82 & $-0.40[12]$ \\
$\mathrm{Ce}$ & $1.55[1]$ & 1.45 & $-0.10[12]$ & 1.30 & $-0.25[12]$ \\
$\mathrm{Nd}$ & $1.50[1]$ & 1.60 & $+0.10[12]$ & 1.40 & $-0.20[12]$ \\
$\mathrm{Eu}$ & $0.51[1]$ & 0.74 & $+0.23[7]$ & 0.41 & $-0.10[12]$ \\
\hline \hline
\end{tabular}




\subsection{Ajuste e derivação das abundâncias}

O ajuste dos espectros sintéticos ao espectro observado foi feito visualmente para terse mais controle na estimativa do nível do contínuo. O processo de determinação é feito sobrepondo-se os espectros observados com os sintéticos em diferentes abundâncias para cada elemento. A convolução dos espectros sintéticos também é ajustada para reproduzir corretamente o perfil da linha espectral a ser medida. O valor da abundância da linha é estimado de acordo com o nível do espectro observado em relação aos espectros sintéticos, como mostrado nos exemplos da figura 4.5 .

Para a derivação das abundâncias de carbono, nitrogênio e oxigênio, devido ao equilíbrio dissociativo entre as moléculas de $\mathrm{C}_{2}, \mathrm{CO}$ e $\mathrm{CN}$, o ajuste foi feito de maneira simultânea para estes elementos, de modo a acompanhar corretamente suas variações interdependentes. Para isto, utilizou-se novamente o reg_analysis para realizar as sínteses decompostas em tempo real, afim de distinguir entre linhas moleculares e atômicas, como exemplificado na Figura 4.4. As abundâncias foram variadas iterativamente neste processo.
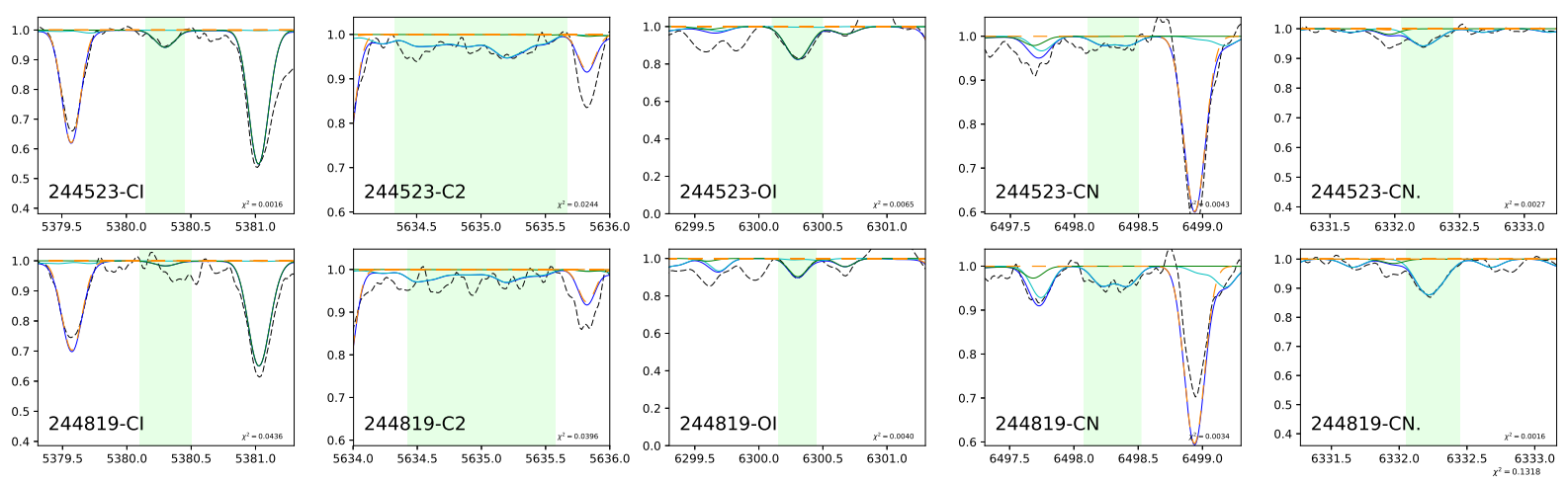

Figura 4.4: Exemplo da derivação do carbono, nitrogênio e oxigênio utilizando o reg_analysis.

\subsubsection{LinePlot}

Para auxiliar na determinação das abundâncias considerando o grande número de linhas espectrais, foi desenvolvido o LinePlot, um software de plotagem em Python 3. O LinePlot toma como entrada um arquivo de parâmetros contendo os nomes dos arquivos dos espectros observados, os espectros sintéticos individuais ou em lista (indica-se que o arquivo é uma lista de outros arquivos por um @ no inicio do campo), a espécie química, o comprimento de onda, intervalo de plotagem, correções no comprimento de onda e no 
fluxo, estilos e cores das curvas, bem como uma opção de suavização do espectro utilizando a função gaussian_filter da biblioteca scipy.

O software formata automaticamente a área de plotagem com base no número de gráficos (tipicamente um quadro por linha espectral), colunas estipuladas, e parâmetros fornecidos. Por meio da edição do arquivo de parâmetros, as figuras podem ser atualizadas com um simples comando de Enter no terminal. O código foi escrito de modo a carregar o mínimo necessário de arquivos entre cada atualização e troca de espectros, e para isso, a estrutura interna de dados se baseia em uma biblioteca de arquivos que os carrega conforme a demanda. A atualização de informações foi desenvolvida de modo a remover e inserir somente elementos necessários na janela de plotagem, de modo a agilizar a execução. Também é possível produzir os gráficos de resíduos via comando no terminal. Um exemplo de arquivo de entrada juntamente com as figuras dos espectros e resíduos é exibido na figura 4.5 


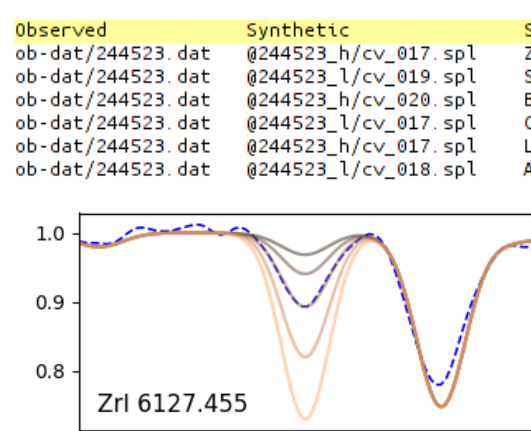

$6126.80 \quad 6127.106127 .406127 .70 \quad 6128.00$

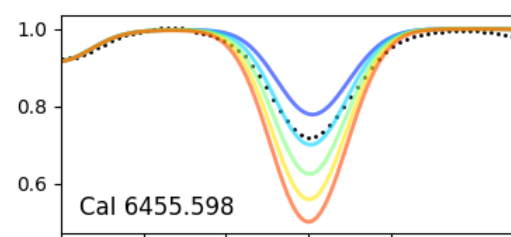

6455.006455 .206455 .406455 .606455 .80
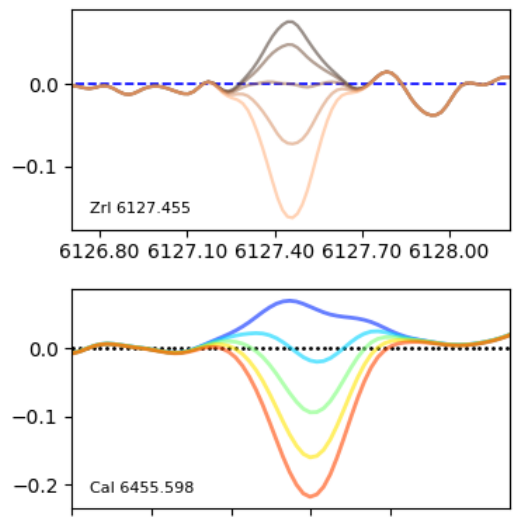

6455.006455 .206455 .406455 .606455 .80

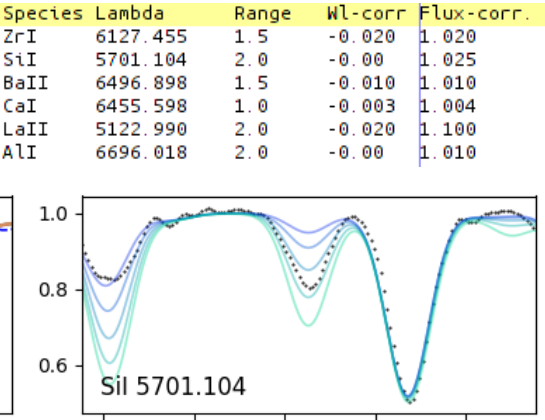

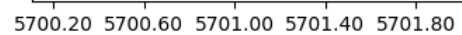

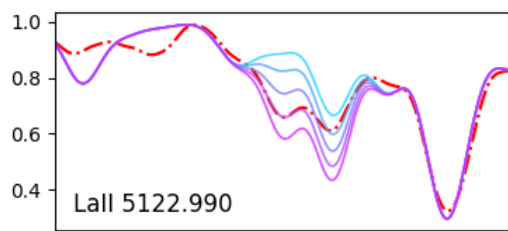

$5122.005122 .40 \quad 5122.80 \quad 5123.20 \quad 5123.60$
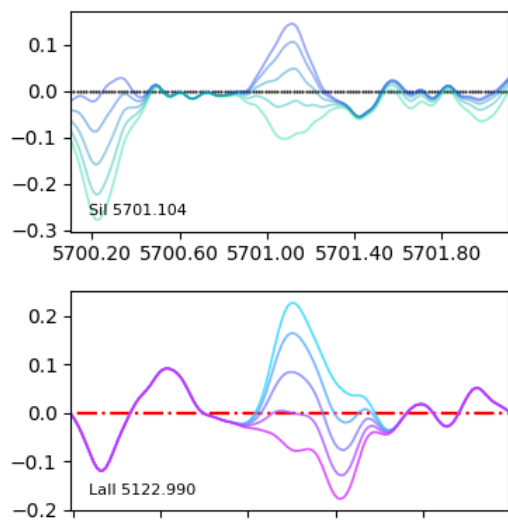

5122.005122 .405122 .805123 .205123 .60

$\begin{array}{llllll}\text { OBstyle } & \text { 0Bwidth } & \text { 0Bsmth } & \text { Smap } & \text { Swidth } & \text { Salph } \\ \text { b-- } & 1.2 & 1.7 & \text { copper } & 1.6 & 0.5 \\ \text { k. } & 1.0 & 1.5 & \text { winter } & 1.2 & 0.4 \\ \text { k-- } & 1.5 & 1.5 & \text { plasma } & 1.2 & 0.6 \\ \text { k. } & 2.0 & 2.8 & \text { jet } & 2.0 & 0.6 \\ \text { r- } & 1.6 & 2.6 & \text { cool } & 1.2 & 0.8 \\ \text { k- } & 1.0 & 2.6 & \text { winter } & 1.2 & 0.7\end{array}$

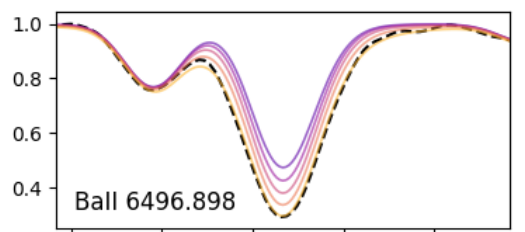

6496.206496 .506496 .806497 .106497 .40

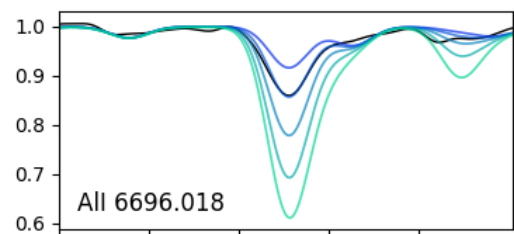

6695.006695 .406695 .806696 .206696 .60
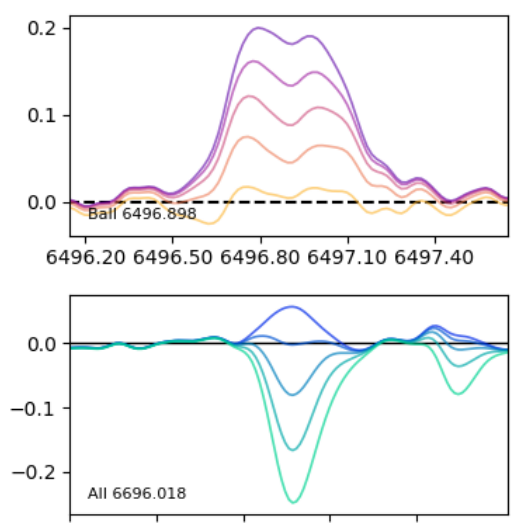

Figura 4.5: Exemplo de utilização do LinePlot. No quadro superior, o arquivo de parâmetros.

No quadro central, a figura com os quadros de cada região de plotagem. No quadro inferior, os gráficos de resíduos correspondentes. 


\subsection{Elementos analisados}

Barbuy et al. (2018) apresenta uma discussão sobre a origem, comportamento e atuais dados observacionais para os elementos analisados no bojo da Galáxia. Uma referência para o padrão das abundâncias elementais no sol é exibida na figura 4.6 .

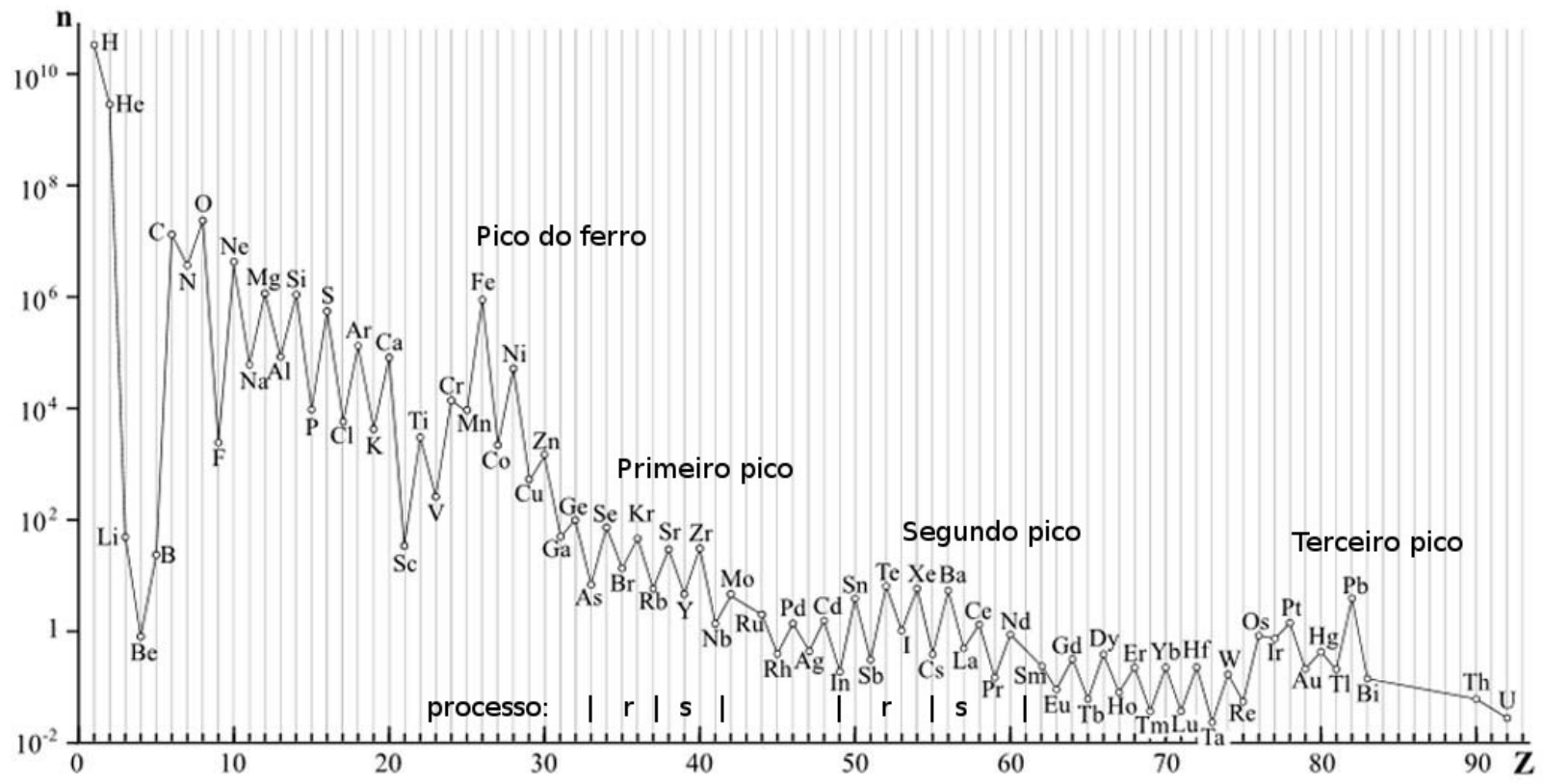

Figura 4.6: Abundâncias químicas dos elementos no sol vs número atômico. São explicitados os picos nas abundâncias e uma referência do processo de captura de nêutrons responsável pela maior parte da nucleossíntese dos elementos de primeiro e segundo pico.

\subsubsection{Elementos leves}

Os elementos leves vêm desempenhando papel importante em separar múltiplas populações estelares em aglomerados globulares, principalmente via as conhecidas anti-correlações $\mathrm{Na}-\mathrm{O}$ e Mg-Al (Carretta et al., 2009). Correlações N-C (bem como índices espectrais CN$\mathrm{CH})$ e anti-correlações $\mathrm{Na}-\mathrm{C}$ também são usadas para identificar padrões em múltiplas populações (como por exemplo em Schiavon et al. 2017 e Dias et al. 2018).

\subsubsection{Carbono}

Na presente análise, as estimativas foram feitas com base na linha atômica em 5380.325 $\AA$ (disponível apenas nos espectros do UVES), e pela banda molecular de $\operatorname{Swan} \mathrm{C}_{2}(0,1)$ 
em $5635.5 \AA$, ambas detectáveis porém fracas na maioria dos espectros, permitindo apenas uma estimativa de limite superior. Um exemplo do ajuste é exibido na figura 4.7.
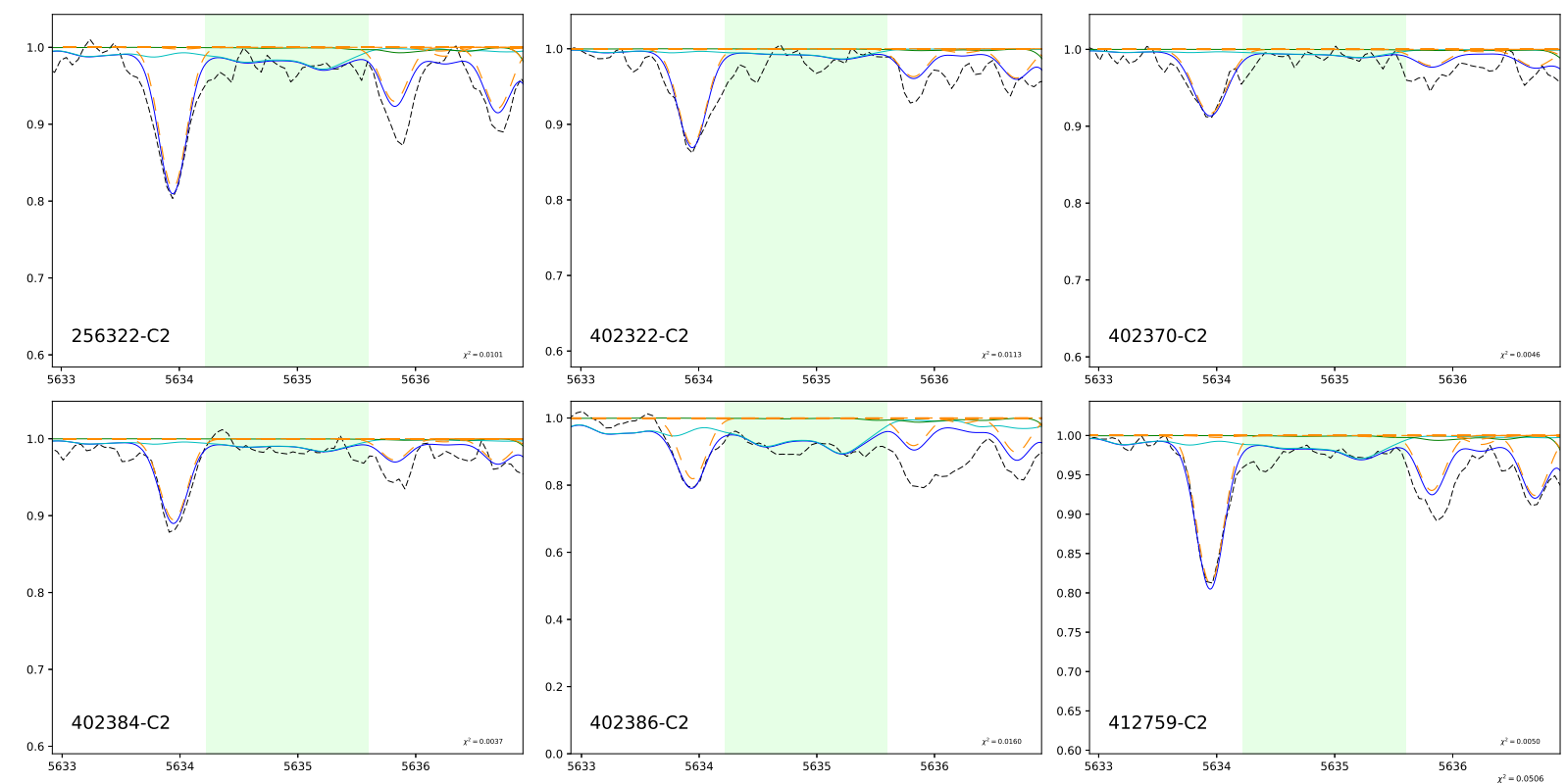

Figura 4.7: Estimativa da abundância de carbono e nitrogênio utilizando as bandas moleculares de $\mathrm{C}_{2}$ em $5635.5 \AA$ e CN em $5634.5 \AA$ em 6 estrelas da amostra GI2012.

\subsubsection{Nitrogênio}

Para a amostra UV2016 foi utilizada a banda CN(5, 1) em 6332.16 A. Para a amostra GI2012, foi utilizada a banda de CN em $5634.5 \AA$, ao lado da banda de $\mathrm{C}_{2}$. Na amostra GI2016, foi utilizada a banda de CN $(5,1)$ em $6332.16 \AA$ e CN em $5634.5 \AA$.

\subsubsection{Sódio e Alumínio}

Nesta análise, as linhas de Na apresentam boa qualidade no espectros observados e puderam ser bem ajustadas. As duas linhas de Al estavam disponíveis somente nos espectros UVES, com boa qualidade. A linha em 6698.66 A apresenta um leve blend molecular na asa esquerda. Para o Na, foi contabilizada a estrutura hiperfina para as linhas em 6154.22 $\AA$ e $6160.74 \AA$.

\subsubsection{Elementos- $\alpha$}

Estes elementos, principais produtos das supernovas de colapso de núcleo (em geral supernovas de Tipo II), são importantes traçadores de populações estelares onde houve 
rápido enriquecimento inicial por estas, e uma subsequente cessão da formação estelar. Os produtos das supernovas de Tipo Ia (tipicamente elementos do pico do ferro) que poluíram o meio mais tardiamente devido ao longo tempo de evolução de suas progenitoras (em comparação às progenitoras de supernovas de colapso de núcleo) não contribuiu para as abundâncias observadas devido a uma rápida rarefação do gás nestas regiões, que impediu o processo de formação de novas estrelas. Desta forma, uma razão $[\alpha / \mathrm{Fe}]$ elevada indica uma população estelar fruto de um predominante enriquecimento inicial por supernovas de colapso de núcleo, e portanto, mais antiga.

\subsubsection{Oxigênio}

Nesta análise foi considerada somente a linha em $6300.3 \AA$, que dependendo das condições de observação e velocidade radial da estrela, pode apresentar a linha telúrica em emissão ocultando-a completamente, ou linhas telúricas em absorção contaminando-a. No caso, só foi possível utilizar duas das exposições da amostra do UVES, onde a linha telúrica em emissão se apresentava deslocada por conta do movimento terrestre combinado à velocidade radial das estrelas, e linhas telúricas em absorção não contaminavam esta linha estelar do oxigênio.

\subsubsection{Magnésio}

Nesta análise não foram consideradas as linhas do tripleto do Mg I por estas não serem adequadas para a análise em alta resolução.As três linhas do Mg selecionadas, apresentadas na tabela 4.1, apresentavam muito boa qualidade nos espectros analisados e foi possível sua medição em todas as estrelas onde estas se apresentavam disponíveis.

\subsubsection{Silício e cálcio}

O grande número de linhas utilizadas nesta análise proporciona derivações de boa confiabilidade, sendo que a grande maioria das linhas se apresentavam com perfil muito bem conservado e de fácil ajuste, de modo que o espalhamento linha-a-linha se manteve baixo, como é possível notar nos erros apresentados mais adiante no capítulo 5. 


\subsubsection{Titânio}

Na presente análise foram consideradas 20 linhas de Ti na amostra UV2016, 7 linhas na amostra GI2012 e 4 linhas na amostra GI2016, todas com boa qualidade, com exceção da linha em $5384.63 \AA$ que foi medida somente na estrela 234816 da amostra do UVES.

\subsubsection{Elementos do pico do ferro}

Como apresentado em Barbuy et al. (2018), os elementos do pico do ferro são separados entre o baixo pico do ferro (do Sc ao Fe, produzidos em queima explosiva de $\mathrm{O}$ e Si)e alto pico do ferro (do Co ao Ge, produzidos principalmente pelo processo-s fraco e por alpharich freezeout). O processo s-fraco é responsável pela nucleossíntese de elementos que vão do pico do ferro até o estrôncio e ítrio, que ocorre no final da queima de He e C em estrelas massivas por meio de captura de nêutrons por elementos do grupo do Fe. O alpha-rich freezeout (congelamento rico em $\alpha$ ) é um fenômeno que ocorre em supernovas de colapso de núcleo, onde a onda de choque causada pela matéria colapsando no núcleo da estrela se expande em altas temperaturas, suficientes para romper os núcleos principalmente de Si em partículas- $\alpha$, de modo que a rápida expansão e resfriamento da matéria forme núcleos pesados, porém com uma grande quantidade de partículas- $\alpha$ restando sem recombinar, resultando em um 'congelamento' das abundâncias.

\subsubsection{Manganês}

Para todas as linhas analisadas, foi contabilizada a estrutura hiperfina das linhas de Mn, e um exemplo do ajuste das linhas nas estrelas de referência é exibido na figura A.1.

\subsubsection{Cobre}

Para todas as linhas de $\mathrm{Cu}$ analisadas foi contabilizada a estrutura hiperfina. A linha em 5105.54 A possui blends moleculares nas asas, porém a maior parte do perfil é conservado, conforme o ajuste das linhas nas estrelas de referência exibido na figura A.2.

\subsubsection{Zinco}

A linha de Zn em 4810.53 Å, disponível apenas nos espectros UVES, é limpa e apresenta boa qualidade. A linha em $6362.35 \AA$, usada em todas as amostras, apresenta um blend 
com linhas moleculares, que podem subestimar os valores reais.

\subsubsection{Elementos pesados}

Os elementos pesados são produzidos por processos de captura de nêutrons por núcleos mais leves, o que os caracteriza como elementos secundários, ou seja, que dependem da nucleossíntese prévia de núcleos mais leves. Os dois principais processos conhecidos são o processo-s (s de slow, captura lenta de nêutrons), subdividido em processo-s fraco, processos principal e processo-s forte, e o processo-r (r de rapid, captura rápida de nêutrons), onde suas origens não são tão bem estabelecidas como no processo-s.

A análise de elementos pesados em estrelas pobres em metais não é uma tarefa fácil, visto que a maior parte das linhas se encontra nas porções mais azuis do espectro óptico e no ultravioleta, dificultando a obtenção de dados de boa qualidade. Além disso, as linhas disponíveis nas faixas espectrais analisadas são muito fracas e/ou apresentam blends com outras linhas espectrais. Por conta disso, foi realizada a seleção e cuidadosa calibração citada na seção 4.3 , tornando possível uma análise que contabiliza a influência dos blends e melhora a confiabilidade das abundâncias derivadas.

\subsubsection{Elementos do primeiro pico - estrôncio, ítrio e zircônio}

Os elementos Sr, Y e Zr são principalmente produzidos pelo processo-s, com possíveis contribuições do processo-r.

Para o Sr, as duas linhas disponíveis nos espectros do UVES são muito fracas e aparecem em blends com linhas mais fortes (como mostrado na figura A.3), de modo que a presente análise deste elemento representa apenas uma estimativa para os valores de suas abundâncias. O Y e o Zr já apresentam um maior número de linhas limpas e mais fortes, sendo estas mais confiáveis (um exemplo de linhas de Zr é exibido na figura A.4).

\subsubsection{Elementos do segundo pico - bário, lantânio, cério e neodímio}

Os elementos $\mathrm{Ba}$, La, Ce e Nd são produzidos majoritariamente pelo processo-s, porém também passíveis de contribuição por processo-r. Para traçar a origem nucleossintética destes elementos, é necessária uma comparação entre estes e o elemento de processo-r puro Eu. 
As linhas de Ba e La utilizadas na análise levam em conta a estrutura hiperfina e principalmente as linhas de Ba apresentam excelente qualidade e bom ajuste nas estrelas de referência (como mostra a figura A.5). As linhas de La são mais fracas e se situam em regiões de maior aglutinação de linhas, porém se ajustam muito bem aos espectros das estrelas de referência, como exibido na figura A.6. Para as linhas de Ce e Nd não foi contabilizada a estrutura hiperfina.

\subsubsection{Európio}

O Eu pode ser utilizado como um traçador do processo-r nas estrelas, sendo aqui utilizado em comparação com os outros elementos pesados afim de identificar o enriquecimento por processo-s, onde um dos indicadores para caracterizar tal enriquecimento é uma abundância do elemento em questão maior que a abundância de Eu.

Nas linhas utilizadas nesta análise, é contabilizada a estrutura hiperfina. Na linha em 6437.6 A (figura A.7), é possível notar um blend com uma linha atômica no lado direito da linha para o sol e $\mu$ Leo, porém esta não está presente em Arcturus, provavelmente devido à metalicidade mais baixa desta, o que a habilitou para a análise considerando a baixa metalicidade das amostras.

\subsubsection{Abundâncias linha-a-linha}

A seguir são apresentadas as tabelas de abundâncias derivadas das linhas espectrais para cada amostra. As abundâncias para a amostra UV2016 são apresentadas na tabela 4.3, a amostra GI2012 é exibida na tabela 4.4, e finalmente a amostra GI2016 é exibida na tabela 4.5

O cálculo das abundâncias finais para cada elemento foi realizado utilizando a mediana de Harrell-Davis, afim de dar mais importância às linhas com abundâncias próximas, minimizando o efeito de abundâncias muito desviantes. Pra tal, foi utilizada a função hdquantiles do pacote SciPy.

\subsection{Análise de erros}

Os erros nas abundâncias elementais podem ser estimados pelo impacto que os erros nos parâmetros atmosféricos produzem na derivação das abundâncias linha-a-linha, visto 
Tabela 4.3 - Abundâncias linha-a-linha dos elementos analisados na amostra UV2016.

\begin{tabular}{|c|c|c|c|c|c|c|c|c|c|c|c|c|c|c|c|}
\hline Ion & $\lambda$ & 4816 & 4523 & 44819 & 256289 & 2322 & 402370 & Ion & $\lambda$ & 34816 & 244523 & 244819 & 256289 & 402322 & 402370 \\
\hline C I & 80.32 & .00 & .20 & 0.10 & 0.50 & +0.00 & 000 & i I & 37.809 & 70 & 40 & & +0.05 & +0.00 & 0.10 \\
\hline & 0.304 & - & - & & & & & & 526 & & & & & .00 & 0.20 \\
\hline I & 33 & 0.50 & +0.00 & & & & & & & & & & & & \\
\hline & & & & & & & & & & & & & & & \\
\hline & & & & & & & & & & & & & & & \\
\hline a I & 4.226 & & & & & & & & & & & & & 0.30 & -0.30 \\
\hline a I & 60.747 & 0.50 & & & & & & & 09 & & & & & 05 & - \\
\hline $\mathrm{I}$ & 05 & 0.55 & & & & & & & & & & - & & -0.00 & +0.30 \\
\hline I & & 0.60 & & & & & & & & & & 30 & & & 0.30 \\
\hline g I & & & & & & & & & & & & & & +0.20 & 00 \\
\hline 1 & & & & & & & & & & & & & & & 35 \\
\hline I & 698 & $0.7 \mathrm{C}$ & & & & & & & & & & & & & .35 \\
\hline i I & 5645. & 0.55 & & & & +0 & & & 70 & & & & & & 0.35 \\
\hline & 566 & & & & & & & & & & & & & & 35 \\
\hline & 77 & 60 & & & & - & & & & & & & & & -0.30 \\
\hline & & & & & & +0.25 & & & & & & & & & \\
\hline 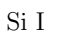 & & & & & & & & & & & & & & & -0.35 \\
\hline I & & 0.5 & +0 & & & + & & $1 \mathrm{I}$ & & & & & & - & +0.05 \\
\hline & & 066 & - & - & - & - & - & & & & & 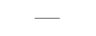 & & - & - \\
\hline I & 594 & 0.5 & +0 & +0 & +0.10 & +0 & & & & & & 70.10 & & - & +0.20 \\
\hline & & 60 & & & 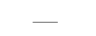 & - & & & & & - & - & & - & - \\
\hline & & & & & 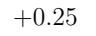 & +0.15 & & & & & & + & & - & +0.35 \\
\hline & & & & & & & & & & & & & & -0.15 & -0.00 \\
\hline & & & & & & & & & & & & & & & .05 \\
\hline & & & & & & & & & & & & & - & & 30 \\
\hline & 49 & 0 & & & & & & & & & & & +0.05 & & - \\
\hline & & & & & & & & & & & & & & & 40 \\
\hline & & & & & & & & & & & & & & & .60 \\
\hline & & & & & & & & & & & & & +0.00 & & 65 \\
\hline & & & & & & & & & & & & & & & 65 \\
\hline & & & & & & & & & & & & & & - & 65 \\
\hline & & & & & & & & & & & & & & & - \\
\hline & & & & & & & & & & & & & & & -0.40 \\
\hline & & & & & & & & & & & & & & & .30 \\
\hline & & & & & & & & & & & & & & & 30 \\
\hline & & & & & & & & & & & & & & & 35 \\
\hline & & & & & & & & & & & & & & & 10 \\
\hline & & & & & & & & & & & & +0 & & & +0.25 \\
\hline & & & & & & & & & & & & & & & +0.30 \\
\hline & & & & & & & & & & & & +0 & & & +0.45 \\
\hline & & & & & & +0 & & & & & & & & & +0.30 \\
\hline & & - & & & & & & & & & & - & & & - \\
\hline & & & & & & & & & & & & & & & +0.25 \\
\hline 111 & 504 & 000 & +0 & & +0.20 & -0.05 & +0.1 & & & +0.30 & & +0.30 & 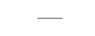 & 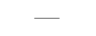 & +0.60 \\
\hline & & & & & -0.10 & -0 & 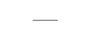 & & & +0.30 & & - & - & +0.00 & - \\
\hline & & & 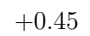 & & & +0 & +0 & & & & & + & +0 & +0.30 & +0.15 \\
\hline & & & & & 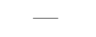 & 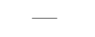 & & & & +0 & & & & - & +0.35 \\
\hline & & & & & & -0.05 & +0 . & & & - & & 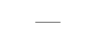 & - & - & - \\
\hline & & & & & & - & & & & & & & & & 0.35 \\
\hline Ti I & & 0.6 & +0 & +0 & & +0.00 & +0 & & 40 & +0.65 & & +0.30 & +0.35 & -0.30 & +0.35 \\
\hline Ti I & 5922.110 & 0.70 & +0.30 & +0.25 & -0.00 & -0.10 & +0.20 & $\mathrm{Eu} \mathrm{II}$ & 6645.064 & +0.70 & +0.60 & +0.40 & +0.45 & +0.35 & +0.45 \\
\hline
\end{tabular}


Tabela 4.4 - Abundâncias linha-a-linha dos elementos analisados na amostra GI2012.

\begin{tabular}{|c|c|c|c|c|c|c|c|c|c|c|c|c|c|c|c|}
\hline Ion & $\lambda$ & 78126 & 89531 & 234816 & 244523 & 244819 & 244853 & 256289 & 256322 & 402322 & 402370 & 402384 & 402386 & 412759 & 554709 \\
\hline $\mathrm{Na} \mathrm{I}$ & 5682.633 & - & +0.25 & +0.30 & -0.05 & +0.60 & +0.30 & -0.15 & +0.20 & +0.60 & -0.30 & +0.60 & +0.60 & +0.00 & +0.10 \\
\hline $\mathrm{Na} \mathrm{I}$ & 5688.193 & - & +0.30 & +0.30 & +0.00 & +0.45 & +0.30 & -0.05 & +0.05 & +0.50 & -0.30 & +0.60 & +0.30 & +0.05 & +0.10 \\
\hline $\mathrm{Na} \mathrm{I}$ & 5688.205 & - & +0.30 & +0.30 & +0.00 & +0.45 & +0.30 & -0.05 & +0.00 & +0.50 & -0.30 & +0.60 & +0.30 & +0.05 & +0.10 \\
\hline Mg I & 5711.088 & - & +0.35 & +0.30 & +0.60 & +0.40 & +0.30 & +0.45 & +0.30 & +0.55 & +0.15 & +0.30 & +0.05 & +0.35 & +0.50 \\
\hline Si I & 5665.555 & - & +0.45 & +0.30 & +0.45 & +0.50 & +0.30 & +0.30 & +0.35 & +0.50 & +0.15 & +0.60 & +0.60 & +0.60 & +0.60 \\
\hline Si I & 5666.677 & - & +0.45 & - & - & - & +0.30 & +0.30 & +0.60 & +0.30 & +0.30 & +0.60 & - & +0.60 & +0.65 \\
\hline Si I & 5690.425 & - & +0.35 & +0.35 & +0.60 & +0.40 & +0.35 & +0.30 & +0.40 & +0.30 & +0.10 & +0.50 & +0.50 & +0.60 & +0.70 \\
\hline Si I & 5701.104 & - & +0.45 & +0.30 & +0.40 & +0.55 & +0.45 & +0.30 & +0.55 & +0.40 & +0.20 & +0.50 & +0.60 & +0.60 & +0.60 \\
\hline Si I & 5772.146 & - & +0.35 & +0.40 & +0.60 & +0.60 & +0.35 & +0.30 & +0.60 & +0.60 & +0.20 & +0.60 & +0.60 & +0.60 & +0.70 \\
\hline Si I & 5793.073 & - & +0.40 & +0.35 & +0.55 & +0.60 & +0.40 & +0.35 & +0.60 & +0.60 & +0.20 & +0.70 & +0.60 & +0.55 & +0.65 \\
\hline Si I & 5948.541 & +0.30 & +0.30 & +0.10 & +0.20 & +0.30 & +0.10 & +0.00 & +0.30 & +0.30 & +0.00 & +0.25 & - & +0.30 & +0.60 \\
\hline Si I & 6131.573 & +0.45 & - & - & +0.60 & - & +0.30 & +0.35 & +0.35 & +0.30 & +0.25 & +0.55 & - & +0.60 & - \\
\hline Si I & 6131.852 & +0.45 & - & +0.30 & +0.45 & - & +0.45 & +0.30 & +0.35 & +0.30 & +0.25 & +0.55 & +0.00 & +0.60 & - \\
\hline Si I & 6145.016 & - & - & - & - & - & - & - & - & - & - & - & +0.00 & +0.00 & - \\
\hline $\mathrm{Ca} \mathrm{I}$ & 5867.562 & +0.30 & +0.25 & - & +0.30 & - & +0.30 & - & - & +0.30 & +0.15 & +0.45 & +0.60 & +0.25 & +0.50 \\
\hline $\mathrm{Ca} \mathrm{I}$ & 6102.723 & +0.30 & +0.30 & +0.15 & +0.15 & +0.30 & +0.30 & +0.30 & -0.25 & +0.30 & +0.20 & +0.35 & +0.60 & +0.25 & +0.30 \\
\hline $\mathrm{Ca} \mathrm{I}$ & 6122.217 & +0.35 & +0.25 & +0.15 & +0.30 & +0.30 & +0.30 & +0.30 & -0.20 & +0.00 & +0.10 & +0.30 & +0.60 & +0.15 & +0.30 \\
\hline Ti I & 5866.451 & +0.00 & +0.20 & +0.05 & +0.20 & +0.30 & +0.00 & +0.00 & -0.30 & +0.30 & -0.30 & +0.00 & & 30 & +0.15 \\
\hline Ti I & 5903.315 & +0.00 & +0.10 & +0.15 & +0.20 & - & - & - & +0.05 & +0.30 & - & +0.30 & +0.05 & +0.15 & +0.45 \\
\hline Ti I & 5918.536 & +0.00 & +0.00 & +0.00 & +0.05 & +0.20 & +0.00 & +0.00 & -0.05 & +0.25 & +0.00 & +0.20 & +0.05 & +0.20 & +0.15 \\
\hline Ti I & 5922.110 & +0.00 & +0.10 & +0.10 & +0.25 & +0.30 & +0.00 & +0.10 & -0.05 & +0.30 & - & +0.20 & +0.00 & +0.20 & +0.30 \\
\hline Ti I & 5937.809 & +0.10 & +0.30 & - & - & +0.20 & - & +0.15 & +0.00 & +0.30 & +0.05 & - & +0.15 & +0.20 & - \\
\hline Ti I & 6064.626 & +0.10 & +0.30 & +0.15 & +0.30 & +0.30 & +0.00 & +0.05 & +0.05 & +0.30 & +0.10 & +0.30 & +0.30 & +0.20 & +0.30 \\
\hline Ti I & 6126.216 & +0.00 & +0.30 & +0.30 & +0.30 & +0.30 & +0.10 & +0.05 & +0.00 & +0.30 & +0.00 & +0.25 & +0.20 & +0.20 & +0.30 \\
\hline Mn I & 6013.510 & +0.10 & +0.00 & -0.10 & -0.05 & -0.30 & -0.30 & -0.30 & -0.05 & -0.30 & -0.45 & -0.30 & +0.00 & -0.30 & -0.20 \\
\hline Mn I & 6016.670 & +0.00 & -0.05 & -0.10 & -0.25 & -0.30 & -0.30 & -0.35 & -0.10 & -0.30 & -0.45 & -0.30 & +0.00 & -0.30 & -0.25 \\
\hline Mn I & 6021.800 & +0.20 & -0.10 & -0.30 & -0.30 & -0.40 & -0.30 & -0.30 & -0.30 & -0.30 & -0.60 & -0.30 & -0.30 & -0.30 & -0.20 \\
\hline $\mathrm{Cu} \mathrm{I}$ & 5782.126 & - & +0.00 & -0.05 & +0.00 & +0.00 & -0.15 & -0.30 & +0.00 & +0.00 & -0.30 & +0.00 & +0.00 & +0.10 & +0.30 \\
\hline Y II & 5728.887 & - & - & +0.00 & +0.35 & +0.70 & - & +0.00 & +0.00 & +0.60 & +0.05 & +0.40 & - & +0.30 & +0.55 \\
\hline Zr I & 6127.455 & +0.00 & +0.00 & +0.00 & +0.30 & +0.75 & +0.00 & +0.40 & -0.20 & +0.50 & +0.00 & - & +0.15 & +0.05 & +0.60 \\
\hline Zr I & 6134.555 & -0.10 & -0.20 & - & +0.30 & +0.60 & - & +0.30 & -0.30 & +0.50 & +0.00 & - & +0.15 & +0.00 & +0.55 \\
\hline Zr I & 6143.200 & - & - & +0.05 & - & - & - & - & - & +0.45 & - & +0.40 & +0.05 & - & +0.60 \\
\hline Ba II & 5853.675 & -0.55 & +0.00 & +0.00 & +1.20 & +0.00 & +0.20 & +0.65 & -0.30 & +0.60 & +0.00 & +0.30 & -0.25 & +0.55 & +0.65 \\
\hline Ba II & 6141.713 & -0.45 & - & +0.00 & - & - & - & - & - & +0.30 & -0.15 & +0.25 & -0.25 & +0.25 & +0.55 \\
\hline Ce II & 5768.891 & - & +0.30 & +0.20 & - & - & +0.20 & - & - & +0.45 & - & - & +0.40 & - & +0.60 \\
\hline Ce II & 5975.818 & - & +0.60 & - & - & - & - & - & - & - & - & - & - & +0.60 & +0.60 \\
\hline Ce II & 6043.373 & +0.00 & -0.20 & - & +1.00 & - & - & - & - & +0.50 & - & +0.30 & +0.30 & - & +0.60 \\
\hline Nd II & 5740.865 & - & +0.15 & +0.30 & +0.85 & - & - & +0.00 & +0.30 & +0.30 & +0.30 & +0.60 & +0.20 & +0.30 & +0.60 \\
\hline $\mathrm{Nd} \mathrm{II}$ & 5842.370 & +0.00 & +0.20 & - & +1.00 & - & - & - & - & - & - & +0.60 & - & - & - \\
\hline
\end{tabular}


Tabela 4.5 - Abundâncias linha-a-linha dos elementos analisados na amostra GI2016.

\begin{tabular}{|c|c|c|c|c|c|c|c|}
\hline Ion & $\lambda$ & 244551 & 244555 & 256298 & 402371 & 402508 & 402608 \\
\hline $\mathrm{Na} \mathrm{I}$ & 5682.633 & +0.15 & +0.05 & +0.25 & -0.30 & +0.40 & -0.15 \\
\hline $\mathrm{Na} \mathrm{I}$ & 5688.193 & +0.05 & +0.15 & +0.35 & -0.30 & +0.50 & -0.20 \\
\hline $\mathrm{Na} \mathrm{I}$ & 5688.205 & +0.05 & +0.15 & +0.35 & -0.30 & +0.50 & -0.20 \\
\hline $\mathrm{Na} \mathrm{I}$ & 6154.226 & +0.10 & +0.15 & +0.35 & -0.05 & +0.45 & +0.00 \\
\hline $\mathrm{Na} \mathrm{I}$ & 6160.747 & +0.15 & +0.30 & +0.35 & -0.05 & +0.45 & -0.15 \\
\hline Mg I & 5711.088 & +0.50 & +0.30 & +0.30 & +0.30 & +0.35 & +0.35 \\
\hline Mg I & 6318.720 & +0.60 & +0.50 & +0.35 & +0.35 & +0.60 & +0.45 \\
\hline Si I & 5645.613 & +0.30 & +0.00 & +0.35 & +0.50 & +0.35 & +0.40 \\
\hline Si I & 5665.555 & +0.30 & +0.50 & +0.25 & +0.15 & +0.30 & - \\
\hline Si I & 5666.677 & +0.30 & +0.35 & +0.20 & - & - & - \\
\hline Si I & 5684.484 & +0.30 & +0.30 & +0.30 & +0.30 & +0.25 & +0.15 \\
\hline Si I & 5690.425 & +0.25 & +0.25 & +0.20 & +0.20 & +0.10 & +0.00 \\
\hline Si I & 5701.104 & +0.30 & +0.35 & +0.20 & +0.50 & +0.40 & +0.30 \\
\hline Si I & 5772.146 & - & +0.40 & +0.30 & +0.30 & +0.50 & +0.35 \\
\hline Si I & 6131.573 & +0.30 & +0.35 & +0.35 & +0.30 & +0.30 & +0.30 \\
\hline Si I & 6131.852 & +0.40 & +0.35 & +0.35 & +0.30 & - & +0.30 \\
\hline Si I & 6145.016 & +0.30 & +0.30 & +0.25 & +0.40 & +0.35 & - \\
\hline Si I & 6155.134 & +0.30 & +0.25 & +0.30 & +0.30 & +0.35 & +0.00 \\
\hline Ca I & 6122.217 & +0.25 & +0.25 & +0.20 & +0.20 & +0.20 & +0.00 \\
\hline Ca I & 6156.023 & +0.30 & +0.30 & - & - & - & - \\
\hline Ca I & 6161.297 & +0.25 & +0.20 & +0.20 & +0.15 & +0.25 & +0.25 \\
\hline Ca I & 6162.173 & +0.25 & +0.20 & +0.05 & +0.20 & + & +0.15 \\
\hline Ca I & 6163.755 & +0.25 & +0.30 & +0.30 & +0.15 & +0.30 & +0.30 \\
\hline Ca I & 6166.439 & +0.30 & +0.20 & +0.10 & +0.30 & +0.15 & +0.30 \\
\hline Ca I & 6169.042 & +0.30 & +0.30 & +0.30 & +0.15 & +0.30 & +0.15 \\
\hline Ca I & 6169.563 & +0.20 & +0.15 & +0.30 & +0.15 & +0.20 & +0.15 \\
\hline Ca I & 6439.075 & +0.30 & +0.30 & +0.25 & +0.30 & +0.25 & +0.30 \\
\hline Ca I & 6455.598 & +0.20 & +0.15 & +0.00 & +0.05 & +0.10 & +0.30 \\
\hline Ca I & 6471.662 & +0.25 & +0.20 & +0.15 & +0.10 & +0.15 & +0.30 \\
\hline Ca I & 6493.781 & +0.30 & +0.25 & +0.30 & +0.30 & +0.30 & +0.30 \\
\hline Ca I & 6499.650 & +0.30 & +0.30 & +0.10 & +0.00 & +0.30 & +0.30 \\
\hline Ti I & 6126.216 & +0.15 & +0.25 & +0.30 & +0.30 & +0.20 & +0.40 \\
\hline Ti I & 6312.236 & +0.15 & +0.25 & +0.15 & - & +0.30 & - \\
\hline Ti I & 6336.099 & +0.15 & +0.30 & +0.30 & +0.30 & - & +0.30 \\
\hline Ti I & 6554.223 & +0.15 & +0.30 & +0.25 & - & -0.25 & +0.30 \\
\hline $\mathrm{Cu} \mathrm{I}$ & 5782.126 & -0.30 & -0.20 & +0.05 & +0.00 & +0.05 & +0.00 \\
\hline Zn I & 6362.350 & +0.00 & +0.25 & - & +0.35 & +0.30 & +0.60 \\
\hline Y II & 5728.887 & - & +0.40 & +0.70 & +0.60 & +0.35 & +0.30 \\
\hline Y I & 6435.005 & +0.15 & +0.30 & +0.30 & - & - & - \\
\hline Zr I & 6127.455 & +0.30 & +0.30 & +0.55 & +0.30 & +0.30 & - \\
\hline Zr I & 6134.555 & - & - & +0.40 & +0.35 & +0.35 & - \\
\hline Zr I & 6143.200 & +0.30 & +0.35 & +0.35 & +0.50 & +0.40 & +0.60 \\
\hline Ba II & 5853.675 & -0.05 & +0.00 & +0.05 & +0.35 & -0.20 & -0.30 \\
\hline Ba II & 6141.713 & +0.00 & +0.15 & +0.05 & +0.60 & -0.20 & -0.10 \\
\hline La II & 6262.300 & -0.15 & +0.00 & +0.30 & +0.30 & +0.00 & +0.30 \\
\hline Nd II & 5740.865 & +0.30 & - & - & - & +0.00 & - \\
\hline $\mathrm{Eu}$ II & 6437.640 & - & +0.45 & +0.45 & - & - & - \\
\hline Eu II & 6645.064 & +0.35 & +0.20 & +0.45 & +0.30 & +0.35 & +0.30 \\
\hline
\end{tabular}


Tabela 4.6 - Faixas da escala de calibração para os erros nas abundâncias em função dos erros nos parâmetros atmosféricos e estrelas utilizadas para cada faixa de temperatura e gravidade.

\begin{tabular}{|c|c|c|c|c|}
\hline \multirow{2}{*}{$\begin{array}{l}\text { Parâmetro } \\
\mathrm{T}_{\text {eff }}\end{array}$} & \multirow[b]{2}{*}{$4000-4250$} & \multicolumn{2}{|c|}{ Faixas } & \multirow[b]{2}{*}{$4750-5000$} \\
\hline & & $4250-4500$ & $4500-4750$ & \\
\hline $\log g$ & $0.75-1.25$ & $1.25-1.75$ & $1.75-2.25$ & $2.25-2.75$ \\
\hline vt & $0.8-1.1$ & $1.1-1.4$ & $1.4-1.7$ & $1.7-2.0$ \\
\hline referência & 402386 & 234816 & 554709 & 402608 \\
\hline
\end{tabular}

que o perfil e força das linhas é dependente da temperatura e pressão do ambiente físico da fotosfera.

Na estimativa do impacto de cada parâmetro atmosférico nas abundâncias derivadas, foi criada uma escala de calibração da amostra para estimar a variação da abundância em função da variação de cada parâmetro em faixas de temperatura, gravidade e velocidade de micro-turbulência. Assim, os erros nas abundâncias de cada elemento para cada estrela podem ser calculados diretamente com base nos erros dos parâmetros determinados para cada uma, e na dispersão das abundâncias linha-a-linha.

\subsubsection{Escala de calibração da variação das abundâncias}

Para efetuar a calibração, foram selecionadas quatro estrelas das amostras do GIRAFFE que cobrissem de maneira razoavelmente uniforme o espaço amostral de temperaturas e gravidades. Para a velocidade de micro-turbulência, as estrelas selecionadas cobriam uma faixa mais limitada do espaço amostral, portanto foi feita uma extrapolação para as faixas não cobertas. As estrelas foram selecionadas também de modo que o valor de sua metalicidade não desviasse em mais de 0.2 do valor estabelecido de $[\mathrm{Fe} / \mathrm{H}]=-1.0$. Na tabela 4.6 são exibidas as faixas de parâmetros e as estrelas selecionadas para compor a escala de calibração.

Como o objetivo desta análise de erros é determinar apenas as variações nas abundâncias, estas foram fixadas nos valores solares para cada estrela e realizada a síntese espectral com os parâmetros originais de cada uma para que esta fosse usada como um espectro de referência, de modo que todos os elementos disponíveis na amostra do UVES também pudessem ser avaliados. Após isso, foram realizadas sínteses variando-se a temperatura em $\pm 80 \mathrm{~K}$, a gravidade em \pm 0.25 dex, e a velocidade de micro-turbulência em $\pm 0.20 \mathrm{~km} / \mathrm{s}$. 
Tabela 4.7 - Variações nas abundâncias de cada elemento em função da variação da temperatura efetiva, separadas por faixas.

\begin{tabular}{|c|c|c|c|c|c|c|c|c|}
\hline \multirow{3}{*}{$\begin{array}{l}\mathrm{T}_{e f f}(\mathrm{~K}) \\
\Delta \mathrm{T}_{e f f}(\mathrm{~K})\end{array}$} & \multicolumn{2}{|c|}{402386} & \multicolumn{2}{|c|}{234816} & \multicolumn{2}{|c|}{554709} & \multicolumn{2}{|c|}{402608} \\
\hline & \multicolumn{2}{|c|}{4020} & \multicolumn{2}{|c|}{4380} & \multicolumn{2}{|c|}{4690} & \multicolumn{2}{|c|}{4930} \\
\hline & +80 & -80 & +80 & -80 & +80 & -80 & +80 & -80 \\
\hline $\mathrm{Na}$ & +0.08 & -0.08 & +0.05 & -0.10 & +0.05 & -0.07 & +0.10 & -0.07 \\
\hline $\mathrm{Mg}$ & +0.00 & +0.00 & +0.05 & +0.00 & +0.05 & -0.05 & +0.12 & -0.05 \\
\hline $\mathrm{Al}$ & +0.08 & -0.05 & +0.05 & -0.10 & +0.05 & -0.05 & +0.10 & -0.05 \\
\hline $\mathrm{Si}$ & -0.05 & +0.07 & -0.03 & +0.05 & +0.00 & +0.00 & -0.05 & +0.01 \\
\hline $\mathrm{Ca}$ & +0.10 & -0.08 & +0.10 & -0.10 & +0.08 & -0.08 & +0.15 & -0.07 \\
\hline $\mathrm{Ti}$ & +0.15 & -0.15 & +0.17 & -0.15 & +0.12 & -0.15 & +0.25 & -0.15 \\
\hline $\mathrm{Mn}$ & +0.05 & -0.02 & +0.12 & -0.10 & +0.13 & -0.12 & +0.25 & -0.12 \\
\hline $\mathrm{Cu}$ & +0.03 & +0.00 & +0.03 & -0.05 & +0.08 & -0.05 & +0.20 & -0.08 \\
\hline $\mathrm{Zn}$ & -0.08 & +0.08 & -0.05 & +0.05 & -0.02 & +0.03 & +0.00 & +0.00 \\
\hline $\mathrm{Sr}$ & +0.10 & -0.15 & +0.10 & -0.15 & +0.05 & -0.10 & +0.15 & -0.10 \\
\hline Y & -0.03 & +0.03 & -0.03 & +0.00 & -0.02 & +0.02 & +0.00 & +0.00 \\
\hline $\mathrm{Zr}$ & +0.18 & -0.15 & +0.15 & -0.20 & +0.15 & -0.18 & +0.30 & -0.18 \\
\hline $\mathrm{Ba}$ & +0.00 & +0.00 & +0.05 & -0.05 & +0.05 & -0.05 & +0.10 & -0.07 \\
\hline $\mathrm{La}$ & +0.05 & -0.03 & +0.02 & -0.03 & +0.02 & -0.05 & +0.15 & -0.10 \\
\hline $\mathrm{Ce}$ & +0.00 & +0.00 & +0.00 & +0.00 & +0.05 & +0.00 & +0.03 & -0.01 \\
\hline $\mathrm{Nd}$ & +0.03 & -0.03 & +0.03 & -0.05 & +0.02 & -0.03 & +0.05 & -0.02 \\
\hline $\mathrm{Eu}$ & -0.02 & +0.02 & -0.02 & +0.00 & +0.00 & +0.00 & +0.00 & +0.00 \\
\hline
\end{tabular}

Na calibração das faixas de temperatura, no caso de elementos cujas linhas cobriam uma amplitude de mais de $2 \mathrm{eV}$ no valor do $\chi_{e x c}$, foram consideradas ao menos três linhas com diferentes valores de $\chi_{e x c}$, e delas tomada uma média afim de minimizar os efeitos de desvio do equilíbrio de excitação, visto que este parâmetro de formação é sensível à temperatura. Para elementos cujas linhas apresentavam a amplitude no $\chi_{\text {exc }}$ menor que 2 eV, foi escolhida apenas uma linha espectral o mais livre possível de blends. As variações nas abundâncias foram determinadas ajustando-se as linhas às sínteses, da mesma forma que foi feita a determinação das dos valores das abundâncias. Os valores usados para a calibração são exibidos nas tabelas $4.7,4.8$ e 4.9 .

Para cada faixa e para cada elemento foi ajustado um polinômio de segundo grau na variação da abundância versus a variação no parâmetro atmosférico, de modo a calibrar cada um deles para poder refletir os erros determinados nos parâmetros atmosféricos para cada estrela.

Foi notado que o erro nas abundâncias devido à velocidade de micro-turbulência (vt) possuem uma dependência com a temperatura, de modo que as variações nas abundâncias são mais sensíveis a variações na vt em temperaturas mais baixas. Para contabilizar 
Tabela 4.8 - Variações nas abundâncias de cada elemento em função da variação da gravidade, separadas por faixas.

\begin{tabular}{|c|c|c|c|c|c|c|c|c|}
\hline & \multicolumn{2}{|c|}{402386} & \multicolumn{2}{|c|}{234816} & \multicolumn{2}{|c|}{554709} & \multicolumn{2}{|c|}{402608} \\
\hline $\log g$ & 0. & 32 & & 76 & & 22 & & \\
\hline og & .25 & 25 & 25 & -0 & 25 & 5 & 0.25 & -0 \\
\hline $\mathrm{Na}$ & .03 & +0.00 & 0.00 & +0.00 & +0.00 & +0.00 & +0.00 & +0.00 \\
\hline $\mathrm{Mg}$ & 0.03 & -0.02 & 0.02 & -0.02 & +0.00 & +0.00 & +0.00 & +0.0 \\
\hline $\mathrm{Al}$ & .00 & +0.00 & .00 & +0.00 & +0.00 & +0.00 & +0.00 & +0.0 \\
\hline $\mathrm{Si}$ & & -0.0 & & & & -0.05 & 0.03 & -0.04 \\
\hline $\mathrm{Ca}$ & .05 & -0.02 & 00 & +0 & +0.00 & +0.00 & +0.00 & +0.00 \\
\hline $\mathrm{Ti}$ & .04 & -0.0 & .03 & -0. & +0.00 & +0.00 & +0.00 & +0.00 \\
\hline $\mathrm{Mn}$ & .10 & -0.0 & .07 & -0 . & 0.03 & -0.02 & -0.00 & +0.0 \\
\hline $\mathrm{Cu}$ & .10 & -0.1 & 05 & -0. & +0.05 & -0.04 & +0.03 & -0.02 \\
\hline $\mathrm{Zn}$ & +0.07 & -0.0 & +0.08 & -0.0 & +0.09 & -0.07 & -0.07 & -0.08 \\
\hline $\mathrm{Sr}$ & .00 & -0 . & & & +0.00 & +0.00 & +0.00 & +0.00 \\
\hline Y & +0.10 & -0.12 & .12 & -0.13 & +0.10 & -0.13 & +0.09 & -0.13 \\
\hline $\mathrm{Zr}$ & +0.07 & -0 . & & -0 & +0.01 & -0.01 & +0.00 & +0.0 \\
\hline $\mathrm{Ba}$ & +0.10 & -0 & 10 & -0.13 & +0.12 & -0.12 & +0.08 & -0.11 \\
\hline $\mathrm{La}$ & +0.13 & +0.00 & +0.10 & -0.12 & +0.08 & -0.10 & +0.07 & -0.09 \\
\hline $\mathrm{Ce}$ & +0.10 & -0.10 & +0.10 & -0.12 & +0.07 & -0.12 & +0.08 & -0.12 \\
\hline $\mathrm{Nd}$ & +0.10 & -0.12 & +0.10 & -0.13 & +0.08 & -0.12 & +0.08 & -0.13 \\
\hline $\mathrm{Eu}$ & +0.10 & -0.13 & +0.10 & -0.12 & +0.08 & -0.12 & +0.09 & -0.13 \\
\hline
\end{tabular}

Tabela 4.9 - Variações nas abundâncias de cada elemento em função da variação da velocidade de micro-turbulência.

\begin{tabular}{|c|c|c|c|c|c|c|c|c|}
\hline \multirow{3}{*}{$\begin{array}{l}\text { vt }(\mathrm{km} / \mathrm{s}) \\
\Delta \mathrm{vt}(\mathrm{km} / \mathrm{s})\end{array}$} & \multicolumn{2}{|c|}{402386} & \multicolumn{2}{|c|}{234816} & \multicolumn{2}{|c|}{554709} & \multicolumn{2}{|c|}{402608} \\
\hline & \multicolumn{2}{|c|}{1.54} & \multicolumn{2}{|c|}{1.25} & \multicolumn{2}{|c|}{1.45} & \multicolumn{2}{|c|}{1.22} \\
\hline & +0.2 & -0.2 & +0.2 & -0.2 & +0.2 & -0.2 & +0.2 & -0.2 \\
\hline $\mathrm{Na}$ & +0.00 & +0.02 & +0.00 & +0.01 & +0.00 & +0.00 & +0.00 & +0.00 \\
\hline $\mathrm{Mg}$ & -0.07 & +0.07 & -0.07 & +0.07 & -0.03 & +0.03 & -0.02 & +0.02 \\
\hline $\mathrm{Al}$ & -0.01 & +0.02 & -0.01 & +0.02 & +0.00 & +0.00 & +0.00 & +0.00 \\
\hline $\mathrm{Si}$ & +0.00 & +0.01 & -0.01 & +0.01 & +0.00 & +0.00 & +0.00 & +0.00 \\
\hline $\mathrm{Ca}$ & -0.07 & +0.10 & -0.07 & +0.08 & -0.03 & +0.03 & -0.02 & +0.02 \\
\hline $\mathrm{Ti}$ & -0.07 & +0.10 & -0.06 & +0.06 & -0.01 & +0.01 & +0.00 & +0.00 \\
\hline $\mathrm{Mn}$ & -0.09 & +0.10 & -0.08 & +0.08 & -0.04 & +0.07 & -0.01 & +0.01 \\
\hline $\mathrm{Cu}$ & -0.05 & +0.10 & -0.07 & +0.07 & -0.03 & +0.05 & -0.03 & +0.03 \\
\hline $\mathrm{Zn}$ & -0.07 & +0.09 & -0.10 & +0.10 & -0.07 & +0.08 & -0.07 & +0.07 \\
\hline $\mathrm{Sr}$ & -0.01 & -0.02 & +0.00 & +0.00 & +0.00 & +0.00 & +0.00 & +0.00 \\
\hline Y & +0.00 & +0.00 & +0.00 & +0.00 & +0.00 & +0.00 & +0.00 & +0.00 \\
\hline $\mathrm{Zr}$ & -0.05 & +0.08 & -0.02 & +0.02 & +0.00 & +0.00 & +0.00 & +0.00 \\
\hline $\mathrm{Ba}$ & -0.30 & +0.27 & -0.28 & +0.25 & -0.23 & +0.23 & -0.22 & +0.23 \\
\hline $\mathrm{La}$ & +0.08 & +0.06 & +0.00 & +0.00 & +0.00 & +0.00 & +0.00 & +0.00 \\
\hline $\mathrm{Ce}$ & -0.03 & +0.04 & -0.02 & +0.03 & +0.00 & +0.00 & +0.00 & +0.00 \\
\hline $\mathrm{Nd}$ & +0.00 & +0.00 & +0.00 & +0.00 & +0.00 & +0.00 & +0.00 & +0.00 \\
\hline $\mathrm{Eu}$ & +0.00 & +0.00 & +0.00 & +0.00 & +0.00 & +0.00 & +0.00 & +0.00 \\
\hline
\end{tabular}


propriamente este efeito, para cada elemento, foram ajustadas três superfícies, uma para cada variação da vt (cada variação é uma amostragem da calibração, correspondendo a -0.2 $\mathrm{km} / \mathrm{s},+0 \mathrm{~km} / \mathrm{s}$ e $+0.2 \mathrm{~km} / \mathrm{s}$ ), com o domínio de cada uma sendo a temperatura e a vt, e o terceiro eixo correspondendo às variações nas abundâncias determinadas via síntese. Para cada estrela, são avaliadas as variações das abundâncias em cada uma das três superfícies na coordenada correspondente à temperatura e vt, e com estes é traçado o polinômio de calibração para a determinação do erro nas abundâncias relacionado ao erro na vt.

No cálculo final dos erros, para cada elemento é tomada a raiz da soma quadrática dos erros nas abundâncias devido a cada parâmetro atmosférico (obtendo-se um erro total dos parâmetros atmosféricos refletidos nas abundâncias), e o erro-padrão da mediana das abundâncias linha-a-linha (utilizando a técnica do jackknife pela função hdquantiles_sd do pacote $S c i P y)$. Como erro final, é tomada a raiz da soma quadrática destas duas grandezas. Desta forma, são levados em conta tanto os erros nos parâmetros atmosféricos quanto a incerteza devido ao espalhamento das abundâncias linha-a-linha.

As abundâncias finais e respectivos erros são apresentadas no capítulo 5 para a amostra UV2016 na tabela 5.4, para a amostra GI2012 na tabela C.2, e para a amostra GI2016 na tabela C.3. 
Capítulo 5

\section{Resultados}

Na Iniciação Científica (2012-2016) participei de todos os passos da análise dos dados para as 4 estrelas do aglomerado NGC 6522 com dados UVES. Deste trabalho resultou o artigo (Barbuy et al. (2014)):

"High resolution abundance analysis of red giants in the bulge globular cluster NGC 6522", B. Barbuy, C. Chiappini, E. Cantelli, E. Depagne, M. Pignatari, R. Hirschi, G. Cescutti, S. Ortolani, V. Hill, M. Zoccali, D. Minniti, M. Trevisan, E. Bica, A. Gómez: 2014, Astronomy \& Astrophysics, 570, A76

Também contribuí principalmente com redução de dados e medidas de larguras equivalentes para os trabalhos publicados em:

"Looking for imprints from the first stellar generation in metal-poor bulge field stars", C. Siqueira-Mello, B. Barbuy, C. Chiappini, K. Freeman, M. Ness, E. Depagne, M. Pignatari, R. Hirschi, U. Frischknecht, G. Meynet, A. Maeder, E. Cantelli: 2016, Astronomy \& Astrophysics, 593, 79

"High-resolution abundance analysis of red giants in the metal-poor bulge globular cluster HP 1", B. Barbuy, E. Cantelli, A. Vemado, H. Ernandes, S. Ortolani, I. Saviane, E. Bica, D. Minniti, B. Dias, Y. Momany, V. Hill, M. Zoccali, C. Siqueira-Mello: 2016, Astronomy \& Astrophysics, 591, 53

Na presente dissertação, o objetivo é a análise da amostra GI2012 e das amostras GI2016 e UV2016, conforme descrito no capítulo 2. Apresentamos aqui portanto os resultados anteriores obtidos para o NGC 6522, e os parâmetros atmosféricos e resultados de abundâncias para a nova amostra. 


\subsection{Resultados anteriores}

Em Barbuy et al. (2009), foram apresentados os primeiros resultados espectroscópicos de 8 estrelas gigantes do aglomerado globular NGC 6522. Recentemente com dados fotométricos do telescópio espacial Hubble, Kerber et al. (2018) concluiu que o aglomerado tem pelo menos duas populações estelares. Portanto, NGC 6522 é um importante protótipo das primeiras fases do enriquecimento químico do bojo, e em termos mais gerais, do Universo. As razões $[\alpha / F e]$ medidas em Barbuy et al. (2009) e Barbuy et al. (2014) mostram excesso de elementos- $\alpha$, sugerindo que o gás a partir do qual essas estrelas se formaram teria sido enriquecido por estrelas massivas que poluíram o meio via supernovas de tipo II. Com respeito a elementos pesados de captura de nêutrons, Barbuy et al. (2009) mostrou que o elemento de processo-r Eu e os elementos de processo-s Ba e La também foram encontrados superabundantes, com uma dispersão de estrela-a-estrela, como mostrado na figura 1.2. As abundâncias finais para cada estrela são exibidas na tabela 5.1. Enquanto a sobreabundância de Eu é consistente com a assinatura de enriquecimento por estrelas massivas, o enriquecimento anômalo de Ba e La em algumas das estrelas era difícil de reconciliar com a alta idade de NGC 6522. A questão é que a maior parte do Ba e La encontrados no sistema solar e na Galáxia, foram produzidos por estrelas de baixa massa no ramo assintótico das gigantes (AGB), que no cenário do bojo, não teriam tido tempo de evoluir e enriquecer o meio interestelar antes das estrelas presentes atualmente no aglomerado se formarem.

Como sugerido em Chiappini et al. (2011), com base nos excessos de abundâncias de $\mathrm{Ba}, \mathrm{Y}, \mathrm{La}, \mathrm{Sr}$ e limites superiores da abundância de Carbono (figura 1.2), são possíveis os cenários onde o enriquecimento de $\mathrm{Sr}, \mathrm{Y}, \mathrm{Ba}$ e La se deu por processo-s em estrelas massivas com rápida rotação, ou por processo-s em estrelas AGB em sistemas binários, com metalicidade inicial coincidindo com a metalicidade do aglomerado $([\mathrm{Fe} / \mathrm{H}] \sim-1)$. Como mostrado em Chiappini et al. (2011), o primeiro cenário é capaz de reproduzir o conjunto de abundâncias de todas as estrelas observadas, enquanto que o segundo cenário só explicaria 5 delas, e não explicaria aquelas com valores mais altos de Y e Ba.

Em Barbuy et al. (2014), 4 das estrelas de Barbuy et al. (2009) foram re-analisadas em mais alta resolução (amostra UV2012), tendo seus parâmetros atmosféricos re-derivados e suas abundâncias elementais também re-derivadas. Com os novos resultados, a adequação 
Tabela 5.1 - Parâmetros espectroscópicos, abundâncias elementais para as estrelas analisadas em Barbuy et al. (2009).

\begin{tabular}{|c|c|c|c|c|c|c|c|c|}
\hline Estrela & B-8 & B-107 & B-108 & B-118 & B-122 & B-128 & B-130 & F-121 \\
\hline \multicolumn{9}{|c|}{ Parâmetros espectroscópicos } \\
\hline $\mathrm{T}_{e f f}(\mathrm{~K})$ & 4600 & 4900 & 4700 & 4700 & 4800 & 4800 & 4800 & 4750 \\
\hline $\log G$ & 2.0 & 2.1 & 2.6 & 2.6 & 2.6 & 2.7 & 2.3 & 2.3 \\
\hline$[\mathrm{Fe} / \mathrm{H}]$ & -1.03 & -1.11 & -1.10 & -0.84 & -0.87 & -0.79 & -1.09 & -1.15 \\
\hline $\mathrm{vt}(\mathrm{km} / \mathrm{s})$ & 1.40 & 1.40 & 0.80 & 1.30 & 1.10 & 1.30 & 1.40 & 1.30 \\
\hline \multicolumn{9}{|c|}{ Abundâncias elementais } \\
\hline$[\mathrm{O} / \mathrm{Fe}]$ & +0.25 & +0.50 & +0.70 & +0.30 & +0.70 & - & +0.50 & +0.50 \\
\hline$[\mathrm{Na} / \mathrm{Fe}]$ & +0.35 & -0.30 & -0.15 & +0.10 & +0.15 & +0.10 & +0.15 & -0.10 \\
\hline$[\mathrm{Mg} / \mathrm{Fe}]$ & +0.10 & +0.27 & +0.33 & +0.20 & +0.20 & +0.25 & +0.40 & +0.40 \\
\hline$[\mathrm{Si} / \mathrm{Fe}]$ & +0.34 & +0.20 & +0.20 & +0.29 & +0.13 & +0.24 & +0.35 & +0.27 \\
\hline$[\mathrm{Ca} / \mathrm{Fe}]$ & +0.15 & +0.04 & +0.18 & +0.21 & +0.21 & +0.16 & +0.23 & +0.16 \\
\hline$[\mathrm{Ti} / \mathrm{Fe}]$ & +0.12 & +0.14 & +0.21 & +0.11 & +0.19 & +0.17 & +0.21 & +0.16 \\
\hline$[\mathrm{Eu} / \mathrm{Fe}]$ & +0.50 & +0.00 & +0.50 & +0.50 & +0.30 & +0.00 & +0.80 & +0.50 \\
\hline$[\mathrm{Ba} / \mathrm{Fe}]$ & +0.95 & +0.50 & +0.00 & +1.00 & +0.60 & +0.90 & +0.25 & -0.25 \\
\hline$[\mathrm{La} / \mathrm{Fe}]$ & +0.50 & +0.50 & +0.30 & +0.50 & +0.30 & - & - & +0.00 \\
\hline
\end{tabular}


da razão $[\mathrm{Y} / \mathrm{Ba}]$ aos novos modelos deixou em aberto as duas possibilidades: enriquecimento por spinstars ou transferência de massa em estrelas AGB.
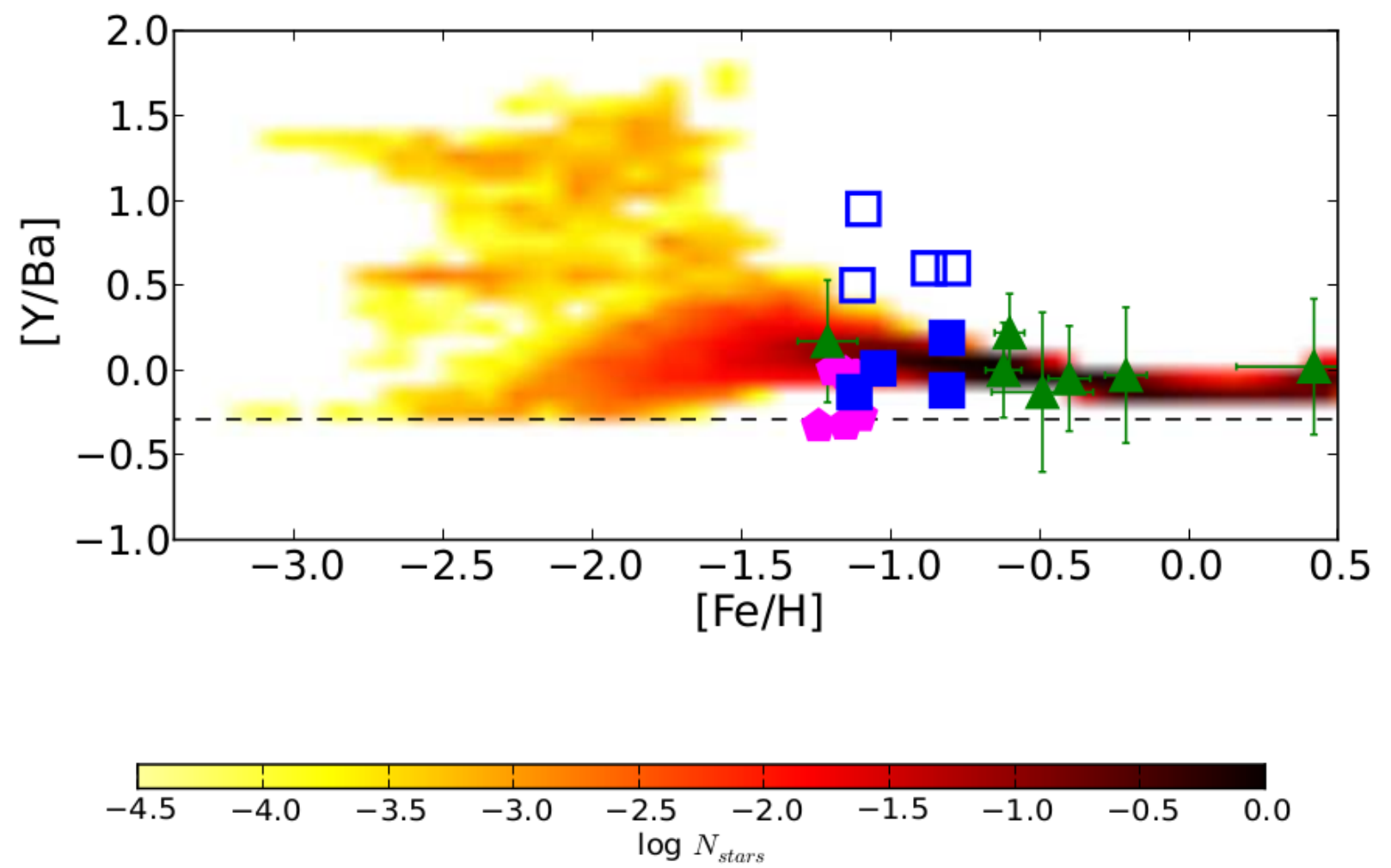

Figura 5.1: Razão [Y/Ba] vs [Fe/H] (Barbuy et al., 2014) das 4 estrelas re-analisadas (quadrados azuis cheios), valores anteriores de Barbuy et al. (2009) (quadrados azuis vazios) em comparação com as abundâncias da literatura de Yong et al. (2014) para M 62 (pentágonos magenta) e Bensby et al. (2013) para as estrelas com mais de 11 Gyr (triângulos verdes). Também mostramos as previsões do modelo de evolução química para o bojo (veja escala de densidade na barra de cores na parte inferior a figura), onde a contribuição de ambas spinstars e supernovas dirigidas magneto-rotacionalmente (MRD) são levadas em consideração (ver Chiappini et al. (2014), Cescutti, Chiappini (2014), Cescutti et al. (2013)).

\subsection{Resultados atuais}

\subsubsection{Parâmetros atmosféricos}

Como resultados da análise realizada, são apresentados os parâmetros atmosféricos espectroscópicos das estrelas da amostra do UVES na tabela 5.3 , e resultados preliminares das amostras do GIRAFFE na tabela C.1 do apêndice C, bem como seus respectivos erros determinados pelo método descrito na seção 3.4 .4 . 
Tabela 5.2 - Parâmetros espectroscópicos, abundâncias e razões elementais para as estrelas analisadas em Barbuy et al. (2014). Os valores de $\mathrm{Na}$ e $\mathrm{Al}$ foram corrigidos das tendências nas temperaturas.

\begin{tabular}{lcccc}
\hline \hline Estrela & B-107 & B-122 & B-128 & B-130 \\
\hline \multicolumn{1}{c}{ Parâmetros } & espectroscópicos \\
$\mathrm{T}_{\text {eff }}(\mathrm{K})$ & 4990 & 4900 & 4800 & 4850 \\
$\log \mathrm{G}$ & 2.0 & 2.7 & 2.5 & 2.2 \\
{$[\mathrm{Fe} / \mathrm{H}]$} & -1.12 & -0.81 & -0.81 & -1.04 \\
$\mathrm{vt}(\mathrm{km} / \mathrm{s})$ & 1.40 & 1.55 & 1.25 & 1.45 \\
\hline \multicolumn{5}{c}{ Abundâncias elementais } \\
{$[\mathrm{C} / \mathrm{Fe}]$} & +0.00 & -0.20 & +0.10 & +0.00 \\
{$[\mathrm{~N} / \mathrm{Fe}]$} & - & +0.70 & +0.60 & +0.70 \\
{$[\mathrm{O} / \mathrm{Fe}]$} & +0.50 & +0.20 & +0.23 & +0.50 \\
{$[\mathrm{Na} / \mathrm{Fe}]$} & +0.03 & +0.09 & +0.01 & +0.05 \\
{$[\mathrm{Al} / \mathrm{Fe}]$} & +0.28 & +0.18 & +0.08 & +0.26 \\
{$[\mathrm{Mg} / \mathrm{Fe}]$} & +0.33 & +0.10 & +0.23 & +0.27 \\
{$[\mathrm{Si} / \mathrm{Fe}]$} & +0.17 & +0.06 & +0.14 & +0.13 \\
{$[\mathrm{Ca} / \mathrm{Fe}]$} & +0.16 & +0.00 & +0.20 & +0.15 \\
{$[\mathrm{TiI} / \mathrm{Fe}]$} & +0.03 & +0.03 & +0.05 & +0.03 \\
{$[\mathrm{TiII} / \mathrm{Fe}]$} & +0.17 & +0.15 & +0.17 & +0.18 \\
{$[\mathrm{Eu} / \mathrm{Fe}]$} & +0.40 & +0.30 & +0.30 & +0.20 \\
{$[\mathrm{Ba} / \mathrm{Fe}]$} & +0.45 & +0.05 & +0.55 & +0.22 \\
{$[\mathrm{La} / \mathrm{Fe}]$} & +0.20 & +0.35 & +0.35 & +0.00 \\
{$[\mathrm{Y} / \mathrm{Fe}]$} & +0.32 & +0.24 & +0.43 & +0.23 \\
{$[\mathrm{Sr} / \mathrm{Fe}]$} & +0.00 & +0.40 & +0.20 & +0.30 \\
{$[\mathrm{Zr} / \mathrm{Fe}]$} & +0.20 & +0.10 & +0.40 & +0.00 \\
{$[\mathrm{Ba} / \mathrm{Eu}]$} & +0.05 & -0.25 & +0.25 & +0.02 \\
{$[\mathrm{Y} / \mathrm{Ba}]$} & -0.13 & +0.19 & -0.12 & +0.01 \\
{$[\mathrm{Sr} / \mathrm{Ba}]$} & -0.45 & +0.35 & -0.35 & +0.08 \\
\hline \hline & & & &
\end{tabular}


Tabela 5.3 - Parâmetros espectroscópicos da amostra do UVES da presente análise.

\begin{tabular}{|c|c|c|c|c|c|c|c|c|}
\hline \multirow[t]{2}{*}{ Objeto } & \multicolumn{2}{|c|}{$\mathrm{T}_{e f f}(\mathrm{~K})$} & \multicolumn{2}{|c|}{$\log G$} & \multicolumn{2}{|c|}{$[\mathrm{Fe} / \mathrm{H}]$} & \multicolumn{2}{|c|}{$\mathrm{vt}(\mathrm{km} / \mathrm{s})$} \\
\hline & Manual & DOOp & Manual & DOOp & Manual & DOOp & Manual & DOOp \\
\hline \multicolumn{9}{|c|}{ UV2016 } \\
\hline 234816 & $4530_{-187}^{+115}$ & $4440_{-29}^{+26}$ & $2.20_{-0.45}^{+0.74}$ & $2.02_{-0.12}^{+0.14}$ & $-1.04 \pm 0.21$ & $-0.78 \pm 0.06$ & $1.20_{-0.30}^{+0.43}$ & $1.11_{-0.10}^{+0.07}$ \\
\hline 244523 & $4850_{-91}^{+79}$ & $4630_{-25}^{+12}$ & $2.40_{-0.46}^{+0.34}$ & $1.90_{-0.17}^{+0.04}$ & $-0.97 \pm 0.12$ & $-0.95 \pm 0.06$ & $2.10_{-0.39}^{+0.74}$ & $1.51_{-0.03}^{+0.04}$ \\
\hline 244819 & $4660_{-45}^{+70}$ & $4630_{-44}^{+36}$ & $2.25_{-0.14}^{+0.44}$ & $2.13_{-0.21}^{+0.16}$ & $-1.13 \pm 0.09$ & $-1.16 \pm 0.08$ & $1.50_{-0.20}^{+0.13}$ & $1.35_{-0.09}^{+0.09}$ \\
\hline 256289 & $4800_{-49}^{+56}$ & $4680_{-33}^{+27}$ & $2.50_{-0.15}^{+0.21}$ & $1.96_{-0.17}^{+0.16}$ & $-1.05 \pm 0.06$ & $-1.30 \pm 0.05$ & $1.30_{-0.19}^{+0.06}$ & $1.20_{-0.07}^{+0.07}$ \\
\hline 402322 & $4720_{-61}^{+95}$ & $4610_{-55}^{+48}$ & $2.20_{-0.26}^{+0.29}$ & $1.97_{-0.23}^{+0.19}$ & $-1.14 \pm 0.09$ & $-1.15 \pm 0.10$ & $1.30_{-0.13}^{+0.17}$ & $1.00_{-0.11}^{+0.11}$ \\
\hline 402370 & $4720_{-25}^{+60}$ & $4665_{-42}^{+37}$ & $2.30_{-0.12}^{+0.13}$ & $1.93_{-0.19}^{+0.16}$ & $-1.15 \pm 0.03$ & $-1.34 \pm 0.07$ & $1.30_{-0.11}^{+0.13}$ & $1.10_{-0.09}^{+0.09}$ \\
\hline
\end{tabular}

\subsubsection{Abundâncias elementais}

As abundâncias elementais determinadas para as estrelas analisadas da amostra do UVES são listadas na tabela 5.4, e resultados preliminares para as amostras do GIRAFFE nas tabelas C.2 e C.3 no apêndice C, juntamente com seus respectivos erros.

A seguir são apresentadas as abundâncias dos elementos em função da metalicidade para cada estrela analisada, separadas por grupos de elementos leves (figura 5.2), elementos$\alpha$ (figura 5.3), elementos do pico do ferro (figura 5.4) e elementos pesados (figura $5.5 \mathrm{e}$ 5.6) para as estrelas do UVES. Como referência, são evidenciadas as estrelas onde foi realizada a limpeza de movimentos próprios, descrita no apêndice $\mathrm{D}$. O foco do trabalho são es estrelas da amostra do UVES, portanto a amostra do GIRAFFE onde foi feita a análise preliminar está presente nas figuras do apêndice C. Em cada figura, a área em verde claro representa a faixa de metalicidades considerada para estrelas prováveis-membros do aglomerado $(-1.2<[\mathrm{Fe} / \mathrm{H}]<0.8)$, considerando as metalicidades de Barbuy et al. (2014) que apresenta membros de até $[\mathrm{Fe} / \mathrm{H}]=-0.81$, e Fernández-Trincado et al. (2018), que apresenta um membro de $[\mathrm{Fe} / \mathrm{H}]=-1.2$. 
Tabela 5.4 - Abundâncias finais e erros para as estrelas da amostra UV2016, incluindo o número de linhas utilizadas.

\begin{tabular}{|c|c|c|c|c|c|c|c|c|c|c|c|c|}
\hline \multirow[b]{2}{*}{ Ele. } & \multicolumn{2}{|l|}{234816} & \multicolumn{2}{|l|}{244523} & \multicolumn{2}{|l|}{244819} & \multicolumn{2}{|l|}{256289} & \multicolumn{2}{|l|}{402322} & \multicolumn{2}{|l|}{402370} \\
\hline & {$[\mathrm{X} / \mathrm{Fe}]$} & $\mathrm{N}$ & {$[\mathrm{X} / \mathrm{Fe}]$} & $\mathrm{N}$ & {$[\mathrm{X} / \mathrm{Fe}]$} & $\mathrm{N}$ & {$[\mathrm{X} / \mathrm{Fe}]$} & $\mathrm{N}$ & {$[\mathrm{X} / \mathrm{Fe}]$} & $\mathrm{N}$ & {$[\mathrm{X} / \mathrm{Fe}]$} & $\mathrm{N}$ \\
\hline $\mathrm{C}$ & +0.00 & 2 & +0.20 & 2 & +0.25 & 2 & +0.00 & 2 & +0.20 & 2 & +0.00 & 2 \\
\hline $\mathrm{N}$ & +0.50 & 1 & +0.70 & 1 & +0.90 & 1 & +0.30 & 1 & +0.80 & 1 & +0.50 & 1 \\
\hline $\mathrm{O}$ & - & - & - & - & +0.40 & 1 & +0.40 & 1 & +0.40 & 1 & +0 . & 1 \\
\hline $\mathrm{Na}$ & $+0.40 \pm 0.06$ & 5 & $+0.02 \pm 0.04$ & 5 & $+0.45 \pm 0.03$ & 5 & $-0.39 \pm 0.03$ & 5 & $+0.32 \pm 0.03$ & 5 & $-0.35 \pm 0.02$ & 5 \\
\hline $\mathrm{Mg}$ & $+0.63 \pm 0.16$ & 3 & $+0.56 \pm 0.15$ & 3 & $+0.33 \pm 0.15$ & 3 & $+0.17 \pm 0.16$ & 3 & $+0.15 \pm 0.15$ & 3 & $+0.20 \pm 0.15$ & 3 \\
\hline $\mathrm{Al}$ & $+0.65 \pm 0.06$ & 2 & $+0.30 \pm 0.11$ & 2 & $+0.50 \pm 0.15$ & 2 & $+0.10 \pm 0.03$ & 2 & $+0.88 \pm 0.13$ & 2 & $-0.13 \pm 0.13$ & 2 \\
\hline $\mathrm{Si}$ & $+0.59 \pm 0.06$ & 12 & $+0.50 \pm 0.07$ & 11 & $+0.36 \pm 0.07$ & 11 & $+0.19 \pm 0.07$ & 10 & $+0.29 \pm 0.06$ & 11 & $+0.20 \pm 0.07$ & 9 \\
\hline $\mathrm{Ca}$ & $+0.56 \pm 0.12$ & 17 & $+0.22 \pm 0.12$ & 17 & $+0.27 \pm 0.12$ & 17 & $+0.07 \pm 0.12$ & 16 & $+0.23 \pm 0.12$ & 16 & $+0.11 \pm 0.12$ & 17 \\
\hline $\mathrm{Ti}$ & $+0.60 \pm 0.08$ & 19 & $+0.39 \pm 0.08$ & 19 & $+0.19 \pm 0.08$ & 18 & $+0.06 \pm 0.09$ & 17 & $+0.18 \pm 0.08$ & 16 & $-0.01 \pm 0.08$ & 15 \\
\hline Mn & $+0.12 \pm 0.29$ & 4 & $-0.10 \pm 0.29$ & 4 & $-0.37 \pm 0.29$ & 4 & $-0.47 \pm 0.29$ & 4 & $-0.35 \pm 0.29$ & 4 & $-0.55 \pm 0.29$ & 4 \\
\hline $\mathrm{Cu}$ & $+0.25 \pm 0.12$ & 2 & $-0.08 \pm 0.12$ & 2 & $-0.15 \pm 0.13$ & 2 & $-0.40 \pm 0.12$ & 2 & $-0.30 \pm 0.12$ & 1 & $-0.40 \pm 0.15$ & 2 \\
\hline $\mathrm{Zn}$ & $-0.13 \pm 0.22$ & 2 & $+0.15 \pm 0.23$ & 2 & $+0.25 \pm 0.18$ & 2 & $-0.35 \pm 0.18$ & 2 & $-0.15 \pm 0.27$ & 2 & $-0.15 \pm 0.18$ & 1 \\
\hline $\mathrm{Sr}$ & $+0.67 \pm 0.15$ & 3 & $+0.45 \pm 0.03$ & 1 & $+0.65 \pm 0.03$ & 1 & $+0.40 \pm 0.03$ & 1 & $+0.30 \pm 0.03$ & 1 & $+0.30 \pm 0.03$ & 1 \\
\hline $\mathrm{Y}$ & $+0.21 \pm 0.07$ & 6 & $+0.51 \pm 0.09$ & 6 & $+0.68 \pm 0.09$ & 6 & $-0.04 \pm 0.08$ & 4 & $+0.24 \pm 0.13$ & 5 & $+0.03 \pm 0.09$ & 5 \\
\hline $\mathrm{Zr}$ & $+0.37 \pm 0.19$ & 6 & $+0.67 \pm 0.19$ & 6 & $+0.76 \pm 0.19$ & 6 & $-0.14 \pm 0.24$ & 4 & $+0.62 \pm 0.19$ & 5 & $+0.19 \pm 0.24$ & 5 \\
\hline $\mathrm{Ba}$ & $+0.29 \pm 0.12$ & 3 & $+0.90 \pm 0.09$ & 3 & $-0.24 \pm 0.12$ & 3 & $+0.06 \pm 0.09$ & 3 & $+0.31 \pm 0.09$ & 3 & $-0.01 \pm 0.09$ & 3 \\
\hline $\mathrm{La}$ & $+0.27 \pm 0.14$ & 4 & $+0.95 \pm 0.15$ & 4 & $+0.35 \pm 0.14$ & 2 & $+0.11 \pm 0.16$ & 3 & $+0.28 \pm 0.15$ & 4 & $+0.12 \pm 0.14$ & 4 \\
\hline $\mathrm{Ce}$ & $+0.27 \pm 0.07$ & 3 & $+1.07 \pm 0.08$ & 4 & $+0.38 \pm 0.10$ & 2 & $+0.26 \pm 0.08$ & 3 & $+0.36 \pm 0.12$ & 3 & $+0.22 \pm 0.12$ & 3 \\
\hline $\mathrm{Nd}$ & $+0.45 \pm 0.11$ & 3 & $+1.01 \pm 0.11$ & 5 & $+0.26 \pm 0.07$ & 3 & $+0.35 \pm 0.06$ & 2 & $+0.30 \pm 0.09$ & 3 & $+0.22 \pm 0.12$ & 3 \\
\hline $\mathrm{Eu}$ & $+0.68 \pm 0.06$ & 2 & $+0.60 \pm 0.06$ & 2 & $+0.35 \pm 0.08$ & 2 & $+0.40 \pm 0.08$ & 2 & $+0.40 \pm 0.08$ & 2 & $+0.32 \pm 0.06$ & 2 \\
\hline
\end{tabular}



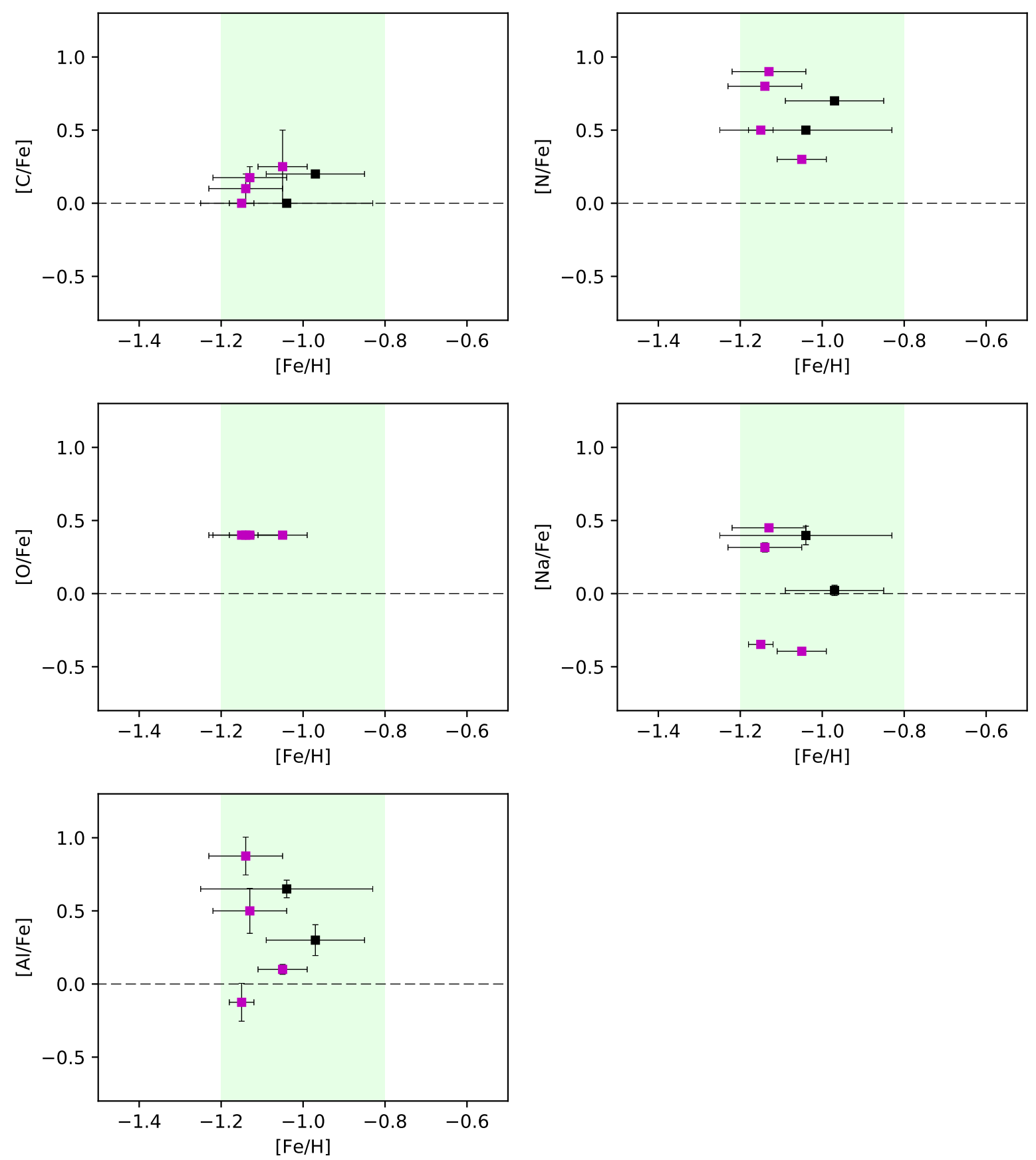

Figura 5.2: Abundâncias dos elementos leves em função da metalicidade. Quadrados representam as estrelas UVES. Os pontos em magenta são as estrelas selecionadas pela limpeza de movimento próprio. 

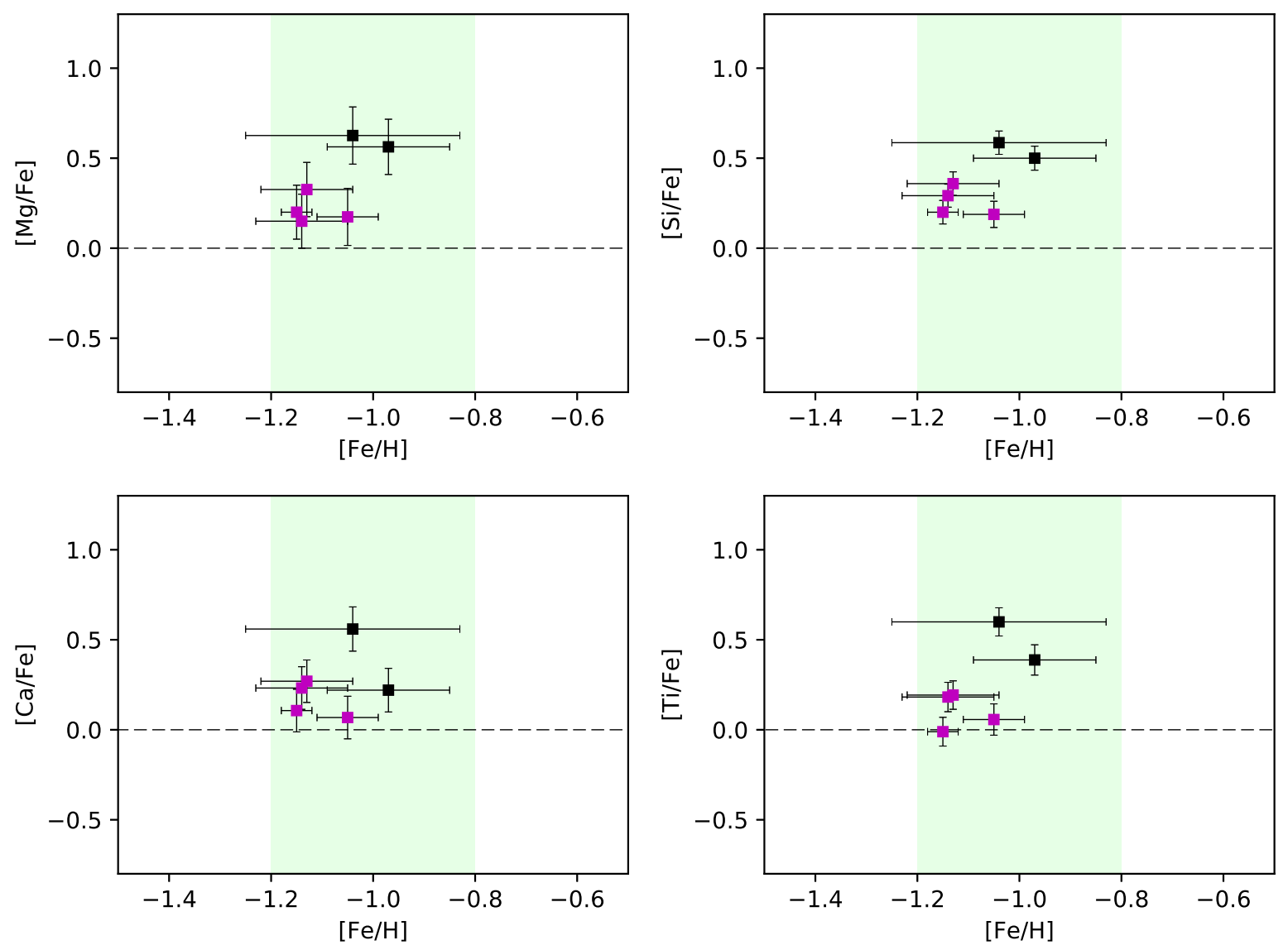

Figura 5.3: Abundâncias dos elementos- $\alpha$ em função da metalicidade. Quadrados representam as estrelas UVES. Os pontos em magenta são as estrelas selecionadas pela limpeza de movimento próprio. 

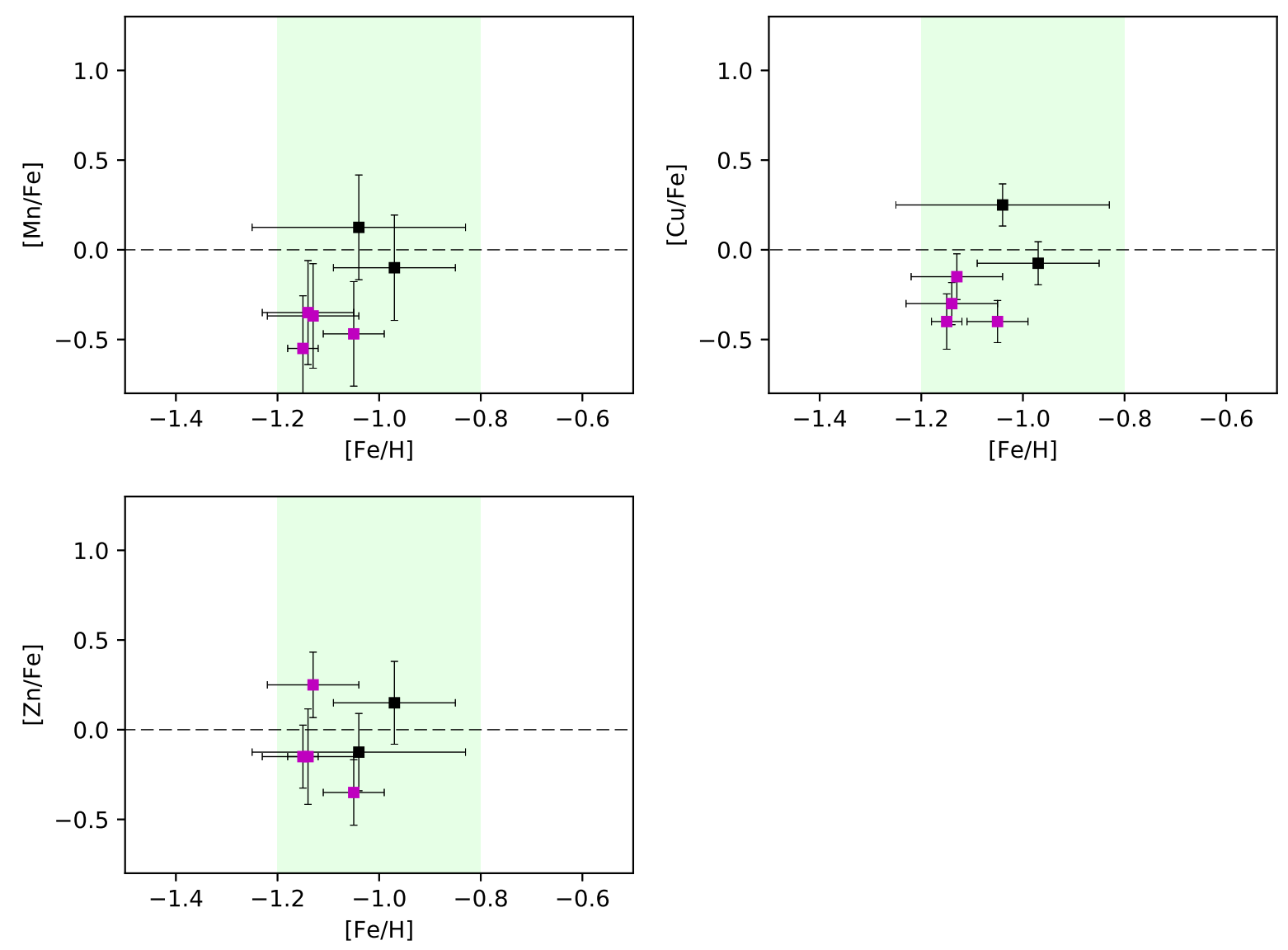

Figura 5.4: Abundâncias dos elementos do pico do ferro em função da metalicidade. Quadrados representam as estrelas UVES. Os pontos em magenta são as estrelas selecionadas pela limpeza de movimento próprio. 

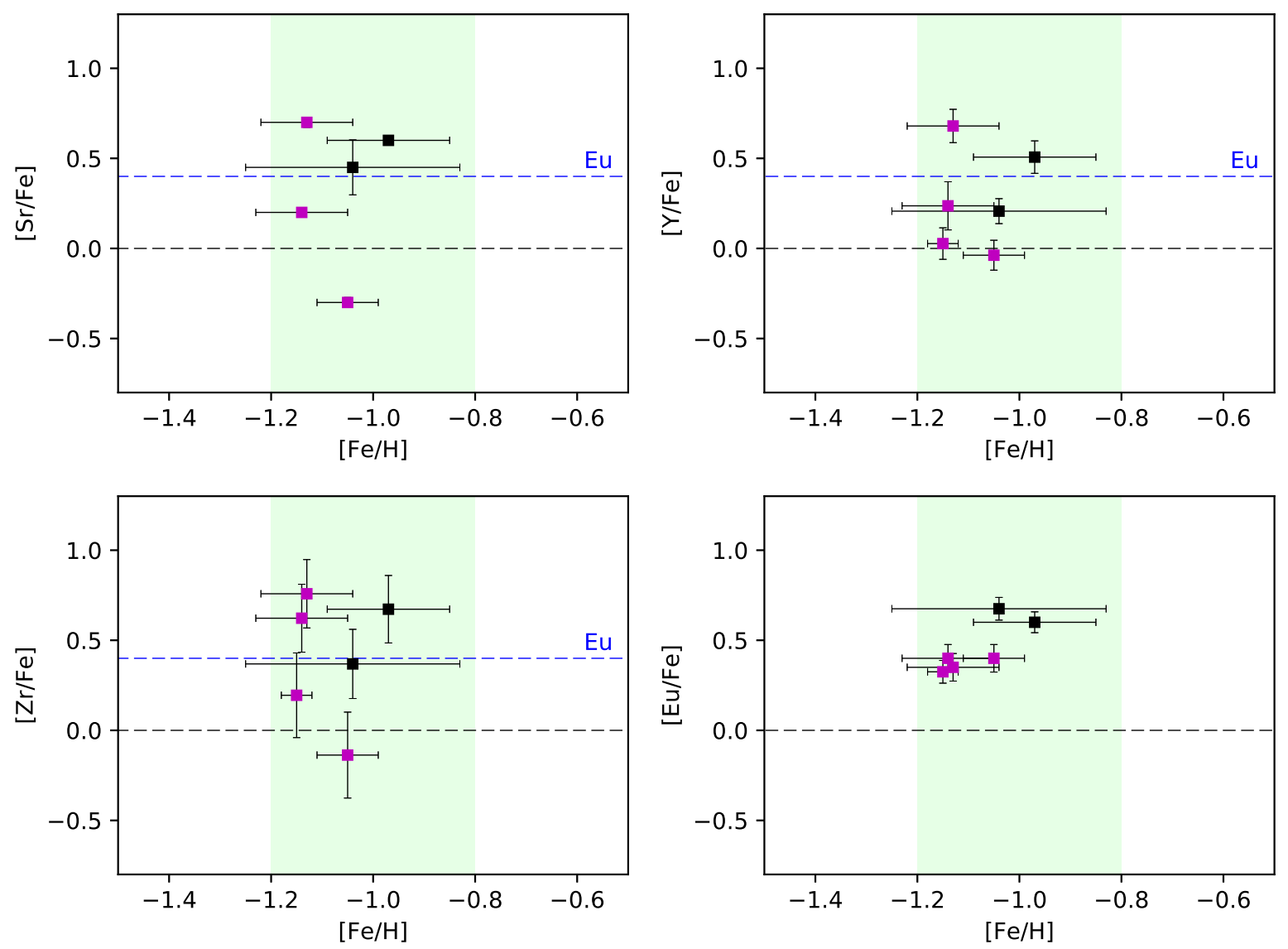

Figura 5.5: Abundâncias dos elementos do primeiro pico em função da metalicidade e o elemento de referência do processo-r, Eu. Quadrados representam as estrelas UVES. Os pontos em magentasão as estrelas selecionadas pela limpeza de movimento próprio. A linha tracejada em azul representa o valor médio da abundância de Eu. 

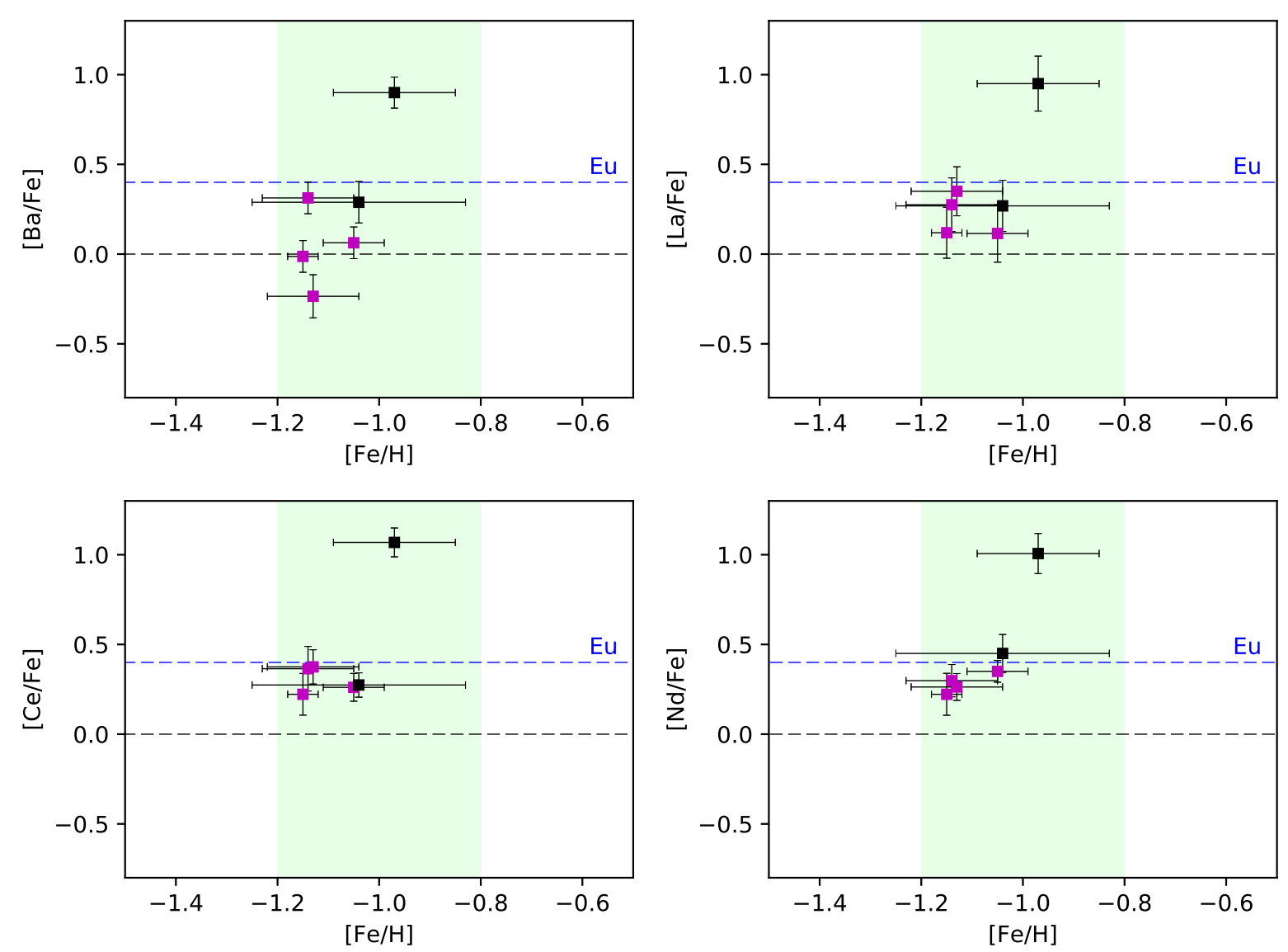

Figura 5.6: Abundâncias dos elementos do segundo pico em função da metalicidade. Quadrados representam as estrelas UVES. Os pontos em magenta são as estrelas selecionadas pela limpeza de movimento próprio. A linha tracejada em azul representa o valor médio da abundância de Eu. 


\section{Capítulo 6}

\section{Discussão}

Neste capítulo são discutidas as abundâncias elementais para as amostras. O foco do trabalho é nas estrelas da amostra do UVES, onde a alta resolução é determinante para conclusões robustas. As estrelas GIRAFFE, por ainda apresentarem resultados preliminares são exibidas no apêndice C, e uma discussão sobre as metalicidades preliminares é feita no apêndice E. Os movimentos próprios determinados no apêndice D são citados apenas como referência.

\subsection{Padrões das abundâncias}

A seguir é feita uma discussão das abundâncias apresentadas para cada grupo de elementos.

\subsubsection{Elementos leves}

O carbono apresentou comportamento razoavelmente uniforme e com pequeno enriquecimento para as amostras, conforme exibido na figura 5.2. Os modelos de transferência de massa por companheiras de ramo assintótico das gigantes (Bisterzo et al., 2010) prediz alto enriquecimento em carbono $(\mathrm{de}+1.24 \mathrm{a}+2.24 \mathrm{dex}$ em $[\mathrm{C} / \mathrm{Fe}]$ para $[\mathrm{Fe} / \mathrm{H}]$ entre -1.0 e -1.3 dex), desfavorecendo este cenário para as estrelas analisadas.

O nitrogênio apresentou dispersão e valores mais elevados para as estrelas, o que pode indicar enriquecimento por estrelas massivas de alta rotação, conforme citado na seção 4.6.1.2,

O sódio também apresentou dispersão pronunciada nas estrelas da amostra, porém para estabelecer melhores correlações, as abundâncias de oxigênio desempenham um papel muito 
importante e indispensável na análise de múltiplas populações em aglomerados globulares.

O Alumínio também apresenta grande dispersão nas estrelas da amostra.

Como exposto anteriormente na seção 4.6.2.1, devido à presença de linhas telúricas de emissão nos espectros do GIRAFFE, somente foi possível determinar as abundâncias de oxigênio para as estrelas do UVES, onde apenas duas exposições puderam ser aproveitadas. Desta forma, não foi possível estabelecer uma relação confiável para a anti-correlação Na-O, exibida na figura 6.1.
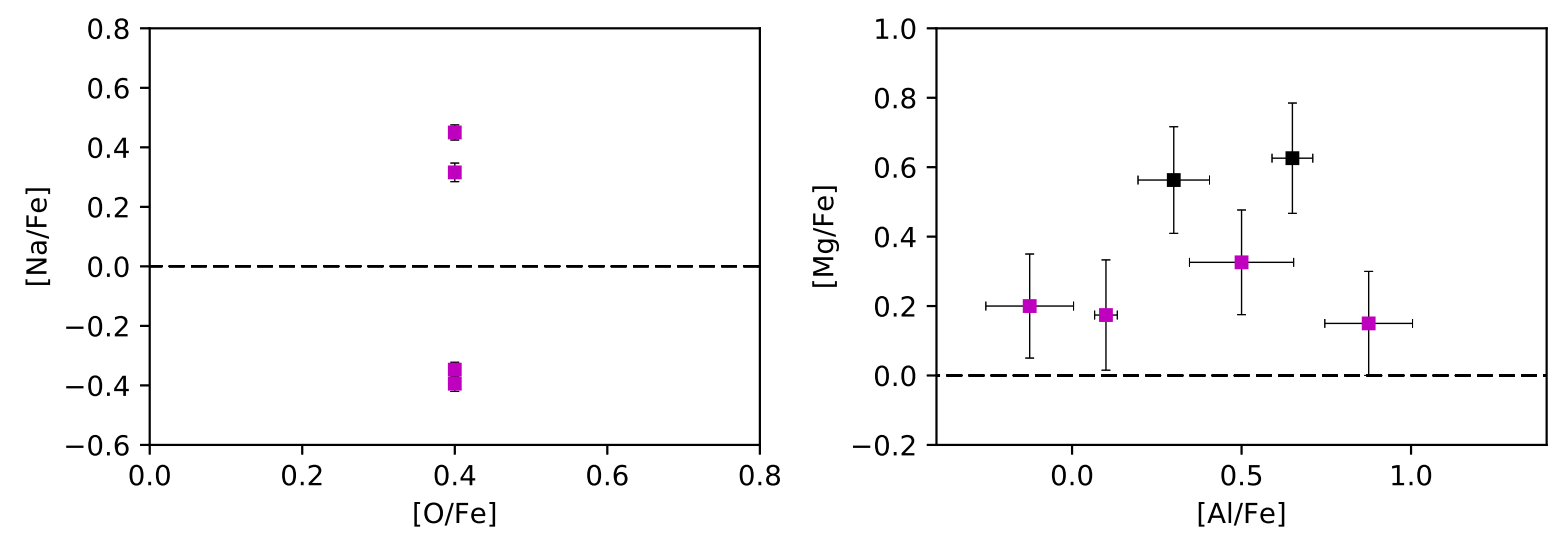

Figura 6.1: Relações Na-O e Mg-Al. Os pontos em magenta são as estrelas selecionadas pela limpeza de movimento próprio.

Também, não é clara a anti-correlação $\mathrm{Mg}-\mathrm{Al}$ exibida na figura 6.1.

\subsubsection{Elementos- $\alpha$}

As 4 estrelas consideradas membro pelos movimentos próprios apresentam um comportamento similar nas razões $[\alpha / \mathrm{Fe}]$, de acordo com o esperado para o bojo segundo Barbuy et al. (2018), confirmando que o aglomerado foi enriquecido por supernovas de colapso de núcleo. É interessante notar que as estrelas consideradas como de campo apresentam um valor mais alto de $[\alpha / \mathrm{Fe}]$ em relação às estrelas consideradas membro por limpeza de movimentos próprios, conforme a figura 5.3 .

\subsubsection{Elementos do pico do Fe}

De acordo com a figura 5.4, é possível notar que as estrelas consideradas membro por limpeza de movimentos próprios apresentam valores subsolares, enquanto as estrelas 
consideradas como de campo apresentam valores mais próximos do solar, de acordo com o esperado para esta faixa de metalicidades segundo Barbuy et al. (2018).

Os valores de $[\mathrm{Cu} / \mathrm{Fe}]$ das estrelas consideradas membro apresentam um bom acordo com os apresentados em Ernandes et al. (2018).

Para o Zn, duas estrelas apresentam $[\mathrm{Zn} / \mathrm{Fe}]$ superiores ao valor solar, enquanto as outras 4 apresentam valores sub-solares. As duas que se apresentam enriquecidas, uma delas apresenta enriquecimento significativo em elementos do primeiro pico e a outra em elementos do segundo pico. Nomoto et al. (2013) aponta que progenitoras de hipernovas a baixas metalicidades podem ser estrelas massivas em alta rotação, o que coincide com o padrão de enriquecimento de elementos pesados apresentado a seguir.

\subsubsection{Elementos pesados}

Para os elementos de primeiro pico Sr, Y e Zr, as estrelas-membro apresentam enriquecimento nas abundâncias, como mostrado na figura 5.5, onde a amostra de estrelas de campo também se mostra, em geral, moderadamente enriquecida. A razão [Sr/Fe] só está disponível para a amostra do UVES, onde duas das estrelas consideradas aparecem enriquecidas com valores superiores à média de $[\mathrm{Eu} / \mathrm{Fe}]$, uma concorda com o valor médio de $[\mathrm{Eu} / \mathrm{Fe}]=+0.35 \pm 0.05$, uma se apresenta moderadamente enriquecida e uma se apresenta com valor subsolar.

Para a razão $[\mathrm{Y} / \mathrm{Fe}]$, as estrelas apresentam um espalhamento ao redor do valor médio de $[\mathrm{Eu} / \mathrm{Fe}]$, onde duas estrelas se mostram acima da média de [Eu/Fe], duas moderadamente enriquecidas e mais duas com valor solar.

A razão $[\mathrm{Zr} / \mathrm{Fe}]$ apresenta espalhamento, onde 3 estrelas possuem $[\mathrm{Zr} / \mathrm{Fe}]$ maior que a média de $[\mathrm{Eu} / \mathrm{Fe}]$.

Os elementos de segundo pico Ba, La, Ce e Nd apresentam em geral enriquecimento moderado nas abundâncias para a amostra das estrelas consideradas membro membro, porém em geral inferiores à média de $[\mathrm{Eu} / \mathrm{Fe}]$.

Um grande espalhamento é observado na razão $[\mathrm{Ba} / \mathrm{Fe}]$ entre as estrelas, onde uma delas (244523) apresenta abundâncias acima da média de [Eu/Fe]. Para a razão [La/Fe], as estrelas apresentam enriquecimento moderado, abaixo da média de [Eu/Fe], novamente com a 244523 se apresentando enriquecida. Quanto às razões [Ce/Fe] e [Nd/Fe], as estrelas UVES se mostram concordantes com a média de [Eu/Fe], com exceção da 244523, que se 
mostra enriquecida em relação às outras estrelas UVES.

A estrela 244523 apresenta valores superiores a 0.9 dex para todos estes elementos na amostra do UVES, concordando com seus respectivos valores do GIRAFFE para Ce e Nd, discordando apenas na abundância de Ba, onde o valor para o GIRAFFE é 0.3 dex maior.
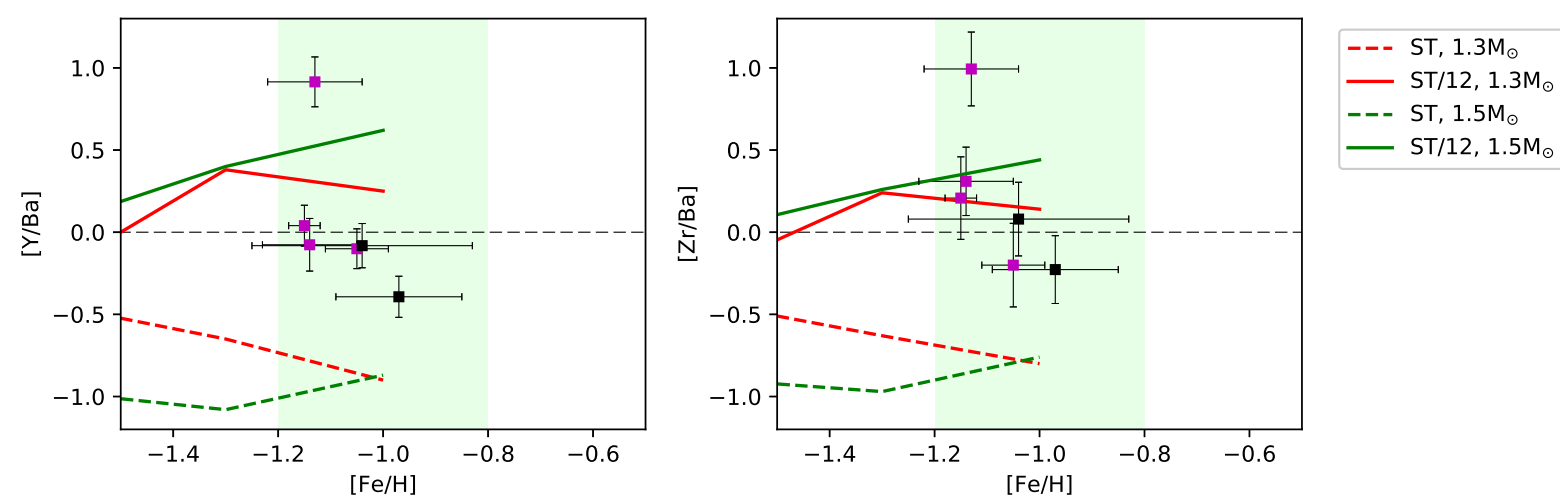

Figura 6.2: Razões de Y/Ba e Zr/Ba em função da metalicidade. Quadrados representam as estrelas UVES. Os pontos em magenta são as estrelas selecionadas pela limpeza de movimento próprio. As linhas cheias e tracejadas representam os modelos de Bisterzo et al. (2010), os mesmos descritos na figura 1 de Chiappini et al. (2011).

Na figura 6.2, são apresentadas as razões $[\mathrm{Y} / \mathrm{Ba}]$ e $[\mathrm{Zr} / \mathrm{Ba}]$ vs $[\mathrm{Fe} / \mathrm{H}]$, onde é possível notar claramente uma grande dispersão em $[\mathrm{Fe} / \mathrm{H}] \sim-1.15$, o que pode indicar o enriquecimento por spinstars, visto que esta dispersão em algumas estrelas ainda é muito alta para ser produzida pelo cenário de transferência de massa em sistemas binários por estrelas AGB segundo os modelos de Bisterzo et al. (2010), também exibidos na figura 6.2. É importante notar que as menores massas empregadas nos modelos de Bisterzo et al. (2010) são de 1.3 $\mathrm{M}_{\odot}$, que ainda assim são elevadas em comparação à massa efetiva de $M_{\text {eff }} \approx 0.79 M_{\odot}$ obtida pela análise dinâmica de Kamann et al. (2018), considerando que massas maiores predizem valores maiores para as razões $[\mathrm{Y} / \mathrm{Ba}]$ e $[\mathrm{Zr} / \mathrm{Ba}]$ segundo os modelos.

Para contabilizar conjuntamente os padrões de primeiro e segundo pico, a figura 6.3 apresenta a razão entre as médias das abundâncias dos elementos Sr, Y e Ba pela média das abundâncias de Ba, La, Ce e Nd.

Conforme as razões $[\mathrm{Zr} / \mathrm{Ba}]$ e $[\mathrm{Y} / \mathrm{Ba}]$, a razão do primeiro pico pelo segundo pico também mostra um máximo da dispersão em $[\mathrm{Fe} / \mathrm{H}] \sim-1.15$.

Frischknecht et al. (2016) apresenta modelos que incluem estrelas de $25 \mathrm{M}_{\odot} \operatorname{com}[\mathrm{Fe} / \mathrm{H}]$ $=-1.8$, e para estas, predizem valores de $[\mathrm{Sr} / \mathrm{Ba}]=0.13$ para os modelos sem rotação e 


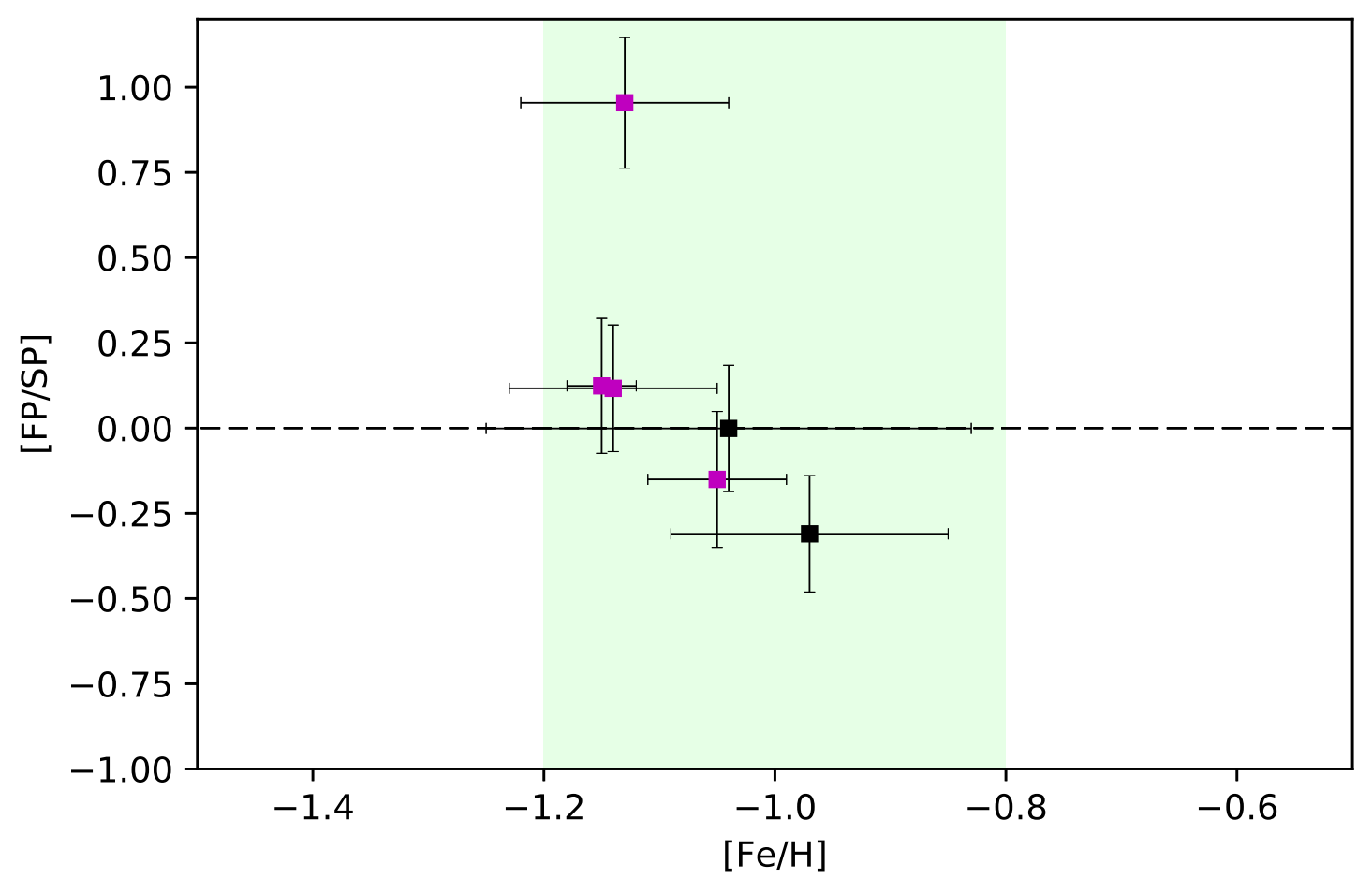

Figura 6.3: Razão das médias dos elementos do primeiro pico sobre os de segundo pico, em função da metalicidade. Quadrados representam as estrelas UVES. Os pontos em magenta são as estrelas selecionadas pela limpeza de movimento próprio.

$[\mathrm{Sr} / \mathrm{Ba}]=2.12$ para modelos com rotação. Os elementos $\mathrm{Y}$ e $\mathrm{Zr}$ apresentam as mesmas tendências que o Sr nos modelos, tornando razoável utilizar as razões $[\mathrm{Y} / \mathrm{Ba}]$ e $[\mathrm{Zr} / \mathrm{Ba}]$ para a mesma finalidade. Estas razões chegam a apresentar valores de até $\sim+0.9$ dex para a estrela 244819, conforme a figura 6.2, o que pode sustentar a possibilidade do enriquecimento via spinstars. 


\section{Conclusões}

Utilizando os dados obtidos pelo instrumento muti-objetos FLAMES, foram determinados os parâmetros atmosféricos e metalicidades de 32 estrelas dentro de um campo de 16' ao redor do aglomerado globular NGC 6522 com espectros obtidos pelo espectrógrafo GIRAFFE, onde 6 destas tiveram seus parâmetros determinados com espectros obtidos pelo espectrógrafo UVES. Destas, 20 estrelas do GIRAFFE com metalicidades $[\mathrm{Fe} / \mathrm{H}]<$ -0.6 e as 6 estrelas UVES tiveram suas abundâncias elementais determinadas. Adicionalmente, foram determinados os parâmetros atmosféricos e metalicidades de uma amostra de 1191 estrelas do campo central do NGC 6522 obtidas pela extração de um cubo de dados do espectrógrafo de campo integral panorâmico MUSE para comparação com a amostra do FLAMES.

A análise das abundâncias confirma o excesso em elementos- $\alpha$, típico de populações enriquecidas por supernovas de colapso de núcleo. A análise dos elementos pesados mostra ao menos uma estrela com valores elevados para as razões $[\mathrm{Y} / \mathrm{Ba}]$ e $[\mathrm{Zr} / \mathrm{Ba}]$, bem como um enriquecimento em $\mathrm{N}$ e Zn que sugerem que ao menos uma estrela da amostra UVES sofreu enriquecimento por estrelas massivas de alta rotação.

Para uma confirmação mais robusta e definitiva, é necessária uma maior amostra de estrelas-membro confirmadas tanto por critério dinâmico quanto químico, onde seja possível uma análise mais detalhada dos elementos leves e dos elementos pesados, afim de encontrar possíveis correlações entre diferentes populações. 


\section{Referências Bibliográficas}

Alonso A., Arribas S., Martínez-Roger C., The effective temperature scale of giant stars (F0-K5). II. Empirical calibration of $\mathrm{T}_{\text {eff }}$ versus colours and [Fe/H], A\&AS, 1999, vol. 140, p. 261

Aoki W., Suda T., Boyd R. N., Kajino T., Famiano M. A., Explaining the Sr and Ba Scatter in Extremely Metal-poor Stars, ApJ, 2013, vol. 766, p. L13

Arcones A., Martínez-Pinedo G., Dynamical r-process studies within the neutrino-driven wind scenario and its sensitivity to the nuclear physics input, Phys. Rev. C, 2011, vol. 83, p. 045809

Armandroff T. E., The properties of the disk system of globular clusters, AJ, 1989, vol. 97, p. 375

Baade W., A Search For the Nucleus of Our Galaxy, PASP, 1946, vol. 58, p. 249

Bacon R., Accardo M., Adjali L., Anwand H., Bauer S., Biswas I., Blaizot J., Boudon D., Brau-Nogue S., Brinchmann J., et al. The MUSE second-generation VLT instrument. In Ground-based and Airborne Instrumentation for Astronomy III , vol. 7735 of Proc. SPIE, 2010, p. 773508

Ballero S. K., Matteucci F., Origlia L., Rich R. M., Formation and evolution of the Galactic bulge: constraints from stellar abundances, A\&A, 2007, vol. 467, p. 123

Barbuy B., Nitrogen and oxygen as indicators of primordial enrichment, A\&A, 1983, vol. 123 , p. 1 
Barbuy B., Cantelli E., Vemado A., Ernandes H., Ortolani S., Saviane I., Bica E., Minniti D., Dias B., Momany Y., Hill V., Zoccali M., Siqueira-Mello C., High-resolution abundance analysis of red giants in the metal-poor bulge globular cluster HP 1, A\&A, 2016, vol. 591, p. A53

Barbuy B., Chiappini C., Cantelli E., Depagne E., Pignatari M., Hirschi R., Cescutti G., Ortolani S., Hill V., Zoccali M., Minniti D., Trevisan M., Bica E., Gómez A., Highresolution abundance analysis of red giants in the globular cluster NGC 6522, A\&A, 2014, vol. 570, p. A76

Barbuy B., Chiappini C., Gerhard O., Chemodynamical history of the Galactic Bulge, ArXiv e-prints, 2018

Barbuy B., Zoccali M., Ortolani S., Hill V., Minniti D., Bica E., Renzini A., Gómez A., VLT-FLAMES analysis of 8 giants in the bulge metal-poor globular cluster NGC 6522: oldest cluster in the Galaxy?, A\&A, 2009, vol. 507, p. 405

Barbuy B., Zoccali M., Ortolani S., Minniti D., Hill V., Renzini A., Bica E., Gómez A., NGC 6558: A Blue Horizontal Branch Moderately Metal-Poor Globular Cluster in the Bulge, AJ, 2007, vol. 134, p. 1613

Barbuy B., Zoccali M., Ortolani S., Momany Y., Minniti D., Hill V., Renzini A., Rich R. M., Bica E., Pasquini L., Yadav R. K. S., VLT-UVES analysis of two giants in the bulge metal-poor globular cluster HP-1. Analysis of two giants in HP-1, A\&A, 2006, vol. 449 , p. 349

Bica E., Bonatto C., Barbuy B., Ortolani S., Globular cluster system and Milky Way properties revisited, A\&A, 2006, vol. 450, p. 105

Bica E., Ortolani S., Barbuy B., Globular Clusters in the Galactic Bulge, PASA, 2016, vol. 33, p. e028

Bisterzo S., Gallino R., Straniero O., Cristallo S., Käppeler F., s-Process in low-metallicity stars - I. Theoretical predictions, MNRAS, 2010, vol. 404, p. 1529

Blanco V. M., Blanco B. M., A B, V sequence in Baade's Window, PASP, 1984, vol. 96, p. 603 
Blecha A., Cayatte V., North P., Royer F., Simond G., Data-reduction software for GIRAFFE, the VLT medium-resolution multi-object fiber-fed spectrograph, SPIE, 2000, vol. 4008 , p. 467

Bonnarel F., Fernique P., Bienaymé O., Egret D., Genova F., Louys M., Ochsenbein F., Wenger M., Bartlett J. G., The ALADIN interactive sky atlas. A reference tool for identification of astronomical sources, A\&AS, 2000, vol. 143, p. 33

Cantat-Gaudin T., Donati P., Pancino E., Bragaglia A., Vallenari A., Friel E. D., Sordo R., Jacobson H. R., Magrini L., DOOp, an automated wrapper for DAOSPEC, A\&A, 2014, vol. 562, p. A10

Carretta E., Bragaglia A., Gratton R. G., Lucatello S., Catanzaro G., Leone F., Bellazzini M., Claudi R., D’Orazi V., Momany Y., Ortolani S., Pancino E., Piotto G., Recio-Blanco A., Sabbi E., Na-O anticorrelation and HB. VII. The chemical composition of first and second-generation stars in 15 globular clusters from GIRAFFE spectra, A\&A, 2009, vol. 505 , p. 117

Cassisi S., Bragaglia A., Gratton R., Milone A., Piotto G., Renzini A., Evidence for Sub-Populations in Globular Clusters: Their Properties and Relationship with Cluster Properties, The Messenger, 2008, vol. 134, p. 13

Castilho B. V., Síntese espectral no ultravioleta próximo : determinação da abundância de berílio em gigantes ricas em lítio e síntese de populações estelares simples., Universidade de São Paulo - Instituto de Astronomia, Geofísica e Ciências Atmosféricas, 1999, Tese de Doutorado

Cayrel R., Depagne E., Spite M., Hill V., Spite F., François P., Plez B., Beers T., Primas F., Andersen J., Barbuy B., Bonifacio P., Molaro P., Nordström B., First stars V Abundance patterns from $\mathrm{C}$ to $\mathrm{Zn}$ and supernova yields in the early Galaxy, $\mathrm{A} \& \mathrm{~A}$, 2004, vol. 416, p. 1117

Cenarro A. J., Peletier R. F., Sánchez-Blázquez P., Selam S. O., Toloba E., Cardiel N., Falcón-Barroso J., Gorgas J., Jiménez-Vicente J., Vazdekis A., Medium-resolution Isaac Newton Telescope library of empirical spectra - II. The stellar atmospheric parameters, MNRAS, 2007, vol. 374, p. 664 
Cescutti G., Chiappini C., Explaining the Ba, Y, Sr, and Eu abundance scatter in metalpoor halo stars: constraints to the r-process, A\&A, 2014, vol. 565, p. A51

Cescutti G., Chiappini C., Hirschi R., Meynet G., Frischknecht U., The s-process in the Galactic halo: the fifth signature of spinstars in the early Universe?, A\&A, 2013, vol. 553, p. A51

Chiappini C., Cescutti G., Barbuy B., Meynet G., Hirschi R., New eyes on the first stars: the old bulge component and the important role of PNe in this context, IAU General Assembly, 2015, vol. 22, p. 2255871

Chiappini C., Frischknecht U., Meynet G., Hirschi R., Barbuy B., Pignatari M., Decressin T., Maeder A., Imprints of fast-rotating massive stars in the Galactic Bulge, NATURE, 2011, vol. 472, p. 454

Chiappini C., Hirschi R., Meynet G., Ekström S., Maeder A., Matteucci F., A strong case for fast stellar rotation at very low metallicities, A\&A, 2006, vol. 449, p. L27

Coelho P., Barbuy B., Meléndez J., Schiavon R. P., Castilho B. V., A library of high resolution synthetic stellar spectra from $300 \mathrm{~nm}$ to $1.8 \mu \mathrm{m}$ with solar and $\alpha$-enhanced composition, A\&A, 2005, vol. 443, p. 735

Dékány I., Minniti D., Catelan M., Zoccali M., Saito R. K., Hempel M., Gonzalez O. A., VVV Survey Near-infrared Photometry of Known Bulge RR Lyrae Stars: The Distance to the Galactic Center and Absence of a Barred Distribution of the Metal-poor Population, ApJ, 2013, vol. 776, p. L19

Dekker H., D’Odorico S., Kaufer A., Delabre B., Kotzlowski H., Design, construction, and performance of UVES, the echelle spectrograph for the UT2 Kueyen Telescope at the ESO Paranal Observatory, SPIE, 2000, vol. 4008, p. 534

Dias B., Araya I., Nogueira-Cavalcante J. P., Saker L., Shokry A., Galactic or extragalactic chemical tagging for NGC 3201?. Discovery of an anomalous CN-CH relation, A\&A, 2018, vol. 614, p. A146

Dias B., Barbuy B., Saviane I., Held E. V., Da Costa G. S., Ortolani S., Vasquez S., Gullieuszik M., Katz D., FORS2/VLT survey of Milky Way globular clusters. I. Description 
of the method for derivation of metal abundances in the optical and application to NGC 6528, NGC 6553, M 71, NGC 6558, NGC 6426, and Terzan 8, A\&A, 2015, vol. 573, p. A13

Diemand J., Madau P., Moore B., The distribution and kinematics of early high- $\sigma$ peaks in present-day haloes: implications for rare objects and old stellar populations, MNRAS, 2005, vol. 364 , p. 367

Ernandes H., Barbuy B., Alves-Brito A., Friaca A., Siqueira-Mello C., Allen D. M., Ironpeak elements Sc, V, Mn, Cu and Zn in Galactic bulge globular clusters, ArXiv e-prints, 2018

Fernández-Trincado J. G., Zamora O., Souto D., Cohen R. E., Dell'Agli F., GarcíaHernández D. A., Masseron T., Schiavon R. P., et al. H-band discovery of additional second-generation stars in the Galactic bulge globular cluster NGC 6522, ArXiv e-prints, 2018

Freudling W., Romaniello M., Bramich D. M., Ballester P., Forchi V., García-Dabló C. E., Moehler S., Neeser M. J., Automated data reduction workflows for astronomy. The ESO Reflex environment, A\&A, 2013, vol. 559, p. A96

Frischknecht U., Hirschi R., Pignatari M., Maeder A., Meynet G., Chiappini C., Thielemann F.-K., Rauscher T., Georgy C., Ekström S., s-process production in rotating massive stars at solar and low metallicities, MNRAS, 2016, vol. 456, p. 1803

Frischknecht U., Hirschi R., Thielemann F.-K., Non-standard s-process in low metallicity massive rotating stars, A\&A, 2012, vol. 538, p. L2

Gaia Collaboration Brown A. G. A., Vallenari A., Prusti T., de Bruijne J. H. J., Babusiaux C., Bailer-Jones C. A. L., Gaia Data Release 2. Summary of the contents and survey properties, ArXiv e-prints, 2018

Gaia Collaboration Prusti T., de Bruijne J. H. J., Brown A. G. A., Vallenari A., Babusiaux C., Bailer-Jones C. A. L., Bastian U., Biermann M., Evans D. W., et al. The Gaia mission, A\&A, 2016, vol. 595, p. A1 
Goriely S., Sida J.-L., Lemaître J.-F., Panebianco S., Dubray N., Hilaire S., Bauswein A., Janka H.-T., New Fission Fragment Distributions and r-Process Origin of the Rare-Earth Elements, Physical Review Letters, 2013, vol. 111, p. 242502

Gray D. F., The Observation and Analysis of Stellar Photospheres 3 edn. Cambridge University Press, 2005

Gustafsson B., Edvardsson B., Eriksson K., Jorgensen U. G., Nordlund A., Plez B., A grid of MARCS model atmospheres for late-type stars. I. Methods and general properties, A\&A, 2008, vol. 486, p. 951

Hammer F., Hill V., Cayatte V., GIRAFFE sur le VLT: un instrument dédié à la physique stellaire et extragalactique, Journal des Astronomes Francais, 1999, vol. 60, p. 19

Hansen C. J., Bergemann M., Cescutti G., François P., Arcones A., Karakas A. I., Lind K., Chiappini C., LTE or non-LTE, that is the question. The NLTE chemical evolution of strontium in extremely metal-poor stars, A\&A, 2013, vol. 551, p. A57

Harris W. E., A Catalog of Parameters for Globular Clusters in the Milky Way, AJ, 1996, vol. 112 , p. 1487

Husser T.-O., Kamann S., Dreizler S., Wendt M., Wulff N., Bacon R., Wisotzki L., Brinchmann J., Weilbacher P. M., Roth M. M., Monreal-Ibero A., MUSE crowded field 3D spectroscopy of over 12000 stars in the globular cluster NGC 6397. I. The first comprehensive HRD of a globular cluster, A\&A, 2016, vol. 588, p. A148

Kamann S., , 2018 PampelMuse: Crowded-field 3D spectroscopy Astrophysics Source Code Library

Kamann S., Husser T.-O., Brinchmann J., Emsellem E., Weilbacher P. M., Wisotzki L., Wendt M., Krajnović D., Roth M. M., Bacon R., Dreizler S., MUSE crowded field 3D spectroscopy of over 12000 stars in the globular cluster NGC 6397. II. Probing the internal dynamics and the presence of a central black hole, A\&A, 2016, vol. 588, p. A149

Kamann S., Husser T.-O., Dreizler S., Emsellem E., Weilbacher P. M., Martens S., Bacon R., den Brok M., Giesers B., Krajnović D., Roth M. M., Wendt M., Wisotzki L., A 
stellar census in globular clusters with MUSE: The contribution of rotation to cluster dynamics studied with 200000 stars, MNRAS, 2018, vol. 473, p. 5591

Katz D., Automatic determination of stellar atmospheric parameters, Journal of Astronomical Data, 2001, vol. 7

Kerber L., Nardiello D., Ortolani S., Barbuy B., Bica E., Cassisi S., Libralato M., Vieira R. G., Ages of the Bulge Globular Clusters NGC 6522 and NGC 6626 (M28) from HST Proper-motion-cleaned Color-Magnitude Diagrams, Apj, 2018, vol. 853, p. 15

Kraft R. P., Ivans I. I., A Globular Cluster Metallicity Scale Based on the Abundance of Fe II, PASP, 2003, vol. 115, p. 143

Kramida A., Ralchenko Y., Reader J., Current Status of Atomic Spectroscopy Databases at NIST, APS Division of Atomic and Molecular Physics Meeting, 2016, p. Q1.202

Lecureur A., Hill V., Zoccali M., Barbuy B., Gómez A., Minniti D., Ortolani S., Renzini A., Oxygen, sodium, magnesium, and aluminium as tracers of the galactic bulge formation, A\&A, 2007, vol. 465, p. 799

Lee Y.-W., Evidence for an old Galactic bulge from RR Lyrae stars in Baade's window - Implications for the formation of the Galaxy and the age of the universe, AJ, 1992, vol. 104 , p. 1780

Lee Y.-W., Gim H. B., Casetti-Dinescu D. I., Kinematic Decoupling of Globular Clusters with the Extended Horizontal Branch, ApJ, 2007, vol. 661, p. L49

Meléndez J. L., Espectroscopia no infravermelho abundâncias de oxigênio em estrelas pobres em metais., Universidade de São Paulo - Instituto de Astronomia, Geofísica e Ciências Atmosféricas, 2000, Tese de Doutorado

Milone A., Sansom A. E., Sánchez-Blázquez P., The Mg/Fe characterization of the MILES library for stellar populations studies. In Stellar Populations - Planning for the Next Decade , vol. 262 of IAU Symposium, 2010, p. 394

Minniti D., Lucas P. W., Emerson J. P., Saito R. K., Hempel M., Pietrukowicz P., Ahumada A. V., Alonso M. V., Alonso-Garcia J., Arias J. I., Bandyopadhyay R. M., Barbá R. H., 
Barbuy B., Bedin L. R., Bica E., VISTA Variables in the Via Lactea (VVV): The public ESO near-IR variability survey of the Milky Way, New A, 2010, vol. 15, p. 433

Minniti D., Olszewski E. W., Rieke M., IR Color-Magnitude Diagrams of 20 Galactic Globular Clusters and Bulge Fields, AJ, 1995, vol. 110, p. 1686

Modigliani A., Mulas G., Porceddu I., Wolff B., Damiani F., Banse B. K., The FLAMESUVES Pipeline, The Messenger, 2004, vol. 118, p. 8

Monroe T. R., Meléndez J., Ramírez I., Yong D., Bergemann M., Asplund M., Bedell M., Tucci Maia M., Bean J., Lind K., Alves-Brito A., Casagrande L., Castro M., do Nascimento J., Bazot M., Freitas F. C., High Precision Abundances of the Old Solar Twin HIP 102152: Insights on Li Depletion from the Oldest Sun, ApJL, 2013, vol. 774, p. L32

Moore B., Diemand J., Madau P., Zemp M., Stadel J., Globular clusters, satellite galaxies and stellar haloes from early dark matter peaks, MNRAS, 2006, vol. 368, p. 563

Nakamura K., Kajino T., Mathews G. J., Sato S., Harikae S., a Review of r-PROCESS Nucleosynthesis in the Collapsar Jet, International Journal of Modern Physics E, 2013, vol. 22 , p. 1330022

Ness M., Asplund M., Casey A. R., NGC 6522: a typical globular cluster in the Galactic bulge without signatures of rapidly rotating Population III stars, MNRAS, 2014, vol. 445, p. 2994

Nomoto K., Kobayashi C., Tominaga N., Nucleosynthesis in Stars and the Chemical Enrichment of Galaxies, ARA\&A, 2013, vol. 51, p. 457

Origlia L., Rich R. M., High-Resolution Infrared Spectra of Bulge Globular Clusters: The Extreme Chemical Abundances of Terzan 4 and Terzan 5, AJ, 2004, vol. 127, p. 3422

Pasquini L., Avila G., Blecha A., Cacciari C., Cayatte V., Colless M., Damiani F., de Propris R., Dekker H., di Marcantonio P., Farrell T., Gillingham P., Guinouard I., Hammer F., Kaufer A., Hill V., Marteaud M. e. a., Installation and commissioning of FLAMES, the VLT Multifibre Facility, The Messenger, 2002, vol. 110, p. 1 
Pignatari M., Gallino R., Meynet G., Hirschi R., Herwig F., Wiescher M., The s-Process in Massive Stars at Low Metallicity: The Effect of Primary ${ }^{14} \mathrm{~N}$ from Fast Rotating Stars, ApjL, 2008, vol. 687, p. L95

Piotto G., King I. R., Djorgovski S. G., Sosin C., Zoccali M., Saviane I., De Angeli F., Riello M., Recio-Blanco A., Rich R. M., Meylan G., Renzini A., HST color-magnitude diagrams of 74 galactic globular clusters in the HST F439W and F555W bands, A\&A, 2002, vol. 391, p. 945

Qian Y.-Z., Astrophysical models of r-process nucleosynthesis: An update. In American Institute of Physics Conference Series, vol. 1484 of American Institute of Physics Conference Series, 2012, p. 201

Recio-Blanco A., Rojas-Arriagada A., de Laverny P., Mikolaitis S., Hill V., Zoccali M., Fernández-Trincado J. G., Robin A. C., Babusiaux C., et al. The Gaia-ESO Survey: Low- $\alpha$ element stars in the Galactic bulge, A\&A, 2017, vol. 602, p. L14

Rich R. M., Ortolani S., Bica E., Barbuy B., VI Photometry of the Post-Core-Collapse Globular Cluster NGC 6558 and the Adjacent Bulge Field Population, AJ, 1998, vol. 116, p. 1295

Rojas-Arriagada A., Recio-Blanco A., de Laverny P., Mikolaitis Š., Matteucci F., Spitoni E., Schultheis M., Hayden M., Hill V., Zoccali M., et al. The Gaia-ESO Survey: Exploring the complex nature and origins of the Galactic bulge populations, A\&A, 2017, vol. 601, p. A140

Rossi L. J., Ortolani S., Barbuy B., Bica E., Bonfanti A., Proper motions and kinematics of selected bulge globular clusters, MNRAS, 2015, vol. 45, p. 3270

Rutledge G. A., Hesser J. E., Stetson P. B., Galactic Globular Cluster Metallicity Scale from the Ca II Triplet II. Rankings, Comparisons, and Puzzles, PASP, 1997, vol. 109, p. 907

Rutledge G. A., Hesser J. E., Stetson P. B., Mateo M., Simard L., Bolte M., Friel E. D., Copin Y., Galactic Globular Cluster Metallicity Scale from the Ca II Triplet I. Catalog, PASP, 1997, vol. 109, p. 883 
Ryabchikova T., Piskunov N., Kurucz R. L., Stempels H. C.; Heiter U., Pakhomov Y., Barklem P. S., A major upgrade of the VALD database, PhyS, 2015, vol. 90, p. e4005R

Sánchez-Blázquez P., Peletier R. F., Jiménez-Vicente J., Cardiel N., Cenarro A. J., FalcónBarroso J., Gorgas J., Selam S., Vazdekis A., Medium-resolution Isaac Newton Telescope library of empirical spectra, MNRAS, 2006, vol. 371, p. 703

Schiavon R. P., Síntese espectral no infravermelho próximo com a aplicação à síntese de populações estelares., Universidade de São Paulo - Instituto de Astronomia, Geofísica e Ciências Atmosféricas, 1998, Tese de Doutorado

Schiavon R. P., Johnson J. A., Frinchaboy P. M., Zasowski G., Mészáros S., GarcíaHernández D. A., Cohen R. E., Tang B., Villanova S., et al. APOGEE chemical abundances of globular cluster giants in the inner Galaxy, MNRAS, 2017, vol. 466, p. 1010

Skrutskie M. F., Cutri R. M., Stiening R., Weinberg M. D., Schneider S., Carpenter J. M., Beichman C., Capps R., Chester T., Elias J., Huchra J., Liebert J., Lonsdale C., The Two Micron All Sky Survey (2MASS), AJ, 2006, vol. 131, p. 1163

Spite M., Huille S., Spite F., Francois P., High resolution observations of stars in the peculiar globular cluster Omega CEN, A\&A, 1987, vol. 71, p. 591

Stetson P., Pancino E., DAOSPEC: An Automatic Code for Measuring Equivalent Widths in High-Resolution Stellar Spectra, PASP, 2008, vol. 120, p. 1332S

Taylor M., TOPCAT - Tool for OPerations on Catalogues And Tables, Starlink User Note, 2013, vol. 253

Terndrup D. M., Popowski P., Gould A., Rich R. M., Sadler E. M., The Proper Motion of NGC 6522 in Baade's Window, AJ, 1998, vol. 115, p. 1476

Terndrup D. M., Walker A. R., Blue horizontal branch stars in NGC 6522 and Baade's Window, AJ, 1994, vol. 107, p. 1786

Trager S. C., King I. R., Djorgovski S., Catalogue of Galactic globular-cluster surfacebrightness profiles, AJ, 1995, vol. 109, p. 218

Truran J. W., A new interpretation of the heavy element abundances in metal-deficient stars, A\&A, 1981, vol. 97, p. 391 
Walker A. R., Mack P., CCD observations of some RR Lyrae stars and a standard sequence in Baade's window, MNRAS, 1986, vol. 220, p. 69

Walker A. R., Terndrup D. M., The metallicity of RR Lyrae stars in Baade's window, ApJ, 1991, vol. 378, p. 119

Wanajo S., The r-process in Proto-neutron-star Wind Revisited, ApJ, 2013, vol. 770, p. L22

Weilbacher P. M., Roth M. M., Pécontal-Rousset A., Bacon R., The MUSE data reduction pipeline, New A Rev., 2006, vol. 50, p. 405

Winteler C., Käppeli R., Perego A., Arcones A., Vasset N., Nishimura N., Liebendörfer M., Thielemann F.-K., Magnetorotationally Driven Supernovae as the Origin of Early Galaxy r-process Elements?, ApJ, 2012, vol. 750, p. L22

Zinn R., The globular cluster system of the galaxy. IV - The halo and disk subsystems, ApJ, 1985, vol. 293, p. 424

Zoccali M., Hill V., Lecureur A., Barbuy B., Renzini A., Minniti D., Gómez A., Ortolani S., The metal content of bulge field stars from FLAMES-GIRAFFE spectra, A\&A, 2008, vol. 486 , p. 177

Zoccali M., Vasquez S., Gonzalez O. A., Valenti E., Rojas-Arriagada A., Minniti J., Rejkuba M., Minniti D., McWilliam A., Babusiaux C., Hill V., Renzini A., The GIRAFFE Inner Bulge Survey (GIBS). III. Metallicity distributions and kinematics of 26 Galactic bulge fields, A\&A, 2017, vol. 599, p. A12 
Apêndice 



\section{Apêndice $A$}

\section{Ajustes das linhas espectrais para derivação das}

\section{abundâncias nas estrelas de referência}
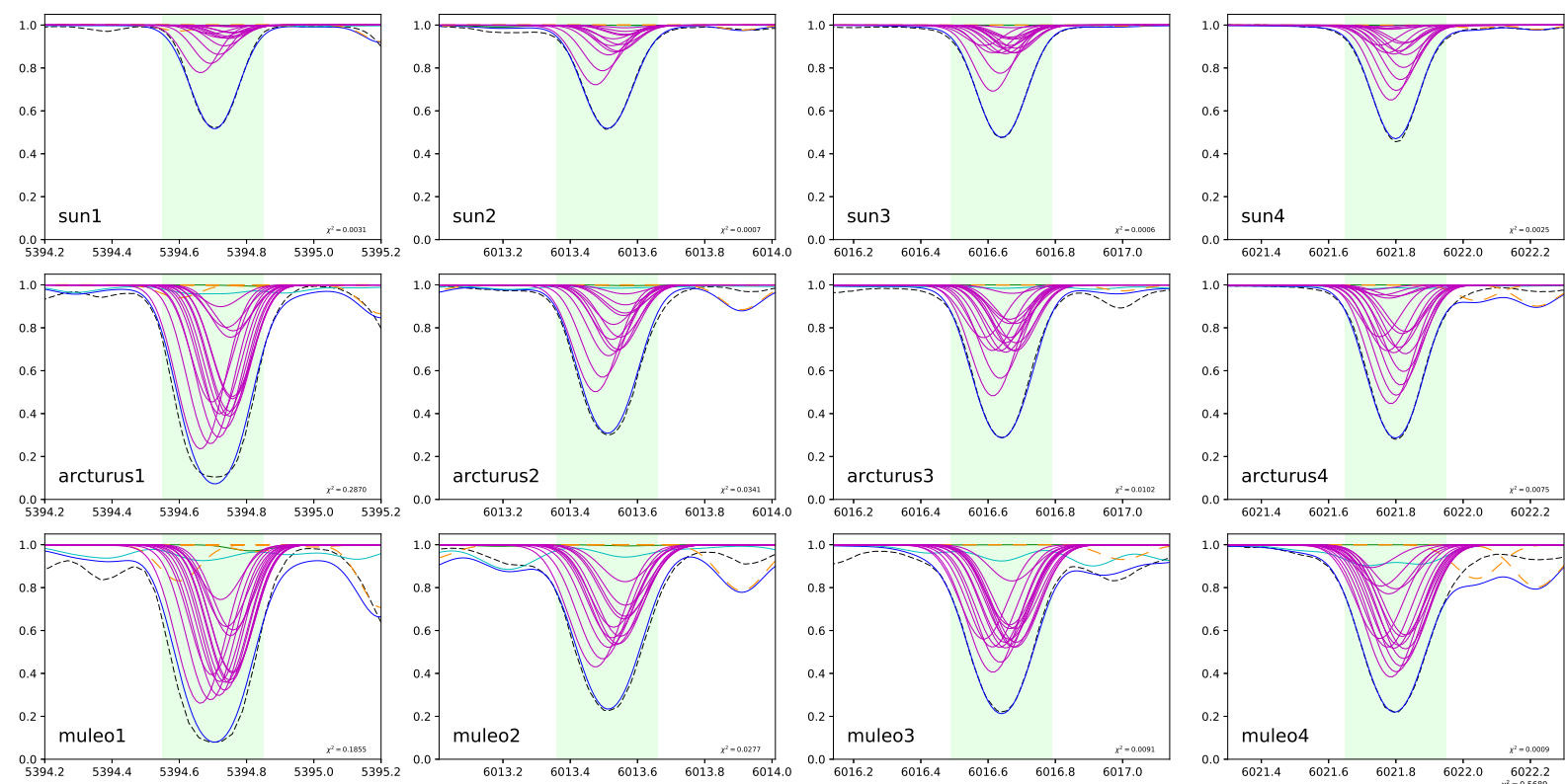

Figura A.1: Sínteses decompostas com os ajustes das linhas espectrais de manganês nas estrelas de referência. As múltiplas linhas em magenta representam as componentes da estrutura hiperfina. 

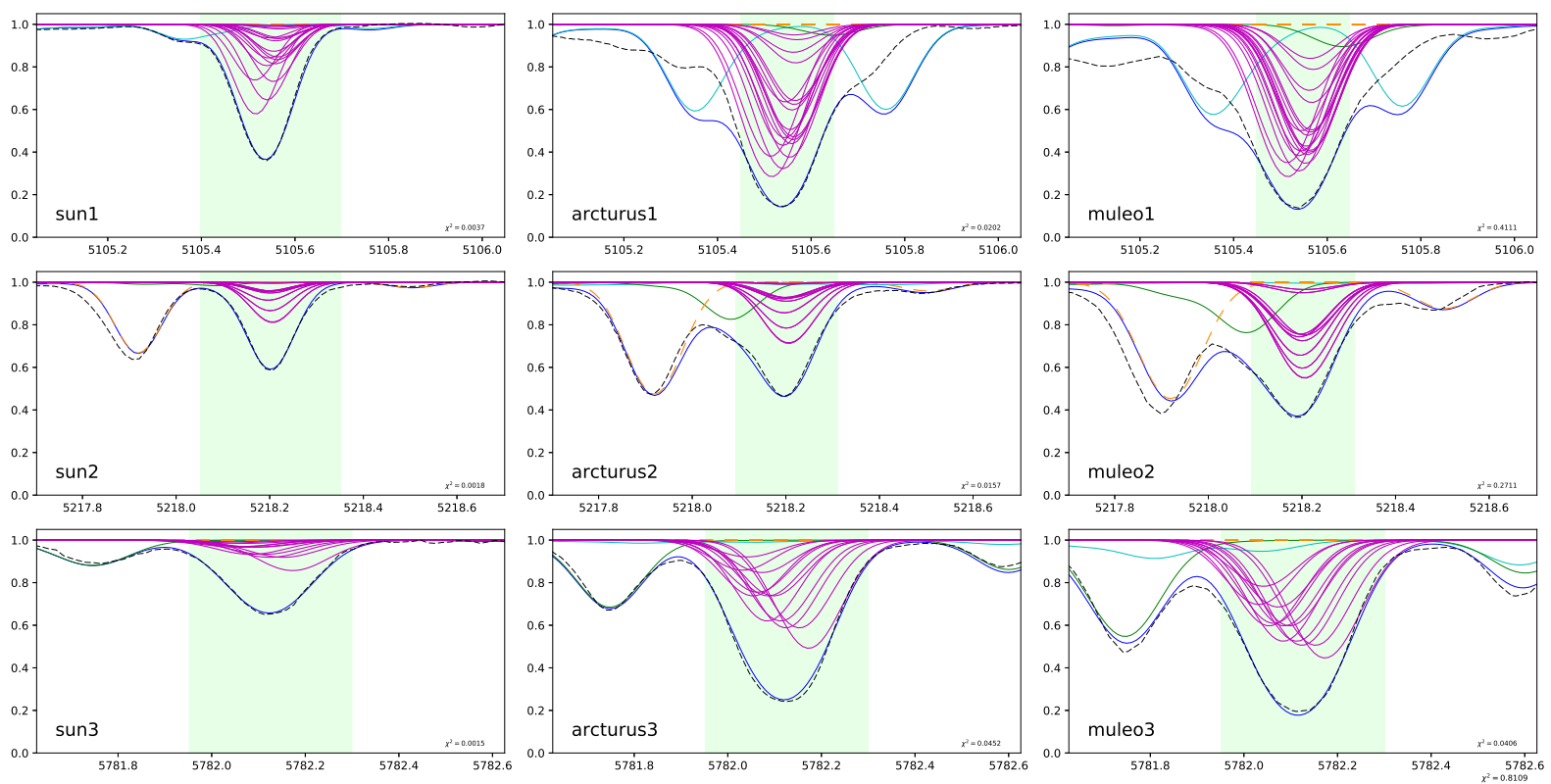

Figura A.2: Sínteses decompostas com os ajustes das linhas espectrais de cobre nas estrelas de referência. As múltiplas linhas em magenta representam as componentes da estrutura hiperfina.
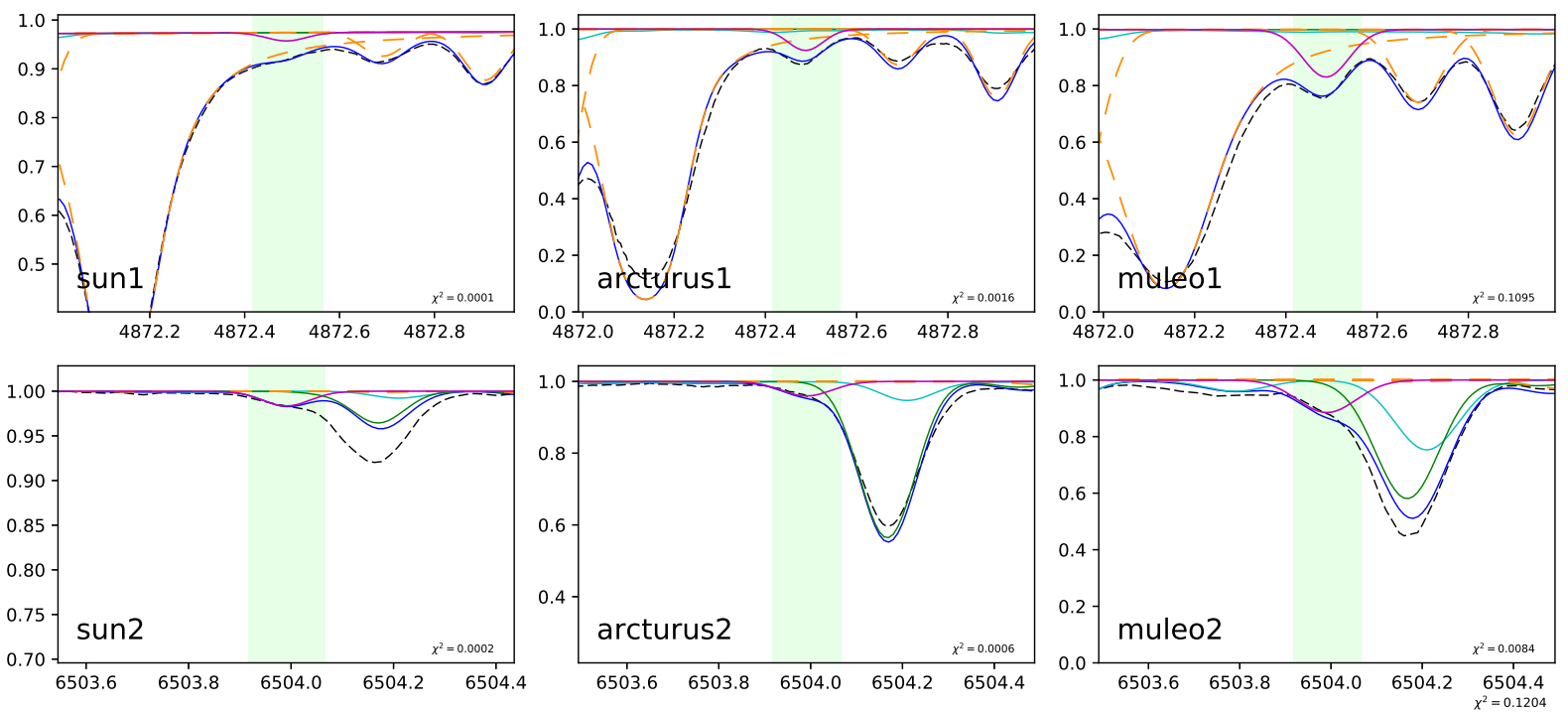

Figura A.3: Sínteses decompostas com os ajustes das linhas espectrais de estrôncio nas estrelas de referência. 

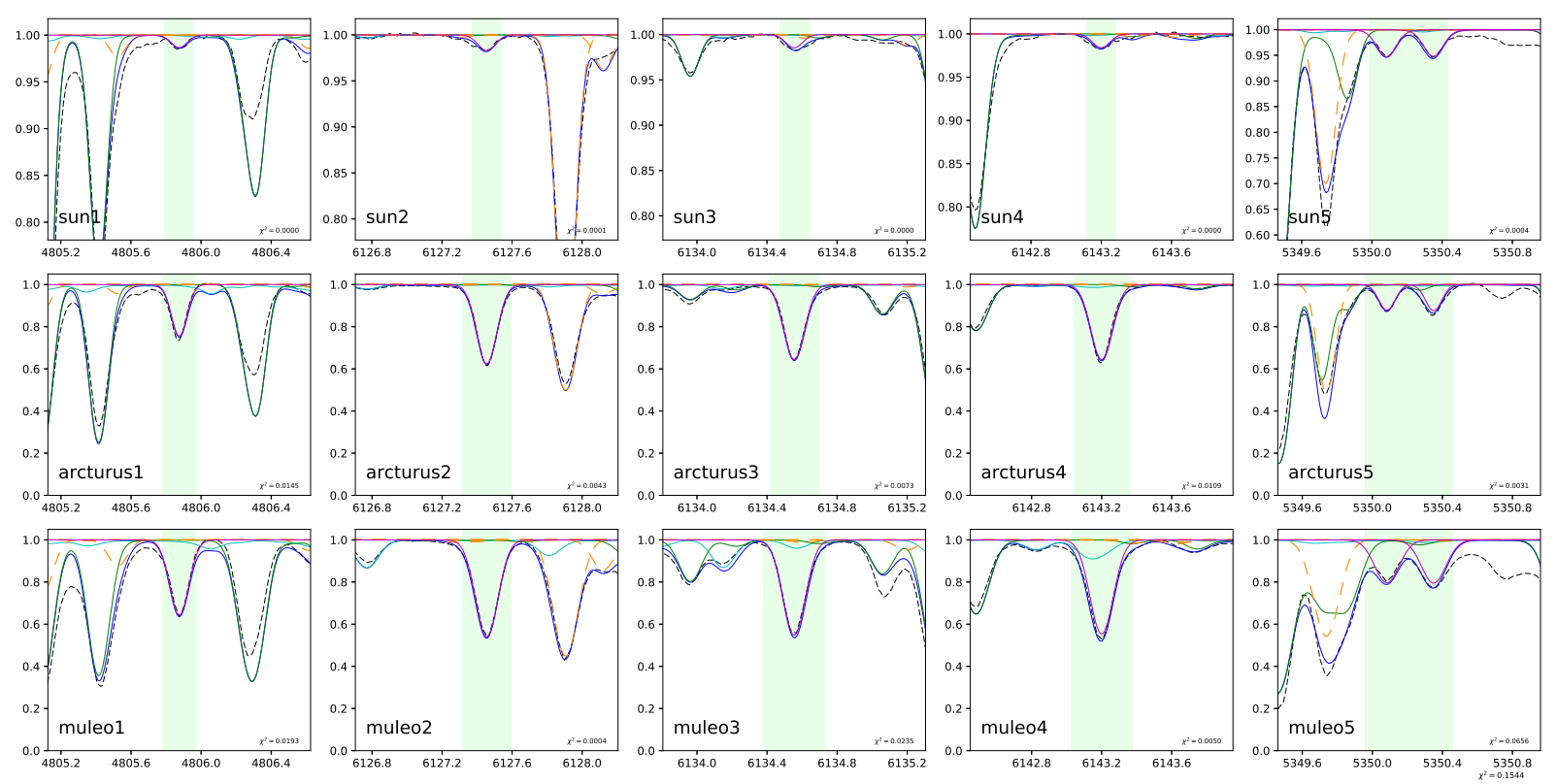

Figura A.4: Sínteses decompostas com os ajustes das linhas espectrais de zircônio nas estrelas de referência.
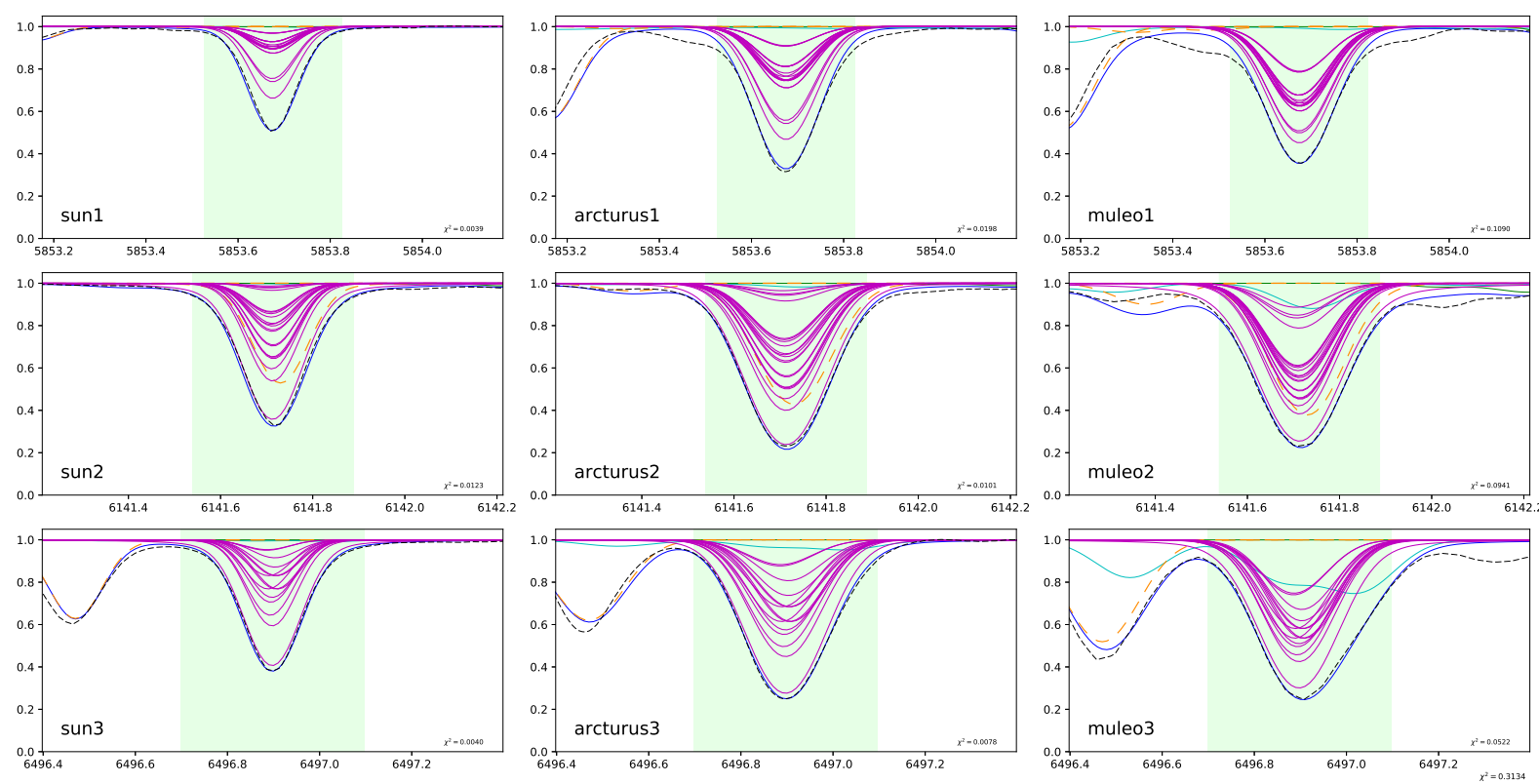

Figura A.5: Sínteses decompostas com os ajustes das linhas espectrais de bário nas estrelas de referência. As múltiplas linhas em magenta representam as componentes da estrutura hiperfina. 

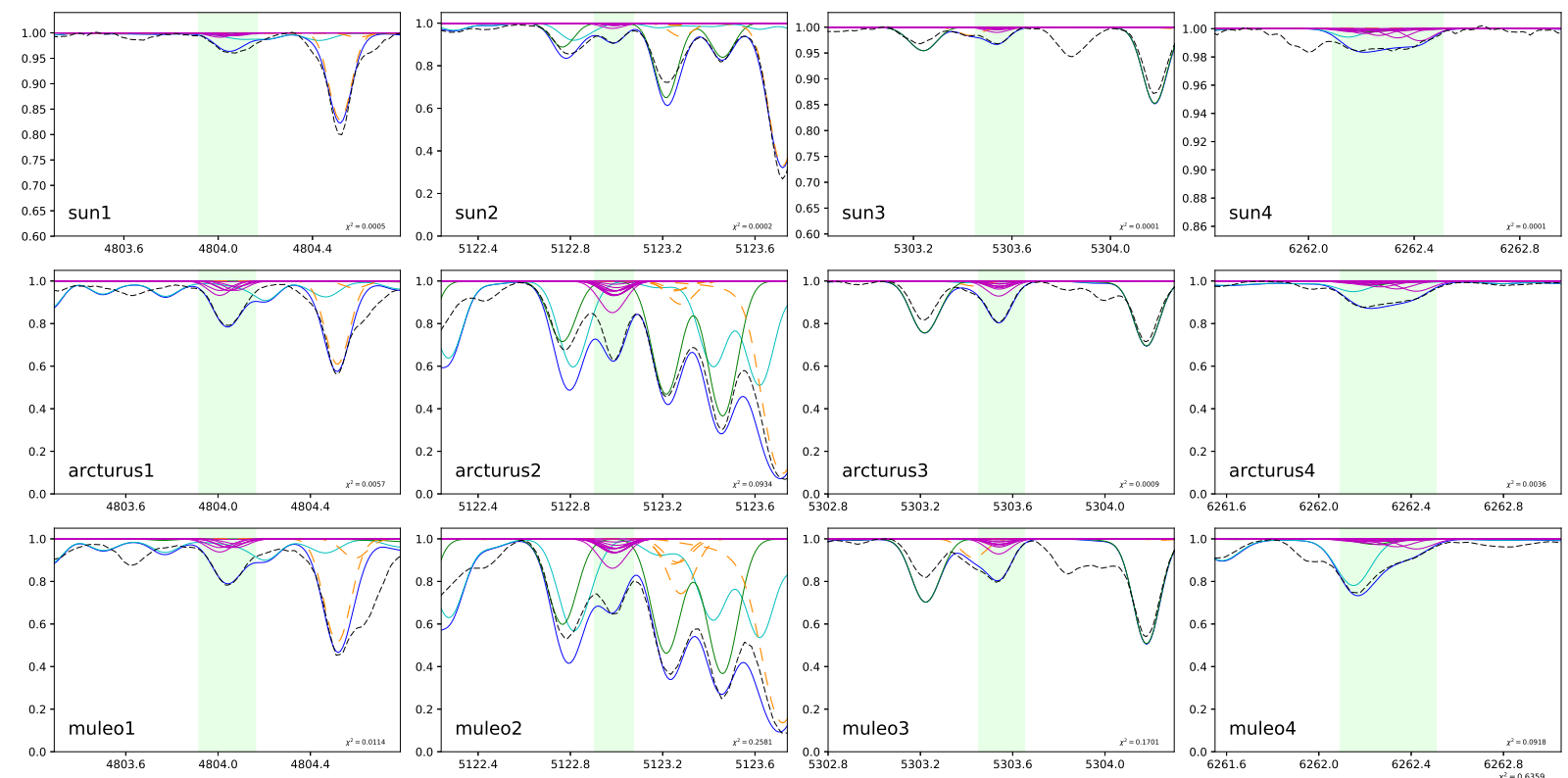

Figura A.6: Sínteses decompostas com os ajustes das linhas espectrais de lantânio nas estrelas de referência. As múltiplas linhas em magenta representam as componentes da estrutura hiperfina.
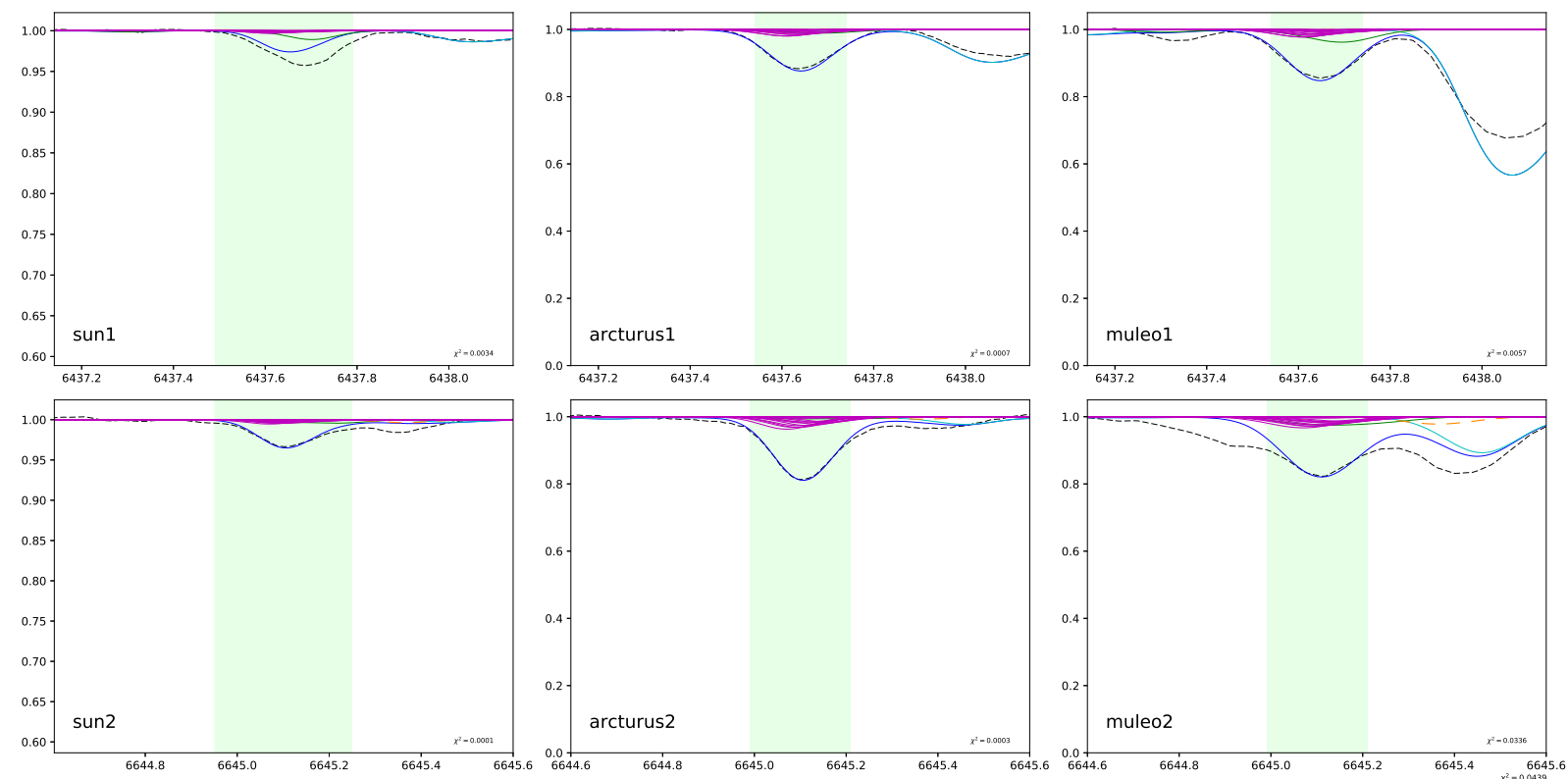

Figura A.7: Sínteses decompostas com os ajustes das linhas espectrais de európio nas estrelas de referência. As múltiplas linhas em magenta representam as componentes da estrutura hiperfina. 


\section{Apêndice B}

\section{Estruturas hiperfinas calculadas}

As estruturas hiperfinas aqui apresentadas foram calculadas e apresentadas nos trabalhos de Barbuy et al. (2014) para Na, Ba, La e Eu, e Ernandes et al. (2018) para Mn e $\mathrm{Cu}$.

Tabela B.1 - Estruturas hiperfinas calculadas para as linhas de Na em Barbuy et al. (2014).

\begin{tabular}{|c|c|c|c|c|c|c|c|c|c|}
\hline \multicolumn{10}{|c|}{$\mathrm{NaI}$} \\
\hline$\lambda$ & isótopo & $\chi_{e x c}$ & $\log g f$ & C6 & $\lambda$ & isótopo & $\chi_{e x c}$ & $\log g f$ & C6 \\
\hline 6154.223 & & 2.102 & -2.052 & $9.000 \mathrm{E}-32$ & 6160.746 & & 2.104 & -2.052 & $3.000 \mathrm{E}-31$ \\
\hline 6154.225 & & 2.102 & -2.052 & $9.000 \mathrm{E}-32$ & 6160.747 & & 2.104 & -1.605 & $3.000 \mathrm{E}-31$ \\
\hline 6154.227 & & 2.102 & -2.052 & $9.000 \mathrm{E}-32$ & 6160.748 & & 2.104 & -2.052 & $3.000 \mathrm{E}-31$ \\
\hline
\end{tabular}


Tabela B.2 - Estruturas hiperfinas calculadas para as linhas de Mn em Ernandes et al. (2018).

\begin{tabular}{|c|c|c|c|c|c|c|c|c|c|}
\hline \multicolumn{10}{|c|}{ Mn I } \\
\hline$\lambda$ & isótopo & $\chi_{e x c}$ & $\log g f$ & C6 & $\lambda$ & isótopo & $\chi_{e x c}$ & $\log g f$ & C6 \\
\hline 5394.758 & & 0.000 & -5.106 & $0.300 \mathrm{E}-31$ & 6013.559 & & 3.072 & -1.906 & $0.300 \mathrm{E}-29$ \\
\hline 5394.758 & & 0.000 & -5.076 & $0.300 \mathrm{E}-31$ & 6013.549 & & 3.072 & -1.584 & $0.300 \mathrm{E}-29$ \\
\hline 5394.749 & & 0.000 & -4.821 & $0.300 \mathrm{E}-31$ & 6013.529 & & 3.072 & -1.760 & $0.300 \mathrm{E}-29$ \\
\hline 5394.760 & & 0.000 & -5.855 & $0.300 \mathrm{E}-31$ & 6013.563 & & 3.072 & -1.952 & $0.300 \mathrm{E}-29$ \\
\hline 5394.750 & & 0.000 & -4.900 & $0.300 \mathrm{E}-31$ & 6013.543 & & 3.072 & -1.429 & $0.300 \mathrm{E}-29$ \\
\hline 5394.735 & & 0.000 & -4.599 & $0.300 \mathrm{E}-31$ & 6013.514 & & 3.072 & -1.350 & $0.300 \mathrm{E}-29$ \\
\hline 5394.752 & & 0.000 & -5.775 & $0.300 \mathrm{E}-31$ & 6013.564 & & 3.072 & -2.128 & $0.300 \mathrm{E}-29$ \\
\hline 5394.737 & & 0.000 & -4.833 & $0.300 \mathrm{E}-31$ & 6013.535 & & 3.072 & -1.408 & $0.300 \mathrm{E}-29$ \\
\hline 5394.717 & & 0.000 & -4.415 & $0.300 \mathrm{E}-31$ & 6013.496 & & 3.072 & -1.077 & $0.300 \mathrm{E}-29$ \\
\hline 5394.740 & & 0.000 & -5.900 & $0.300 \mathrm{E}-31$ & 6013.563 & & 3.072 & -2.508 & $0.300 \mathrm{E}-29$ \\
\hline 5394.720 & & 0.000 & -4.859 & $0.300 \mathrm{E}-31$ & 6013.524 & & 3.072 & -1.554 & $0.300 \mathrm{E}-29$ \\
\hline 5394.693 & & 0.000 & -4.257 & $0.300 \mathrm{E}-31$ & 6013.475 & & 3.072 & -0.865 & $0.300 \mathrm{E}-29$ \\
\hline 5394.723 & & 0.000 & -6.252 & $0.300 \mathrm{E}-31$ & & & & & \\
\hline 5394.697 & & 0.000 & -5.035 & $0.300 \mathrm{E}-31$ & & & & & \\
\hline 5394.663 & & 0.000 & -4.117 & $0.300 \mathrm{E}-31$ & & & & & \\
\hline 6016.665 & & 3.073 & -1.772 & $0.300 \mathrm{E}-29$ & 6021.829 & & 3.075 & -1.656 & $0.300 \mathrm{E}-29$ \\
\hline 6016.681 & & 3.073 & -1.772 & $0.300 \mathrm{E}-29$ & 6021.819 & & 3.075 & -1.626 & $0.300 \mathrm{E}-29$ \\
\hline 6016.671 & & 3.073 & -2.538 & $0.300 \mathrm{E}-29$ & 6021.799 & & 3.075 & -2.405 & $0.300 \mathrm{E}-29$ \\
\hline 6016.651 & & 3.073 & -1.510 & $0.300 \mathrm{E}-29$ & 6021.828 & & 3.075 & -1.371 & $0.300 \mathrm{E}-29$ \\
\hline 6016.683 & & 3.073 & -1.510 & $0.300 \mathrm{E}-29$ & 6021.809 & & 3.075 & -1.450 & $0.300 \mathrm{E}-29$ \\
\hline 6016.664 & & 3.073 & -1.839 & $0.300 \mathrm{E}-29$ & 6021.779 & & 3.075 & -2.325 & $0.300 \mathrm{E}-29$ \\
\hline 6016.634 & & 3.073 & -1.408 & $0.300 \mathrm{E}-29$ & 6021.823 & & 3.075 & -1.149 & $0.300 \mathrm{E}-29$ \\
\hline 6016.681 & & 3.073 & -1.408 & $0.300 \mathrm{E}-29$ & 6021.794 & & 3.075 & -1.383 & $0.300 \mathrm{E}-29$ \\
\hline 6016.652 & & 3.073 & -1.392 & $0.300 \mathrm{E}-29$ & 6021.755 & & 3.075 & -2.450 & $0.300 \mathrm{E}-29$ \\
\hline 6016.613 & & 3.073 & -1.413 & $0.300 \mathrm{E}-29$ & 6021.814 & & 3.075 & -0.965 & $0.300 \mathrm{E}-29$ \\
\hline 6016.675 & & 3.073 & -1.413 & $0.300 \mathrm{E}-29$ & 6021.775 & & 3.075 & -1.409 & $0.300 \mathrm{E}-29$ \\
\hline 6016.636 & & 3.073 & -1.061 & $0.300 \mathrm{E}-29$ & 6021.726 & & 3.075 & -2.802 & $0.300 \mathrm{E}-29$ \\
\hline 6016.587 & & 3.073 & -1.576 & $0.300 \mathrm{E}-29$ & 6021.801 & & 3.075 & -0.807 & $0.300 \mathrm{E}-29$ \\
\hline 6016.663 & & 3.073 & -1.576 & $0.300 \mathrm{E}-29$ & 6021.752 & & 3.075 & -1.585 & $0.300 \mathrm{E}-29$ \\
\hline 6016.614 & & 3.073 & -0.798 & $0.300 \mathrm{E}-29$ & 6021.785 & & 3.075 & -0.667 & $0.300 \mathrm{E}-29$ \\
\hline
\end{tabular}


Tabela B.3 - Estruturas hiperfinas calculadas para as linhas de Cu em Ernandes et al. (2018).

\begin{tabular}{|c|c|c|c|c|c|c|c|c|c|}
\hline \multicolumn{10}{|c|}{$\mathrm{Cu} \mathrm{I}$} \\
\hline$\lambda$ & isótopo & $\chi_{e x c}$ & $\log g f$ & C6 & $\lambda$ & isótopo & $\chi_{e x c}$ & $\log g f$ & C6 \\
\hline 5105.562 & 63 & 1.389 & -2.886 & $0.120 \mathrm{E}-31$ & 5218.195 & 63 & 3.816 & -1.204 & $0.300 \mathrm{E}-31$ \\
\hline 5105.563 & 63 & 1.389 & -2.931 & $0.120 \mathrm{E}-31$ & 5218.197 & 63 & 3.816 & -1.250 & $0.300 \mathrm{E}-31$ \\
\hline 5105.554 & 63 & 1.389 & -2.563 & $0.120 \mathrm{E}-31$ & 5218.197 & 63 & 3.816 & -0.882 & $0.300 \mathrm{E}-31$ \\
\hline 5105.567 & 63 & 1.389 & -3.886 & $0.120 \mathrm{E}-31$ & 5218.201 & 63 & 3.816 & -2.204 & $0.300 \mathrm{E}-31$ \\
\hline 5105.558 & 63 & 1.389 & -2.819 & $0.120 \mathrm{E}-31$ & 5218.201 & 63 & 3.816 & -1.137 & $0.300 \mathrm{E}-31$ \\
\hline 5105.540 & 63 & 1.389 & -2.314 & $0.120 \mathrm{E}-31$ & 5218.201 & 63 & 3.816 & -0.632 & $0.300 \mathrm{E}-31$ \\
\hline 5105.562 & 63 & 1.389 & -4.062 & $0.120 \mathrm{E}-31$ & 5218.206 & 63 & 3.816 & -2.380 & $0.300 \mathrm{E}-31$ \\
\hline 5105.544 & 63 & 1.389 & -2.916 & $0.120 \mathrm{E}-31$ & 5218.206 & 63 & 3.816 & -1.234 & $0.300 \mathrm{E}-31$ \\
\hline 5105.516 & 63 & 1.389 & -2.108 & $0.120 \mathrm{E}-31$ & 5218.206 & 63 & 3.816 & -0.416 & $0.300 \mathrm{E}-31$ \\
\hline 5105.564 & 65 & 1.389 & -3.362 & $0.120 \mathrm{E}-31$ & 5218.194 & 65 & 3.816 & -1.204 & $0.300 \mathrm{E}-31$ \\
\hline 5105.566 & 65 & 1.389 & -3.408 & $0.120 \mathrm{E}-31$ & 5218.196 & 65 & 3.816 & -1.250 & $0.300 \mathrm{E}-31$ \\
\hline 5105.555 & 65 & 1.389 & -3.040 & $0.120 \mathrm{E}-31$ & 5218.196 & 65 & 3.816 & -0.881 & $0.300 \mathrm{E}-31$ \\
\hline 5105.570 & 65 & 1.389 & -4.362 & $0.120 \mathrm{E}-31$ & 5218.201 & 65 & 3.816 & -2.204 & $0.300 \mathrm{E}-31$ \\
\hline 5105.559 & 65 & 1.389 & -3.295 & $0.120 \mathrm{E}-31$ & 5218.201 & 65 & 3.816 & -1.137 & $0.300 \mathrm{E}-31$ \\
\hline 5105.540 & 65 & 1.389 & -2.790 & $0.120 \mathrm{E}-31$ & 5218.201 & 65 & 3.816 & -0.632 & $0.300 \mathrm{E}-31$ \\
\hline 5105.564 & 65 & 1.389 & -4.538 & $0.120 \mathrm{E}-31$ & 5218.206 & 65 & 3.816 & -2.380 & $0.300 \mathrm{E}-31$ \\
\hline 5105.545 & 65 & 1.389 & -3.392 & $0.120 \mathrm{E}-31$ & 5218.206 & 65 & 3.816 & -1.234 & $0.300 \mathrm{E}-31$ \\
\hline 5105.514 & 65 & 1.389 & -2.584 & $0.120 \mathrm{E}-31$ & 5218.206 & 65 & 3.816 & -0.426 & $0.300 \mathrm{E}-31$ \\
\hline 5782.064 & 63 & 1.642 & -3.285 & $0.120 \mathrm{E}-31$ & & & & & \\
\hline 5782.073 & 63 & 1.642 & -3.589 & $0.120 \mathrm{E}-31$ & & & & & \\
\hline 5782.084 & 63 & 1.642 & -2.888 & $0.120 \mathrm{E}-31$ & & & & & \\
\hline 5782.113 & 63 & 1.642 & -2.888 & $0.120 \mathrm{E}-31$ & & & & & \\
\hline 5782.124 & 63 & 1.642 & -2.787 & $0.120 \mathrm{E}-31$ & & & & & \\
\hline 5782.173 & 63 & 1.642 & -2.441 & $0.120 \mathrm{E}-31$ & & & & & \\
\hline 5782.032 & 65 & 1.642 & -3.632 & $0.120 \mathrm{E}-31$ & & & & & \\
\hline 5782.042 & 65 & 1.642 & -3.935 & $0.120 \mathrm{E}-31$ & & & & & \\
\hline 5782.054 & 65 & 1.642 & -3.234 & $0.120 \mathrm{E}-31$ & & & & & \\
\hline 5782.086 & 65 & 1.642 & -3.234 & $0.120 \mathrm{E}-31$ & & & & & \\
\hline 5782.098 & 65 & 1.642 & -3.234 & $0.120 \mathrm{E}-31$ & & & & & \\
\hline 5782.153 & 65 & 1.642 & -2.787 & $0.120 \mathrm{E}-31$ & & & & & \\
\hline
\end{tabular}


Tabela B.4 - Estruturas hiperfinas calculadas para as linhas de Ba em Barbuy et al. (2014).

\begin{tabular}{|c|c|c|c|c|c|c|c|c|c|}
\hline \multicolumn{10}{|c|}{ Ba II } \\
\hline$\lambda$ & isótopo & $\chi_{e x c}$ & $\log g f$ & C6 & $\lambda$ & isótopo & $\chi_{e x c}$ & $\log g f$ & C6 \\
\hline 5853.675 & 134 & 0.604 & -2.9062 & $0.400 \mathrm{E}-30$ & 6141.713 & 134 & 0.704 & -1.217 & $3.000 \mathrm{E}-32$ \\
\hline 5853.673 & 135 & 0.604 & -2.4941 & $0.400 \mathrm{E}-30$ & 6141.709 & 135 & 0.704 & -1.985 & $3.000 \mathrm{E}-32$ \\
\hline 5853.674 & 135 & 0.604 & -2.4941 & $0.400 \mathrm{E}-30$ & 6141.709 & 135 & 0.704 & -2.031 & $3.000 \mathrm{E}-32$ \\
\hline 5853.674 & 135 & 0.604 & -2.8921 & $0.400 \mathrm{E}-30$ & 6141.708 & 135 & 0.704 & -2.985 & $3.000 \mathrm{E}-32$ \\
\hline 5853.673 & 135 & 0.604 & -2.2900 & $0.400 \mathrm{E}-30$ & 6141.712 & 135 & 0.704 & -1.663 & $3.000 \mathrm{E}-32$ \\
\hline 5853.677 & 135 & 0.604 & -2.2900 & $0.400 \mathrm{E}-30$ & 6141.710 & 135 & 0.704 & -1.918 & $3.000 \mathrm{E}-32$ \\
\hline 5853.676 & 135 & 0.604 & -2.1931 & $0.400 \mathrm{E}-30$ & 6141.705 & 135 & 0.704 & -3.161 & $3.000 \mathrm{E}-32$ \\
\hline 5853.671 & 135 & 0.604 & -2.2980 & $0.400 \mathrm{E}-30$ & 6141.714 & 135 & 0.704 & -1.413 & $3.000 \mathrm{E}-32$ \\
\hline 5853.679 & 135 & 0.604 & -2.2980 & $0.400 \mathrm{E}-30$ & 6141.709 & 135 & 0.704 & -2.015 & $3.000 \mathrm{E}-32$ \\
\hline 5853.675 & 135 & 0.604 & -1.6959 & $0.400 \mathrm{E}-30$ & 6141.715 & 135 & 0.704 & -1.207 & $3.000 \mathrm{E}-32$ \\
\hline 5853.675 & 136 & 0.604 & -2.3951 & $0.400 \mathrm{E}-30$ & 6141.713 & 136 & 0.704 & -0.705 & $3.000 \mathrm{E}-32$ \\
\hline 5853.673 & 137 & 0.604 & -2.4941 & $0.400 \mathrm{E}-30$ & 6141.713 & 137 & 0.704 & -1.754 & $3.000 \mathrm{E}-32$ \\
\hline 5853.674 & 137 & 0.604 & -2.4941 & $0.400 \mathrm{E}-30$ & 6141.713 & 137 & 0.704 & -1.800 & $3.000 \mathrm{E}-32$ \\
\hline 5853.674 & 137 & 0.604 & -2.8921 & $0.400 \mathrm{E}-30$ & 6141.712 & 137 & 0.704 & -2.740 & $3.000 \mathrm{E}-32$ \\
\hline 5853.673 & 137 & 0.604 & -2.2900 & $0.400 \mathrm{E}-30$ & 6141.714 & 137 & 0.704 & -1.432 & $3.000 \mathrm{E}-32$ \\
\hline 5853.677 & 137 & 0.604 & -2.2900 & $0.400 \mathrm{E}-30$ & 6141.713 & 137 & 0.704 & -1.687 & $3.000 \mathrm{E}-32$ \\
\hline 5853.676 & 137 & 0.604 & -2.1931 & $0.400 \mathrm{E}-30$ & 6141.707 & 137 & 0.704 & -2.930 & $3.000 \mathrm{E}-32$ \\
\hline 5853.670 & 137 & 0.604 & -2.3480 & $0.400 \mathrm{E}-30$ & 6141.715 & 137 & 0.704 & -1.182 & $3.000 \mathrm{E}-32$ \\
\hline 5853.680 & 137 & 0.604 & -2.3480 & $0.400 \mathrm{E}-30$ & 6141.709 & 137 & 0.704 & -1.784 & $3.000 \mathrm{E}-32$ \\
\hline 5853.674 & 137 & 0.604 & -1.7459 & $0.400 \mathrm{E}-30$ & 6141.711 & 137 & 0.704 & -0.976 & $3.000 \mathrm{E}-32$ \\
\hline 5853.675 & 138 & 0.604 & -1.4345 & $0.400 \mathrm{E}-30$ & 6141.713 & 138 & 0.704 & 0.344 & $3.000 \mathrm{E}-32$ \\
\hline 6496.897 & 134 & 0.604 & -1.637 & $1.000 \mathrm{E}-31$ & & & & & \\
\hline 6496.903 & 135 & 0.604 & -2.404 & $1.000 \mathrm{E}-31$ & & & & & \\
\hline 6496.904 & 135 & 0.604 & -2.006 & $1.000 \mathrm{E}-31$ & & & & & \\
\hline 6496.886 & 135 & 0.604 & -2.705 & $1.000 \mathrm{E}-31$ & & & & & \\
\hline 6496.907 & 135 & 0.604 & -2.006 & $1.000 \mathrm{E}-31$ & & & & & \\
\hline 6496.889 & 135 & 0.604 & -2.006 & $1.000 \mathrm{E}-31$ & & & & & \\
\hline 6496.894 & 135 & 0.604 & -1.558 & $1.000 \mathrm{E}-31$ & & & & & \\
\hline 6496.897 & 136 & 0.604 & -1.125 & $1.000 \mathrm{E}-31$ & & & & & \\
\hline 6496.903 & 137 & 0.604 & -2.175 & $1.000 \mathrm{E}-31$ & & & & & \\
\hline 6496.905 & 137 & 0.604 & -1.777 & $1.000 \mathrm{E}-31$ & & & & & \\
\hline 6496.885 & 137 & 0.604 & -2.676 & $1.000 \mathrm{E}-31$ & & & & & \\
\hline 6496.909 & 137 & 0.604 & -1.777 & $1.000 \mathrm{E}-31$ & & & & & \\
\hline 6496.888 & 137 & 0.604 & -1.777 & $1.000 \mathrm{E}-31$ & & & & & \\
\hline 6496.893 & 137 & 0.604 & -1.330 & $1.000 \mathrm{E}-31$ & & & & & \\
\hline 6496.897 & 138 & 0.604 & -0.164 & $1.000 \mathrm{E}-31$ & & & & & \\
\hline
\end{tabular}


Tabela B.5 - Estruturas hiperfinas calculadas para as linhas de La em Barbuy et al. (2014).

\begin{tabular}{|c|c|c|c|c|c|c|c|c|c|}
\hline \multicolumn{10}{|c|}{ La II } \\
\hline$\lambda$ & isótopo & $\chi_{e x c}$ & $\log g f$ & C6 & $\lambda$ & isótopo & $\chi_{e x c}$ & $\log g f$ & C6 \\
\hline 4804.007 & & 0.235 & -2.044 & $3.000 \mathrm{e}-32$ & 5122.982 & 73 & 0.320 & -1.487 & $0.300 \mathrm{E}-31$ \\
\hline 4804.009 & & 0.235 & -2.240 & $3.000 \mathrm{e}-32$ & 5122.982 & 73 & 0.320 & -2.057 & $0.300 \mathrm{E}-31$ \\
\hline 4804.045 & & 0.235 & -2.240 & $3.000 \mathrm{e}-32$ & 5122.988 & 73 & 0.320 & -1.884 & $0.300 \mathrm{E}-31$ \\
\hline 4804.048 & & 0.235 & -3.425 & $3.000 \mathrm{e}-32$ & 5122.988 & 73 & 0.320 & -2.057 & $0.300 \mathrm{E}-31$ \\
\hline 4804.050 & & 0.235 & -2.244 & $3.000 \mathrm{e}-32$ & 5122.989 & 73 & 0.320 & -1.898 & $0.300 \mathrm{E}-31$ \\
\hline 4804.079 & & 0.235 & -2.244 & $3.000 \mathrm{e}-32$ & 5122.990 & 73 & 0.320 & -3.905 & $0.300 \mathrm{E}-31$ \\
\hline \multirow[t]{8}{*}{4804.081} & & 0.235 & -2.499 & $3.000 \mathrm{e}-32$ & 5122.993 & 73 & 0.320 & -1.898 & $0.300 \mathrm{E}-31$ \\
\hline & & & & & 5122.993 & 73 & 0.320 & -2.581 & $0.300 \mathrm{E}-31$ \\
\hline & & & & & 5122.994 & 73 & 0.320 & -1.910 & $0.300 \mathrm{E}-31$ \\
\hline & & & & & 5122.997 & 73 & 0.320 & -1.910 & $0.300 \mathrm{E}-31$ \\
\hline & & & & & 5122.997 & 73 & 0.320 & -4.007 & $0.300 \mathrm{E}-31$ \\
\hline & & & & & 5122.998 & 73 & 0.320 & -2.082 & $0.300 \mathrm{E}-31$ \\
\hline & & & & & 5123.000 & 73 & 0.320 & -2.082 & $0.300 \mathrm{E}-31$ \\
\hline & & & & & 5123.001 & 73 & 0.320 & -2.258 & $0.300 \mathrm{E}-31$ \\
\hline 5303.539 & 71 & 0.320 & -1.913 & $0.660 \mathrm{E}-32$ & 6262.164 & & 0.403 & -2.511 & $3.000 \mathrm{e}-31$ \\
\hline 5303.539 & 71 & 0.320 & -2.403 & $0.660 \mathrm{E}-32$ & 6262.166 & & 0.403 & -2.636 & $3.000 \mathrm{e}-31$ \\
\hline 5303.540 & 71 & 0.320 & -3.102 & $0.660 \mathrm{E}-32$ & 6262.208 & & 0.403 & -2.326 & $3.000 \mathrm{e}-31$ \\
\hline 5303.541 & 71 & 0.320 & -2.206 & $0.660 \mathrm{E}-32$ & 6262.212 & & 0.403 & -2.575 & $3.000 \mathrm{e}-31$ \\
\hline 5303.541 & 71 & 0.320 & -4.435 & $0.660 \mathrm{E}-32$ & 6262.215 & & 0.403 & -3.330 & $3.000 \mathrm{e}-31$ \\
\hline 5303.542 & 71 & 0.320 & -2.287 & $0.660 \mathrm{E}-32$ & 6262.266 & & 0.403 & -2.170 & $3.000 \mathrm{e}-31$ \\
\hline 5303.542 & 71 & 0.320 & -2.662 & $0.660 \mathrm{E}-32$ & 6262.271 & & 0.403 & -2.571 & $3.000 \mathrm{e}-31$ \\
\hline 5303.543 & 71 & 0.320 & -2.406 & $0.660 \mathrm{E}-32$ & 6262.275 & & 0.403 & -3.440 & $3.000 \mathrm{e}-31$ \\
\hline 5303.543 & 71 & 0.320 & -2.662 & $0.660 \mathrm{E}-32$ & 6262.338 & & 0.403 & -2.034 & $3.000 \mathrm{e}-31$ \\
\hline \multirow[t]{5}{*}{5303.544} & 71 & 0.320 & -2.390 & $0.660 \mathrm{E}-32$ & 6262.343 & & 0.403 & -2.637 & $3.000 \mathrm{e}-31$ \\
\hline & & & & & 6262.348 & & 0.403 & -3.652 & $3.000 \mathrm{e}-31$ \\
\hline & & & & & 6262.422 & & 0.403 & -1.913 & $3.000 \mathrm{e}-31$ \\
\hline & & & & & 6262.429 & & 0.403 & -2.842 & $3.000 \mathrm{e}-31$ \\
\hline & & & & & 6262.434 & & 0.403 & -4.055 & $3.000 \mathrm{e}-31$ \\
\hline
\end{tabular}


Tabela B.6 - Estruturas hiperfinas calculadas para as linhas de Eu em Barbuy et al. (2014).

\begin{tabular}{|c|c|c|c|c|c|c|c|c|c|}
\hline \multicolumn{10}{|c|}{ Eu II } \\
\hline$\lambda$ & isótopo & $\chi_{e x c}$ & $\log g f$ & C6 & $\lambda$ & isótopo & $\chi_{e x c}$ & $\log g f$ & C6 \\
\hline 6437.611 & 151 & 1.319 & -1.061 & $0.120 \mathrm{E}-31$ & 6645.071 & 151 & 1.379 & -0.718 & $0.120 \mathrm{E}-31$ \\
\hline 6437.619 & 151 & 1.319 & -2.292 & $0.120 \mathrm{E}-31$ & 6645.078 & 151 & 1.379 & -3.668 & $0.120 \mathrm{E}-31$ \\
\hline 6437.629 & 151 & 1.319 & -2.292 & $0.120 \mathrm{E}-31$ & 6645.085 & 151 & 1.379 & -4.133 & $0.120 \mathrm{E}-31$ \\
\hline 6437.636 & 151 & 1.319 & -1.171 & $0.120 \mathrm{E}-31$ & 6645.097 & 151 & 1.379 & -0.873 & $0.120 \mathrm{E}-31$ \\
\hline 6437.643 & 151 & 1.319 & -2.308 & $0.120 \mathrm{E}-31$ & 6645.104 & 151 & 1.379 & -1.829 & $0.120 \mathrm{E}-31$ \\
\hline 6437.650 & 151 & 1.319 & -2.057 & $0.120 \mathrm{E}-31$ & 6645.112 & 151 & 1.379 & -3.350 & $0.120 \mathrm{E}-31$ \\
\hline 6437.656 & 151 & 1.319 & -1.388 & $0.120 \mathrm{E}-31$ & 6645.118 & 151 & 1.379 & -1.784 & $0.120 \mathrm{E}-31$ \\
\hline 6437.662 & 151 & 1.319 & -2.111 & $0.120 \mathrm{E}-31$ & 6645.126 & 151 & 1.379 & -3.278 & $0.120 \mathrm{E}-31$ \\
\hline 6437.666 & 151 & 1.319 & -2.111 & $0.120 \mathrm{E}-31$ & 6645.133 & 151 & 1.379 & -0.955 & $0.120 \mathrm{E}-31$ \\
\hline 6437.672 & 151 & 1.319 & -1.478 & $0.120 \mathrm{E}-31$ & 6645.137 & 151 & 1.379 & -4.609 & $0.120 \mathrm{E}-31$ \\
\hline 6437.676 & 151 & 1.319 & -2.308 & $0.120 \mathrm{E}-31$ & 6645.144 & 151 & 1.379 & -1.836 & $0.120 \mathrm{E}-31$ \\
\hline 6437.679 & 151 & 1.319 & -2.308 & $0.120 \mathrm{E}-31$ & 6645.150 & 151 & 1.379 & -3.446 & $0.120 \mathrm{E}-31$ \\
\hline 6437.684 & 151 & 1.319 & -1.529 & $0.120 \mathrm{E}-31$ & 6645.152 & 151 & 1.379 & -1.040 & $0.120 \mathrm{E}-31$ \\
\hline 6437.687 & 151 & 1.319 & -1.061 & $0.120 \mathrm{E}-31$ & 6645.158 & 151 & 1.379 & -2.031 & $0.120 \mathrm{E}-31$ \\
\hline 6437.689 & 151 & 1.319 & -1.061 & $0.120 \mathrm{E}-31$ & 6645.163 & 151 & 1.379 & -1.122 & $0.120 \mathrm{E}-31$ \\
\hline 6437.692 & 151 & 1.319 & -2.292 & $0.120 \mathrm{E}-31$ & 6645.072 & 153 & 1.379 & -2.024 & $0.120 \mathrm{E}-31$ \\
\hline 6437.610 & 153 & 1.319 & -1.061 & $0.120 \mathrm{E}-31$ & 6645.074 & 153 & 1.379 & -3.668 & $0.120 \mathrm{E}-31$ \\
\hline 6437.613 & 153 & 1.319 & -2.292 & $0.120 \mathrm{E}-31$ & 6645.074 & 153 & 1.379 & -2.024 & $0.120 \mathrm{E}-31$ \\
\hline 6437.624 & 153 & 1.319 & -2.292 & $0.120 \mathrm{E}-31$ & 6645.087 & 153 & 1.379 & -2.086 & $0.120 \mathrm{E}-31$ \\
\hline 6437.627 & 153 & 1.319 & -1.171 & $0.120 \mathrm{E}-31$ & 6645.089 & 153 & 1.379 & -0.794 & $0.120 \mathrm{E}-31$ \\
\hline 6437.630 & 153 & 1.319 & -2.099 & $0.120 \mathrm{E}-31$ & 6645.094 & 153 & 1.379 & -1.829 & $0.120 \mathrm{E}-31$ \\
\hline 6437.634 & 153 & 1.319 & -2.099 & $0.120 \mathrm{E}-31$ & 6645.096 & 153 & 1.379 & -3.350 & $0.120 \mathrm{E}-31$ \\
\hline 6437.637 & 153 & 1.319 & -1.282 & $0.120 \mathrm{E}-31$ & 6645.101 & 153 & 1.379 & -0.794 & $0.120 \mathrm{E}-31$ \\
\hline 6437.639 & 153 & 1.319 & -2.057 & $0.120 \mathrm{E}-31$ & 6645.104 & 153 & 1.379 & -1.784 & $0.120 \mathrm{E}-31$ \\
\hline 6437.640 & 153 & 1.319 & -2.057 & $0.120 \mathrm{E}-31$ & 6645.107 & 153 & 1.379 & -3.278 & $0.120 \mathrm{E}-31$ \\
\hline 6437.641 & 153 & 1.319 & -2.111 & $0.120 \mathrm{E}-31$ & 6645.109 & 153 & 1.379 & -1.040 & $0.120 \mathrm{E}-31$ \\
\hline 6437.642 & 153 & 1.319 & -2.308 & $0.120 \mathrm{E}-31$ & 6645.110 & 153 & 1.379 & -1.836 & $0.120 \mathrm{E}-31$ \\
\hline 6437.642 & 153 & 1.319 & -2.099 & $0.120 \mathrm{E}-31$ & 6645.113 & 153 & 1.379 & -1.122 & $0.120 \mathrm{E}-31$ \\
\hline 6437.643 & 153 & 1.319 & -2.111 & $0.120 \mathrm{E}-31$ & 6645.116 & 153 & 1.379 & -3.446 & $0.120 \mathrm{E}-31$ \\
\hline 6437.644 & 153 & 1.319 & -2.099 & $0.120 \mathrm{E}-31$ & 6645.116 & 153 & 1.379 & -0.873 & $0.120 \mathrm{E}-31$ \\
\hline 6437.644 & 153 & 1.319 & -1.282 & $0.120 \mathrm{E}-31$ & & & & & \\
\hline 6437.645 & 153 & 1.319 & -2.057 & $0.120 \mathrm{E}-31$ & & & & & \\
\hline
\end{tabular}


Apêndice C

\section{Resultados preliminares da amostra do GIRAFFE}

Por conta das metalicidades muito baixas em comparação aos valores de referência para o aglomerado NGC $6522([\mathrm{Fe} / \mathrm{H}]=-0.95$ para Barbuy et al. 2014, $[\mathrm{Fe} / \mathrm{H}]=-1.15$ para Ness et al. 2014), os atuais resultados serão submetidos a uma re-inspeção da análise dos parâmetros e abundâncias. São apresentados a seguir os resultados obtidos pela análise atual, onde os parâmetros atmosféricos espectroscópicos são exibidos na tabela C.1 e as abundâncias elementais são exibidas nas tabelas C.2 e C.3.

Em seguida são apresentadas figuras das abundâncias do elementos separados em grupos em função da metalicidade, com os elementos leves na figura C.1, elementos- $\alpha$ na figura C.2, elementos do pico do ferro na figura C.3 e elementos pesados nas figuras C.4 e.5. As razãoes $[\mathrm{Y} / \mathrm{Ba}]$ e $[\mathrm{Zr} / \mathrm{Ba}]$ são apresentadas na figura C.6 Para contabilizar conjuntamente os padrões de primeiro e segundo pico, a figura C.7 apresenta a razão entre as médias das abundâncias dos elementos Sr, Y e Ba pela média das abundâncias de Ba, La, Ce e Nd, juntamente com uma estimativa para a dispersão dos valores, que pesa a frequência de cada ponto pela sua dispersão. 
Tabela C.1 - Parâmetros espectroscópicos das amostras do GIRAFFE da presente análise.

\begin{tabular}{|c|c|c|c|c|c|c|c|c|}
\hline \multirow[t]{2}{*}{ Objeto } & \multicolumn{2}{|c|}{$\mathrm{T}_{e f f}(\mathrm{~K})$} & \multicolumn{2}{|c|}{$\log g$} & \multicolumn{2}{|c|}{$[\mathrm{Fe} / \mathrm{H}]$} & \multicolumn{2}{|c|}{$\mathrm{vt}(\mathrm{km} / \mathrm{s})$} \\
\hline & Manual & DOOp & Manual & DOOp & Manual & DOOp & Manual & DOOp \\
\hline \multicolumn{9}{|c|}{ GI2012 } \\
\hline 78126 & 4220 & $4300_{-65}^{+75}$ & 1.24 & $1.45_{-0.32}^{+0.32}$ & -0.70 & $-0.65 \pm 0.08$ & 1.56 & $1.84_{-0.16}^{+0.30}$ \\
\hline 89531 & 4430 & $4400_{-37}^{+42}$ & 1.98 & $1.82_{-0.16}^{+0.16}$ & -0.75 & $-0.80 \pm 0.06$ & 1.25 & $1.22_{-0.12}^{+0.13}$ \\
\hline 234816 & 4380 & $4380_{-45}^{+64}$ & 1.85 & $1.76_{-0.25}^{+0.23}$ & -0.81 & $-0.92 \pm 0.08$ & 1.02 & $1.25_{-0.16}^{+0.13}$ \\
\hline 244523 & 4500 & $4610_{-35}^{+39}$ & 1.58 & $1.68_{-0.19}^{+0.14}$ & -1.11 & $-1.10 \pm 0.06$ & 1.46 & $1.72_{-0.13}^{+0.19}$ \\
\hline 244819 & 4550 & $4550_{-55}^{+53}$ & 1.62 & $1.62_{-0.25}^{+0.28}$ & -1.33 & $-1.35 \pm 0.07$ & 1.30 & $1.45_{-0.21}^{+0.28}$ \\
\hline 244853 & 4840 & $4630_{-37}^{+37}$ & 1.92 & $1.52_{-0.23}^{+0.16}$ & -1.30 & $-1.43 \pm 0.06$ & 1.20 & $1.20_{-0.12}^{+0.13}$ \\
\hline 256289 & 4800 & $4650_{-22}^{+36}$ & 1.86 & $1.70_{-0.10}^{+0.17}$ & -1.37 & $-1.34 \pm 0.05$ & 1.50 & $0.88_{-0.12}^{+0.16}$ \\
\hline 256322 & 4350 & $4360_{-38}^{+50}$ & 1.67 & $1.75_{-0.20}^{+0.23}$ & -1.13 & $-1.07 \pm 0.06$ & 1.70 & $1.60_{-0.14}^{+0.18}$ \\
\hline 402322 & 4620 & $4660_{-46}^{+54}$ & 1.50 & $1.65_{-0.23}^{+0.22}$ & -1.30 & $-1.23 \pm 0.08$ & 1.43 & $1.33_{-0.21}^{+0.27}$ \\
\hline 402370 & 4650 & $4650_{-31}^{+37}$ & 2.00 & $1.88_{-0.15}^{+0.16}$ & -1.31 & $-1.42 \pm 0.06$ & 1.05 & $1.30_{-0.15}^{+0.26}$ \\
\hline 402386 & 4330 & $4020_{-54}^{+73}$ & 1.60 & $0.82_{-0.19}^{+0.31}$ & -1.23 & $-1.18 \pm 0.04$ & 1.74 & $1.54_{-0.09}^{+0.09}$ \\
\hline 554709 & 4800 & $4690_{-65}^{+94}$ & 2.45 & $2.22_{-0.27}^{+0.36}$ & -1.04 & $-1.13 \pm 0.08$ & 1.55 & $1.45_{-0.19}^{+0.30}$ \\
\hline 234822 & - & $4750_{-20}^{+44}$ & - & $1.83_{-0.18}^{+0.14}$ & - & $-0.45 \pm 0.07$ & - & $1.26_{-0.16}^{+0.10}$ \\
\hline 234932 & - & $4140_{-44}^{+41}$ & - & $1.22_{-0.19}^{+0.14}$ & - & $-0.38 \pm 0.05$ & - & $1.29_{-0.13}^{+0.10}$ \\
\hline 267939 & - & $4190_{-33}^{+30}$ & - & $1.68_{-0.13}^{+0.10}$ & - & $-0.51 \pm 0.03$ & - & $1.35_{-0.09}^{+0.13}$ \\
\hline 392942 & - & $4600_{-125}^{+114}$ & - & $2.50_{-0.28}^{+0.22}$ & - & $-0.03 \pm 0.16$ & - & $1.18_{-0.35}^{+0.24}$ \\
\hline 402384 & - & $4580_{-71}^{+73}$ & - & $1.95_{-0.23}^{+0.30}$ & - & $-1.42 \pm 0.10$ & - & $1.50_{-0.27}^{+0.37}$ \\
\hline 412759 & - & $4490_{-35}^{+92}$ & - & $1.90_{-0.23}^{+0.24}$ & - & $-1.00 \pm 0.08$ & - & $1.60_{-0.16}^{+0.18}$ \\
\hline \multicolumn{9}{|c|}{ GI2016 } \\
\hline 78161 & - & $4940_{-86}^{+99}$ & - & $3.78_{-0.28}^{+0.32}$ & - & $+0.12 \pm 0.07$ & - & $1.82_{-0.27}^{+0.37}$ \\
\hline 89489 & - & $5130_{-69}^{+105}$ & - & $4.06_{-0.30}^{+0.33}$ & - & $-0.07 \pm 0.08$ & - & $1.50_{-0.23}^{+0.26}$ \\
\hline 89544 & - & $5050_{-125}^{+78}$ & - & $4.10_{-0.29}^{+0.35}$ & - & $+0.03 \pm 0.08$ & - & $2.07_{-0.47}^{+0.34}$ \\
\hline 244551 & - & $4680_{-57}^{+51}$ & - & $2.15_{-0.29}^{+0.22}$ & - & $-1.30 \pm 0.07$ & - & $1.40_{-0.15}^{+0.15}$ \\
\hline 244555 & - & $4720_{-57}^{+83}$ & - & $2.21_{-0.32}^{+0.23}$ & - & $-1.29 \pm 0.09$ & - & $1.32_{-0.14}^{+0.16}$ \\
\hline 256298 & - & $4740_{-62}^{+101}$ & - & $2.33_{-0.22}^{+0.28}$ & - & $-1.07 \pm 0.09$ & - & $1.52_{-0.14}^{+0.19}$ \\
\hline 256386 & - & $4690_{-61}^{+56}$ & - & $2.14_{-0.13}^{+0.11}$ & - & $+0.05 \pm 0.10$ & - & $1.48_{-0.18}^{+0.36}$ \\
\hline 256646 & - & $4650_{-42}^{+37}$ & - & $2.82_{-0.41}^{+0.34}$ & - & $-0.33 \pm 0.06$ & - & $1.29_{-0.15}^{+0.13}$ \\
\hline 402371 & - & $5050_{-62}^{+54}$ & - & $2.24_{-0.21}^{+0.24}$ & - & $-1.26 \pm 0.10$ & - & $1.51_{-0.15}^{+0.19}$ \\
\hline 402508 & - & $4790_{-91}^{+54}$ & - & $2.72_{-0.40}^{+0.35}$ & - & $-1.18 \pm 0.07$ & - & $1.40_{-0.13}^{+0.17}$ \\
\hline 402537 & - & $4480_{-107}^{+121}$ & - & $2.57_{-0.28}^{+0.27}$ & - & $-0.36 \pm 0.09$ & - & $1.57_{-0.28}^{+0.48}$ \\
\hline 402608 & - & $4930_{-65}^{+63}$ & - & $2.63_{-0.26}^{+0.55}$ & - & $-1.17 \pm 0.10$ & - & $1.22_{-0.22}^{+0.20}$ \\
\hline 412777 & - & $4500_{-118}^{+80}$ & - & $3.49_{-0.43}^{+0.37}$ & - & $-0.20 \pm 0.09$ & - & $1.24_{-0.19}^{+0.21}$ \\
\hline 413052 & - & $4830_{-100}^{+100}$ & - & $3.58_{-0.08}^{+0.50}$ & - & $+0.07 \pm 0.13$ & - & $1.64_{-0.43}^{+0.39}$ \\
\hline
\end{tabular}


Tabela C.2 - Abundâncias finais e erros para as estrelas da amostra GI2012, incluindo o número de linhas utilizadas.

\begin{tabular}{|c|c|c|c|c|c|c|c|c|c|c|c|c|c|c|}
\hline \multirow[b]{2}{*}{ Ele. } & \multicolumn{2}{|l|}{78126} & \multicolumn{2}{|l|}{89531} & \multicolumn{2}{|l|}{234816} & \multicolumn{2}{|l|}{244523} & \multicolumn{2}{|l|}{244819} & \multicolumn{2}{|l|}{244853} & \multicolumn{2}{|l|}{256289} \\
\hline & {$[\mathrm{X} / \mathrm{Fe}]$} & $\mathrm{N}$ & {$[\mathrm{X} / \mathrm{Fe}]$} & $\mathrm{N}$ & {$[\mathrm{X} / \mathrm{Fe}]$} & $\mathrm{N}$ & {$[\mathrm{X} / \mathrm{Fe}]$} & $\mathrm{N}$ & {$[\mathrm{X} / \mathrm{Fe}]$} & $\mathrm{N}$ & {$[\mathrm{X} / \mathrm{Fe}]$} & $\mathrm{N}$ & {$[\mathrm{X} / \mathrm{Fe}]$} & $\mathrm{N}$ \\
\hline $\mathrm{C}$ & - & 1 & +0.05 & 1 & +0.05 & 1 & +0.20 & 1 & +0.25 & 1 & +0.10 & 1 & - & 1 \\
\hline $\mathrm{N}$ & - & 1 & +0.55 & 1 & +0.00 & 1 & +0.00 & 1 & +0.50 & 1 & +0.75 & 1 & - & 1 \\
\hline $\mathrm{Na}$ & - & - & $+0.29 \pm 0.04$ & 3 & $+0.30 \pm 0.05$ & 3 & $-0.01 \pm 0.03$ & 3 & $+0.49 \pm 0.06$ & 3 & $+0.30 \pm 0.03$ & 3 & $-0.08 \pm 0.04$ & 3 \\
\hline $\mathrm{Mg}$ & - & - & $+0.35 \pm 0.04$ & 1 & $+0.30 \pm 0.05$ & 1 & $+0.60 \pm 0.12$ & 1 & $+0.40 \pm 0.07$ & 1 & $+0.30 \pm 0.04$ & 1 & $+0.45 \pm 0.15$ & 1 \\
\hline $\mathrm{Si}$ & $+0.41 \pm 0.15$ & 3 & $+0.40 \pm 0.05$ & 7 & $+0.32 \pm 0.06$ & 7 & $+0.51 \pm 0.09$ & 8 & $+0.51 \pm 0.09$ & 6 & $+0.34 \pm 0.06$ & 9 & $+0.30 \pm 0.06$ & 9 \\
\hline $\mathrm{Ca}$ & $+0.31 \pm 0.22$ & 3 & $+0.26 \pm 0.07$ & 3 & $+0.15 \pm 0.09$ & 2 & $+0.26 \pm 0.11$ & 3 & $+0.30 \pm 0.08$ & 2 & $+0.30 \pm 0.05$ & 3 & $+0.30 \pm 0.12$ & 2 \\
\hline $\mathrm{Ti}$ & $+0.01 \pm 0.21$ & 7 & $+0.20 \pm 0.11$ & 7 & $+0.12 \pm 0.12$ & 6 & $+0.23 \pm 0.10$ & 6 & $+0.28 \pm 0.11$ & 6 & $+0.01 \pm 0.07$ & 5 & $+0.05 \pm 0.08$ & 6 \\
\hline Mn & $+0.10 \pm 0.35$ & 3 & $-0.05 \pm 0.07$ & 3 & $-0.15 \pm 0.12$ & 3 & $-0.21 \pm 0.18$ & 3 & $-0.33 \pm 0.14$ & 3 & $-0.30 \pm 0.08$ & 3 & $-0.31 \pm 0.29$ & 3 \\
\hline $\mathrm{Cu}$ & - & - & $+0.00 \pm 0.05$ & 1 & $-0.05 \pm 0.07$ & 1 & $+0.00 \pm 0.10$ & 1 & $+0.00 \pm 0.09$ & 1 & $-0.15 \pm 0.06$ & 1 & $-0.30 \pm 0.12$ & 1 \\
\hline Y & - & - & - & - & $+0.00 \pm 0.11$ & 1 & $+0.35 \pm 0.08$ & 1 & $+0.70 \pm 0.13$ & 1 & - & - & $+0.00 \pm 0.07$ & 1 \\
\hline $\mathrm{Zr}$ & $-0.05 \pm 0.27$ & 2 & $-0.10 \pm 0.13$ & 2 & $+0.02 \pm 0.12$ & 2 & $+0.30 \pm 0.13$ & 2 & $+0.67 \pm 0.14$ & 2 & $+0.00 \pm 0.08$ & 1 & $+0.35 \pm 0.19$ & 2 \\
\hline $\mathrm{Ba}$ & $-0.50 \pm 0.18$ & 2 & $+0.00 \pm 0.18$ & 1 & $+0.00 \pm 0.23$ & 2 & $+1.20 \pm 0.12$ & 1 & $+0.00 \pm 0.33$ & 1 & $+0.20 \pm 0.18$ & 1 & $+0.65 \pm 0.09$ & 1 \\
\hline $\mathrm{Ce}$ & $+0.00 \pm 0.14$ & 1 & $+0.25 \pm 0.24$ & 3 & $+0.20 \pm 0.09$ & 1 & $+1.00 \pm 0.08$ & 1 & - & - & $+0.20 \pm 0.09$ & 1 & - & - \\
\hline \multirow[t]{2}{*}{$\mathrm{Nd}$} & $+0.00 \pm 0.15$ & 1 & $+0.17 \pm 0.07$ & 2 & $+0.30 \pm 0.10$ & 1 & $+0.93 \pm 0.11$ & 2 & - & - & - & - & $.00 \pm 0.06$ & 1 \\
\hline & \multicolumn{2}{|l|}{256322} & \multicolumn{2}{|l|}{402322} & \multicolumn{2}{|l|}{402370} & \multicolumn{2}{|l|}{402384} & \multicolumn{2}{|l|}{402386} & \multicolumn{2}{|l|}{412759} & \multicolumn{2}{|l|}{554709} \\
\hline Ele.o & {$[\mathrm{X} / \mathrm{Fe}]$} & $\bar{N}$ & {$[\mathrm{X} / \mathrm{Fe}]$} & $\bar{N}$ & {$[\mathrm{X} / \mathrm{Fe}]$} & $\bar{N}$ & {$[\mathrm{X} / \mathrm{Fe}]$} & $\bar{N}$ & {$[\mathrm{X} / \mathrm{Fe}]$} & $\overline{\mathrm{N}}$ & {$[\mathrm{X} / \mathrm{Fe}]$} & $\overline{\mathrm{N}}$ & {$[\mathrm{X} / \mathrm{Fe}]$} & $\overline{\mathrm{N}}$ \\
\hline $\mathrm{C}$ & +0.10 & 1 & +0.05 & 1 & +0.10 & 1 & +0.15 & 1 & +0.20 & 1 & +0.10 & 1 & +0.15 & 1 \\
\hline $\mathrm{N}$ & +0.25 & 1 & +0.00 & 1 & +0.20 & 1 & +0.50 & 1 & +0.15 & 1 & +0.00 & 1 & +0.60 & 1 \\
\hline $\mathrm{Na}$ & $+0.08 \pm 0.07$ & 3 & $+0.53 \pm 0.05$ & 3 & $-0.30 \pm 0.03$ & 3 & $+0.60 \pm 0.05$ & 3 & $+0.38 \pm 0.12$ & 3 & $+0.04 \pm 0.05$ & 3 & $+0.10 \pm 0.06$ & 3 \\
\hline $\mathrm{Mg}$ & $+0.30 \pm 0.02$ & 1 & $+0.55 \pm 0.08$ & 1 & $+0.15 \pm 0.06$ & 1 & $+0.30 \pm 0.06$ & 1 & $+0.05 \pm 0.04$ & 1 & $+0.35 \pm 0.04$ & 1 & $+0.50 \pm 0.06$ & 1 \\
\hline $\mathrm{Si}$ & $+0.44 \pm 0.11$ & 9 & $+0.35 \pm 0.09$ & 9 & $+0.20 \pm 0.04$ & 9 & $+0.56 \pm 0.06$ & 9 & $+0.51 \pm 0.14$ & 7 & $+0.59 \pm 0.06$ & 10 & $+0.64 \pm 0.07$ & 7 \\
\hline $\mathrm{Ca}$ & $-0.23 \pm 0.06$ & 2 & $+0.22 \pm 0.13$ & 3 & $+0.15 \pm 0.07$ & 3 & $+0.36 \pm 0.10$ & 3 & $+0.60 \pm 0.09$ & 3 & $+0.22 \pm 0.09$ & 3 & $+0.35 \pm 0.11$ & 3 \\
\hline $\mathrm{Ti}$ & $-0.01 \pm 0.10$ & 7 & $+0.30 \pm 0.10$ & 7 & $+0.00 \pm 0.08$ & 5 & $+0.23 \pm 0.13$ & 6 & $+0.11 \pm 0.14$ & 7 & $+0.20 \pm 0.13$ & 7 & $+0.28 \pm 0.14$ & 6 \\
\hline $\mathrm{Mn}$ & $-0.14 \pm 0.11$ & 3 & $-0.30 \pm 0.13$ & 3 & $-0.49 \pm 0.10$ & 3 & $-0.30 \pm 0.13$ & 3 & $-0.08 \pm 0.15$ & 3 & $-0.30 \pm 0.10$ & 3 & $-0.21 \pm 0.15$ & 3 \\
\hline $\mathrm{Cu}$ & $+0.00 \pm 0.05$ & 1 & $+0.00 \pm 0.10$ & 1 & $-0.30 \pm 0.07$ & 1 & $+0.00 \pm 0.09$ & 1 & $+0.00 \pm 0.09$ & 1 & $+0.10 \pm 0.05$ & 1 & $+0.30 \pm 0.10$ & 1 \\
\hline Y & $+0.00 \pm 0.11$ & 1 & $+0.60 \pm 0.11$ & 1 & $+0.05 \pm 0.07$ & 1 & $+0.40 \pm 0.12$ & 1 & - & - & $+0.30 \pm 0.11$ & 1 & $+0.55 \pm 0.14$ & 1 \\
\hline $\mathrm{Zr}$ & $-0.25 \pm 0.12$ & 2 & $+0.49 \pm 0.11$ & 3 & $+0.00 \pm 0.07$ & 2 & $+0.40 \pm 0.15$ & 1 & $+0.12 \pm 0.16$ & 3 & $+0.02 \pm 0.14$ & 2 & $+0.59 \pm 0.16$ & 3 \\
\hline $\mathrm{Ba}$ & $-0.30 \pm 0.21$ & 1 & $+0.45 \pm 0.36$ & 2 & $-0.08 \pm 0.28$ & 2 & $+0.28 \pm 0.40$ & 2 & $-0.25 \pm 0.17$ & 2 & $+0.40 \pm 0.26$ & 2 & $+0.60 \pm 0.33$ & 2 \\
\hline $\mathrm{Ce}$ & - & - & $+0.47 \pm 0.10$ & 2 & - & - & $+0.30 \pm 0.10$ & 1 & $+0.35 \pm 0.11$ & 2 & $+0.60 \pm 0.09$ & 1 & $+0.60 \pm 0.11$ & 3 \\
\hline $\mathrm{Nd}$ & $+0.30 \pm 0.10$ & 1 & $+0.30 \pm 0.11$ & 1 & $+0.30 \pm 0.06$ & 1 & $+0.60 \pm 0.10$ & 2 & $+0.20 \pm 0.11$ & 1 & $+0.30 \pm 0.10$ & 1 & $+0.60 \pm 0.12$ & 1 \\
\hline
\end{tabular}


Tabela C.3 - Abundâncias finais e erros para as estrelas da amostra GI2016, incluindo o número de linhas utilizadas.

\begin{tabular}{|c|c|c|c|c|c|c|c|c|c|c|c|c|}
\hline \multirow[b]{2}{*}{ Razão } & \multicolumn{2}{|l|}{244551} & \multicolumn{2}{|l|}{244555} & \multicolumn{2}{|l|}{256298} & \multicolumn{2}{|l|}{402371} & \multicolumn{2}{|l|}{402508} & \multicolumn{2}{|l|}{402608} \\
\hline & {$[\mathrm{X} / \mathrm{Fe}]$} & $\mathrm{N}$ & {$[\mathrm{X} / \mathrm{Fe}]$} & $\mathrm{N}$ & {$[\mathrm{X} / \mathrm{Fe}]$} & $\mathrm{N}$ & {$[\mathrm{X} / \mathrm{Fe}]$} & $\mathrm{N}$ & {$[\mathrm{X} / \mathrm{Fe}]$} & $\mathrm{N}$ & {$[\mathrm{X} / \mathrm{Fe}]$} & $\mathrm{N}$ \\
\hline $\mathrm{C}$ & +0.20 & 1 & +0.25 & 1 & +0.05 & 1 & +0.40 & 1 & +0.10 & 1 & +0.40 & 1 \\
\hline $\mathrm{N}$ & +1.10 & 2 & +0.35 & 2 & +1.00 & 2 & +0.70 & 2 & +1.00 & 2 & +0.00 & 2 \\
\hline $\mathrm{Na}$ & $+0.10 \pm 0.04$ & 5 & $+0.15 \pm 0.03$ & 5 & $+0.34 \pm 0.03$ & 5 & $-0.22 \pm 0.10$ & 5 & $+0.46 \pm 0.03$ & 5 & $-0.16 \pm 0.04$ & 5 \\
\hline $\mathrm{Mg}$ & $+0.55 \pm 0.16$ & 2 & $+0.40 \pm 0.18$ & 2 & $+0.32 \pm 0.15$ & 2 & $+0.32 \pm 0.15$ & 2 & $+0.47 \pm 0.19$ & 2 & $+0.40 \pm 0.16$ & 2 \\
\hline $\mathrm{Si}$ & $+0.30 \pm 0.06$ & 10 & $+0.33 \pm 0.07$ & 11 & $+0.28 \pm 0.07$ & 11 & $+0.31 \pm 0.07$ & 10 & $+0.33 \pm 0.07$ & 9 & $+0.26 \pm 0.09$ & 8 \\
\hline $\mathrm{Ca}$ & $+0.27 \pm 0.12$ & 13 & $+0.24 \pm 0.12$ & 13 & $+0.20 \pm 0.13$ & 12 & $+0.17 \pm 0.12$ & 12 & $+0.22 \pm 0.12$ & 12 & $+0.27 \pm 0.12$ & 12 \\
\hline $\mathrm{Ti}$ & $+0.15 \pm 0.08$ & 4 & $+0.27 \pm 0.08$ & 4 & $+0.26 \pm 0.09$ & 4 & $+0.30 \pm 0.08$ & 2 & $+0.11 \pm 0.19$ & 3 & $+0.33 \pm 0.08$ & 3 \\
\hline $\mathrm{Cu}$ & $-0.30 \pm 0.12$ & 1 & $-0.20 \pm 0.12$ & 1 & $+0.05 \pm 0.12$ & 1 & $+0.00 \pm 0.12$ & 1 & $+0.05 \pm 0.12$ & 1 & $+0.00 \pm 0.12$ & 1 \\
\hline $\mathrm{Zn}$ & $+0.00 \pm 0.18$ & 1 & $+0.25 \pm 0.18$ & 1 & - & - & $+0.35 \pm 0.18$ & 1 & $+0.30 \pm 0.18$ & 1 & $+0.60 \pm 0.18$ & 1 \\
\hline $\mathrm{Y}$ & $+0.15 \pm 0.07$ & 1 & $+0.35 \pm 0.08$ & 2 & $+0.50 \pm 0.21$ & 2 & $+0.60 \pm 0.07$ & 1 & $+0.35 \pm 0.07$ & 1 & $+0.30 \pm 0.07$ & 1 \\
\hline $\mathrm{Zr}$ & $+0.30 \pm 0.19$ & 2 & $+0.32 \pm 0.19$ & 2 & $+0.43 \pm 0.20$ & 3 & $+0.38 \pm 0.20$ & 3 & $+0.35 \pm 0.19$ & 3 & $+0.60 \pm 0.19$ & 1 \\
\hline $\mathrm{Ba}$ & $-0.03 \pm 0.09$ & 2 & $+0.07 \pm 0.11$ & 2 & $+0.05 \pm 0.09$ & 2 & $+0.47 \pm 0.15$ & 2 & $-0.20 \pm 0.09$ & 2 & $-0.20 \pm 0.13$ & 2 \\
\hline $\mathrm{La}$ & $-0.15 \pm 0.14$ & 1 & $+0.00 \pm 0.14$ & 1 & $+0.30 \pm 0.14$ & 1 & $+0.30 \pm 0.14$ & 1 & $+0.00 \pm 0.14$ & 1 & $+0.30 \pm 0.14$ & 1 \\
\hline $\mathrm{Nd}$ & $+0.30 \pm 0.06$ & 1 & - & - & - & - & - & - & $+0.00 \pm 0.06$ & 1 & - & - \\
\hline $\mathrm{Eu}$ & $+0.35 \pm 0.06$ & 1 & $+0.32 \pm 0.14$ & 2 & $+0.45 \pm 0.06$ & 2 & $+0.30 \pm 0.06$ & 1 & $+0.35 \pm 0.06$ & 1 & $+0.30 \pm 0.06$ & 1 \\
\hline
\end{tabular}



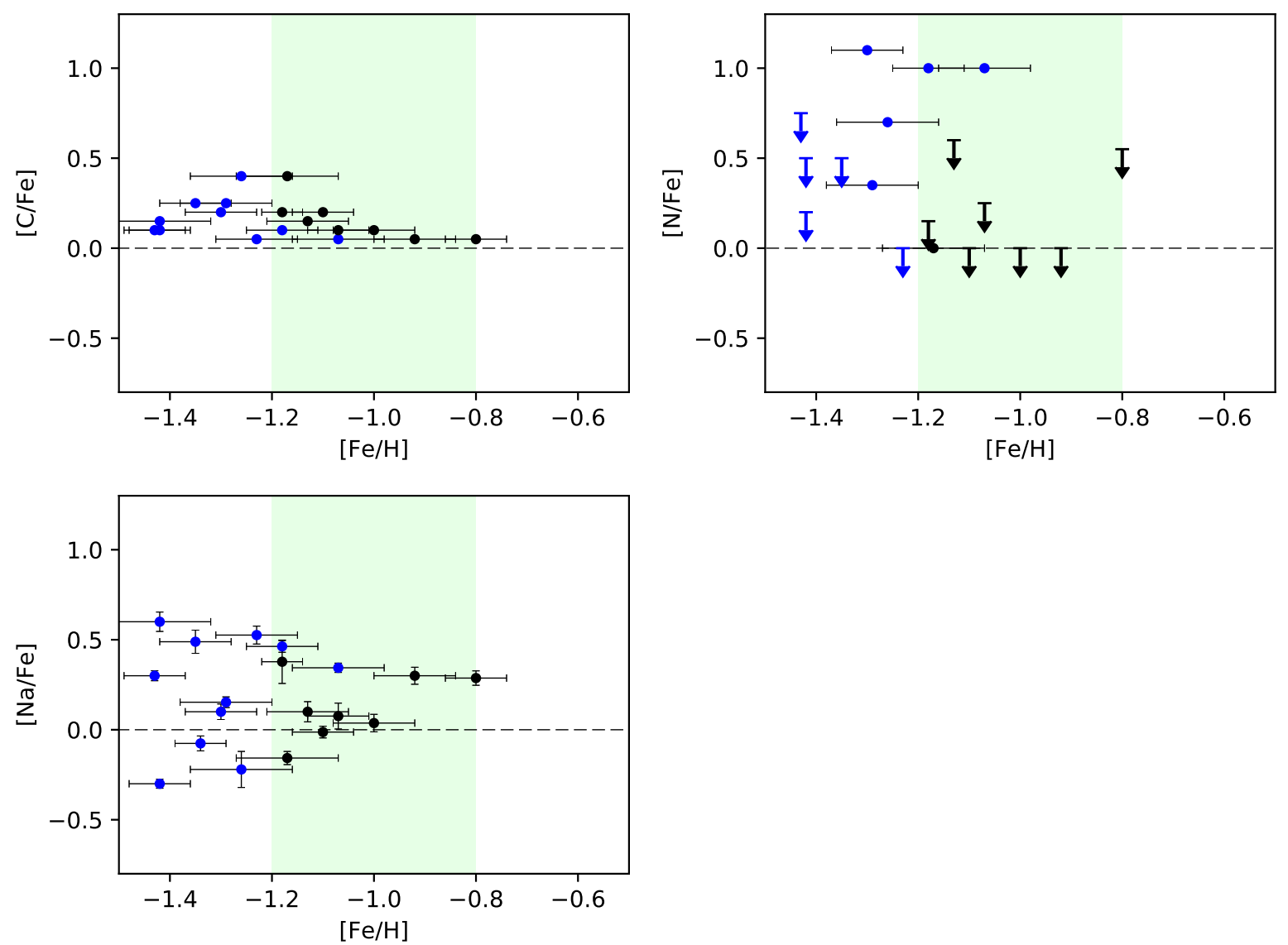

Figura C.1: Abundâncias dos elementos leves em função da metalicidade. Círculos representam as estrelas GIRAFFE. Os pontos em azul são as estrelas selecionadas pela limpeza de movimento próprio. 

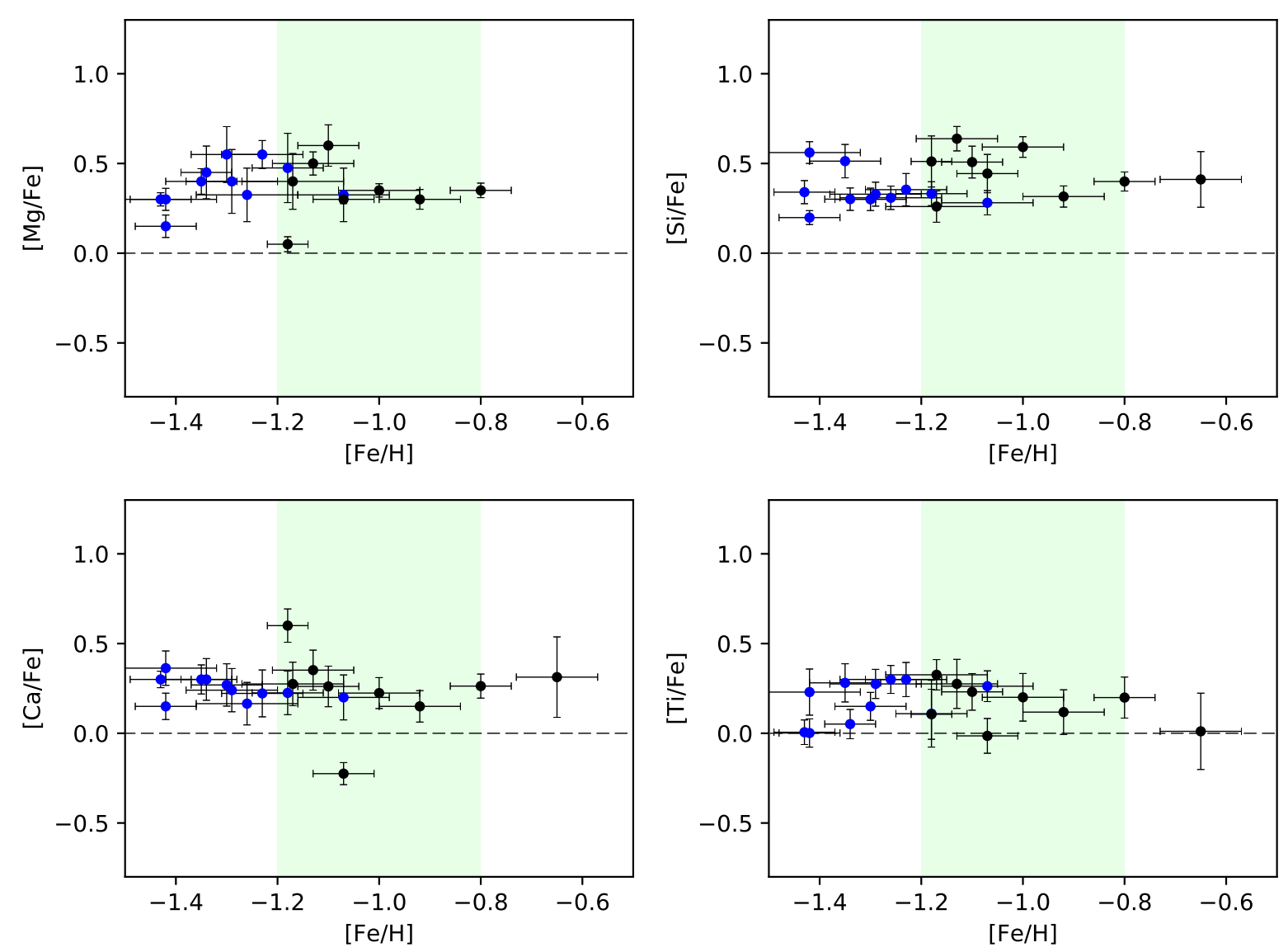

Figura C.2: Abundâncias dos elementos- $\alpha$ em função da metalicidade. Círculos representam as estrelas GIRAFFE. Os pontos em azul são as estrelas selecionadas pela limpeza de movimento próprio. 

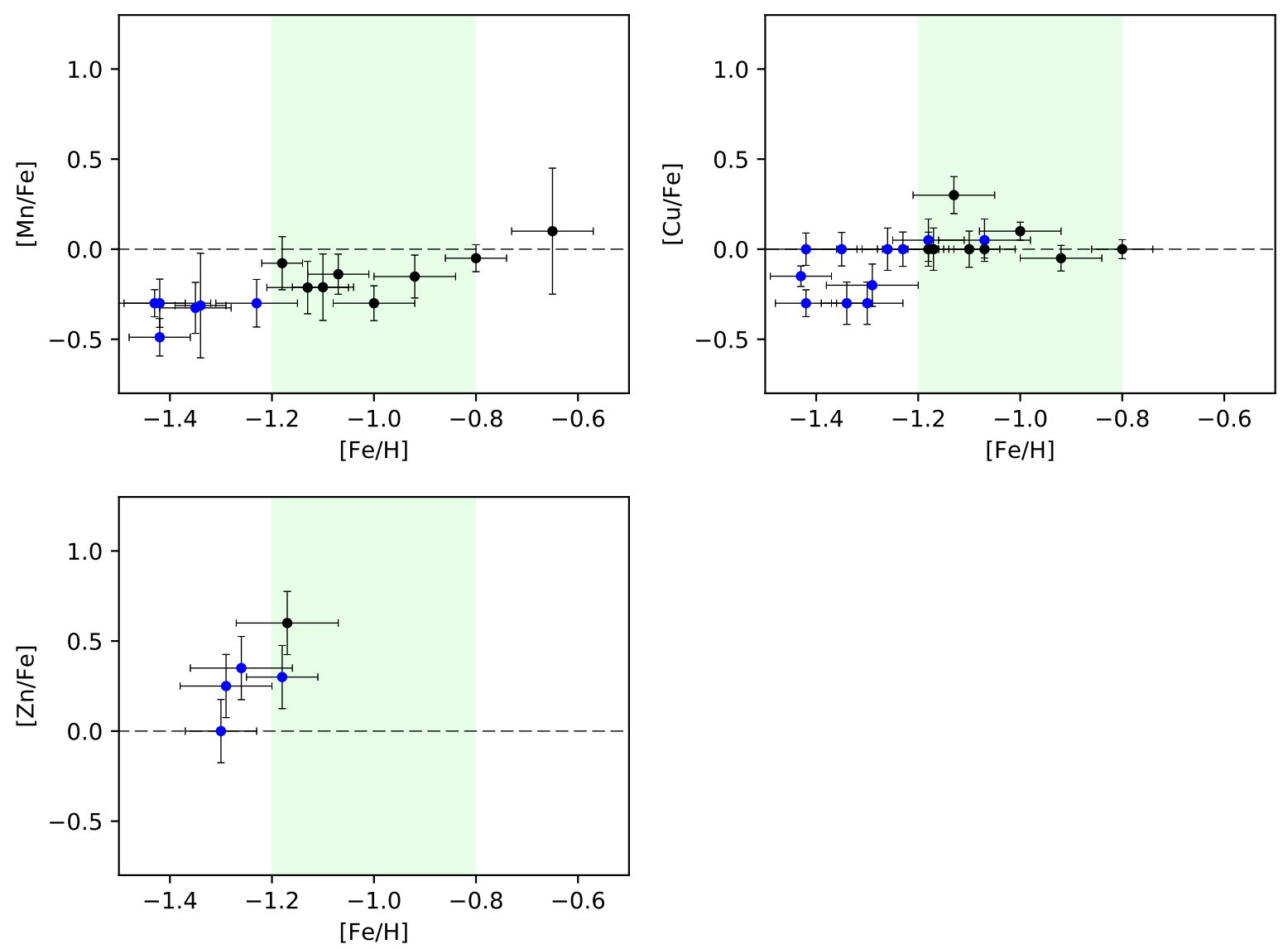

Figura C.3: Abundâncias dos elementos do pico do ferro em função da metalicidade. Círculos representam as estrelas GIRAFFE. Os pontos emazul são as estrelas selecionadas pela limpeza de movimento próprio. 

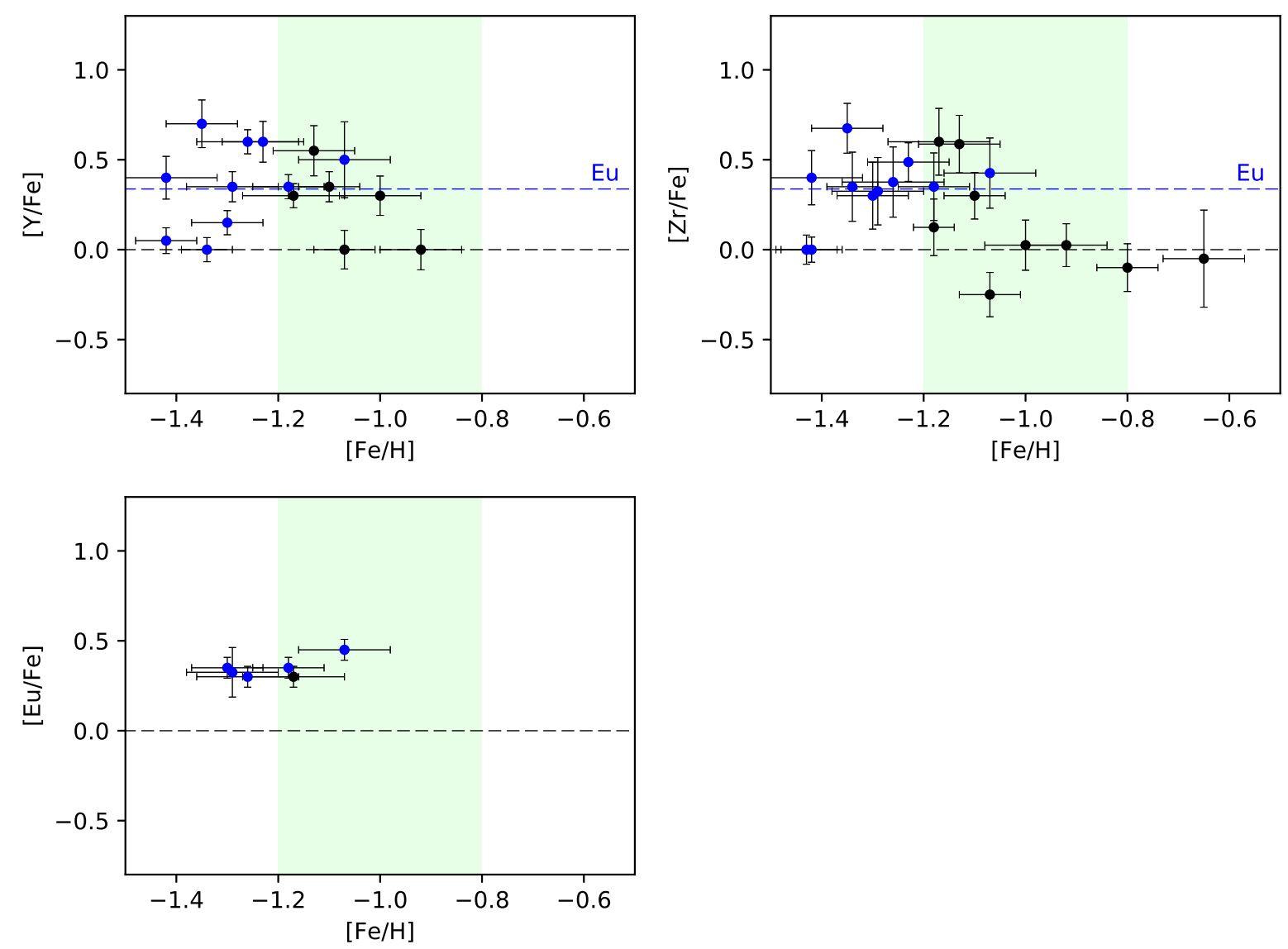

Figura C.4: Abundâncias dos elementos do primeiro pico em função da metalicidade e o elemento de referência do processo-r, Eu. Círculos representam as estrelas GIRAFFE. Os pontos em azul são as estrelas selecionadas pela limpeza de movimento próprio. A linha tracejada em azul representa o valor médio da abundância de Eu. 

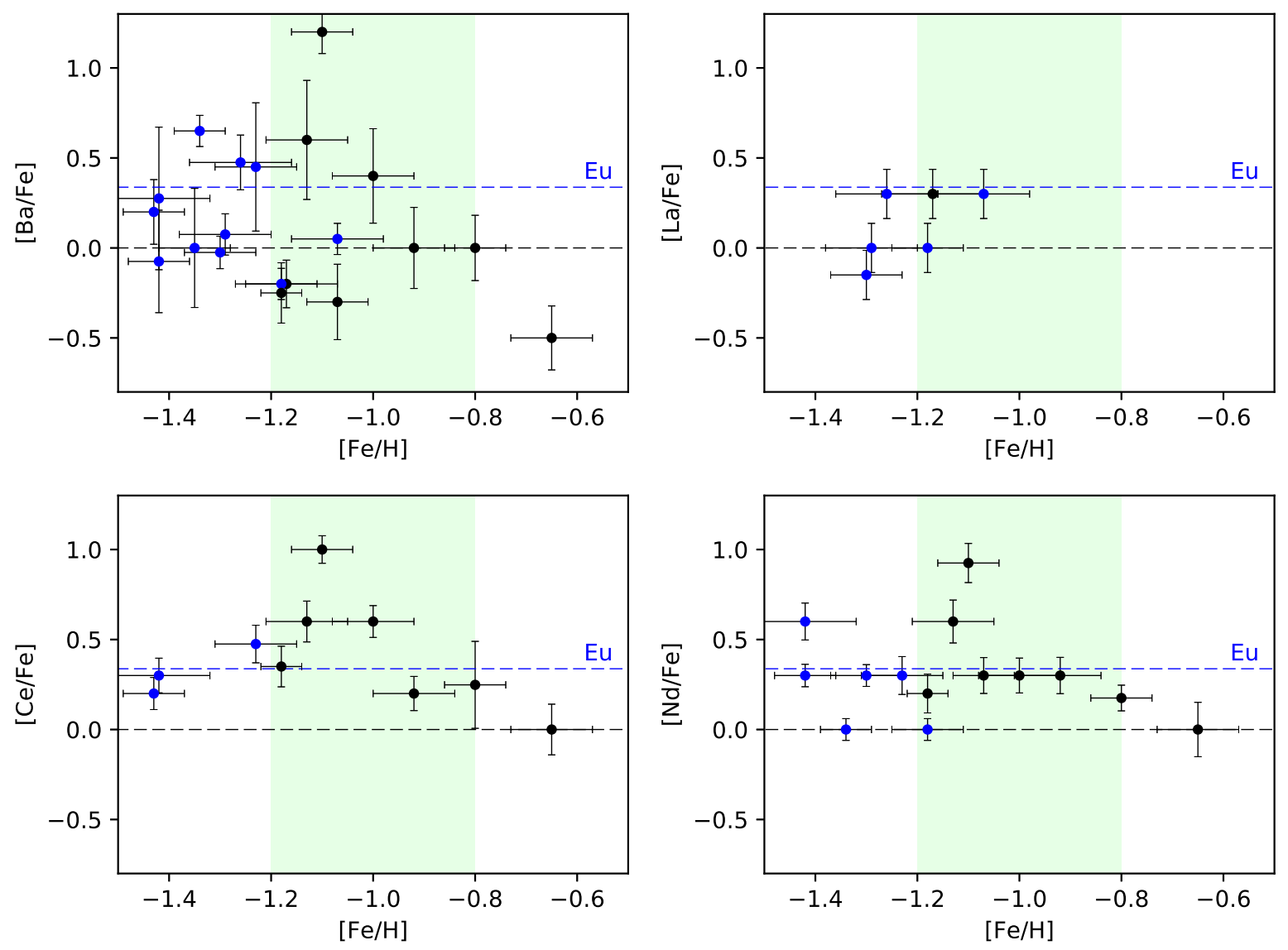

Figura C.5: Abundâncias dos elementos do segundo pico em função da metalicidade. Círculos representam as estrelas GIRAFFE. Os pontos em azul são as estrelas selecionadas pela limpeza de movimento próprio. A linha tracejada em azul representa o valor médio da abundância de Eu.
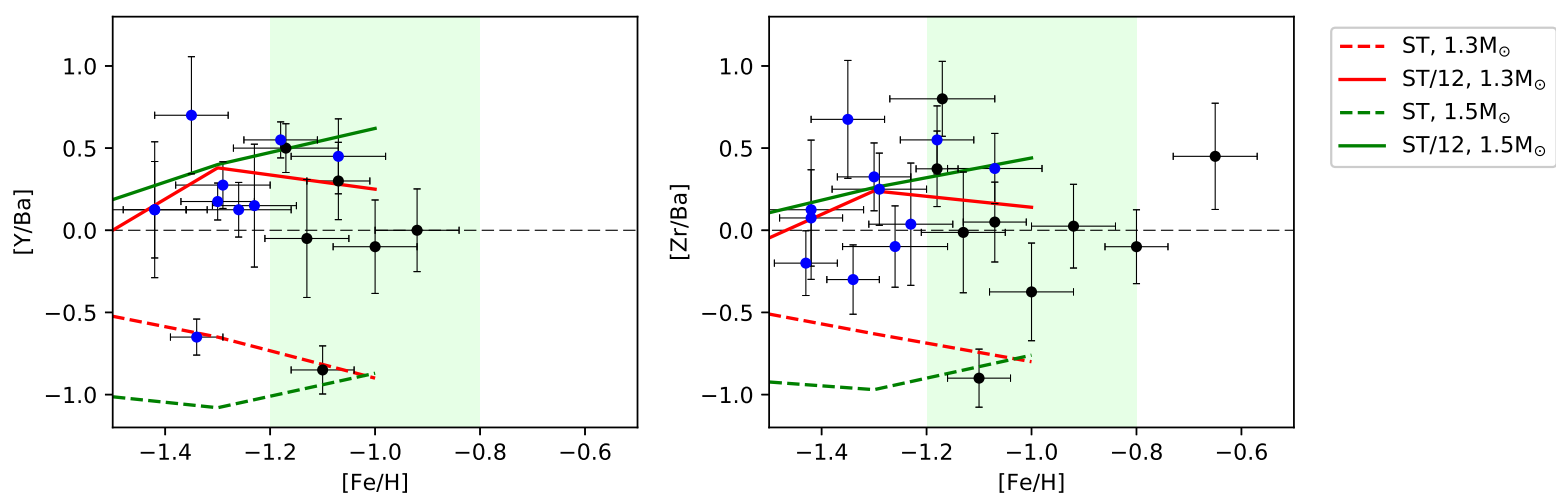

Figura C.6: Razões de Y/Ba e Zr/Ba em função da metalicidade. Círculos representam as estrelas GIRAFFE. Os pontos em azul são as estrelas selecionadas pela limpeza de movimento próprio. As linhas cheias e tracejadas representam os modelos de Bisterzo et al. (2010), os mesmos descritos na figura 1 de Chiappini et al. (2011). 


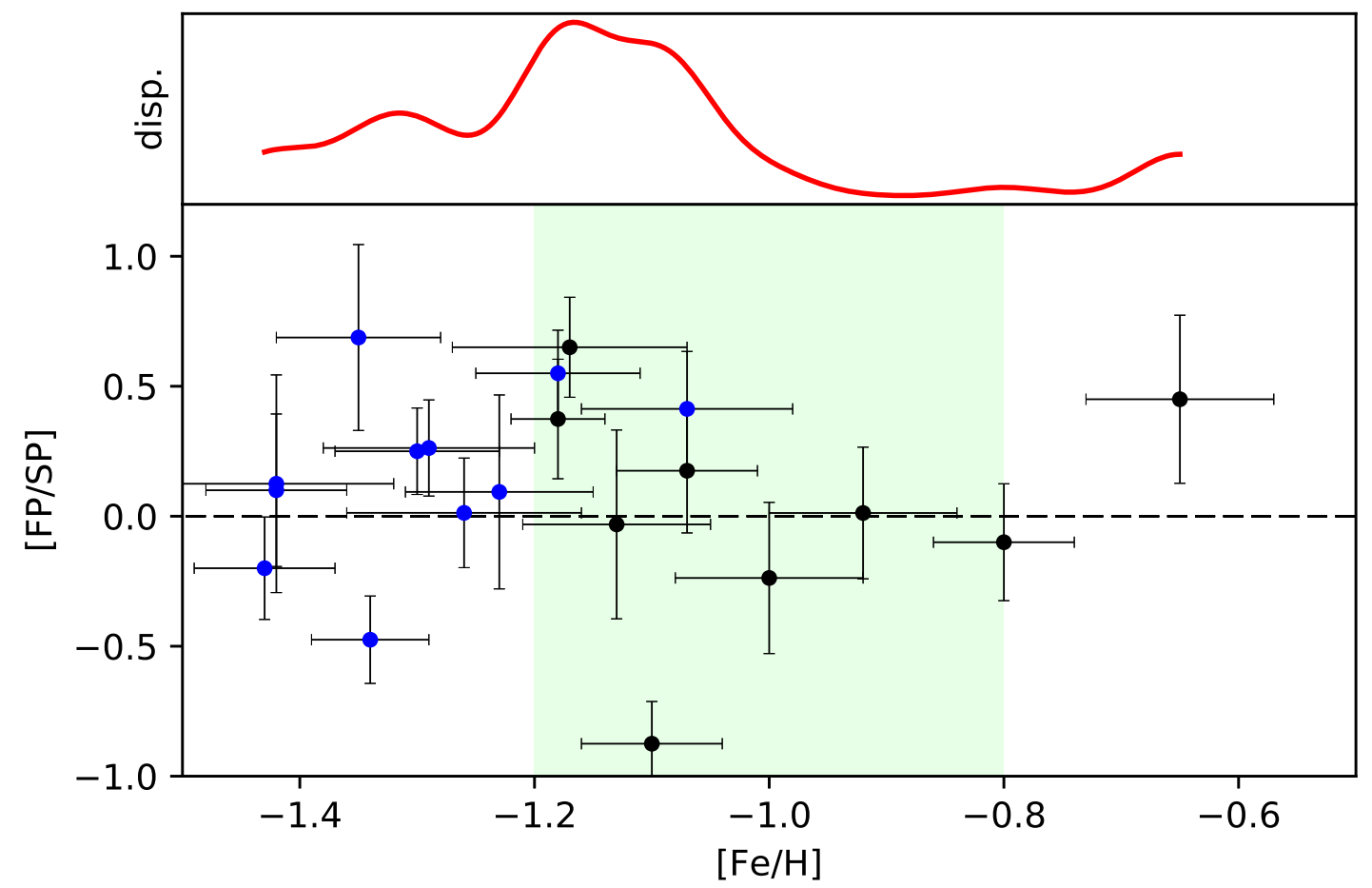

Figura C.7: Razão das médias dos elementos do primeiro pico sobre os de segundo pico, em função da metalicidade. Círculos representam as estrelas GIRAFFE. Os pontos em azul são as estrelas selecionadas pela limpeza de movimento próprio. No quadro superior, é apresentada uma estimativa para a dispersão dos valores em função da metalicidade. 
Apêndice D

\section{Movimentos próprios}

Com a disponibilidade dos dados do segundo data release (Gaia Collaboration et al. 2018) da missão espacial Gaia (Gaia Collaboration et al., 2016), foi possível identificar e correlacionar as estrelas desta análise via o software Aladin (Bonnarel et al., 2000). Foi selecionada uma região circular do céu com raio de 8' ao redor do centro do NGC 6522, dentro da qual o catálogo do Gaia possui 44735 fontes. Utilizando a função cross-match foi possível correlacionar e obter as informações do catálogo do Gaia para todas as 46 estrelas do FLAMES selecionadas por velocidade radial, e para 765 das 1191 estrelas do MUSE, das quais apenas 421 possuíam movimentos próprios determinados. Isto é consequência da alta densidade populacional de estrelas no campo do aglomerado, onde mesmo a excelente resolução espacial do Gaia não é suficiente para separar e distinguir as fontes.

Após isso, foi utilizado o software Topcat (Taylor, 2013) para realizar a limpeza de movimento próprio nas amostras do FLAMES e do MUSE. Em um gráfico de movimento próprio em ascensão reta vs movimento próprio em declinação, é possível distinguir a população de estrelas de campo do aglomerado, como exibido na figura D.1, para todas as estrelas do catálogo do Gaia dentro de 8' do centro do aglomerado. Para filtrar as prováveis estrelas-membro, foi determinada uma região elipsoidal com $1.78<M P_{R A}<$ $3.60 \mathrm{mas} /$ ano e $-7.09<M P_{\text {Dec }}<-5.65 \mathrm{mas} /$ ano, representada pelo tracejado verde na figura D.1. Ao aplicar este filtro para a amostra do FLAMES, 11 estrelas se enquadraram no critério e foram consideradas como prováveis membros do aglomerado.

Para a amostra do MUSE, 113 se enquadraram no critério. Dado que a região considerada no espaço de movimentos próprios também possui contaminação de estrelas de campo cujos movimentos próprios coincidem, é esperado que algumas das estrelas selecionadas não sejam membro, e o mesmo vale para a amostra do FLAMES, considerando que 


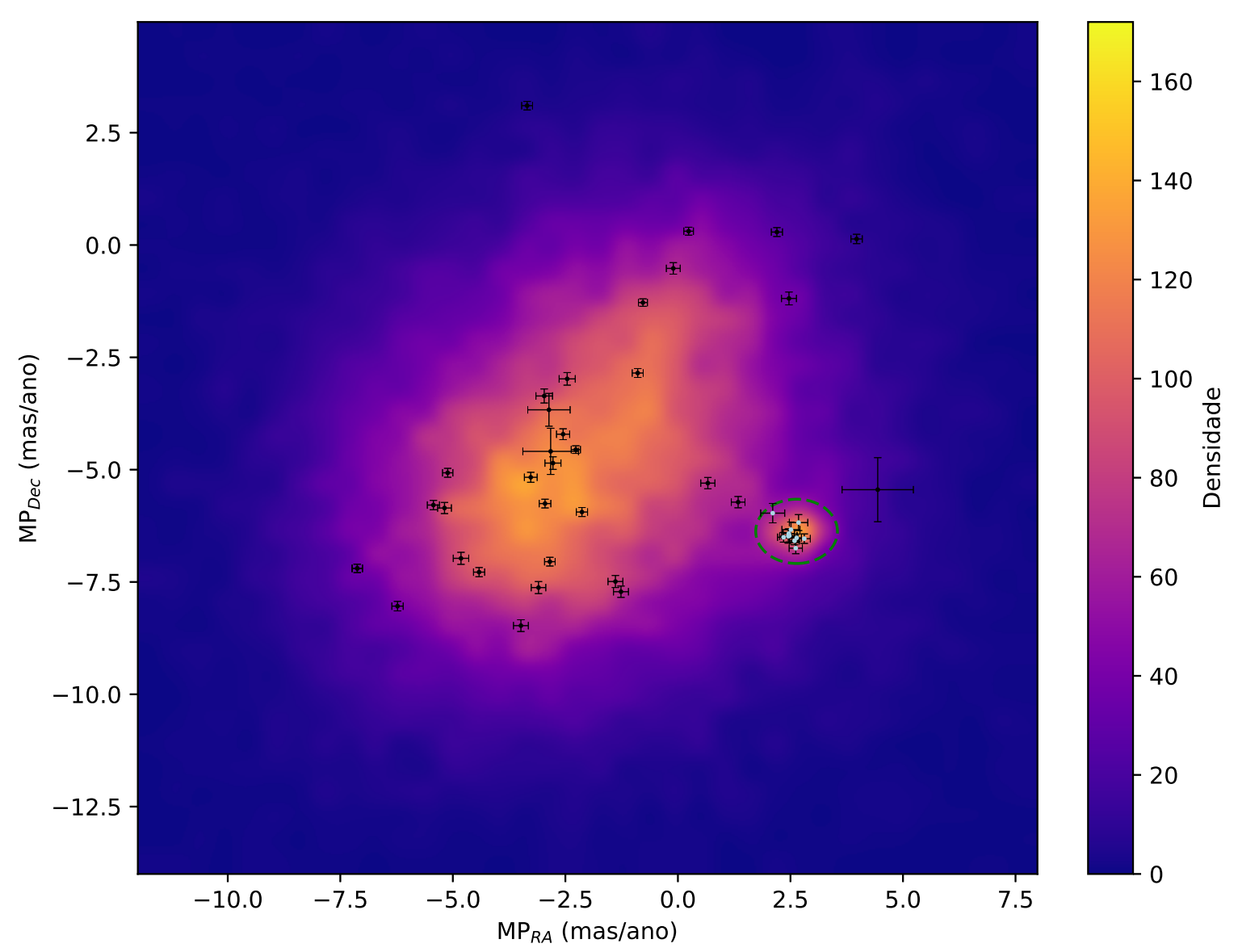

Figura D.1: Espaço de movimentos próprios com a densidade de estrelas em um campo de raio 8' do centro do NGC6522. O tracejado verde engloba a região onde é possível notar uma concentração de movimentos próprios muito próximos, que representa as estelas do aglomerado. Pontos em ciano: estrelas do FLAMES consideradas membro; pontos em preto: demais estrelas do FLAMES.

a amostra do MUSE se concentra em um campo de 1 x 1 arcmin, e a amostra do FLAMES se distribui ao longo de um campo circular de 8 arcmin de raio.

As propriedades cinemáticas e metalicidades das estrelas prováveis membros da amostra do FLAMES são exibidas na tabela D.1. As estrelas do FLAMES analisadas, evidenciando a limpeza de movimentos próprios, são exibidas no espaço de metalicidade vs velocidade radial na figura D.2, para a amostra do MUSE na figura D.3.

Na amostra do FLAMES com limpeza de movimento próprio, a média das velocidades radiais retorna um valor de $-14.12 \mathrm{~km} / \mathrm{s}$ e desvio-padrão de $6.76 \mathrm{~km} / \mathrm{s}$, de acordo com o 
Tabela D.1 - Parâmetros dinâmicos das estrelas-membro da amostra do GIRAFFE: distância central $\left(\mathrm{r}_{c}\right)$, movimento próprio $\left(\mathrm{mp}_{R A}\right.$ e $\left.\mathrm{mp}_{D E C}\right)$, velocidade radial $(\mathrm{VR})$ e metalicidade $([\mathrm{Fe} / \mathrm{H}])$.

\begin{tabular}{cccccc}
\hline \hline Objeto & $\mathrm{r}_{c}(")$ & $\mathrm{mp}_{R A}$ (mas/ano) & $\mathrm{mp}_{D E C}$ (mas/ano) & $\mathrm{VR}(\mathrm{km} / \mathrm{s})$ & {$[\mathrm{Fe} / \mathrm{H}]$} \\
\hline 244551 & 41.34 & $2.106 \pm 0.267$ & $-5.968 \pm 0.216$ & $-8.63 \pm 0.47$ & $-1.30 \pm 0.07$ \\
244555 & 28.16 & $2.680 \pm 0.205$ & $-6.178 \pm 0.178$ & $-2.33 \pm 0.50$ & $-1.29 \pm 0.09$ \\
244819 & 32.24 & $2.464 \pm 0.126$ & $-6.422 \pm 0.104$ & $-19.42 \pm 0.56$ & $-1.35 \pm 0.07$ \\
244853 & 16.99 & $2.807 \pm 0.134$ & $-6.536 \pm 0.106$ & $-11.79 \pm 1.07$ & $-1.43 \pm 0.06$ \\
256289 & 91.78 & $2.452 \pm 0.192$ & $-6.481 \pm 0.156$ & $-15.11 \pm 0.99$ & $-1.34 \pm 0.05$ \\
256298 & 101.15 & $2.638 \pm 0.106$ & $-6.518 \pm 0.085$ & $-22.39 \pm 0.71$ & $-1.07 \pm 0.09$ \\
402322 & 142.20 & $2.511 \pm 0.201$ & $-6.335 \pm 0.170$ & $-22.93 \pm 0.38$ & $-1.23 \pm 0.08$ \\
402370 & 107.40 & $2.591 \pm 0.107$ & $-6.584 \pm 0.088$ & $-10.86 \pm 0.23$ & $-1.42 \pm 0.00$ \\
402371 & 50.79 & $2.618 \pm 0.147$ & $-6.748 \pm 0.123$ & $-17.52 \pm 0.69$ & $-1.26 \pm 0.10$ \\
402384 & 113.14 & $2.348 \pm 0.134$ & $-6.505 \pm 0.108$ & $-20.04 \pm 0.88$ & $-1.42 \pm 0.17$ \\
402508 & 104.35 & $2.476 \pm 0.171$ & $-6.471 \pm 0.140$ & $-4.32 \pm 0.30$ & $-1.18 \pm 0.07$ \\
\hline \hline
\end{tabular}

valor adotado para a seleção, de Barbuy et al. (2014), e a média das metalicidades retorna $[\mathrm{Fe} / \mathrm{H}]=-1.30$ com um desvio-padrão de 0.1 dex.

Para a amostra do MUSE com limpeza de movimento próprio, um ajuste bimodal de perfis lorentzianos na distribuição indica um pico em $-6.38 \mathrm{~km} / \mathrm{s}$, a média das velocidades radiais retorna $-7.61 \mathrm{~km} / \mathrm{s}$ com desvio-padrão de $7.42 \mathrm{~km} / \mathrm{s}$, e a média das velocidades resulta em $[\mathrm{Fe} / \mathrm{H}]=-1.31$ com desvio-padrão de 0.29 dex. Na distribuição do MUSE foram consideradas apenas estrelas com $[\mathrm{Fe} / \mathrm{H}]$ inferior a -0.8 dex.

A seguir são apresentados diagramas gravidade versus temperatura para a amostra do FLAMES na figura D.4, e do MUSE na figura D.5 


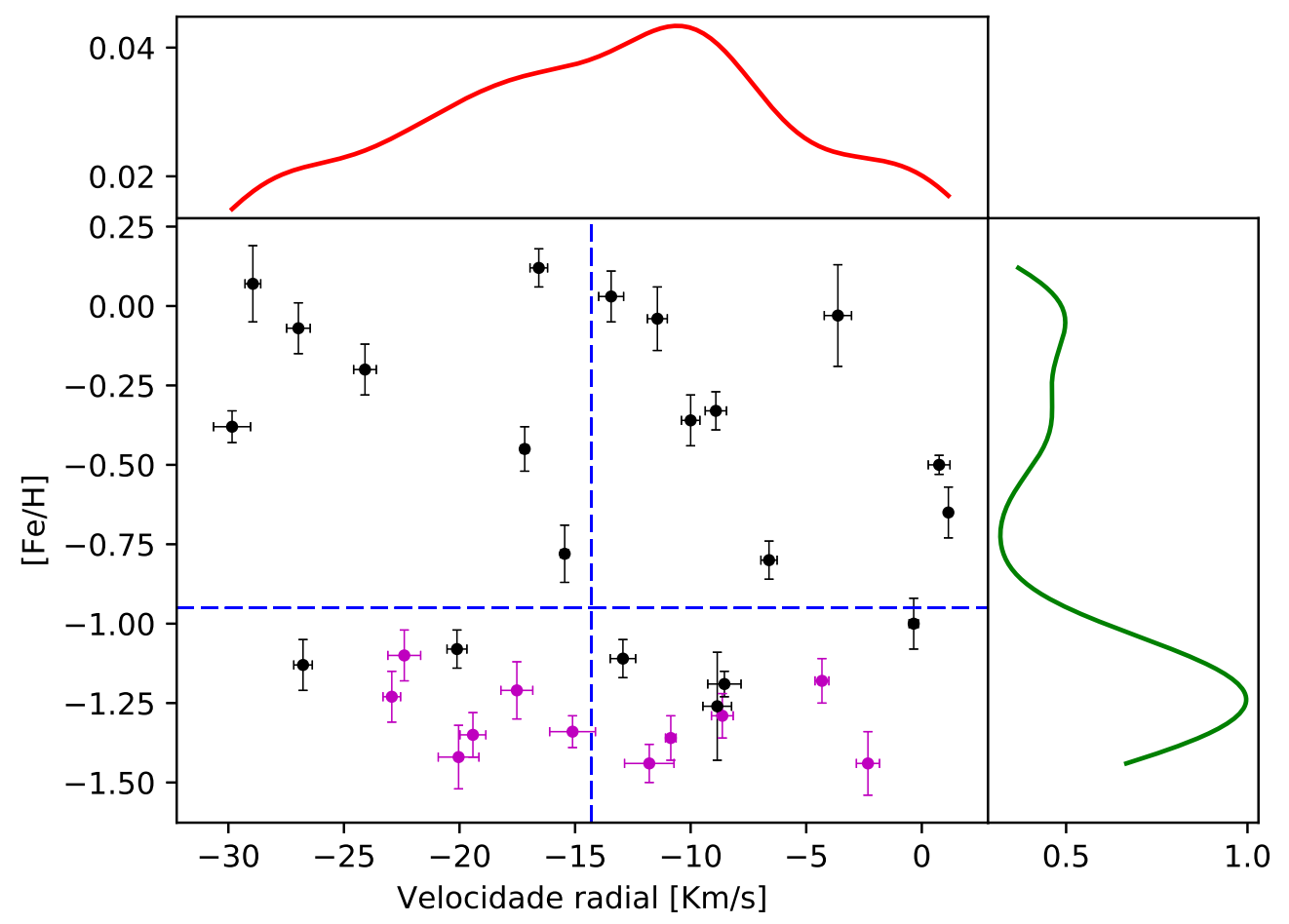

Figura D.2: Distribuição de metalicidades e velocidades radiais das estrelas GIRAFFE. No quadro maior são plotadas as estrelas com seus respectivos erros, onde os pontos em magenta são as estrelas selecionadas por limpeza do movimento próprio, e as linhas tracejadas azuis são os valores de referência determinados em Barbuy et al. (2014). No quadro superior em vermelho: distribuição de velocidades radiais. No quadro lateral em verde: distribuição de metalicidades. 


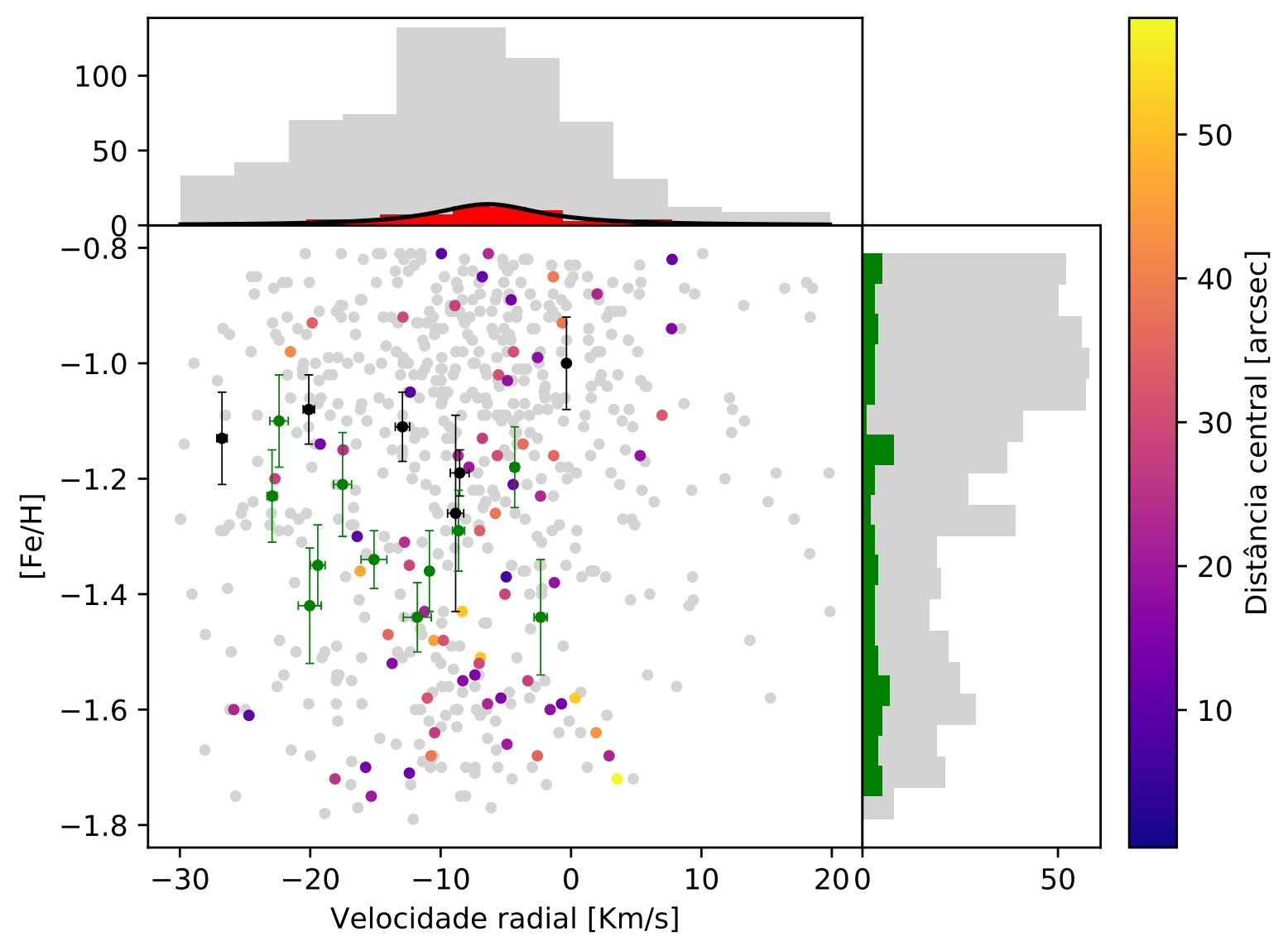

Figura D.3: Distribuição de metalicidades e velocidades radiais das estrelas do MUSE depois de realizada a limpeza de movimento próprio. No quadro maior são plotadas as estrelas de toda a amostra em cinza, e as selecionadas pela limpeza de movimento próprio em escala de cor de distância central. As estrelas analisadas no FLAMES são plotadas para referência, em preto: fora da faixa de movimento próprio, em verde: limpas do movimento próprio. No quadro superior: distribuição de velocidades radiais, em cinza: de toda a amostra, em vermelho: estrelas com limpeza de movimento próprio. No quadro lateral: distribuição de metalicidades, em cinza: toda a amostra, em verde: estrelas com limpeza de movimento próprio. 

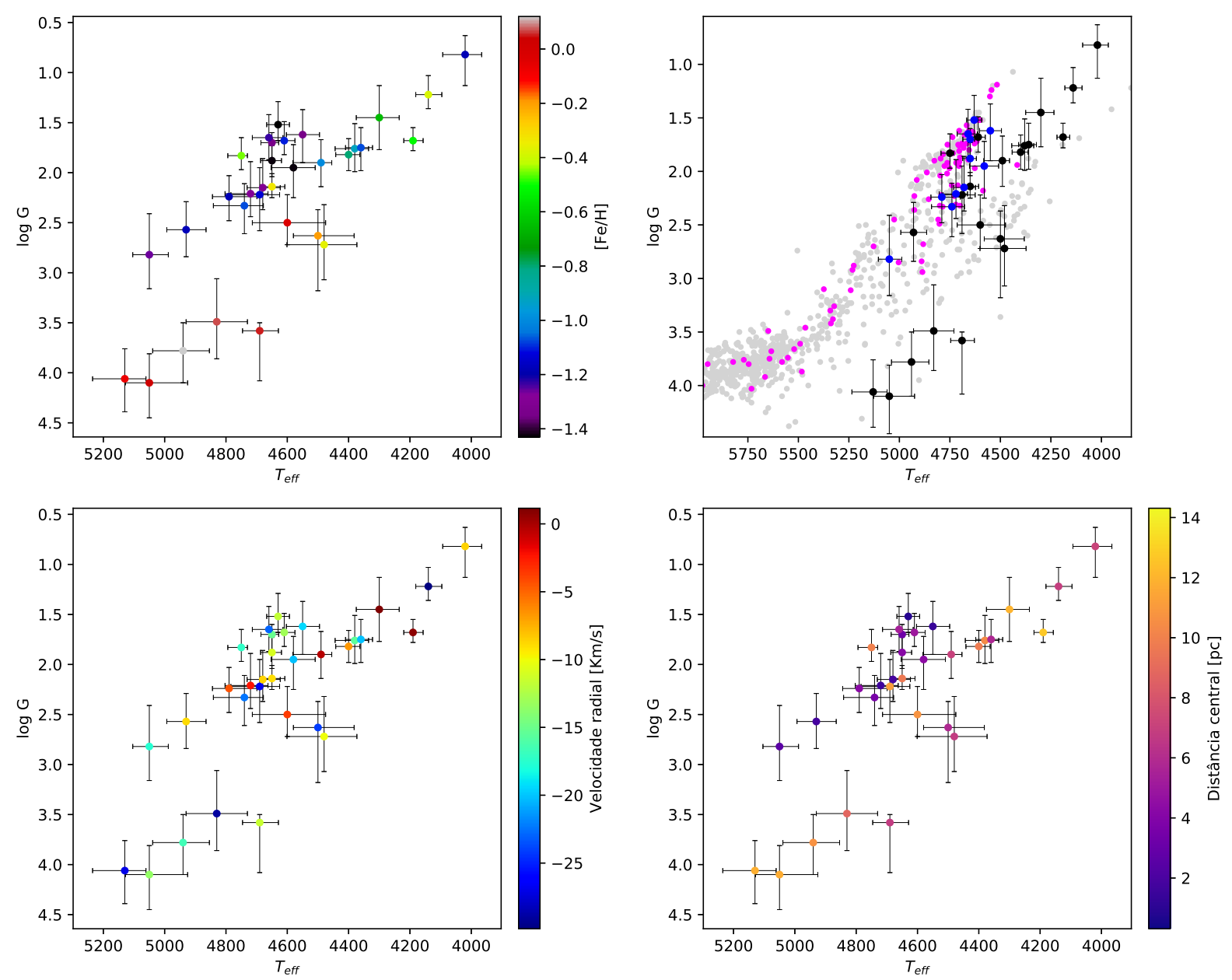

Figura D.4: Diagramas gravidade x temperatura das estrelas do FLAMES com as cores representando metalicidade (quadro superior esquerdo), velocidade radial (quadro inferior esquerdo) e distância ao centro do aglomerado (quadro inferior direito). No quadro superior direito, são exibidas as estrelas da amostra do MUSE, em cinza: toda a amostra, em magenta: com limpeza do movimento próprio; e as estrelas da amostra do FLAMES, em preto: toda a amostra, em azul: com limpeza do movimento próprio. 

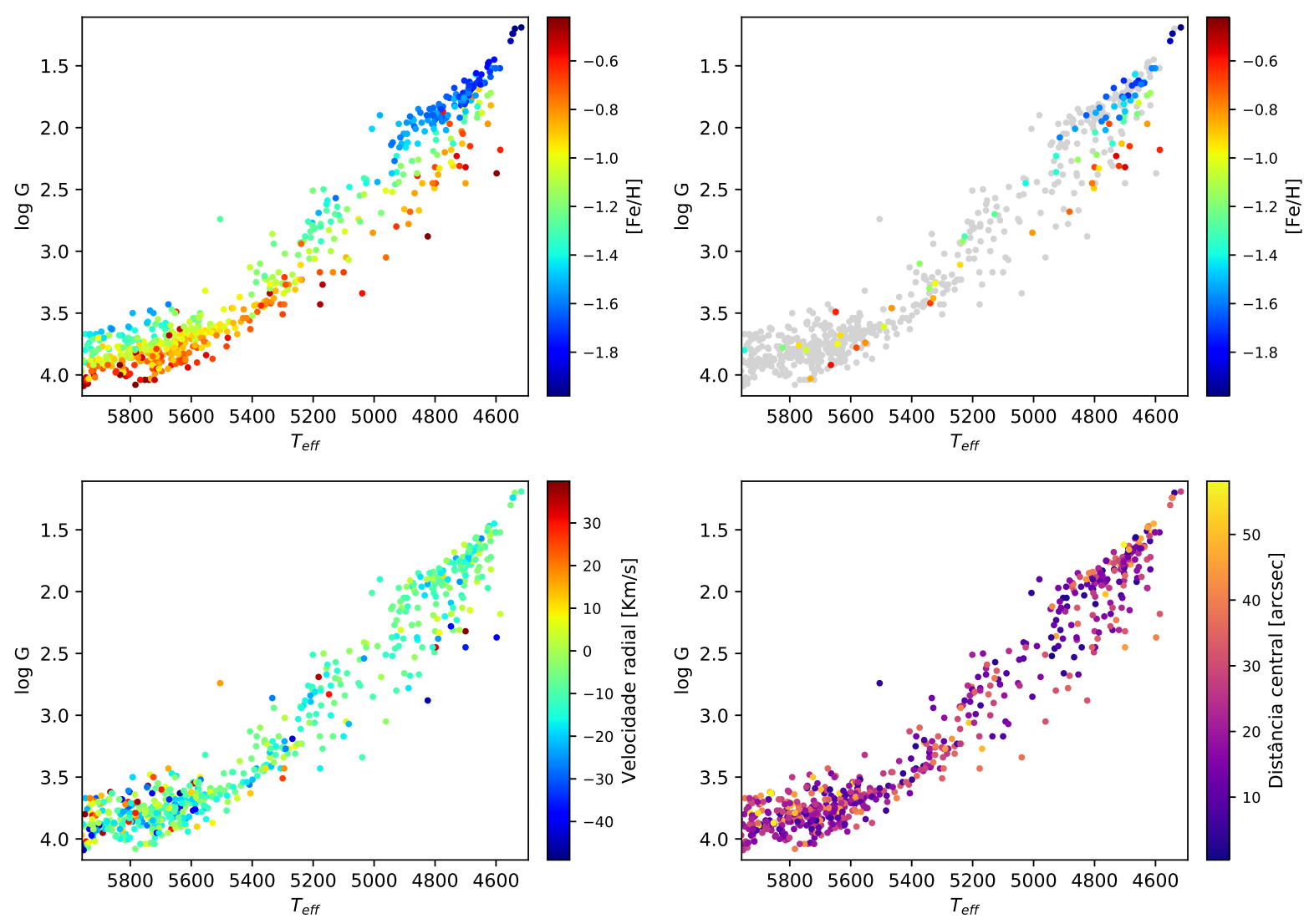

Figura D.5: Diagramas gravidade x temperatura das estrelas do MUSE com as cores representando metalicidade (quadro superior esquerdo), velocidade radial (quadro inferior esquerdo) e distância ao centro do aglomerado (quadro inferior direito). No quadro superior direito, são exibidas em cinza a amostra total, e em cores com a limpeza do movimento próprio. 
Apêndice E

\section{Análise de pertinência das amostras GIRAFFE}

A análise de pertinência das estrelas ao aglomerado foi feita de maneira a considerar os parâmetros dinâmicos (velocidade radial e movimento próprio) e a metalicidade, deixando

a distância central como parâmetro auxiliar, visto que mesmo uma estrela distante pode estar gravitacionalmente associada ao sistema. A metalicidade é fator fundamental para separar as diferentes populações de estrelas no campo de um aglomerado globular, visto que suas estrelas-membro devem apresentar metalicidades muito próximas.

Afim de comparar as estrelas analisadas anteriormente, foram resgatadas as velocidades radiais e seus movimentos próprios, conforme exibido na tabela E.1. Por limpeza de movimento-próprio, as estrelas B-108 e B-130 não podem ser consideradas membros do aglomerado.

As metalicidades apresentadas nas tabelas 5.3 e.1 e a metalicidade média da amostra do GIRAFFE $([\mathrm{Fe} / \mathrm{H}]=-1.30)$ discorda dos valores apresentados em Barbuy et al. (2009) e Barbuy et al. (2014), porém está próximo dos valores determinados em estudos anteriores, exibidos na tabela 1.1, e também concorda muito bem com a metalicidade determinada com limpeza de movimento próprio da amostra do MUSE.

Evidentemente, as 113 estrelas restantes da amostra do MUSE representam menos de $10 \%$ da amostra original, onde a função de distribuição de metalicidades não pode ser tomada como representativa para o aglomerado em si, sendo que a amostra original exibe um claro pico em $[\mathrm{Fe} / \mathrm{H}] \approx-1.0$ e populações amostrais acumuladas em $[\mathrm{Fe} / \mathrm{H}] \approx-1.3$ e em $[\mathrm{Fe} / \mathrm{H}] \approx$-1.6. A explicação para esta ocultação do pico em $[\mathrm{Fe} / \mathrm{H}] \approx-1.0$ na amostra com limpeza de movimento próprio se deve ao fato de que as estrelas identificadas e presentes no catálogo do Gaia são gigantes brilhantes do campo central do aglomerado, e segundo os resultados do MUSE, é possível notar pela figura D.5 que as estrelas de metalicidade $[\mathrm{Fe} / \mathrm{H}]$ 
Tabela E.1 - Parâmetros dinâmicos das estrelas analisadas em Barbuy et al. (2009).

\begin{tabular}{lccccc}
\hline \hline Objeto & ID OGLE & $\mathrm{r}_{c}(")$ & $\mathrm{mp}_{R A}(\mathrm{mas} / \mathrm{ano})$ & $\mathrm{mp}_{D E C}(\mathrm{mas} / \mathrm{ano})$ & $\mathrm{VR}_{2009}(\mathrm{~km} / \mathrm{s})$ \\
\hline B-008 & 412752 & 178.90 & $2.511 \pm 0.201$ & $-6.335 \pm 0.170$ & -8.95 \\
B-107 & 402361 & 23.39 & $2.782 \pm 0.131$ & $-6.139 \pm 0.108$ & -6.89 \\
B-108 & 245265 & 0.67 & $1.332 \pm 0.365$ & $-5.258 \pm 0.305$ & -13.76 \\
B-118 & 402322 & 141.64 & $2.755 \pm 0.273$ & $-6.953 \pm 0.224$ & -23.21 \\
B-122 & 244582 & 28.81 & $2.328 \pm 0.162$ & $-7.063 \pm 0.125$ & -16.61 \\
B-128 & 402607 & 141.23 & $2.462 \pm 0.142$ & $-6.167 \pm 0.108$ & -13.56 \\
B-130 & 402539 & 104.28 & $7.120 \pm 0.799$ & $-8.776 \pm 0.648$ & -16.33 \\
B-134 & 402590 & 90.84 & $2.704 \pm 0.110$ & $-5.802 \pm 0.090$ & -22.10 \\
F-121 & 244829 & 23.10 & $2.622 \pm 0.146$ & $-6.194 \pm 0.117$ & -9.04 \\
\hline \hline
\end{tabular}

-1.0 são mais anãs, o que dificulta a separação e identificação destas estrelas, bem como a determinação dos movimentos próprios, vista a alta aglutinação de estrelas no campo mais central do aglomerado. Desta forma, as estrelas passíveis de identificação são as mais gigantes, com uma distribuição mais uniforme ao longo das metalicidades. Esta distribuição sustentaria o argumento de que a amostra do FLAMES, com metalicidades mais baixas que as encontradas anteriormente, pode indicar a presença de populações estelares adicionais no aglomerado, o que contraria a concepção atual de que os aglomerados globulares possuem sempre uma metalicidade aproximadamente uniforme, o que sugere que este aglomerado é um objeto peculiar entre os outros aglomerados globulares conhecidos.

Fernández-Trincado et al. (2018) apresenta parâmetros atmosféricos e abundâncias para 5 estrelas do NGC 6522 (onde todas se enquadram dentro do intervalo de movimentos próprios aqui estabelecido), e uma delas com metalicidade de $[\mathrm{Fe} / \mathrm{H}] \sim-1.2 \pm 0.05$, que também sustenta a possibilidade da presença de populações com metalicidade inferior no aglomerado. Esta estrela também é a mais gigante da amostra, com $\mathrm{T}_{\text {eff }}=3977.2 \mathrm{~K} \mathrm{e}$ $\log g=0.50$, que se posicionaria em uma região dos diagramas gravidade vs temperatura da figura D.4 consistente com os parâmetros encontrados para o FLAMES.

Na análise de Kamann et al. (2018), o NGC 6522 foi o aglomerado que mais sofreu rejeição de estrelas na determinação de pertinência (onde as estrelas-membro eram selecionadas com base na velocidade radial e metalicidade), chegando a rejeitar $32 \%$ da amostra. Isto pode levantar questões quanto a este aglomerado possuir uma distribuição mais complexa de metalicidades, conforme encontrado pela presente analise. É importante ressaltar 
que os dados observacionais para o MUSE utilizados nesta análise são os mesmos utilizados na análise de Kamann et al. (2018), diferindo apenas na redução e análise. Os estudos publicados para aglomerados globulares usando o MUSE (Kamann et al.2016, Kamann et al. 2018 e Husser et al. 2016) mostram altas dispersões em metalicidade (cerca de $\sim 0.7$ dex em torno do valor médio) pelo método adotado, em contraste com $\sim 0.4$ dex de dispersão em torno do pico em $[\mathrm{Fe} / \mathrm{H}] \approx-1.0$ aqui apresentado. A figura 3.14 mostra uma distribuição de metalicidades multimodal que possui uma clara distinção entre o que aparenta ser uma segunda população em $[\mathrm{Fe} / \mathrm{H}] \sim-1.6$, e um ligeiro excesso populacional em $[\mathrm{Fe} / \mathrm{H}] \approx-1.30$, que pode ser de fato uma terceira componente ou uma flutuação na distribuição.

Na figura D.5, também é possível notar que as estrelas mais gigantes são as de menor metalicidade, com as velocidades radiais destas estrelas e das estrelas de metalicidade $[\mathrm{Fe} / \mathrm{H}] \sim-1.0$ muito próximas de $\sim-14 \mathrm{~km} / \mathrm{s}$, sugerindo que estas pertencem ao aglomerado. Mesmo com a limpeza de movimento próprio, as mais gigantes ainda podem ser consideradas estrelas-membro no critério da dinâmica. Isto implica que as estrelas mais gigantes (e portanto mais brilhantes) presentes no campo do FLAMES que se enquadrariam como membros do aglomerado, apresentam grande probabilidade de serem mais pobres em metais. As estrelas do FLAMES desta análise foram selecionadas automaticamente pelo software do $\mathrm{OzPoz}$ com o critério de alocar o maior número de fibras, o que leva em conta apenas a localização espacial das estrelas (dado o tamanho do campo, as partes mais centrais do aglomerado ficam pouco acessíveis devido ao alcance e trombamento das fibras), e considerando que a lista de alvos para o software apresenta apenas estrelas uma magnitude mais brilhantes que o red clump, as metalicidades encontradas para as estrelas do FLAMES são consistentes com o esperado para suas posições no espaço gravidade vs temperatura de acordo com os resultados do MUSE. Ainda, o corte amostral que a limpeza de movimento próprio impôs à amostra do MUSE se deu principalmente por conta das magnitudes e da aglutinação, o que a torna passível de comparação com a amostra do FLAMES. De fato, a média das metalicidades com limpeza de movimento próprio da amostra do FLAMES concorda com a do MUSE, como citado anteriormente.

Desta forma, a análise independente da amostra do MUSE sustenta o argumento de que as estrelas do FLAMES com metalicidade inferior à -1.2 dex poderiam ser consideradas membros do aglomerado, e sugere que o NGC 6522 pode ser um aglomerado globular anômalo, com largo espalhamento e multimodalidade na distribuição de metalicidades. 
Na figura E.1 são comparadas as estrelas de Barbuy et al. (2009), Barbuy et al. (2014) e Fernández-Trincado et al. (2018) com a amostra do presente trabalho no espaço de parâmetros.

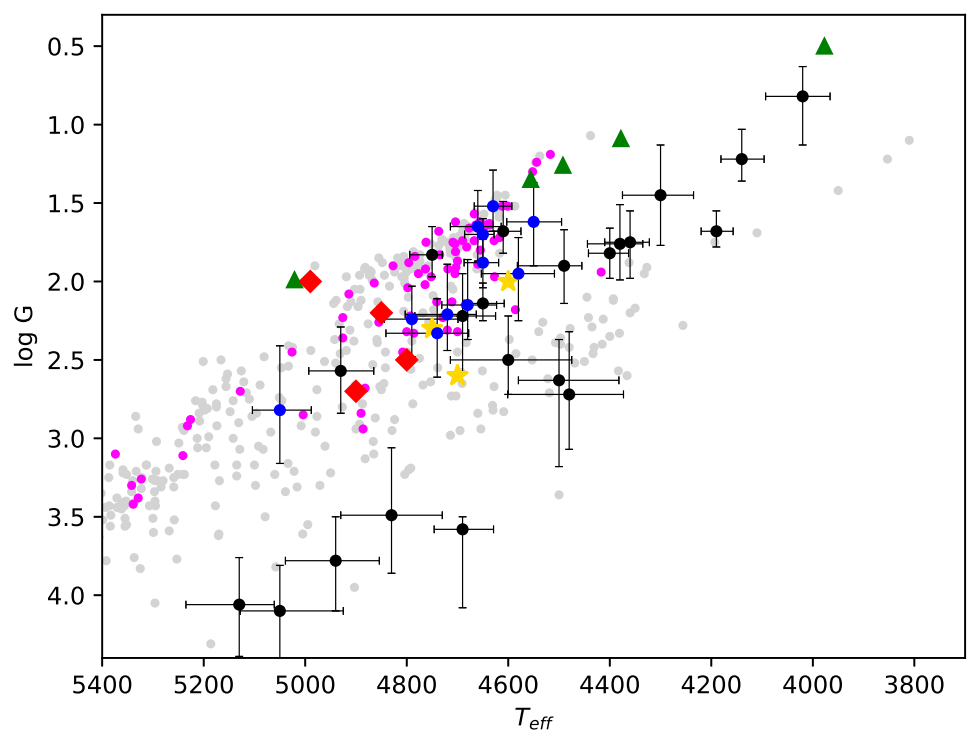

Figura E.1: Diagramas gravidade x temperatura das estrelas da presente amostra. Em cinza: toda a amostra MUSE; em magenta: MUSE com limpeza do movimento próprio; em preto: toda a amostra FLAMES, em azul: FLAMES com limpeza do movimento próprio; triângulos verdes: Fernández-Trincado et al. (2018); estrelas amarelas: Barbuy et al. (2009); losangos vermelhos: Barbuy et al. (2014).

Outra característica interessante do NGC 6522 aparece ao se analisar imagens do telescópio espacial Galex (faixa do ultavioleta) e do observatório espacial Chandra (faixa dos raios-x) exibidas na figura E.2, onde é possível notar uma fonte em raios-x proveniente do centro do aglomerado sem nenhuma contrapartida estelar, e devido à sua localização, uma baixa probabilidade de esta fonte estar associada com objetos extra-galáticos. Esta fonte se localiza em uma região que se assemelha a uma lacuna de estrelas no centro do aglomerado. Também é possível notar uma emissão difusa no ultravioleta, em toda a região central do aglomerado.

Cassisi et al. (2008) sugeriu que buracos negros de massa intermediária podem invocar múltiplos eventos de formação estelar em aglomerados globulares. Atualmente não é possível sugerir que estas emissões em ultravioleta e raios-x tenham qualquer associação com um possível buraco negro, dada a ausência de dados com alta resolução espacial 


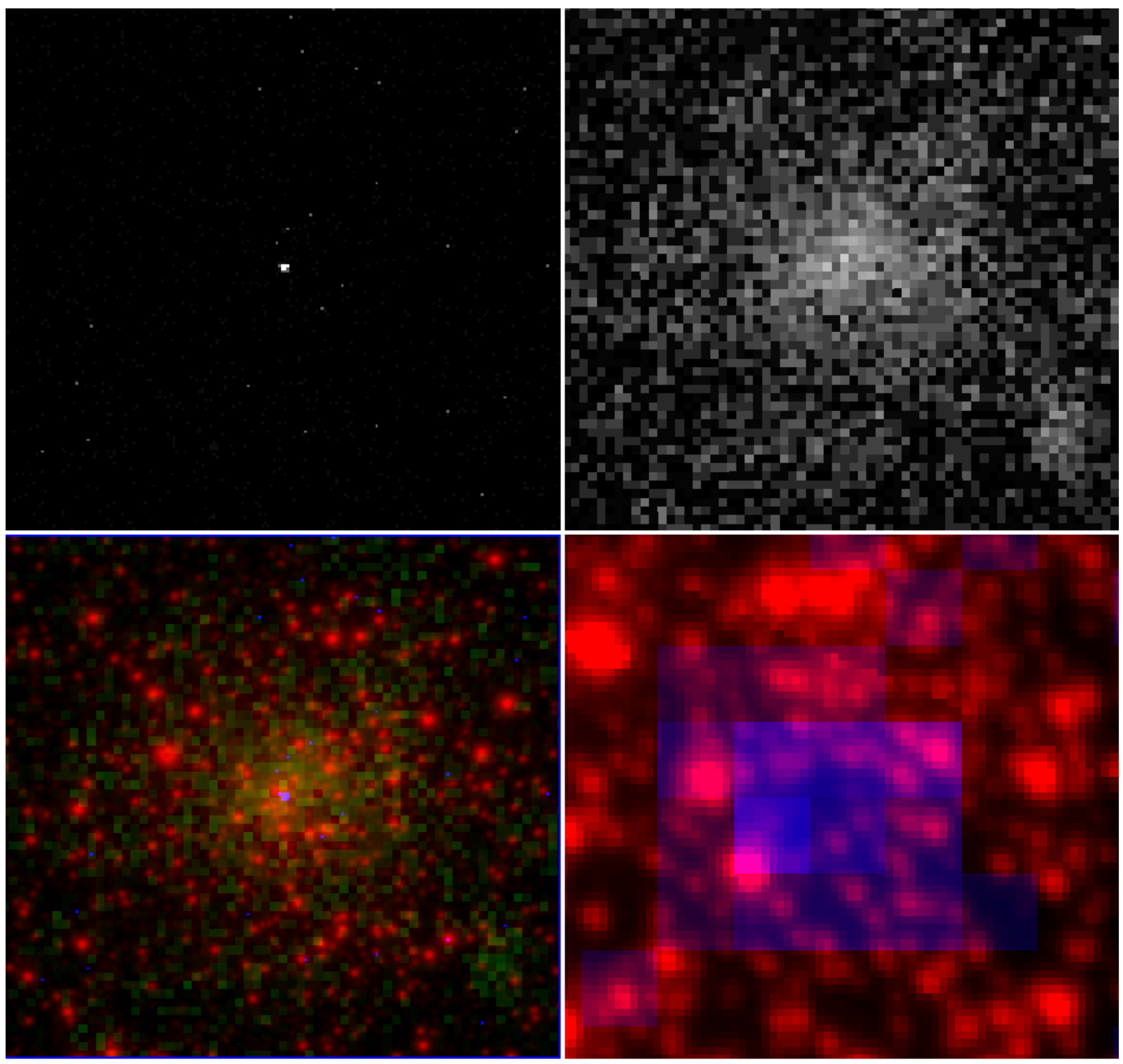

Figura E.2: Imagens em diferentes bandas do espectro. No quadro superior esquerdo: imagem em raios-x do telescópio Chandra; no quadro superior direito: imagem na banda NUV (Near UltraViolet, ultravioleta próximo) do Galex; no quadro inferior esquerdo: imagens no ótico (vermelho) do telescópio vista, ultravioleta (verde), e raios-x (azul); no quadro inferior direito: imagens no ótico (vermelho) do telescópio espacial Hubble e raios-x (azul) com ampliação na região central.

em múltiplas regiões do espectro eletromagnético. Mais dados espectroscópicos em alta resolução são necessários para que o espalhamento em metalicidades possa ser revisado frente à improbabilidade deste fenômeno em aglomerados globulares, segundo o atual consenso científico acerca destes objetos.

Tudo indica que o NGC 6522 é um objeto de grande interesse científico, que necessita de mais dados em diferentes bandas espectrais e uma profunda análise de suas características. 